\title{
OXFORD
}

\section{MANUFACTURING TRANSFORMATION}

COMPARATIVE STUDIES OF INDUSTRIAL DEVELOPMENT IN AFRICA AND EMERGING ASIA

\section{Edited by}

Carol Newman, John Page,

John Rand, Abebe Shimeles,

Måns Söderbom, and Finn Tarp

UNU-WIDER STUDIES IN DEVELOPMENT ECONOMICS 
Manufacturing Transformation 
UNU World Institute for Development Economics Research (UNU-WIDER) was established by the United Nations University as its first research and training centre and started work in Helsinki, Finland, in 1985. The mandate of the institute is to undertake applied research and policy analysis on structural changes affecting developing and transitional economies, to provide a forum for the advocacy of policies leading to robust, equitable, and environmentally sustainable growth, and to promote capacity strengthening and training in the field of economic and social policy-making. Its work is carried out by staff researchers and visiting scholars in Helsinki and via networks of collaborating scholars and institutions around the world.

United Nations University World Institute for Development Economics Research (UNU-WIDER) Katajanokanlaituri 6B, 00160 Helsinki, Finland www.wider.unu.edu 


\section{Manufacturing Transformation}

\section{Comparative Studies of Industrial Development in Africa and Emerging Asia}

Edited by

Carol Newman, John Page, John Rand, Abebe Shimeles, Måns Söderbom, and Finn Tarp

A study prepared by the United Nations University World Institute for Development Economics Research (UNU-WIDER)

\section{OXFORD}




\section{OXFORD}

UNIVERSITY PRESS

Great Clarendon Street, Oxford, OX2 6DP, United Kingdom

Oxford University Press is a department of the University of Oxford.

It furthers the University's objective of excellence in research, scholarship, and education by publishing worldwide. Oxford is a registered trade mark of Oxford University Press in the UK and in certain other countries.

(c) United Nations University World Institute for Development Economics Research (UNU-WIDER) 2016

The moral rights of the editor and authors have been asserted

First Edition published in 2016

Impression: 1

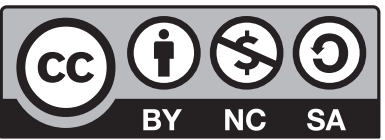

Some rights reserved. This is an open access publication. Except where otherwise noted, this work is distributed under the terms of a Creative Commons Attribution-Non Commercial-Share Alike 3.0 IGO licence (CC BY-NC-SA 3.0 IGO), a copy of which is available at https://creativecommons.org/licenses/by-nc-sa/3.0/igo/.

It is permitted to reuse, share and adapt this work, subject to the following terms:

(2) Attribution - appropriate credit is given to the original work, the copyright holder and creator, and any changes made to the work are properly indicated.

Gon-Commercial - the work, or any adaptation of the work, may not be used, distributed or reproduced in any format, by any means, for commercial purposes

(0) Share-Alike - the work, or any adaptation of the work is distributed under the same licence terms as the original, with a URL link provided to the licence.

Enquiries concerning use outside the terms of the Creative Commons licence should be sent to the Rights Department, Oxford University Press, at the above address or to academic.permissions@oup.com.

Published in the United States of America by Oxford University Press 198 Madison Avenue, New York, NY 10016, United States of America

British Library Cataloguing in Publication Data

Data available

Library of Congress Control Number: 2015958530

ISBN 978-0-19-877698-7

Printed in Great Britain by

Clays Ltd, St Ives plc

Links to third party websites are provided by Oxford in good faith and for information only. Oxford disclaims any responsibility for the materials contained in any third party website referenced in this work. 


\section{Foreword}

This book presents the results of a comparative, country-based research programme entitled Learning to Compete (L2C)—led collaboratively by the African Development Bank, the Brookings Institution, and UNU-WIDER-that sought to answer a seemingly simple but puzzling question: why is there so little industry in Africa? It brings together the results of eleven detailed country case studies - eight from sub-Saharan Africa (SSA), one from North Africa, and two from newly industrializing East Asia—conducted by teams of national researchers in partnership with international experts on industrial development; and provides the most comprehensive description and analysis available to date of the contemporary industrialization experience in low-income Africa. It also compares the SSA industrial development story with the more successful industrial development experiences of Tunisia, Cambodia, and Vietnam.

The editors' Introduction-'The Pursuit of Industry: Policies and Outcomes'-describes the motivation for the book and explores some of the cross-cutting themes that emerge from the individual case studies; while the concluding chapter sets out the implications of the country cases for policy. Africa's failure to industrialize is partly due to bad luck. After a brief period of post-independence state-led import substitution (IS) the macroeconomic chaos and subsequent reforms of the 'structural adjustment' period brought more than twenty years of low growth and low investment. By 2000, as African governments began to focus again on industrial development, Africa was not simply competing with the industrial 'North'-it was competing with China. But the failure to industrialize is due also to bad policy. This book shows a remarkable similarity in the policies for industrial development followed by the eight SSA countries: state-led IS, structural adjustment, and reform of the investment climate. The latter two of these policy regimes strongly reflect the priorities and dogmas of the aid community. It is fair to conclude that none has succeeded in sparking dynamic industrial growth. This book demonstrates how this state of affairs can start changing and what is required to make that happen.

I hereby sincerely express my appreciation and admiration of the academic and analytical skills of the L2C team and the detailed knowledge of the case countries brought out so clearly in this volume.

Finn Tarp

Helsinki, May 2016 



\section{Preface}

Meeting the challenge of industrialization will need new thinking both in Africa and among its development partners. Put bluntly, Africa will not succeed in industrializing if the conventional wisdom offered by the international aid community to African governments continues to define their public policies to spur industrial development. One of the unifying themes in the eight SSA country case studies in this volume is the predominant role of donor-driven investment climate reforms. In our view while investment climate reforms are necessary, they need to be re-prioritized and refocused. Urgent action is needed to address Africa's growing infrastructure and skills gap with the rest of the world.

For most African countries, investment climate reforms alone are unlikely to be enough to overcome the advantages of the world's existing industrial locations. Drawing from the policy histories of Cambodia and Vietnam and-because these to a great extent reflect a shared approach to industrialization in East Asia—on Asia's experience more broadly, we identify three new initiatives to address Africa's industrialization challenge.

- Breaking into export markets will need an 'export push' of the type undertaken by Cambodia, Vietnam, and Tunisia: a concerted set of public investments, policy, and institutional reforms focused on increasing the share of industrial exports in GDP. Because governments have limited scope for public investment and public action, the export push needs a government-wide commitment to focus investments and policy actions first on boosting non-traditional exports.

- In Cambodia and Vietnam the export push was accompanied by policies designed to promote the formation of industrial clusters. Spatial industrial policies are complementary to both the export push and capability building. African governments can foster export-oriented industrial agglomerations by concentrating investment in high-quality institutions, social services, and infrastructure in a limited physical area such as an export processing zone (EPZ) - an industrial agglomeration designed to serve the global market-but African governments have not yet succeeded in doing so. 
- Cambodia, Vietnam, and Tunisia each recognized that policies and institutions for attracting foreign direct investment (FDI) are a key tool in capability building. The institutional design of successful FDI agencies is well known. The SSA countries that we studied had all created institutions intended to attract FDI, but we did not find any examples of high-level government commitment to the promotion of FDI, and implementation has not achieved best practice. Building better investment promotion institutions is essential.

Finally, perhaps the single most important insight to emerge from the country studies in this book is that any one of the above initiatives taken in isolation is likely to fail. Two decades of piecemeal reforms have not succeeded in pushing a single low-income African country over the threshold above which industrial growth becomes-as it has been in Vietnam-explosive. Africa will learn to compete only once donors and policy makers accept the need for a comprehensive strategy for industrial development.

Carol Newman, John Page, John Rand, Abebe Shimeles, Måns Söderbom, and Finn Tarp 


\section{Acknowledgements}

Many people worked with the group of editors during the five years that the Learning to Compete project was under implementation. Our greatest debt is to the country-based research teams, who carried out many of the case studies and much of the quantitative research presented in this book.

We are grateful as well to the late Gobind Nankani, then head of the Global Development Network, for early encouragement. We are indebted to Louis Kasekende and Mthuli Ncube, former Chief Economists of the African Development Bank, and Steve Kayizzi-Mugerwa, currently the Acting Chief Economist, for their sustained support for the project. Kemal Dervis, Vice President and Director of the Global Economy and Development Program at Brookings was a sustained supporter. We are also indebted to the UNU-WIDER Board, headed by Ernest Aryeetey, for its support and guidance.

We benefited from the thoughtful advice of Ernest Aryeetey, Arne Bigsten, Howard Pack, and Tony Venables in designing the research programme. Over the years, we have engaged in many discussions with colleagues who study industry and development-these conversations helped shape our thinking and test our assumptions. Without implicating any of them in the perspectives offered in this book, we would like to thank Paul Collier, Hinh Dinh, Ann Harrison, Mark Henstridge, Justin Lin, Margaret McMillan, Celestin Monga, Benno Ndulu, Keijiro Otsuka, Tetsushi Sonobe, Joseph Stiglitz, John Sutton, and Francis Teal.

The African Economic Research Consortium (AERC) and the Economic Commission for Africa (ECA) helped us to organize preparatory workshops with the country teams in Nairobi and Addis Ababa, respectively. We are grateful to the participants in numerous meetings, seminars, and lectures, including the June 2013 WIDER Development Conference in Helsinki, for comments, critiques, and advice. In addition we are grateful to Adam Swallow, Economics Commissioning Editor at Oxford University Press-we can confidently say that the book benefited significantly from his constructive suggestions on refining the original book proposal.

An anonymous donor helped to support Brookings's contributions to the joint work programme. The African Development Bank recognizes the financial support provided by the Government of the Republic of Korea through 
the Korea-Africa Economic Cooperation Trust Fund. UNU-WIDER gratefully acknowledges the support of its donors-the Ministry of Foreign Affairs of Denmark (Danida), the Ministry of Foreign Affairs of Finland, the Swedish International Development Cooperation Agency (Sida), and the UK Department for International Development.

Finally, we would like to express our sincere gratitude to the staff of UNU-WIDER for their never-failing support in the course of the L2C project-in particular to Lorraine Telfer-Taivainen, UNU-WIDER Senior Editorial and Publishing Assistant, for her excellent work on bringing the final manuscript of this book together.

Carol Newman, John Page, John Rand, Abebe Shimeles, Måns Söderbom, and Finn Tarp 


\section{Contents}

List of Figures $\quad$ Xiii

List of Tables $\quad$ XV

List of Abbreviations $\quad$ xix

Notes on Contributors $\quad$ Xxvii

1. The Pursuit of Industry: Policies and Outcomes 1

Carol Newman, John Page, John Rand, Abebe Shimeles,

Måns Söderbom, and Finn Tarp

\section{Part I. Industrial Development in Africa}

2. Industrial Policy and Development in Ethiopia

Mulu Gebreeyesus

3. Industrial Policy in Ghana: Its Evolution and Impact

Charles Ackah, Charles Adjasi, and Festus Turkson

4. Kenya's Industrial Development: Policies, Performance, and Prospects

Dianah Ngui, Jacob Chege, and Peter Kimuyu

5. Mozambique's Industrial Policy: Sufficient to Face the Winds of Globalization?

António Sousa Cruz, Dina Guambe, Constantino Pedro Marrengula, and Amosse Francisco Ubisse

6. Industrial Policy in Nigeria: Opportunities and Challenges in a Resource-rich Country

Louis N. Chete, John O. Adeoti, Foluso M. Adeyinka, and

Femi Oladapo Ogundele

7. Industrial Policy in Senegal: Then and Now

Fatou Cissé, Ji Eun Choi, and Mathilde Maurel

8. Industrial Development in Tanzania 
9. Tunisia: Industrial Policy in the Transition to Middle-income Status

Mohamed Ayadi and Wided Mattoussi

10. The Evolution of Industry in Uganda Isaac Shinyekwa, Julius Kiiza, Eria Hisali, and Marios Obwona

\section{Part II. Industrial Development in Emerging Asia}

11. Cambodia's Path to Industrial Development: Policies, Lessons, and Opportunities

Sokty Chhair and Luyna Ung

12. The Evolution of Vietnamese Industry

Nguyen Thi Tue Anh, Luu Minh Duc, and Trinh Duc Chieu

13. Can Africa Industrialize?

Carol Newman, John Page, John Rand, Abebe Shimeles,

Måns Söderbom, and Finn Tarp

Index 


\section{List of Figures}

3.1 Growth rate of industry and sub-sectors, 1981-2000 54

3.2 Annual labour productivity growth, $2013 \quad 64$

3.3 Annual employment growth, $2013 \quad 65$

5.1 From 1992 onwards, the economy steadily increased its per capita GDP, with a Gini coefficient of around $0.42 \quad 97$

5.2 After its dynamic role in GDP growth between 1995 and 2004, from 2005 the manufacturing sector ceased to be the main driver of growth

5.3 The intra-industrial structure stabilized between 2005 and 2011, although the mining industry is expected to increase significantly in the 2010s and 2020s 102

$\begin{array}{lll}7.1 & \text { Sectoral decomposition of GDP in Senegal } & 137\end{array}$

7.2 Contribution of labour reallocation to TFP 148

10.1 Manufacturing as a share of GDP, 1980-2008 194

10.2 Cumulative flow of investment in Uganda between 1991 and 2009 (US\$) 195

10.3 Manufacturing value added (\% of GDP), 1988-2009 196

10.4 Manufactured exports (\% of total exports) 196

10.5 Construction industry firms by employment band 201

11.1 Sectoral composition of foreign owned firms 220

11.2 Share of employment by three main sectors 221

$\begin{array}{ll}11.3 & \text { Share of the manufacturing sector } \\ 1222\end{array}$

12.1 Firm size distribution by year, manufacturing only 244

$\begin{array}{lll}13.1 & \text { ODA for economic infrastructure } & 263\end{array}$ 



\section{List of Tables}

1.1 The Africa country cases in context, 2013

1.2 Structural characteristics of the case study countries 4

1.3 Average annual growth of value added in manufacturing, 1965-2010 8

1.4 Manufacturing value added per worker in sub-Saharan African countries, 1995-2010 13

1.5 FDI as a share of gross fixed capital formation (\%), 1990-2013 19

2.1 Number of establishments, employment, and value added by ownership in the Ethiopian MLSM, 1979/80-2010 29

2.2 Ethiopia's economic performance, 2000/01-2009/10 31

2.3 Sectoral distribution of the Ethiopian manufacturing sector (2007/08) 34

2.4 Ranking of top ten manufacturing products in output and export $\begin{array}{ll}\text { contribution } & 35\end{array}$

2.5 Paid-up capital and value added by ownership and industry group (2009/10)

2.6 Export sales and imported raw materials by sector MLSM (2009/10) 38

2.7 Geographical distribution of manufacturing enterprises 39

2.8 Productivity by size category for selected years (1995/96-2008/09) 40

2.9 Productivity and capital intensity in the MLSM, by industry 41

3.1 Relative contributions of industry to GDP, 1984-2000 (\%), period averages $\quad 55$

3.2 Industry share of GDP and sub-sector growth rates, 2001-5 (\%) 56

3.3 Relative contribution of sub-sectors to industrial GDP, 2006-12 (\%) 58

3.4 Employment in industry and sub-sectors, 2000, 2006, and $2012 \quad 60$

3.5 Selected clusters in Ghana $\quad 61$

4.1 Policies, institutions, and laws enacted to promote industry in Kenya $\quad 78$

4.2 Percentage share of total manufacturing value added by sub-sector $\quad 79$

4.3 Manufacturing value added (\% GDP) 80

4.4 Trend in percentage share of employment by sector 82

4.5 Percentage share in the distribution of employment by size/category $\quad 83$ 
4.6 Percentage share in the number of establishments by size/category

4.7 Enterprise ownership by ethnic origin

4.8 Legal status of firms by size category

5.1 Employment in industry and its sub-sectors, 2006-9

6.1 Percentage distribution of real GDP by sectoral group, 1961-2009

6.2 Structure of industry by age of firms

6.3 Average firm size

6.4 Wages per employee

6.5 Technology

6.7 Constraints to firm growth 125

6.8 Labour productivity

7.1 Share of industrial sectors in total industrial value added on a five-year basis, 1980-2010

7.2 Share of the modern industrial sector and the informal sector of the total industrial value added on a five-year basis, 1980-2010

7.3 Employment rates by sector on a five-year basis, 1980-2010

7.4 Average electricity rates in West Africa

8.1 Inter-East Africa trade, 1962-4

8.2 Production by selected industries

8.3 Macroeconomic indicators in Tanzania, 1970-92

8.4 Average capacity utilization rates in the textile industry in Tanzania: A comparison of public and private firms

$\begin{array}{llr}9.1 & \text { Industrial production trend, 2004-8 } & 188\end{array}$

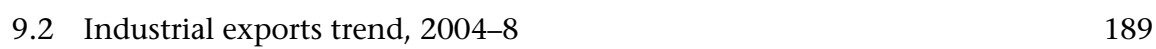

10.1 Distribution of firms in mining and quarrying by employment band 199

10.2 Ownership of firms in mining and quarrying between 2007 and $2009 \quad 200$

10.3 Ownership in the construction industry 202

11.1 Share of employment and value added of industrial establishments

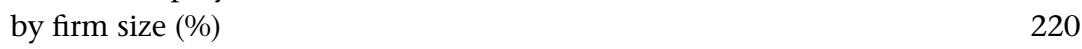

11.2 Number of establishments by sub-sector and age group, 2011

11.3 Provincial spatial distribution of firms in industrial sector by firm size (\%) 223

11.4 Provincial spatial distribution of medium and large firms in FBT and TWF (\%)

11.5 Comparison of growth in exports and value added across sectors

12.1 Vietnam's industrial policy matrix 
12.2 Structure of gross outputs of industrial sub-sectors and share of sub-sectors in GDP, 2000-10 243

12.3 Distribution of firm and employment shares 245

12.4 Shares of total industrial and sub-sector gross output by ownership type (\%)

12.5 Rates of industrial gross output of industries with growth at above average rates (\%)

12.6 Number of firms from 2005-11 in industries with above average firm number growth

12.7 Rates of gross output of industries with growth at below average rates (\%) 254

13.1 Indicators of physical and institutional infrastructure in special economic zones 



\section{List of Abbreviations}

ACGSF Agricultural Credit Guarantee Scheme Fund

ADEPME Agency for the Development and Supervision of SMEs

ADLI Agricultural Development Led Industrialization

AERC African Economic Research Consortium

AFI

Industrial Land Agency

AGOA Africa Growth and Opportunity Act

AIMO Associação Industrial de Moçambique

ANSD National Agency of Statistics and Demography

API

Industrial Promotion Agency

APIX Investment Promotion and Major Projects Agency

ASEAN Association of Southeast Asian Nations

ASEPEX

Senegalese Export Creation Agency

ATL

Akosombo Textile Limited

BAF

Business Assistance Fund

BIS Basic Industrial Strategy

BoI Bank of Industry

BPE Bureau of Public Enterprises

BRIC Brazil, Russia, India, and China

BTA bilateral trade agreement

CADI (AIMO's) Industrial Development Advisory Centre

CBN Central Bank of Nigeria

CDC Council for the Development of Cambodia

CDRI Cambodia Development Resource Institute

CEFP Committee for Economic and Financial Policy

CEPEX Export Promotion Centre

CET common external tariff

CIEM Central Institute for Economic Management (Vietnam)

COMESA Common Market for Eastern and Southern Africa 


\begin{tabular}{|c|c|}
\hline $\mathrm{CPP}$ & Convention Peoples Party \\
\hline CSA & Central Statistics Agency \\
\hline CSAE & Centre for the Study of African Economies \\
\hline CSES & Cambodia's Socio-Economic Surveys \\
\hline CUCI & Centre Unique de Collecte de Information \\
\hline DAC & Development Assistance Committee \\
\hline DERG & Development Economics Research Group \\
\hline EAC & East African Community \\
\hline EAS & East African Strategy \\
\hline EBA & Everything but Arms \\
\hline $\mathrm{EC}$ & Economic Census \\
\hline ECA & Economic Commission for Africa \\
\hline ЕСВР & Engineering Capacity Building Program \\
\hline ECOWAS & Economic Community of West African States \\
\hline EDM & Electricidade de Moçambique \\
\hline EDRI & Ethiopian Development Research Institute \\
\hline EFCC & Economic and Financial Crimes Commission \\
\hline EIC & Economic Institute of Cambodia \\
\hline ELLPTI & Ethiopian Leather and Leather Products Technology Institute \\
\hline EPRC & Economic Policy Research Centre \\
\hline EPRDF & Ethiopian People's Revolutionary Democratic Front \\
\hline $\mathrm{EPZ}$ & Export Processing Zones \\
\hline ERP & Economic Recovery Programme \\
\hline ERS & Economic Recovery Strategy \\
\hline ERS & Export Rebate System \\
\hline ERSAP & Economic Recovery and Structural Adjustment Programme \\
\hline ESAF & Enhanced Structural Adjustment Facility \\
\hline ESAM II & 2001 Senegalese Household Survey \\
\hline ESAP & Economic and Social Action Programme \\
\hline EU-ACP & European Union-African Caribbean and Pacific \\
\hline $\mathrm{EZ}$ & economic zone \\
\hline FBT & food, beverages, and tobacco \\
\hline FDI & foreign direct investment \\
\hline FFYP & First Five-year Plan \\
\hline FI & Federation of Industry \\
\hline FIA & Foreign Investment Agency \\
\hline
\end{tabular}




\begin{tabular}{|c|c|}
\hline FIPAG & Water Supply Investment and Assets Fund \\
\hline FOB & free on board \\
\hline Frelimo & Mozambique Liberation Front \\
\hline FTA & free trade agreement \\
\hline FTZ & free trade zones \\
\hline FUSMED & Fund for Small and Medium Scale Enterprises Development \\
\hline GATT & General Agreement on Tariffs and Trade \\
\hline GDP & gross domestic product \\
\hline GEMS & Governance and Economic Management Support \\
\hline GFZB & Ghana Free Zones Board \\
\hline GHATIG & Ghana Trade and Investment Gateway \\
\hline GIC & Ghana Investment Centre \\
\hline GMAC & Garment Manufacturers Association in Cambodia \\
\hline GPRS & Growth and Poverty Reduction Strategies \\
\hline G-PSF & Government-Private Sector Forum \\
\hline GRS & General Retention Scheme \\
\hline GSLI & (Kearney's) Global Services Location Index \\
\hline GSP & global social product \\
\hline GSP & generalized system preference \\
\hline GTMC & Ghana Textile Manufacturing Company \\
\hline GTP & Growth and Transformation Plan \\
\hline $\mathrm{Ha}$ & hectares \\
\hline HCMC & Ho Chi Minh City \\
\hline ICS & Investment Climate Survey \\
\hline ICT & information and communications technology \\
\hline IDS & Industrial Development Strategy \\
\hline IFIs & international financial institutions \\
\hline IGC & International Growth Centre \\
\hline IIDS & Integrated Industrial Development Strategy \\
\hline ILO & International Labour Organization \\
\hline IMF & International Monetary Fund \\
\hline IPEME & Institute for the Promotion of micro, small, and medium enterprises \\
\hline IPS & Industrial Policy and Strategy \\
\hline IS & import substitution \\
\hline ISI & import substitution industrialization \\
\hline ISIC & International Standard Industrial Classification \\
\hline
\end{tabular}


ISSER Institute of Statistical, Social and Economic Research

IZ industrial zones

JVC joint venture companies

KIPPRA Kenya Institute for Public Policy Research and Analysis

LIDI Leather Industry Development Institute

LPG liquefied petroleum gas

M\&E monitoring and evaluation

M3 broad money

MAFF Ministry of Agri, Forestry \& Fisheries

MDA ministries, departments, and agencies

MDGs Millennium Development Goals

MFA multi-fibre arrangement

MFI micro-finance institutes

MFN most favoured nation

MGS Maximum Growth Strategy

MHESRT Ministry of Higher Education Scientific Research and Technology

MIGA Multilateral Investment Guarantee Agency

MLSM medium and large-scale manufacturing

MoFED Ministry of Finance and Economic Cooperation

MoT Ministry of Tourism

MoTI Ministry of Trade and Industry

MPLA Angolan Liberation Popular Movement

MS Mixed Strategy

MSE micro and small enterprise

MSMEs micro, small, and medium enterprises

MTTI Ministry of Trade, Tourism and Industry (Uganda)

MUB Manufacturing under Bond

NARC National Rainbow Coalition

NBC National Bank of Cambodia

NBS National Bureau of Statistics

n.e.c. not else classified

NEC National Economic Council

NEEDS National Economic Empowerment and Development Strategy

NEPZA Nigeria Export Processing Zone Authority

NERFUND National Economic Reconstruction Fund

NESP National Economic Survival Programme 


\begin{tabular}{|c|c|}
\hline NIE & newly industrialized economies \\
\hline NIP & National Industrial Policy \\
\hline NIPC & Nigerian Investment Promotion Commission Act \\
\hline NIS & National Institute of Statistics \\
\hline NISER & Nigerian Institute of Social and Economic Research \\
\hline NLC & National Liberation Council \\
\hline NPA & new agricultural policy \\
\hline NPI & new industrial policy \\
\hline NSDP & National Strategic Development Plan \\
\hline NTR & normalized trade relationship \\
\hline ODA & official development assistance \\
\hline OECD & Organisation for Economic Co-operation and Development \\
\hline OPIC & Overseas Private Investment Corporation \\
\hline PASDEP & Plan of Action for Sustainable Development and Eradication of Poverty \\
\hline PCS & community solidarity levy \\
\hline PEED & Private Enterprises and Export Development \\
\hline PMAC & Provisional Military Administrative Council \\
\hline PMI & Industrial Modernization Programme \\
\hline PODE & (WB's) Private Sector Development Program \\
\hline PPP & purchasing power parity \\
\hline PRE & Economic Rehabilitation Program \\
\hline PRES & Social and Economic Rehabilitation Program \\
\hline PRI & industrial redeployment policy \\
\hline PRK & People's Republic of Kampuchea \\
\hline PRSP & Poverty Reduction Strategy Programme \\
\hline $\mathrm{R} \& \mathrm{D}$ & research and development \\
\hline RGC & Royal Government of Cambodia \\
\hline RMRDC & Raw Materials Research and Development Council \\
\hline RS & statistical tax \\
\hline S\&T & science and technology \\
\hline SADC & South African Development Community \\
\hline SALs & structural adjustment loans \\
\hline SAPs & structural adjustment programmes \\
\hline SCA & Accelerated Growth Strategy \\
\hline SDPRP & Sustainable Development and Poverty Reduction Program \\
\hline SDR & special drawing rights \\
\hline
\end{tabular}


SEDS Socio-Economic Development Strategy

SEM South and East Mediterranean

SENELEC Senegal National Electricity Company

SEZs special economic zones

SFYP Second Five-year Plan

SGER State of the Ghana Economy

SIDP Sustainable Industrial Development Policy

SME small and medium enterprise

SMEDAN Small and Medium Enterprises Development Agency of Nigeria

SNDES National Social and Economic Development Strategy

SOEs state-owned enterprises

SON Standards Organization of Nigeria

SONEPI National Company for Industrial Research and Development

SPA Seven Point Agenda

SSA(n) sub-Saharan Africa(n)

SSM Survey on Small-scale Manufacturing

SSRS Small-scale Rural Strategy

STC State Trading Corporation

STPI Software Technology Parks of India

TAI Textile and Apparel Institute

TCI special import tax

TCL textiles, clothing, and leather

TDP digressive protection tax

TFP total factor productivity

TIDI Textile Industry Development Institute

TIP Trade and Investment Programme

TIRDO Tanzania Industrial Research Development Organization

TWF textiles, wearing apparel, and footwear

TYP three-year development plan

UIA Ugandan Investment Authority

UN United Nations

UNCTAD UN Conference on Trade and Development

UNDP UN Development Programme

UNIDO UN Industrial Development Organization

UNU-WIDER UN University World Institute for Development Economics Research USPTO United States Patent and Trademark Office 
VES Vietnamese Enterprise Survey

WAMU West African Monetary Union

WAEMU West African Economic and Monetary Union

WB World Bank

WTO World Trade Organization

WWI First World War

WWII Second World War

ZFID Dakar Industrial Free Trade Zone 



\title{
Notes on Contributors
}

\begin{abstract}
Charles Ackah is Senior Research Fellow, Head of Economics Division, at the Institute of Statistical, Social and Economic Research (ISSER), University of Ghana, Legon. He holds a PhD in Economics from University of Nottingham, UK. His primary research interests are in applied trade policy, labour market and poverty analysis, gender and intra-household bargaining, microfinance, and consumer demand analysis. He has worked as consultant for the International Labour Organization (ILO) and the World Bank.
\end{abstract}

John O. Adeoti is a Professor of Development Economics in the Economic Policy Research Department, Nigerian Institute of Social and Economic Research (NISER), Ibadan. He has researched and published extensively on the role of science, technology, and innovation in economic development, economic policy reform, and environmentally sustainable development in sub-Saharan Africa (SSA). He is a leading author and pioneer in the application of the innovation system framework to African economies.

Foluso M. Adeyinka is a Senior Research Fellow in the Economic Policy Research Department, Nigerian Institute of Social and Economic Research (NISER). She holds a $\mathrm{PhD}$ in information science from the University of Ibadan, and a Master's degree in technology and innovation management from SPRU, University of Sussex, Brighton. Her major research interest is in the area of science and technology policy, with a focus on industrial development.

Charles Adjasi is an Associate Professor at the University of Stellenbosch in South Africa, where he also received his $\mathrm{PhD}$ in 2007. He is a development finance specialist with particular interest in the growth and development of African capital markets and development finance impact assessment. He also has interest in analysing firm productivity, pricing and competitive strategy, and small-enterprise development. He has been involved in policy work on corporate governance and international trade policy issues, and has consulted for the World Bank and has been a visiting scholar at the International Monetary Fund (IMF).

Mohamed Ayadi is a Professor on Econometrics in the Department of Quantitative Methods of the Institut Supérieur de Gestion de Tunis, and Director of UAQUAP (Research Unit on Quantitative and Applied Economics), University of Tunis. His research is the applied microeconomics of development with a focus on both household and enterprise behaviour. He has published in the fields of development economics and industrial economics, in particular in the area of household poverty, and enterprise dynamics in developing countries. 
Jacob Chege is a Senior Policy Analyst at the Kenya Institute for Public Policy Research and Analysis (KIPPRA). He has vast experience and training in the field of institutional economics, and has researched and published in areas of firm investment behaviour, value chain analysis, growth and performance of firms, and inter-firm networks. Beyond research, he has been heavily involved in policy process and advocacy, particularly through technical committees and working groups with various government ministries and in the private sector.

Louis N. Chete is Head of Macroeconomic Group in the Surveillance and Forecasting Department of the Nigerian Institute of Social and Economic Research (NISER). He has been a visiting scholar at the World Bank and the International Monetary Fund (IMF) in Washington, DC, and a visiting fellow at the University of Edinburgh. He served as member of the Technical and Drafting Committees of Nigeria's most recent economic blueprints, has accomplished numerous consultancy assignments for federal and state authorities in Nigeria and several regional and international agencies, and has published widely in local and international journals in the areas of trade, industry, finance, and public sector economics.

Sokty Chhair is a Senior Researcher at Cambodian Economic Association. His research is in the field of development economics focusing on collective action in community development and industrialization in developing countries.

Ji Eun Choi is a Senior Research Economist at the African Development Bank.

Fatou Cissé is from Senegal, and works as a Researcher at the Consortium pour la Recherche Économique et Sociale, Dakar.

António Sousa Cruz is a researcher collaborating with UNU-WIDER on projects related to manufacturing, tax benefit, and social accounting matrices. He has longterm experience working in the central statistical office and in the studies unit at the Ministry of Planning and Development, Mozambique, where he was Director during 2006-13. He was also the Director at the Center for Economics and Management Studies at the University Eduardo Mondlane, Mozambique.

Mulu Gebreeyesus is a Senior Researcher at the Ethiopian Development Research Institute (EDRI). He was previously a Research Fellow at UNU-MERIT, Maastricht. His current research interests are: interaction between industrial policy and green growth strategies; development of non-traditional activities; trade orientation and firm performance; and entrepreneurship and small business development. He received his PhD in Economics from the University of Göteborg in 2006.

Dina Guambe, born in Maputo, Mozambique, has an economics degree from the School of Economics at the University Eduardo Mondlane, where she is currently studying for a master's degree in development economics. She began research work in 2010 at the Directorate of Study and Policy Analysis, Ministry of Planning and Development, and currently she is at the Ministry of Economy and Finance, both Mozambique.

Eria Hisali is an Associate Professor at the School of Economics, Makerere University. He also teaches at the Trade Policy Training Center in Africa (TRAPCA). He has previously worked as a visiting Lecturer at the Joint Facility for Electives of the Collaborative 
Master of Arts Programme run by the African Economic Research Consortium (AERC). His current research interests are in the fields of development microeconomics and the microeconomics of the public sector. He has published in internationally peer-reviewed journals. He has also consulted for various local and international organizations.

Julius Kiiza is an Associate Professor of Political Economy and Development in the Department of Political Science and Public Administration at Makerere University. He holds a BA (Hons) degree from Makerere University and a First Class Master of Public Policy from the University of Sydney, where he also got his PhD in Government. He has a growing list of publications on institutional political economy: the economic role of the state in an era of globalization; the political economy of oil-led development; and the changing but not ending significance of industrial policy in an era of economic globalization.

Peter Kimuyu is a Professor of Economics in the School of Economics, University of Nairobi, and a Research Associate with the Kenya Institute of Public Policy Research and Analysis.

Luu Minh Duc received his Bachelor's Degree in International Relations at Hanoi Academy of Diplomacy, an MBA at City College, London, and a graduate certificate in Public Administration at the Australian National University. As a Researcher at the Central Institute for Economic Management, he has contributed in several policy research reports including the Vietnam Competitiveness Report 2010; Competitiveness of Exporting Firms in Vietnam 2011; Social Enterprises in Vietnam 2012. His research interests are privatization, the developmental state, and political economy.

Constantino Pedro Marrengula is an Assistant Professor in the Faculty of Economics at Eduardo Mondlane University in Maputo, Mozambique. He is also a researcher for the International Growth Centre (IGC) in Mozambique. His research and publications have included private sector and small and medium enterprise (SME) performance in Mozambique, limited market participation of firms in the construction and tourism industries, and management skills and social capital in Mozambique's private sector.

Wided Mattoussi is an Assistant Professor in the Department of Quantitative Methods, University of Jendouba. Her research is the microeconomics of development with particular focus on regulation of water institutions. She has published in the field of agricultural economics, specifically the effective design of irrigation cooperative institutions to address water theft by simple manipulation of water meters.

Mathilde Maurel, a Senior Researcher at the Centre national de la recherche scientifique (CNRS) and the Fondation pour les Études et Recherches sur le Développement International (FERDI), specializes in transition and development economics. As regards transition economics she has published extensively in the leading journals of the field. Within development economics, she has recently investigated the issue of migration pressures stemming from climate shocks, the economics of aid consistency, and more generally the most acute obstacles to growth in a developing context.

Jamal Msami works at Research on Poverty Alleviation (REPOA) in Dar es Salaam, and is a Postgraduate Researcher at the University of Bristol, UK. His research interests lie in applied economics, governance, and public policy. He has publications in the fields of 
local government reforms focusing on service delivery and financial management. He is currently working on institutional analyses of sectoral reforms in Tanzania.

Carol Newman is an Associate Professor at the Department of Economics, Trinity College Dublin and a non-resident Senior Research Fellow at UNU-WIDER. Her research is in the microeconomics of development with a focus on both household and enterprise behaviour. She has published widely in the fields of development economics and agricultural economics, in particular in the area of enterprise dynamics and performance in developing countries.

Dianah Ngui has a $\mathrm{PhD}$ in Economics from Martin Luther University in HalleWittenberg, Germany. Currently, she is a Senior Lecturer in Kenyatta University's School of Economics. She has a wealth of teaching and research experience that spans several years in industrial and energy economics, and econometrics, and has published extensively in several prestigious journals.

Nguyen Thi Tue Anh is the Vice President of the Central Institute for Economic Management, Hanoi, a leading government think tank in Vietnam. She holds a PhD in Development Economics from the University of Ulm and University of Frankfurt am Main. Her research interests are within economic growth (with an empirical focus) and international economic integration. She has extensive country experience in Asia from work in Vietnam, Thailand, Singapore, Taiwan, China, and Korea.

Marios Obwona is currently a Senior Economic Advisor to the Minister of Finance and Development Planning under the USAID-funded Governance and Economic Management Support (GEMS) Program to the Government of Liberia. Previously, he was Director of Training at the African Economic Research Consortium (AERC), Nairobi. He also served as Director of Research and Policy Functions at the Central Bank of Uganda, Head of Macroeconomics Division at the National Planning Authority, Government of Uganda, and a principal research fellow at the Economic Policy Research Centre in Uganda.

Femi Oladapo Ogundele is a Senior Research Fellow at the Nigerian Institute of Social and Economic Research (NISER), and an Adjunct Lecturer with Lead City University in Ibadan. In 2009, Dr Ogundele was a visiting research scientist to AfricaRice, and in 2010, a visiting researcher with Africa Growth Initiative, Brookings Institute, Washington, DC.

John Page is a Senior Fellow, Global Economy and Development Program at the Brookings Institution and a Non-Resident Senior Fellow of UNU-WIDER. He is the author of more than ninety published articles on the economics of developing countries, and the co-author of the 2009 UNIDO Industrial Development Report Breaking In and Moving Up: Industrial Challenges for the Bottom Billion and the Middle-Income Countries.

John Rand is a Professor of Development Ecomomics at the Department of Economics, University of Copenhagen, and a member of the Development Economics Research Group (DERG). His main research areas are within development economics, in particular understanding the importance of enterprise dynamics for guiding industrial policy. Recently, his research has focused on the importance of economic complexity and industry linkages for sustainable firm level productivity improvements. 
Abebe Shimeles received his postgraduate degree in economics from Göteborg University, Delhi School of Economics, and a BA from Addis Ababa University. He is currently Acting Director, Development Research Department at the African Development Bank. He is also a research fellow at the Institute for the Study of Labour (IZA), and an adjunct associate professor at University of Cape Town. He has worked for the World Bank, UNECA, ActionAid, and Addis Ababa University in different capacities. His current research focuses on labour markets in Africa, impact evaluation of tax policies, community-based health insurance, and some issues on inequality, market distortions, and domestic violence.

Isaac Shinyekwa is a Research Fellow at the Economic Policy Research Centre (EPRC), where he acts as Head of Department Trade, Regional Integration and Multilateral Arrangements. He previously worked for the Ministry of Agriculture in an arm of the Planning Division where he coordinated research projects. His research and publications are in the areas of rural development, trade, and regional integration. In the recent past, he has been involved in modelling activities using computable general equilibrium models.

Måns Söderbom is a Professor of Economics in the Department of Economics, School of Business, Economics and Law, University of Göteborg. He is also a Research Associate at the Centre for the Study of African Economies (CSAE), Department of Economics, University of Oxford, a Fellow of the European Development Research Network, and a non-resident Senior Research Fellow at UNU-WIDER. His research has been published by leading international journals and he has also contributed to several books on economic development. Industrial development is his main area of interest, but he has also worked on civil conflict, labour markets, and schooling.

Finn Tarp has some thirty-seven years of experience in academic and applied development economics research and teaching. His field experience covers more than twenty years of in-country work in thirty-five countries across Africa and the developing world more generally, including longer-term assignments in Swaziland, Mozambique, Zimbabwe, and Vietnam. He is the Director of UNU-WIDER and Professor of Development Economics at the University of Copenhagen. He is a leading international expert on issues of development strategy and foreign aid, with an interest in poverty, income distribution and growth, micro- and macroeconomic policy and modelling, agricultural sector policy and planning, household and enterprise development, and economic adjustment and reform. He has published close to ninety articles in international academic journals alongside five books, fourteen edited book volumes and special journal issues, and more than forty book chapters.

Trinh Duc Chieu obtained his Bachelor's Degree in Development Economics at Hanoi National Economic University in 1998, and a master's degree in Applied Econometrics at Monash University, Australia, in 2008. He is a Researcher at the Central Institute for Economic Management (Vietnam), and his main area of research is enterprise reform and development. He has contributed to drafting numerous government regulations and policies for state-owned enterprises reform, as well as studies on small and medium-sized enterprise (SME) development. 
Festus Turkson is a Lecturer in the Department of Economics, University of Ghana, Legon, Accra. His main research interests are in the areas of international trade and economic policy, industrial and financial economics, and applied microeconometrics. He received his PhD from the University of Nottingham, UK, and completed course work at Harvard University, USA, during the academic year 2005/06. He has been consulted on economic matters for the World Bank, UNECA, UNU-WIDER, ILO, AFDB, ACEG, IICD, and the AERC.

Amosse Francisco Ubisse is a Research Associate at J-PAL Africa where he works on the Mozambique health project. Prior to joining J-PAL Africa in 2014, he worked at the National Institute of Statistics in Mozambique, compiling the national accounts and global indicators. He also has experience analysing policy for the Mozambican Federation of Industry (AIMO-FI) and as an Assistant Lecturer in the Faculty of Economics at Eduardo Mondlane University (UEM). A native of Maputo, Amosse holds a BA in Economics from UEM.

Luyna Ung, a Cambodian national, joined the Ministry of Economy and Finance (MEF) in 2004, and has held a variety of positions in the Department of Economic and Public Finance Policy. He has been involved in research activities on development issues including macroeconomic policy, agriculture, poverty, and development strategy. In 2013 he was promoted to Deputy Director of the General Department of Budget, and in 2015 he was appointed as Deputy Secretary of Public Financial Management Reform Program in charge of policy. Mr Luyna holds a graduate degree in development economics from the Australian National University.

Samuel Wangwe is the Executive Director of Research on Poverty Alleviation (REPOA) in Dar es Salaam, an independent research institute on policy for development in Tanzania. He has over forty years' experience as an economist, policy researcher, and analyst, and as policy and economic advisor to the Government of Tanzania. His publications have covered areas such as development policy, industrial development, and trade and technology. 


\section{The Pursuit of Industry}

\section{Policies and Outcomes}

Carol Newman, John Page, John Rand, Abebe Shimeles, Måns Söderbom, and Finn Tarp

\subsection{Introduction}

One of the most significant changes in the global economy over the last forty years is the shift of industry from high income to developing countries. Between 1992 and 2012, the share of world manufacturing output produced by developing countries nearly doubled, rising to more than a third of global production. Growth of manufactured exports has greatly exceeded the growth of manufacturing output, and developing countries have gained world market shares in both simple and complex manufactured products. Today, East Asia, led by China, produces more than one-fifth of global manufacturing value added (UNIDO 2013).

Africa's experience with industrialization over the same period has been disappointing. In 2010 the average share of manufacturing in GDP in subSaharan Africa (SSA) was 10 per cent, unchanged from the 1970s. Africa's share of global manufacturing has fallen from about 3 per cent in 1970 to less than 2 per cent in 2010. Manufacturing output per person is about a third of the average for all developing countries and manufactured exports per person are about 10 per cent of the global average for low income countries (Page 2012).

This book contains eleven country studies-eight from SSA, one from North Africa, and two from newly industrializing East Asia-sponsored by the African Development Bank, the Brookings Institution, and UNU-WIDER under a research project called Learning to Compete. The project was undertaken in an effort to understand why Africa has so little industry. The research 
Table 1.1 The Africa country cases in context, 2013

\begin{tabular}{llllrlll}
\hline & $\begin{array}{l}\text { GDP } \\
\text { per } \\
\text { capita }\end{array}$ & $\begin{array}{l}\text { GDP per } \\
\text { capita } \\
\text { rank }\end{array}$ & $\begin{array}{l}\text { Population } \\
\text { share }\end{array}$ & $\begin{array}{l}\text { GDP } \\
\text { share }\end{array}$ & $\begin{array}{l}\text { Share of } \\
\text { manufacturing } \\
\text { value added }\end{array}$ & $\begin{array}{l}\text { GDP } \\
\text { growth } \\
1995-2012\end{array}$ & $\begin{array}{l}\text { Year of } \\
\text { independence }\end{array}$ \\
\hline Ethiopia & 1,354 & 36 & 11.26 & 4.57 & 1.22 & 7.75 & 1941 \\
Ghana & 3,974 & 13 & 3.10 & 3.33 & 1.55 & 6.06 & 1957 \\
Kenya & 2,265 & 22 & 5.31 & 4.52 & 3.16 & 3.71 & 1963 \\
Mozambique & 1,045 & 40 & 3.09 & 1.89 & 1.52 & 7.37 & 1975 \\
Nigeria & 5,601 & 12 & 20.78 & 30.78 & 6.63 & 6.44 & 1960 \\
Senegal & 2,269 & 21 & 1.69 & 1.91 & 1.66 & 4.04 & 1960 \\
Tanzania & 1,775 & 26 & 5.89 & 4.03 & 2.47 & 6.06 & 1961 \\
Uganda & 1,410 & 33 & 4.50 & 2.62 & 1.27 & 6.96 & 1962 \\
\hline
\end{tabular}

Note: Column 2 is rank out of 46 SSA countries excluding South Africa. Somalia and Réunion are also excluded from the computation of total GDP due to a lack of data. Columns 3, 4, and 5 are computed as the share of the total for subSaharan Africa excluding South Africa. Total population for SSA excludes Réunion, total GDP for SSA excludes Somalia and Réunion, and the total manufacturing value added for SSA excludes Cape Verde, Equatorial Guinea, Réunion, and Somalia due to a lack of data.

Source: World Bank (2014) World Development Indicators; UNIDO Statistics (2014) Manufacturing Value Added Database; authors' calculations.

programme sponsored the eleven country studies that appear in this volume and an additional twenty quantitative studies based on firm-level data from the same countries. ${ }^{1}$ The country studies were undertaken to provide a comparative perspective on the role that public policy has played in Africa's industrialization.

The eight SSAn countries included in this volume-Ethiopia, Ghana, Kenya, Mozambique, Nigeria, Senegal, Tanzania, and Uganda-are some of the stars of Africa's growth turnaround. Six of the eight have been among its fastest growing economies since 2000. Together they represent 54 per cent of the region's GDP and 56 per cent of its population (Table 1.1). Their manufacturing sectors make about one-fifth of SSA's manufacturing value added (excluding South Africa). These are Africa's emerging markets, but they are not emerging industrial economies. Senegal has the highest share of manufacturing in GDP at about 18 per cent. Nigeria has the lowest at less than two per cent. On average they are quite similar to Africa as a whole. Their share of manufacturing in GDP is 9.5 per cent, and the policies all eight countries adopted for industrial development closely parallel those of the region more broadly.

The comparator countries took quite different policy approaches to industrialization and had very different industrial development outcomes. Tunisia

\footnotetext{
1 Working paper versions of the research are published on the UNU-WIDER website at <http://www.wider.unu.edu/research/current-programme/en_GB/L2C-2010> and on the Brookings Institution website at <http://www.brookings.edu/about/projects/africa-growth/ learning-to-competes. An overview of the research programme as a whole can be found in Made in Africa: Learning to Compete in Industry (Brookings Institution Press, 2015).
} 
in North Africa gained its independence at about the same time as SSA, but its approach to industrialization diverged early on from that found south of the Sahara. Its manufacturing growth has exceeded that for SSA for three decades. Cambodia and Vietnam had per capita income levels and structural characteristics similar to African economies as recently as 2005 in Cambodia and 2001 in Vietnam (Table 1.2). After an early period of state-led industrialization, both countries have followed industrial development strategies that are similar to those of other emerging East Asian countries with considerable success. Since 1990 manufacturing growth has averaged more than 10 per cent per year in both countries.

The chapter is organized in the following way. Section 1.2 makes the case for renewed attention to industrialization in Africa. Sections 1.3 and 1.4 provide overviews of industrial development policies and outcomes in Africa and in emerging Asia. Section 1.5 presents comparative results from the country studies in four areas identified in the literature as key drivers of industrial development: infrastructure, human capital, and institutions; manufactured exports; agglomerations; and foreign direct investment (FDI). Section 1.6 concludes.

\subsection{Industrialization, Structural Transformation, and Growth}

One of the enduring 'stylized facts' of economic development is that low income countries have large differences in output per worker across sectors. Structural transformation-the shift of resources from lower productivity to higher productivity sectors-is, therefore, often a key driver of growth (Lewis 1954; Chenery 1986). During the course of structural transformation, economy-wide changes in output per worker are the result of labour productivity growth within individual sectors and the change in labour productivity due to labour reallocations across sectors. ${ }^{2}$ When strong within sector productivity growth combines with rapid movement of labour into higher productivity sectors-the pattern of structural transformation seen in East Asia over the last twenty-five years - very rapid growth of output per worker is possible (McMillan and Rodrik 2011).

Because it has the greatest differences across sectors in output per worker, Africa is the developing region with the most to gain from structural transformation. Recent research, however, finds that this potential has not been fully realized. In fact from 1990 until 1999 structural transformation was 'growth reducing'. Africa's higher productivity sectors failed to generate

\footnotetext{
${ }^{2}$ McMillan and Rodrik (2011) and de Vries et al. (2013) present differing formal decompositions.
} 
Table 1.2 Structural characteristics of the case study countries

\begin{tabular}{|c|c|c|c|c|c|c|c|c|}
\hline \multirow[t]{2}{*}{ Country } & \multicolumn{4}{|c|}{ Share of labour force } & \multicolumn{4}{|c|}{ Share of GDP } \\
\hline & Agriculture & Manufacturing & Other industry & Services & Agriculture & Manufacturing & Other industry & Services \\
\hline $\begin{array}{l}\text { Cambodia } 1994 \text { and Vietnam } 1990 \\
\text { (US\$800-1,200) }\end{array}$ & 74.0 & 7.1 & 2.9 & 16.0 & 43.5 & 11.4 & 7.6 & 37.5 \\
\hline Ethiopia 2005 & 75.1 & 6.3 & 2.5 & 16.1 & 45.3 & 4.2 & 6.2 & 44.3 \\
\hline Mozambique 2010 & 71.0 & 3.6 & 0.7 & 24.7 & 24.2 & 14.2 & 10.8 & 50.8 \\
\hline $\begin{array}{l}\text { Cambodia } 2003 \text { and Vietnam } 1992 \\
\text { (US\$1,200-2,000) }\end{array}$ & 68.5 & 8.5 & 2.0 & 21.0 & 34.0 & 15.9 & 10.6 & 39.5 \\
\hline Tanzania 2010 & 73.0 & 2.6 & 3.3 & 21.1 & 27.6 & 9.8 & 14.8 & 47.8 \\
\hline Uganda 2009 & 69.3 & 3.9 & 0.5 & 26.3 & 23.4 & 9.4 & 10.4 & 56.6 \\
\hline $\begin{array}{l}\text { Cambodia } 2010 \text { and Vietnam } 2000 \\
\text { (US\$2,000-3,000) }\end{array}$ & 59.5 & 9.5 & 2.0 & 22.3 & 29.5 & 17.3 & 9.2 & 44.0 \\
\hline Ghana 2010 & 42.0 & 10.8 & 4.5 & 42.7 & 29.7 & 6.7 & 12.2 & 51.4 \\
\hline Kenya 2010 & 48.4 & 12.8 & 3.6 & 35.2 & 24.8 & 11.2 & 7.2 & 56.8 \\
\hline Senegal 2010 & 51.5 & 9.9 & 4.0 & 34.6 & 17.4 & 18.4 & 9.7 & 59.5 \\
\hline Vietnam 2010 (US\$5,000-) & 51.0 & 13.5 & 0.9 & 30.5 & 19.0 & 21.9 & 16.1 & 43.0 \\
\hline Nigeria 2010 & 58.8 & 4.0 & 2.0 & 35.2 & 30.4 & 1.9 & 44.4 & 23.3 \\
\hline Tunisia 2010 & 18.0 & 30.0 & 3.0 & 49.0 & & & & \\
\hline
\end{tabular}

Sources: World Bank (2014) World Development Indicators; McMillan and Rodrik (2011) Database; Groningen Africa Sector Database (2013). 
enough jobs to absorb a rapidly growing labour force, and the share of workers employed in high productivity sectors declined, offsetting positive within sector productivity growth and reducing aggregate growth of output per worker (de Vries et al. 2013; McMillan et al. 2014).

While labour in Africa began to move out of agriculture into more productive employment after 2000, the movement that has taken place has been into 'market services', mainly retail trade and distribution (de Vries et al. 2013). This structural shift from agriculture to services differs from the development experience of other regions, and it represents movement from very low productivity to slightly higher productivity jobs. Output per worker in services in Africa is only about two times higher than output per worker in agriculture. Moreover, services have been absorbing workers faster than output in the sector has been increasing. The relative productivity of African market services fell from 3.0 times the economy-wide average in 1990 to 1.8 in 2010, suggesting that the marginal productivity of new services workers is low and possibly negative (de Vries et al. 2013).

Historically, industry is the sector into which resources have first moved in the course of structural transformation (Chenery 1986). Between 1950 and 2006, about half of the catch-up by developing countries to advanced economy levels of output per worker was explained by rising productivity within industry combined with structural transformation out of agriculture (Duarte and Restuccia 2010). Industry is the pre-eminent destination sector at early stages of development because it is a high productivity sector capable of absorbing large numbers of moderately skilled workers. Average labour productivity in manufacturing in Africa is more than six times that in agriculture (McMillan and Hartgen 2014). It is also a powerful engine of within sector productivity growth. There is evidence that modern manufacturing industries-unlike agriculture or services-converge to global best practice productivity levels 'unconditionally', regardless of geographical disadvantages, poor institutions, or bad policies (Rodrik 2013).

Developing countries with the most rapidly sustained growth have typically reallocated the most labour into manufacturing. Where manufacturing has stagnated and structural transformation has mainly involved reallocation of workers into lower productivity sectors, aggregate per capita income growth has lagged (Duarte and Restuccia 2010). This is not good news for Africa: the share of manufacturing in GDP for Africa as a whole has been declining since the mid-1970s. Many of the region's recent growth success stories-Ethiopia, Ghana, Kenya, Tanzania, and Uganda for example-have shares of manufacturing in GDP that are well below the values predicted by their GDP per person (Dinh et al. 2012). Lack of industrial development combined with declining within sector productivity in services raises the risk that structural transformation in Africa may once again become growth reducing. 


\subsection{Industrial Policies and Outcomes in Africa: From a Dominant State to the Investment Climate}

Despite major differences in history, language, and political structure, the SSAn countries in this volume share a striking uniformity in their approach to industrialization. Broadly, their policies to encourage industrial development fall into three phases: state-led; import substitution; the Washington Consensus and structural adjustment, and reform of the 'investment climate', the physical, institutional, and regulatory environment for firms. Industrial performance has largely followed three phases as well: an early boom, decline, and stagnation.

\subsubsection{State Ownership and Import Substitution, 1960-85}

When Africa gained independence, post-colonial governments saw industrialization as a key driver of economic development. Leaders in English-, French-, and Portuguese-speaking Africa shared similar views, strongly shaped by a desire to modernize their mainly agrarian economies and reduce dependence on the former colonial powers. ${ }^{3}$ The centrepiece of the industrialization effort was the development of large-scale, often capital-intensive manufacturing industries owned and managed by the state. Protection of the domestic market against imports was viewed as necessary and was particularly appealing to post-colonial leaders as a way of securing 'economic independence'. The state became the central actor in the industrialization story for a variety of reasons. Political ideology and nationalism were certainly key motivations (Ndulu 2007). Newly independent African governments invested heavily in manufacturing, setting up state-owned enterprises (SOEs) for the domestic production of consumer goods, building materials, and the processing of primary products.

\subsubsection{EARLY INDUSTRIALIZATION}

Arguably, Ghana set the tone. When it gained independence from Britain in 1957, import substitution, supported by high levels of protection, was used to create a new industrial structure and reduce dependence on Britain. The state invested heavily in the manufacturing of consumer and producers goods. The electrical, electronic, and machinery industries in particular were viewed as essential to provide the inputs needed to industrialize further. Other countries followed similar industrialization strategies upon gaining independence. Senegal pursued state-led import substituting industrialization in the late

\footnotetext{
${ }^{3}$ See Killick (1978) for a survey of the influence of development economics on the strategies pursued by Africa's post-independence leaders.
} 
1960s. Tanzania's 1967 Arusha Declaration stressed socialism and selfreliance. Major industrial firms were nationalized and the public sector assumed a leading role. Industrialization and state ownership featured prominently in Uganda's Second Five-Year Plan. Nigeria's growing revenues from oil exports led the government to undertake ambitious investments in iron and steel, cement, salt, sugar, fertilizer, and pulp and paper.

Kenya adopted a post-independence industrialization strategy in the 1960s that relied on import substitution, but state ownership and management of the industrial sector was limited to a few 'strategic industries'. Two governments followed more explicitly central planning approaches. In Ethiopia the Marxist Dergue government nationalized most privately owned medium- and large-scale manufacturing enterprises and intensified the import substitution strategy that had been in place since the time of the emperor. Beginning in 1975 the Frelimo government in Mozambique introduced a set of policies designed to make the public sector the dominant economic actor.

Tunisia embraced import substitution and state ownership at the beginning of the 1960s, but by 1970 industrial growth had proved disappointing. In response the government adopted an infitâh policy that combined import substitution and export promotion. ${ }^{4}$ The economy was divided into an 'offshore' sector geared towards exports and an 'onshore' sector that was shielded from competition and regulated by the state. Institutional and policy reforms were introduced to attract FDI, mainly from Europe. The offshore sector was dominated by foreign owned firms engaged in assembly-type manufacturing for export to the European market. The onshore private sector primarily consisted of small factory units producing simple consumer goods under high protection. Heavy industry, transport, water, and electricity were state owned.

\subsubsection{THE INDUSTRIALIZATION DRIVE FALTERS}

Africa's state-led push for industrial development had considerable success in the 1960s. Manufacturing grew substantially faster than overall output between 1960 and 1970 and the share of manufacturing in total output increased. Between 1965 and 1970 industrial growth averaged more than 7 per cent per year in all of the African case study countries (except Mozambique which was still in a fierce liberation war). By 1970, however, the industrialization drive was beginning to lose steam, and by 1975 growth of the manufacturing sector had begun to lag GDP growth (Table 1.3). The growth deceleration was particularly sharp in Ethiopia, Ghana, Senegal, and Tanzania.

\footnotetext{
${ }^{4}$ Mauritius was the only SSA country to introduce a similar two-track approach to industrial development, beginning with the development of its free trade zones at about the same time.
} 
Table 1.3 Average annual growth of value added in manufacturing, 1965-2010

\begin{tabular}{|c|c|c|c|c|c|c|c|c|c|}
\hline & $1965-70$ & $1970-5$ & $1975-80$ & $1980-5$ & $1985-90$ & $1990-5$ & 1995-2000 & $2000-5$ & 2005-10 \\
\hline Ethiopia & 8.45 & 3.20 & 4.56 & 3.91 & 1.51 & 1.03 & 3.92 & 5.00 & 9.48 \\
\hline Ghana & 8.22 & 1.43 & -4.74 & -4.36 & 7.53 & -7.38 & 4.68 & 4.54 & 2.60 \\
\hline Kenya & 7.43 & 7.67 & 11.46 & 3.84 & 5.75 & 2.52 & -0.03 & 3.09 & 4.38 \\
\hline Mozambique & & & & & & -1.31 & 18.97 & 15.17 & 3.01 \\
\hline Nigeria & 5.52 & 12.20 & 13.59 & -0.99 & 4.10 & -1.07 & 0.25 & 8.85 & 8.43 \\
\hline Senegal & & 3.17 & 1.27 & 2.64 & 4.05 & 3.19 & 2.90 & 3.11 & 2.02 \\
\hline Tanzania & 9.95 & 4.73 & 2.36 & -5.01 & 2.43 & -0.02 & 5.73 & 8.09 & 8.61 \\
\hline Uganda & & & & 2.14 & 6.38 & 12.81 & 13.45 & 6.13 & 7.13 \\
\hline Tunisia & -0.74 & 20.50 & 13.63 & 6.39 & 0.50 & 5.66 & 5.78 & 2.79 & 4.88 \\
\hline Cambodia & & & & & & 8.86 & 21.04 & 13.86 & 8.70 \\
\hline Vietnam & & & & 9.50 & 2.42 & 10.35 & 11.26 & 11.66 & 9.33 \\
\hline
\end{tabular}

Notes: All growth rates in constant prices. Blank cells indicate that data are not available.

Sources: 1965-90: de Vries et al. (2013); McMillan and Rodrik (2011); 1990-2010: UNIDO Statistics (2014) Manufacturing Value Added Database; Uganda 1980-90, Tunisia 1965-2010, Vietnam 1985-90; World Bank (2014), World Development Indicators; authors' calculations. 
By the 1980s the state-led industrialization effort had reached its limits in most countries. Between 1980 and 1985 manufacturing output began to decline in Ghana, Nigeria, and Tanzania. Contrary to the intent of the import substitution strategy, dependence on imports actually increased due to the heavy reliance of industry on imported capital and intermediate goods. Public investment exceeded the fiscal capacity of the state, and the state's capacity to manage the enterprises. The efficiency of production, measured in terms of international prices, was low, and in some cases goods were produced at negative value added in international prices. There was substantial excess capacity in public manufacturing enterprises, many of which were heavily constrained by lack of imported intermediates and working capital.

\subsubsection{The Washington Consensus, 1985-2000}

In the early 1980s Latin America-the intellectual home of import substitution and its most important laboratory-was engulfed in macroeconomic turbulence. In response the international financial institutions (IFIs) developed a new set of policy-based lending instruments. ${ }^{5}$ These 'structural adjustment loans' (SALs) provided quick disbursing funds for budget and balance of payments support in return for an agreed set of economic reforms. A consensus emerged-at least among the US Treasury, the Federal Reserve, the International Monetary Fund (IMF), and the World Bank-on a set of ten policy reforms considered appropriate for developing countries. Williamson (1990) famously termed these the 'Washington Consensus'. Six of the ten directly affected the policy environment for industry: liberalization of interest rates; liberalization of exchange rates; liberalization of trade; liberalization of foreign investment; privatization; deregulation.

\subsubsection{STRUCTURAL ADJUSTMENT}

The Washington Consensus quickly found its way to Africa. The same external shocks that struck Latin America had left Africa's economies with flagging economic growth and chronic foreign exchange shortages. Governments attempted to sustain growth through expansionary macroeconomic policies leading to widespread loss of fiscal and monetary control. Exchange rates became seriously overvalued, and most governments responded to the lack of foreign exchange by introducing exchange controls and rationing. According to one estimate, the median African currency was 82 per cent overvalued in purchasing power parity (PPP) terms in 1980 (Easterly 2009). Growth ground to a halt and Africa entered structural adjustment. Between 1985 and 2000 more

\footnotetext{
5 While the IMF and the World Bank were the prime movers the regional development banks, including the African Development Bank, also became involved in structural adjustment.
} 
than thirty African countries, including all those in the country studies, would undertake structural adjustment programmes (World Bank 2000).

The initial focus of public policy advice and conditionality by the IFIs in Africa was on macroeconomic stabilization (World Bank 1992). Policy changes designed to improve resource allocation-liberalization of trade and finance and regulatory reform-followed closely thereafter. Across the continent governments liberalized trade and engaged in some deregulation of the domestic market. Privatization became a major objective and was often pushed, even in weak regulatory environments (Megginson and Netter 2001). Divestiture of state-owned enterprises was viewed as important both because it reduced the drain on the budget imposed by poor investment choices and because the state had proved to be a poor entrepreneur (Nellis 1986).

The reform programmes eventually restored macroeconomic balance. Fiscal deficits in the thirty-one countries covered by the Special Programme of Assistance for Africa had dropped to an average of 5.3 per cent of GDP in 1997 (World Bank 2000). The currency in the median African country was at PPP parity or undervalued in the early 1990s, and the black-market premium for foreign exchange had virtually disappeared (Easterly 2009). Quantitative trade restrictions were replaced by tariffs, and trade weighted average tariff rates fell from 30-40 per cent in 1980 to 15 per cent or less by 2000 (World Bank 2000). Privatization was more controversial and less widely embraced. In many countries the principal motivation to privatize was to placate the IFIs (Nellis 2003).

\subsubsection{A SHORT-LIVED INDUSTRIAL RECOVERY}

Perhaps no episode in Africa's contemporary economic history has raised as much debate as structural adjustment. The dramatic about-face in economic policies and more than a decade of very poor development outcomes sparked considerable academic and popular criticism. ${ }^{6}$ The early policy adjustments in combination with increased inflows of foreign aid provided a stimulus to industrial production in some countries, as firms used capacity that had been heavily constrained by lack of imported intermediates. Between 1980 and 1985 and 1985 and 1990 manufacturing growth shifted from negative to positive in Ghana, Nigeria, and Tanzania, and accelerated in Kenya, Senegal, and Uganda while it fell in Ethiopia and Tunisia.

The partial recovery of manufacturing was short-lived, however. Increased competition from imports and rising production costs due to reforms in the foreign exchange and financial markets put considerable pressure on manufacturing enterprises. Import competition, lack of technical expertise, and the

${ }^{6}$ See for example Easterly (2009). 
shortage of working capital resulted in most government-owned firms operating at as little as 10 per cent of capacity. By 1990-5 manufacturing output was falling in Ghana, Mozambique, Nigeria, and Tanzania, and growth of manufacturing had declined in every other country except Uganda. The textile and clothing sector was especially hard hit. In Tanzania twenty-two out of twenty-four textile factories had closed by 1990, and in Nigeria employment in the textile and garments sector fell from 700,000 in 1980 to 40,000 in 1995. Tunisia in contrast maintained manufacturing growth rates of more than 5.5 per cent per year throughout the 1990s, despite embarking on its own structural adjustment programme.

\subsubsection{Investment Climate Reform and New Directions, 2000}

Africa entered the twenty-first century in substantially better macroeconomic shape than it had been in the last decades of the twentieth. The region began to experience positive per capita income growth around 1995, a trend that would accelerate through the 2000s. Improved economic performance led to a retreat from structural adjustment lending, and the Millennium Development Goals set a new agenda for aid to Africa, one mainly centred on human development.

\subsubsection{INVESTMENT CLIMATE REFORMS}

In the area of industrial development, the World Bank and many bilateral donors shifted their focus after 2000 to the 'investment climate'. As defined by the World Bank, the investment climate included: (1) macroeconomic stability; (2) openness; (3) good governance and strong institutions; (4) the quality of the labour force and infrastructure (Stern 2001, 2002). Led by the donors, investment climate reforms became widespread, often becoming key components of budget support programmes. Around one-quarter of official development assistance (some US\$21 billion per year) currently supports investment climate reforms (OECD 2014).

The sub-Saharan case-study countries have all undertaken investment climate reform programmes in the last decade. Ghana has focused on trade policy and regulatory reforms. In Kenya reforms were undertaken to liberalize the regulatory regime. Mozambique adopted a new Industrial Policy and Strategy in which a significant role was assigned to promoting private investment. Nigeria's 2004 National Economic Empowerment and Development Strategy was explicitly targeted at making the industrial sector internationally competitive. The 2005 Senegal Accelerated Growth Strategy set as its main objective establishing a 'business environment consistent with international good practice'. In 2010 Tanzania introduced an Integrated Industrial Development Strategy aimed at creating a 'competitive business environment'. 


\subsubsection{NEW DIRECTIONS}

In addition to implementing the investment climate reform agenda, a number of countries have adopted more activist approaches to industrial development. In 1998 the Ethiopian government launched a strategy aimed at promoting labour-intensive manufactured exports. Kenya's Vision 2030 also emphasizes manufactured export growth. Most of the region's strategy and planning documents list a range of instruments intended to encourage private investment in targeted sectors. Ethiopia has attempted to coordinate private investment in textiles and garments, meat, leather and leather products, and agro-processing industries. Ghana's national industrial policy includes a number of highly sector-specific objectives. A prominent feature of Mozambique's industrialization strategy has been the promotion of large mining, manufacturing, and energy projects, known as 'mega-projects'.

Tunisia was the only African country studied in which the government undertook initiatives aimed at improving the competitiveness of individual industries and enterprises. ${ }^{7}$ An industrial upgrading programme, Programme de mise à niveau, was launched in 1996 followed by the Industrial Modernization Programme (PMI). These programmes were intended to provide technical assistance, training, financial subsidies, and infrastructure upgrades for firms to help them face international competition arising from the preferential trade agreement with the European Union under the Euro-Med initiative.

\subsubsection{NOT YET A TURNING POINT}

For Africa as a whole neither the widespread adoption of investment climate reforms nor the new directions taken by some governments have reversed the four decade decline in industry. Manufacturing growth has remained below the growth rate of GDP. Since 2000 industrial performance among the SSAn countries covered in the country studies has been uneven. There has been some acceleration in the growth of manufacturing in Ethiopia, Kenya, Tanzania, and Uganda (Table 1.3). Manufacturing growth in Ghana and Senegal has remained low and has lagged behind the overall growth of the economy. Nigeria was an exception; manufacturing grew at about 8 per cent per year between 2000 and 2010.

Table 1.4 shows trends in value added per worker in manufacturing between 1995 and 2010. ${ }^{8}$ Only Nigeria has registered rapid long-run manufacturing labour productivity growth. In Ethiopia, Kenya, and Senegal output per

\footnotetext{
7 Interestingly, at about this time, Mauritius also was making efforts to improve the productivity of individual firms (ACET 2014).

${ }^{8}$ The estimates for countries other than Mozambique and Uganda are drawn from the Groningen Africa Database (de Vries et al. 2013). Estimates for Mozambique and Uganda were kindly provided by Margaret McMillan from the extended McMillan-Rodrik database described in McMillan et al. (2014).
} 
Table 1.4 Manufacturing value added per worker in sub-Saharan African countries, 1995-2010

\begin{tabular}{lrrrr}
\hline & 1995 & 2000 & 2005 & 2010 \\
\hline Ethiopia & 100 & 85 & 74 & 64 \\
Ghana & 100 & 123 & 123 & 123 \\
Kenya & 100 & 65 & 53 & 56 \\
Mozambique & & & 100 & 36 \\
Nigeria & 100 & 139 & 192 & 267 \\
Senegal & 100 & 82 & 73 & 66 \\
Tanzania & 100 & 100 & 101 & 107 \\
Uganda & & 100 & 87 & 130 \\
\hline
\end{tabular}

Note: Indexed to 100 in first year of series.

Sources: de Vries et al. (2013); McMillan et al. (2014); authors' calculations.

worker declined between 1995 and 2010. In Ghana and Tanzania productivity growth was near zero. Uganda had a manufacturing productivity growth rate of about 2.7 per cent. In Tunisia growth in value added per worker in manufacturing averaged about 5 per cent per year between 1985 and 2005 (Ben Jelili and Goaied 2009).

\subsection{Policies and Outcomes in Emerging Asia}

Like Africa, Cambodia and Vietnam reacted to their colonial history by embracing state-led industrial development. In both cases early industrialization efforts were derailed by political instability, conflict, and war. Both countries also went through important macroeconomic adjustments in the 1990s accompanied by episodes of liberalization, and in the second half of the 1990s Cambodia and Vietnam followed the examples of other Asian economies by introducing policy and institutional reforms and public investments aimed at promoting manufactured exports.

\subsubsection{Early Industrialization, 1960-85}

When Cambodia gained independence from France in 1953, it focused on building an industrial base through a mixed-market model. Following a period of civil war and political instability, two Marxist regimes-the Khmer Rouge and the People's Republic of Kampuchea (PRK)—held power from 1975 to 1989. The PRK regime collectivized agriculture, nationalized all sectors of the economy, and adopted a policy of self-reliance. International trade, except with a few allied communist countries, was banned. The state controlled finance, transport, and foreign commerce. By the time the PRK left power in 1989 the Cambodian economy had been reduced to subsistence agriculture. 
Industry was decimated; only about 1 per cent of manufacturing establishments had survived.

Vietnam's approach to industrialization did not begin very differently from that of Cambodia. The country's First Five-Year Plan (1961-5) prioritized heavy industry and state entrepreneurship. The plan was disrupted in 1964 by the US-Vietnam war, and when the war ended in 1975, the government adopted a unified and centrally planned economic system. All industrial firms became state-owned enterprises, governed directly by ministries and provincial authorities. Input and output levels in manufacturing were set administratively. Between 1980 and 1985, industrial production increased at an annual rate of 9.5 per cent, but the economy was burdened by low labour productivity, rising inflation, and high unemployment. By 1985 Vietnam was on the brink of a socio-economic crisis.

\subsubsection{Structural Reform and the Export Push, 1985-}

Vietnam's comprehensive reform programme, Doi Moi (renovation), began in 1986. Doi Moi was intended to create a 'socialist-oriented market economy' that would combine state leadership (mostly at the planning stage) with market incentives. Private businesses and foreign owned enterprises were encouraged. The new policy framework included reform of SOEs and a law on foreign investment. In 1989 Vietnam adopted a radical and comprehensive reform package aimed at stabilizing and opening up the economy, increasing the autonomy of firms, and promoting competition.

One of the most important policy decisions that Vietnam made under Doi Moi was to shift from import substitution to an export-oriented industrialization strategy. Macroeconomic and trade policy reforms were targeted at reducing anti-export bias. There was a gradual reduction in export and import controls. Investment loans, post-investment interest subsidies, and export credit guarantees were introduced, together with short-term credit for exporters. Export Processing Zones and Industrial Zones were used to provide the infrastructure needed for new export industries. The Ministry of Planning and Investment was made responsible for the implementation of investment policy, including coordination with the private sector through its Foreign Investment Agency (FIA), Enterprise Development Agency, and Department of Economic Zones.

Spurred by the fall of the Soviet Union and the Doi Moi reforms in Vietnam, Cambodia began a gradual process of economic reform in the early 1990s. The most significant reforms included gradual privatization of state-owned companies and the de-collectivization of agriculture. Trade policies were liberalized and most quantitative restrictions and import licences were eliminated. In the late 1990s Cambodia took a set of steps towards industrial 
export promotion. Barriers to export and to the import of intermediate inputs were reduced or eliminated. Macroeconomic policy was aligned with the objectives of attracting foreign investment and export growth. The government provided generous incentives to FDI, and investments made within special economic zones received favourable treatment. A government-private sector forum was launched to include the private sector in planning and managing the economy.

The response to the reforms was dramatic. In Vietnam manufacturing grew at over 11 per cent per year during the period 1995-2005 and at more than 9 per cent between 2005 and 2010. The average annual growth rate of manufacturing in Cambodia was about 6 per cent per year during 1990-5. It accelerated to 21 per cent per year during 1995-2000. Between 2000 and 2010 manufacturing growth averaged more than 10 per cent per year. During 2000-10, manufacturing productivity growth averaged 2.5 per cent per year in Cambodia and 5 per cent per year in Vietnam (APO 2013).

\subsection{Policy and Performance: A Comparative Framework}

The literature on industrialization in developing countries suggests that four factors have largely shaped the global distribution of industry through their impact on productivity at the firm level. ${ }^{9}$ The first is the presence or absence of some 'basics': infrastructure, human capital, and institutions. The second is the growth of manufactured exports. The third is industrial agglomerations, and the fourth is FDI. Each of these areas is affected by public policy choices. This section presents comparative evidence from the country studies on relative performance in Africa and emerging Asia with respect to each productivity driver.

\subsubsection{The Basics}

Initial conditions matter for industrial development. Cross-country evidence shows that a variety of country-specific factors, including basic infrastructure and human capital, financial depth, and barriers to entry are correlated with industrial development and diversification in low income countries (IMF 2014). Better and more reliable electrical power, lower costs of transport, and workers who are better able to perform their jobs raise the potential productivity of all firms in an economy. A number of econometric studies highlight the productivity penalty that enterprises pay as a result of poor infrastructure

\footnotetext{
9 For a review of the literature on firm-level productivity see Syverson (2011). UNIDO (2009) surveys the evidence on the impact of productivity drivers on choice of industrial location.
} 
and skills (Escribano et al. 2010; Foster and Briceño-Garmendia 2010). Regulatory burdens and poorly functioning institutions inhibit productivity growth by reducing the scope for competition. ${ }^{10}$

Twenty years of stabilization, fiscal austerity, and slow growth left Africa with very large gaps in infrastructure and human capital. Africa started out in the 1960s with stocks of roads that were generally not very different from those in East Asia. The same was true in the 1970s for telephones and in the 1980s for power. By around 2000 it trailed in every infrastructure category (Foster and Briceño-Garmendia 2010). Today, SSA lags at least 20 percentage points behind the average for low income countries on almost all major infrastructure measures (World Bank 2009). In addition the quality of service is low, supplies are unreliable, and disruptions are frequent and unpredictable.

Power emerges as a major constraint in every SSA country case study. Selfreported losses associated with power outages amounted to more than 10 per cent of sales in some countries. Uganda has one of the lowest per capita electricity consumption levels in the world. Manufacturing firms in Tanzania experienced on average almost nine power outages per month, costing about 15.1 per cent of total sales for the firms affected. Transport finishes a close second. Around one-third of firms cite transportation as a major or severe constraint. Ugandan firms on average lost 1.8 per cent of domestic sales and 1.1 per cent of exports due to delays in transportation services. Almost a quarter of the enterprises surveyed in Mozambique considered transportation to be a major obstacle to investment. Currently, it is more expensive to transport cargo within Mozambique than to ship it to a different continent.

Gaps in terms of human capital are equally large. Only 60 per cent of Africa's 15-24-year-olds have completed primary school, and only 19 per cent have gone beyond lower-secondary school (Filmer and Fox 2014). Between 1990 and 2005, as East Asia increased secondary enrolment rates by twenty-one percentage points and tertiary enrolment rates by 13 percentage points, Africa only managed to raise secondary enrolments by 7 percentage points and tertiary enrolments by one percentage point (World Bank 2007).

The political and economic turmoil of the 1980s and 1990s also took a toll on the region's institutions. In 2000 SSA trailed all other developing regions in terms of government effectiveness, regulatory quality, rule of law, and control of corruption, in some cases by wide margins (Kauffman et al. 2010). The country case studies point to the many ways in which regulations and regulatory discretion affect firms. In Uganda senior managers of manufacturing firms spend more than thirteen days a year on average dealing with government officials, and 40 per cent of the manufacturing firms surveyed complained that

${ }^{10}$ For reviews of the literature see the various World Bank Doing Business reports. 
regulations were not interpreted consistently. In Mozambique business regulations - and the opportunities for corruption engendered by the regulatory regime-increase firms' costs and reduce competitiveness.

\subsubsection{Manufactured Exports}

There is an empirical regularity linking exports to higher firm-level productivity in manufacturing, but there is a long-standing debate concerning whether the most productive firms in an economy select exporting or the act of exporting raises productivity. The answer is complex and linked to a country's stage of development. While the most productive firms in an economy or a sector are most likely to become exporters, productivity in exporting firms rises faster than that in non-exporters, especially in lower income countries (Harrison and Rodriguez-Clare 2010). There is increasing evidence that learning by exporting takes place in low income country manufacturing firms, mainly as a result of the transfer of knowledge and working practices. ${ }^{11}$

SSA entered the twenty-first century with few manufactured exports and a small and declining share of the growing global market in manufactures. Manufactured exports per capita for the region as a whole (excluding South Africa) in 2000 were US\$28 compared with US\$291 for all developing economies. In 2000 the manufactured exports per capita of the eight SSAn countries in our study averaged just US\$16.50. The share of manufactured exports in total exports for the region (excluding South Africa) was 25 per cent compared to 77 per cent for all developing countries and 91 per cent for East Asia (UNIDO 2013). The eight SSA case-study countries have had somewhat more success in exporting manufactures than the region as a whole. In 2010 their manufactured exports were on average 37 per cent of total exports. Manufactured exports per capita for the group were US\$87 in the same year, nearly twice the SSA regional average (excluding South Africa), but well below the average for all developing economies of US\$305.

Cambodia, Tunisia, and Vietnam have all achieved considerable success in manufactured exports. As recently as 2000, manufactured exports per capita in Cambodia were only US\$107; by 2010 they had reached US\$335. Tunisia's manufactured exports to EU countries have expanded more than 10 per cent annually since the 1990s. Manufactured exports per capita which were US $\$ 522$ in 2000 had more than doubled to US\$1,381 in 2010. Vietnam's exports increased at an average annual rate of 26.3 per cent during the period 2005-10. Per capita manufactured exports reached US\$764 in 2010. In 2010 the share of manufactured exports in total exports for Cambodia and Vietnam

11 See Bleaney and Söderbom (forthcoming). 
was about 70 per cent. In Tunisia manufactured exports made up 85 per cent of total exports.

\subsubsection{Industrial Agglomerations}

Manufacturing and service industries tend to concentrate in clusters and cities (Fujita et al. 1999). Econometric evidence (Newman et al. 2016) and case studies (Sonobe and Otsuka 2006) document the significant productivity gains to firms from industrial agglomeration in low income countries. This literature further suggests that localization economies derived from the clustering of similar firms are more important as a source of productivity gains in low income countries than urbanization. Productivity gains due to clustering come from a number of sources: a substantial labour market, information and knowledge spillovers, the ability to share common overheads and services, and the opportunity to observe customers and competitors closely (UNIDO 2009).

The country studies give some insight into how the agglomeration of industry is evolving across SSA. Industrial production in Senegal and Mozambique is mainly concentrated in the capital cities of Dakar and Maputo. Ghana's industrial firms are primarily located in its two major urban centres, Accra, the capital, and Kumasi, the capital of the interior Ashanti region. In Uganda, Kampala has emerged as the major industrial centre, accounting for 41 per cent of manufacturing firms. These urban agglomerations are largely composed of firms engaged in unrelated activities, limiting the scope for localization economies.

There is a significant amount of clustering of similar firms in Cambodia and Vietnam. Both countries have been able to attract large numbers of foreign investors producing a limited range of products into their special economic zones (SEZs). There are two main industrial agglomerations in Vietnam, one located in the north near Hanoi and another in the south near Ho Chi Minh City. Over the past decade new clusters, anchored by large firms, have begun to appear in other areas. In Tunisia the degree of industrial concentration grew dramatically between 1995 and 2010, largely as a result of growth in the offshore sector. Relative to African agglomerations clusters in all three countries show a higher concentration of firms operating along the same value chain or producing similar products.

\subsubsection{Foreign Direct Investment}

Foreign owned firms in low income countries generally have higher levels of productivity than domestically owned firms. A large empirical literature finds positive productivity spillovers from foreign to domestic firms in lower 
Table 1.5 FDI as a share of gross fixed capital formation (\%), 1990-2013

\begin{tabular}{lrrrrr}
\hline & $1990-5$ & $1995-2000$ & $2000-5$ & $2005-10$ & $2010-13$ \\
\hline Ethiopia & 0.7 & 9.1 & 16.0 & 6.3 & 4.8 \\
Ghana & 6.0 & 7.9 & 5.7 & 21.8 & 23.3 \\
Kenya & 1.0 & 1.2 & 2.4 & 3.8 & 4.1 \\
Mozambique & 5.6 & 19.7 & 25.0 & 29.3 & 156.8 \\
Nigeria & 36.9 & 59.4 & 38.6 & 50.2 & 24.8 \\
Senegal & 3.2 & 8.4 & 4.5 & 8.7 & 8.8 \\
Tanzania & 1.1 & 13.7 & 17.8 & 17.1 & 18.7 \\
Uganda & 4.1 & 11.3 & 14.7 & 23.5 & 19.2 \\
Tunisia & 9.7 & 12.5 & 20.7 & 22.8 & 12.7 \\
Cambodia & 20.5 & 48.2 & 17.3 & 37.7 & 48.3 \\
Vietnam & 33.5 & 28.7 & 12.6 & 19.9 & 21.4 \\
Africa regional average & 6.1 & 11.2 & 13.0 & 17.1 & 12.4 \\
\hline
\end{tabular}

Source: UNCTAD (2013).

income countries, arising from access to the knowledge and technologies foreign firms have developed in more advanced markets. Not surprisingly, these knowledge spillovers are the result of firm-to-firm interactions and are more likely to occur between firms that are located along value chains than among firms competing in the same market. ${ }^{12}$

Outside of the resource sector, SSA has had some difficulty in attracting foreign investors. Table 1.5 shows FDI as a share of gross fixed capital formation. With the exception of Nigeria, where the oil sector was a major FDI destination, the average share of FDI in total investment was 3.1 per cent during 1990-5 and 10.2 per cent during 1995-2000. Beginning around 2000 the share of FDI in total investment increased to about 15 per cent. Ghana, Mozambique, Tanzania, and Uganda all experienced substantially increased shares of FDI in total investment, but these inflows were driven largely by investments in the extractive sector.

FDI has played a much larger role in the comparator countries. Asian-based FDI has driven Cambodia's manufactured exports. FDI increased from US\$124 million in 1993 to over US\$1,500 million in 2012. During the period 1990-2013 FDI represented 34.4 per cent of total investment. Between 1990 and 2013, FDI as a share of total investment in Vietnam averaged 23.2 per cent. Manufacturing has been the largest and fastest growing FDI sector, taking up over 60 per cent of all FDI. Tunisia's offshore sector was an early magnet for European investors, particularly in textiles and garments. Since 1999 the annual flow of FDI has been about US\$400 million, and between 2000 and 2010 FDI made up more than 20 per cent of gross fixed capital formation.

12 See Harrison and Rodriguez-Clare (2010). 


\subsection{Conclusions}

The idea that Africa should industrialize is certainly not new, but it remains relevant. While it is possible for economies to grow based on abundant land or natural resources-and Africa is well endowed with both-the role of industry in structural transformation makes a persuasive case for continued attention to industrialization. Africa's current pattern of structural transformation-one of workers moving from agriculture to services-runs the risk that structural changes in employment may once again become growth reducing.

Despite their diversity in many other respects, the eight SSAn countries studied in this volume have a remarkable similarity in their approach to industrial policy and in their industrial performance. Each country, like SSA as a whole, has moved from state-led import substitution, to structural adjustment, to reform of the investment climate. Over the long run, industrial growth has followed a start-stop pattern and has failed to exceed the long-run growth of GDP. Cambodia, Tunisia, and Vietnam took a different path. Each undertook investments and institutional and policy reforms to implement an exportoriented industrialization strategy similar to that used by earlier East Asian industrializers. Tunisia is an African industrial success story. Cambodia and Vietnam have had explosive industrial growth since the mid-1990s.

Comparative results from the case studies suggest that policy choices are largely responsible for the differences in industrialization outcomes. SSA and Cambodia, Tunisia, and Vietnam differ strikingly in four areasinfrastructure, human capital, and institutions; exports; agglomerations; and FDI. These are major drivers of industrial growth through their impact on firm-level productivity. The low growth and fiscal austerity of the structural adjustment period left SSA with major gaps in infrastructure, skills, and institutions. This was probably more a matter of bad luck than poor policy.

In the other three areas, however, policy choices played a key role. Cambodia, Tunisia, and Vietnam all took explicit public actions to encourage exports, develop industrial clusters, and attract FDI. The SSAn economies had an opportunity to make such a policy turn after structural adjustment but did not do so. The result has been highly divergent paths towards industrial development.

\section{References}

African Center for Economic Transformation (ACET) (2014). 2014 Africa Transformation Report: Growth with Depth. Accra: ACET.

Asia Productivity Organization (APO) (2013). Asia Productivity Data Book. Tokyo: APO. 
Ben Jelili, R. and Goaied, M. (2009). 'Entry, Exit, and Productivity in Tunisian Manufacturing Industries', in Khalid Sekkat (ed.) Market Dynamics and Productivity in Developing Countries. New York: Springer, 73-108.

Bleaney, M. and Söderbom, M. (forthcoming). 'Learning by Exporting'. Journal of African Economies.

Chenery, H. (1986). 'Growth and Transformation', in H. Chenery, S. Robinson, and M. Syrquin (eds) Industrialization and Growth: A Comparative Study. Oxford: Oxford University Press, 13-36.

de Vries, G., Timmer, M., and de Vries, K. (2013). 'Structural transformation in Africa: Static gains, dynamic losses'. GGDC Research Memorandum 136. Groningen, the Netherlands: University of Groningen.

Dinh, H. T., Palmade, V., Chandra, V., and Cossar, F. (2012). Light Manufacturing in Africa: Targeted Policies to Enhance Private Investment and Create Jobs. Washington, DC: World Bank.

Duarte, M. and Restuccia, D. (2010). 'The Role of the Structural Transformation in Aggregate Productivity'. Quarterly Journal of Economics 121(1): 129-73.

Easterly, W. (2009). 'Can the West Save Africa?' Journal of Economic Literature 47(2): 373-447.

Escribano, A., Guasch, J. L., and Pena, J. (2010). 'Assessing the Impact of Infrastructure Quality on Firm Productivity in Africa: Cross-country Comparisons Based on Investment Climate Surveys from 1999 to 2005'. Policy Research Working Paper 5191. Washington, DC: World Bank.

Filmer, D. and Fox, L. (2014). Youth Employment is Sub-Saharan Africa. Washington, DC: World Bank.

Foster, V. and Briceño-Garmendia, C. (eds) (2010). Africa's Infrastructure: A Time for Transformation. Washington, DC: World Bank.

Fujita, M., Krugman, P., and Venables, A. J. (1999). The Spatial Economy. Cambridge, MA: MIT Press.

Harrison, A. and Rodriguez-Clare, A. (2010). 'Foreign Investment, and Industrial Policy for Developing Countries', in D. Rodrik and M. Rosenzweig (eds) Handbook of Development Economics, vol. 5. The Netherlands: North Holland, 4040-214.

International Monetary Fund (IMF) (2014). 'Sustaining Long-run Growth and Macroeconomic Stability in Low-income Countries-The Role of Structural Transformation and Diversification'. IMF Policy Paper. Washington, DC: IMF.

Kauffman, D., Kray, A., and Mastruzzi, M. (2010). 'The Worldwide Governance Indicators: Methodology and Analytical Issues' Policy Research Working Paper No. 5430 Washington, DC: World Bank.

Killick, T. (1978). Development Economics in Action. New York: St. Martin's Press.

Lewis, W. A. (1954). 'Economic Development with Unlimited Supplies of Labour'. Manchester School 22(2): 139-91.

McMillan, M. and Hartgen, K. (2014). 'What is Driving the Africa Growth Miracle?'. Tunis: African Development Bank.

McMillan, M. and Rodrik, D. (2011). 'Globalization, Structural Change and Productivity Growth'. NBER Working Paper 17/143. Cambridge, MA: National Bureau of Economic Research. 
McMillan, M., Rodrik, D., and Verduzco-Gallo, I. (2014). 'Globalization, Structural Change, and Productivity Growth, with an Update on Africa'. World Development 63: $11-32$.

Megginson, W. L. and Netter, J. M. (2001). 'From State to Market: A Survey of Empirical Studies on Privatization'. Journal of Economic Literature 39(2): 321-89.

Ndulu, B. J. (2007). 'The Evolution of Global Economic Paradigms and their Influence on African Economic Growth', in B. J. Ndulu, R. Bates, S. A. O'Connell, P. Collier, and C. Saludo (eds) The Political Economy of Growth in Africa, Volume 1. New York: Cambridge University Press, 315-47.

Nellis, J. (1986). 'Public Enterprises in sub-Saharan Africa'. Washington, DC: World Bank.

Nellis, J. (2003). 'Privatization in Africa: What has happened? What is to be done?' Working Paper Number 25. Washington, DC: Center for Global Development.

Newman, C., Page, J., Rand, J., Shimeles, A., Söderbom, M., and Tarp, F. (2016). Made in Africa: Learning to Compete in Industry. Washington, DC: Brookings Institution Press.

Organisation for Economic Co-operation and Development (OECD) (2014). 'DAC CRS International Development Statistics (IDS) online databases' available at www.oecd. org/dac/stats/idsonline.htm, accessed 28 October 2014.

Page, J. (2012). 'Can Africa Industrialize?' Journal of African Economies 21 (Special Issue 2): ii86-ii124.

Rodrik, D. (2013). 'Unconditional Convergence in Manufacturing', The Quarterly Journal of Economics 128(1): 165-204.

Sonobe, T. and Otsuka, K. (2006). Cluster-based Industrial Development: An East Asian Model. Basingstoke: Palgrave Macmillan.

Stern, N. (2001). A Strategy for Development. Beijing: People's University.

Stern, N. (2002). The Investment Climate, Governance, and Inclusion in Bangladesh. World Bank Office of the Senior Vice President, Development Economics. Washington, DC: World Bank.

Syverson, C. (2011). 'What Determines Productivity?' Journal of Economic Literature 49(2): 326-65.

UNIDO Statistics (2014) Manufacturing Value Added Database, available at www.unido. org/resources/statistics/statistical-databases.html, accessed 28 January 2016.

United Nations Conference on Trade and Development (UNCTAD) (2013). World Investment Report 2013: Global Value Chains: Investment and Trade for Development. Geneva: UNCTAD.

United Nations Industrial Development Organization (UNIDO) (2009). Industrial Development Report, 2009. Vienna: UNIDO.

United Nations Industrial Development Organization (UNIDO) (2013). Industrial Development Report, 2013. Vienna: UNIDO.

Williamson, J. (1990). 'What Washington Means by Policy Reform', in J. Williamson (ed.) Latin American Adjustment: How Much Has Happened? Washington, DC: Institute for International Economics, 36-58.

World Bank (1992). 'World Bank Structural and Sectoral Adjustment Operations: The Second OED Overview'. Washington, DC: World Bank. 
World Bank (2000). Can Africa Claim the Twenty-first Century? Washington, DC: World Bank.

World Bank (2007). 'Expanding the Possible in Sub-Saharan Africa: How Tertiary Institutions Can Increase Growth and Competitiveness'. Washington, DC: World Bank.

World Bank (2009). Transforming Africa's Infrastructure. Washington, DC: World Bank. World Bank (2014). World Development Indicators, available at <http://data.worldbank. org/products/wdi>, accessed 28 January 2016. 



\section{Part I}

\section{Industrial Development in Africa}





\title{
2
}

\section{Industrial Policy and Development in Ethiopia}

\author{
Mulu Gebreeyesus
}

\subsection{Introduction}

The Ethiopian economy has been on a continuous and high growth trajectory since 2003/04, registering an average annual growth of 10.6 per cent between then and 2010/11. This is about double the average growth rate (5.2 per cent) recorded for sub-Saharan Africa (SSA) over the same period. The industry sector grew by more than 10 per cent annually averaged over the same period. Despite its recent impressive growth performance, Ethiopia remains among the world's poorest countries. Agriculture continues to be the main source of livelihood employing 85 per cent of the country's labour force. The industry contribution to the economy remains at about 14 per cent, far below the average for SSA countries.

Ethiopia is also one of the few African countries that has formulated a fullfledged industrial policy and aggressively pursued it over the last decade. Understanding the policy choices and the implementation as well as their efficacy is of paramount importance not only for providing feedback to the policy process in Ethiopia but also for drawing lessons from which other countries can learn. The current chapter provides a broad and historical account of industrial policies and performance in Ethiopia. Section 2.2 describes the evolution of industry and industrial policy in Ethiopia. Section 2.3 describes the current structure of the Ethiopian manufacturing sector. Section 2.4 discusses productivity across sectors, size categories, and time periods. Section 2.5 examines the current industrial policy of the country. Section 2.6 provides some industry cases on the implementation of the current industrial policy. Section 2.7 concludes with a discussion on some remaining and emerging challenges in realizing Ethiopia's industrialization vision. 


\subsection{Evolution of Industry: Historical Perspective}

A conscious move to stimulate industrial growth in Ethiopia began in the mid1950s with the formulation of the First Five-year Plan (FFYP). Ethiopia has seen three different governments over the last eight decades. In keeping with the political ideologies governing the economic principles of the time, these successive governments adopted different policies for the development of industry in Ethiopia. In what follows, the salient features of the industrial policies and performances of these three periods (the Imperial regime, the Dergue, and the Ethiopian People's Revolutionary Democratic Front (EPRDF)-led government) will be reviewed.

\subsubsection{The Imperial Regime, pre-1974}

The end of WWII marked in Ethiopian history the first attempt at guiding the economy through a comprehensive plan. The first implemented promotion of industrial development was the FFYP that covered the period 1958-62. ${ }^{1}$ The plan envisaged achieving industrial progress through substituting imports with the development of light industry producing consumer goods for the domestic market. In accordance with this strategy, the textile, cement, and food industries were given emphasis in the plan as they were believed to produce products in high demand in the local market which could be produced using the local resources abundantly available in the country. $^{2}$

Two more five-year plans, the Second Five-year Plan and Third Five-year Plan, were launched between 1963 and 1973. ${ }^{3}$ During this period, the government extended the incentives to attract investors and continued to strengthen its presence in economic activities. The implementation of these initiatives envisaged in the three successive five-year plans (1958-73) attracted foreign investors and boosted the manufacturing sector. However, by the end of the plan period, the overall industrial base of the country had remained weak (World Bank, 1985). ${ }^{4}$

\footnotetext{
1 For the policy document see IEG (1957).

2 The cottage and handicrafts sectors were also recognized in the plan as playing an important role for the development of manufacturing industry in the country.

${ }^{3}$ For the two policy documents see IEG $(1962,1968)$.

4 World Bank (1985) provides one of the few detailed and available studies on the Ethiopian manufacturing sector carried out at that time. We would like to acknowledge that because of an absence of other sources, discussions in Subsections 2.2.1-2.2.2 rely heavily on this World Bank (WB) report.
} 


\subsubsection{The Dergue Regime, 1974-91}

In 1974 the Ethiopian Revolution erupted while the country was preparing the fourth five-year development plan. The military government nationalized most of the medium and large manufacturing enterprises and declared 'a socialist economic policy' (PMAC 1975). Industrial activities were reserved exclusively for the state. As a result, the manufacturing sector exhibited a sharp decline, particularly in the first few years following the revolution.

The government had no industrial policy per se until the mid-1980s. A Tenyear Perspective Plan comprising a macroeconomic framework-a Public Investment Programme containing an indicative portfolio of projects and production targets for the period 1984/85-1993/94-was formulated. This was modified in 1986 in the Ten-year Development Plan. According to World Bank (1985) the industrial sector was envisaged to grow at 15.4 per cent per annum over the plan period, which is three times the planned growth of the agriculture sector. Priorities were given to import substitution and labour intensive industries in an effort to address the country's dependence on imported goods and inputs and to generate employment.

The nationalization and continued systematic restriction of the private sector from engaging in major economic activities had reduced the emerging vibrant sector into micro- and small-scale manufacturing activities. In contrast the state became the sole responsible organ owning and operating mediumand large-scale manufacturing activities. In 1985/86, one decade after the revolution, state-owned enterprises (SOEs) generated 95 per cent of the value added and 93 per cent of the employment of all MLSM (Medium and LargeScale Manufacturing) enterprises (see Table 2.1).

Towards the end of the 1980s the SOEs' financial position weakened, and government subsidies and overdraft facilities became instrumental for their survival (UNIDO 1991: 13). Because of the poor quality of products and lack of

Table 2.1 Number of establishments, employment, and value added by ownership in the Ethiopian MLSM, 1979/80-2010

\begin{tabular}{|c|c|c|c|c|c|c|}
\hline & \multicolumn{2}{|c|}{ Number of establishments } & \multicolumn{2}{|c|}{ Number of employments } & \multicolumn{2}{|c|}{ Value added } \\
\hline & Total & Public share (\%) & Total & Public share (\%) & Total (mill. Birr) & Public share (\%) \\
\hline $1979 / 80$ & 351 & 45.3 & 76,631 & 88.85 & 589.7 & 95.0 \\
\hline $1985 / 86$ & 369 & 48.8 & 90,845 & 93.33 & 715.3 & 95.2 \\
\hline $1990 / 91$ & 275 & 52.4 & 84,000 & 93.08 & 460.2 & 94.0 \\
\hline $1995 / 96$ & 627 & 25.7 & 90,039 & 86.25 & $1,593.8$ & 87.9 \\
\hline $1999 / 00$ & 788 & 15.5 & 95,708 & 56.13 & $2,279.3$ & 72.5 \\
\hline $2004 / 05$ & 1,207 & 10.4 & 110,160 & 48.70 & $3,030.6$ & $\mathrm{~N} / \mathrm{A}$ \\
\hline $2009 / 10$ & 2,172 & 6.4 & 186,799 & 25.67 & $11,369.6$ & 31.2 \\
\hline
\end{tabular}

Source: CSA (various years(a), various years(b)); author's calculations. 
experience in export markets, only 6 per cent of the total value of industrial output was exported by SOEs. During the last years of the Dergue regime there was a sharp decline in the Ethiopian economy, particularly in the manufacturing sector. The growth of the manufacturing value added started to fall in 1988 and reached -40 per cent in $1991 .^{5}$ The industry value added at large had also exhibited a similar trend over this period. Policies hostile to the private sector coupled with substantial inefficiency in the public sector were the main causes of this decline.

\subsubsection{The EPRDF Regime, post-1991}

Soon after the EPRDF-led transitional government seized power it announced that the country would follow a market-led economic policy. The first decade of the EPRDF regime (1991-9) was marked by a series of reforms under the structural adjustment programme (SAP) with the aim of reversing the command economic system by way of fostering competition, opening up the economy, and promoting the private sector. In this period the government implemented three phases of IMF/WB sponsored reform programmes. The first phase of the structural and economic reform programmes took place during 1992/93-1994/95. A key measure undertaken during this period was liberalization in various markets.

The second phase of the economic reform programme (1994/95-1996/97) was aimed at limiting the role of the state in economic activity and the promotion of greater private capital participation. In 1996 the country entered a three-year Enhanced Structural Adjustment Facility (ESAF) arrangement with the IMF and began the third phase of the reform programme spanning the period 1996/97-1998/99. Under this arrangement, the government committed itself to achieving broad-based economic growth in a stable macroeconomic environment, while the liberalization measures were further strengthened. ${ }^{6}$

The favourable policy environment created by the economic reforms, coupled with macroeconomic stability, revitalized the manufacturing sector and the economy at large. The high growth period did not last long, however. The value added growth of the industry and the manufacturing sector in the period 1996-2003 averaged only 5 and 3 per cent per annum respectively, which is modest in comparison with preceding years.

\footnotetext{
5 Source: World Development Indicators from the World Bank (WB 2010).

6 For example, the maximum import tariff rate was further reduced from 60 per cent to 50 per cent; fertilizer price control was suspended; liberalization of the foreign exchange system was strengthened; and a foreign exchange retention scheme was introduced.
} 
In 2002/03, the Ethiopian government formulated a full-fledged Industrial Development Strategy (IDS). The IDS was linked to various sub-sector strategies and to successive development plans such as the Sustainable Development and Poverty Reduction Program (SDPRP) 2002/03-2004/05 and the Plan of Action for Sustainable Development and Eradication of Poverty (PASDEP) 2005/06-2009/10. The first development plan put great emphasis on smallholder agriculture, while in the second plan policy scope was broadened to encompass the urban sector and the industrial sector. The industrial sector and the economy at large have shown impressive growth following the implementation of the PASDEP. Recent industrial policy and performance will be discussed in further detail in Sections 2.3-2.6. Table 1 in the working paper version of this chapter (Gebreeyesus 2013) provides a summary of the industrial development periods in Ethiopia.

\subsection{The Current Structure of the Ethiopian Manufacturing Sector}

The Ethiopian economy has recorded continuous and double-digit growth since 2003/04 (Table 2.2). The service sector outperformed other sectors in this period, and its share of GDP increased from 39.7 per cent in 2003/04 to 46 per cent in 2009/10. Despite 10 per cent annual average growth in the same period, the agriculture share in GDP declined from 47 per cent to 42 per cent. The industry sector also grew by about 10 per cent per annum between 2003/04 and 2009/10. However, its share in the economy remained relatively static (12-14 per cent) over the last decade.

Table 2.2 Ethiopia's economic performance, 2000/01-2009/10

\begin{tabular}{|c|c|c|c|c|c|c|c|}
\hline \multirow[b]{2}{*}{ Year } & \multirow{2}{*}{$\frac{\text { GDP }}{\text { Growth (\%) }}$} & \multicolumn{2}{|c|}{ Agriculture value added } & \multicolumn{2}{|c|}{ Service value added } & \multicolumn{2}{|c|}{ Industry value added } \\
\hline & & Growth (\%) & $\begin{array}{l}\text { Share to } \\
\text { GDP (\%) }\end{array}$ & Growth (\%) & $\begin{array}{l}\text { Share to } \\
\text { GDP (\%) }\end{array}$ & Growth (\%) & $\begin{array}{l}\text { Share to } \\
\text { GDP (\%) }\end{array}$ \\
\hline $2000 / 01$ & 8.3 & 9.6 & 50.9 & 5.3 & 38 & 5.1 & 12.1 \\
\hline $2001 / 02$ & 1.5 & -1.9 & 49.1 & 4.3 & 38.6 & 8.3 & 12.9 \\
\hline $2002 / 03$ & -2.2 & -10.5 & 44.9 & 5.8 & 41.7 & 6.5 & 14 \\
\hline $2003 / 04$ & 13.6 & 16.9 & 47 & 6.0 & 39.7 & 11.6 & 14 \\
\hline $2004 / 05$ & 11.8 & 13.5 & 47.4 & 12.7 & 39.7 & 9.4 & 13.6 \\
\hline $2005 / 06$ & 10.8 & 10.9 & 47.1 & 12.8 & 40.4 & 10.2 & 13.4 \\
\hline $2006 / 07$ & 11.5 & 9.4 & 46.1 & 15.2 & 41.7 & 10.2 & 13.2 \\
\hline $2007 / 08$ & 10.8 & 7.5 & 44.6 & 15.3 & 43.5 & 10.4 & 13 \\
\hline $2008 / 09$ & 8.8 & 6.4 & 43.2 & 14.5 & 45.1 & 8.9 & 13 \\
\hline $2009 / 10$ & 10.1 & 5.8 & 42 & 15.2 & 46.1 & 8.8 & 13 \\
\hline
\end{tabular}

Source: World Development Indicators, World Bank (2010). 
The construction and manufacturing sectors grew by 10 per cent and 11.8 per cent respectively between 2003/04 and 2009/10. In 2009/10, the construction and manufacturing sectors respectively accounted for 5.8 and 4.9 per cent of GDP, which is equivalent to 37.7 per cent and 44.5 per cent of the industrial value added. ${ }^{7}$

The Ethiopian Central Statistics Agency (CSA) has been conducting surveys on the country's manufacturing activity since the mid-1970s. The coverage and frequency of the surveys differ by size and type of activity. First, the Survey on MLSM (CSA various years[a]) covers establishments that use power driven machines and employ ten or more workers. This survey has been conducted on a census and annual basis since the mid-1970s. Second, the Survey on Small-Scale Manufacturing (SSM) (CSA various[b]) covers establishments that use power driven machines but employ fewer than ten workers. The CSA has so far conducted four rounds of surveys $(1994 / 95,2001 / 02,2005 / 06,2007 / 08)$ all on a sample basis. Third, the Report on Cottage/Handicraft Manufacturing (CSA 2003) covers establishments performing their activity by hand or using non-power driven machines or tools. Only one survey of this industry, in 2001-2, has been conducted.

Because of a lack of recent data on the cottage/handicraft industry, the discussion below will focus on the SSM and the MLSM enterprises. However, we can shed some light on the relative importance of the cottage/ handicraft industry to the Ethiopian manufacturing sector using the 2001-2 report. The cottage/handicraft sector was estimated to comprise a total number of 974,676 establishments generating employment for above 1.3 million people in $2001-2 .^{8}$ In contrast there were only 31,863 SSM and 909 MLSM establishments employing respectively 97,781 and 98,986 people in that year. The cottage/handicraft industry thus accounted for about 97 per cent and 87 per cent of the total number of manufacturing enterprises and employment respectively. On the other hand, in terms of value added the cottage/handicraft sector contribution was only 21.5 per cent.

Subsections 2.3.1 to 2.3.6 describe in order the size distribution, sectoral composition, sunrise and sunset industries, ownership type, trade orientation, and geographical distribution based on the SSM and MLSM survey reports. When comparing SSM and MLSM we rely on the 2007/08 survey reports, the latest available for both size categories.

\footnotetext{
7 Source: National Bank of Ethiopia (NBE 2010).

8 The dominant activities in this sector were the food and beverage, textile, and non-metallic mineral products combined, accounting for 86 per cent of total cottage/handicraft establishments. About 63.2 per cent was located in rural areas with the remaining 36.8 in towns.
} 


\subsubsection{Size Distribution}

The Ethiopian manufacturing sector is dominated by small and micro-firms. ${ }^{9}$ In $2007 / 08$, for example, 43,338 (96 per cent) of the 45,268 manufacturing establishments that use power driven machineries were micro-firms employing fewer than ten people. When looking at the employment distribution we observe two strong modes, one at the micro-size firms and another at the large firms employing 50+ workers.

In terms of value added the size distribution is skewed to the largest size group (50+ employees). The large size group accounts for about 83 per cent of manufacturing value added, while the micro-firms contribute only 11 per cent of the manufacturing value added.

\subsubsection{Sectoral Composition}

Table 2.3 shows the separate sectoral composition for Ethiopian manufacturing establishments in 2007/08 for SSM and MLSM. The first three columns report the share of the different sectors of the SSM. The grain mills sector is the dominant industry of this size category and accounts for about 53 per cent of the total number of SSMs.

The last three columns of Table 2.3 report the sectoral composition of the MLSM. This formal sector is characterized by a high concentration of a limited range of light manufacturing activities such as food and beverage, textile, leather, non-metallic, and furniture. In 2007/08, the food and beverage sector accounted for about a quarter of the number of establishments, one-third of employment, and 42 per cent of the value added of the MLSM sector. The second important industry is the manufacture of other non-metallic mineral products. Some basic sectors, such as chemical, basic metal, and engineering, are as yet underdeveloped.

\subsubsection{Sunrise and Sunset Industries}

Based on a disaggregated four-digit level of the International Standard Industrial Classification (ISIC) product classification we examined the growing and shrinking manufacturing industries in the MLSM over the last decade and a half. Table 2.4 reports the rank and share of the top ten industrial products in terms of output (gross value of production) and exports for three selected years. In 2009/10 the top ten products include in order of importance:

\footnotetext{
9 The working paper version of this chapter (Gebreeyesus 2013: Table 3) shows the distribution of number of establishments, employment, and value added across the four size categories: micro (1-10 employees); small (11-20 employees); medium (21-50 employees); and large (over 50 employees); firms based on 2007/08 CSA surveys on SSM and MLSM.
} 
Table 2.3 Sectoral distribution of the Ethiopian manufacturing sector $(2007 / 08)$

\begin{tabular}{|c|c|c|c|c|c|c|c|}
\hline \multirow[b]{2}{*}{$\begin{array}{l}\text { ISIC } \\
\text { code }\end{array}$} & & \multicolumn{3}{|c|}{ SSM sectoral share (\%) } & \multicolumn{3}{|c|}{ MLSM sectoral share (\%) } \\
\hline & & Number of establishments & Employment & Value added & Number of establishments & Employment & Value added \\
\hline 15 & $\begin{array}{l}\text { food and beverage } \\
\text { of which grain mills }\end{array}$ & $\begin{array}{l}56.76 \\
(53.2)\end{array}$ & $\begin{array}{c}53.8 \\
(50.4)\end{array}$ & $\begin{array}{r}47 \\
(42)\end{array}$ & 25.1 & 31.2 & 42.3 \\
\hline 16 & tobacco & & & & 0.1 & 0.9 & 3.8 \\
\hline 17 & textile & & & & 1.3 & 9.0 & 2.1 \\
\hline 18 & apparel & 7.2 & 4.7 & 5.3 & 2.0 & 5.7 & 1.3 \\
\hline 19 & leather & & & & 4.3 & 6.5 & 4.0 \\
\hline 20 & wood products & & & & 3.6 & 2.4 & 0.6 \\
\hline $21-22$ & paper and printing & & & & 7.4 & 6.7 & 5.1 \\
\hline 24 & chemicals & & & & 4.1 & 5.8 & 5.8 \\
\hline 25 & rubber and plastic & & & & 4.2 & 6.5 & 4.9 \\
\hline 26 & other non-metallic mineral & & & & 25.3 & 13.2 & 18.6 \\
\hline 27 & basic iron and steel & & & & 0.8 & 1.0 & 3.1 \\
\hline 28 & fabricated metal & 10.1 & 11 & 15.6 & 5.2 & 3.9 & 4.8 \\
\hline 29 & machinery and equipment & & & & 0.2 & 0.2 & 0.1 \\
\hline 34 & $\begin{array}{l}\text { motor vehicles, trailers, and } \\
\text { semi-trailers }\end{array}$ & & & & 0.8 & 1.3 & 1.8 \\
\hline \multirow[t]{3}{*}{36} & furniture & 19.8 & 25 & 24.3 & 15.5 & 5.6 & 1.8 \\
\hline & other & 6 & 5 & 8 & & & \\
\hline & Total & 43,338 & 138,951 & $\begin{array}{c}1.14 \\
\text { (billion Birr) }\end{array}$ & 1,930 & 133,673 & $\begin{array}{c}9.17 \\
\text { (billion Birr) }\end{array}$ \\
\hline
\end{tabular}

Source: CSA (2010); author's calculations. 
Table 2.4 Ranking of top ten manufacturing products in output and export contribution

\begin{tabular}{|c|c|c|c|c|c|c|}
\hline \multicolumn{7}{|c|}{ Top 10 products produced (4-digit level) rank and share (\%) } \\
\hline & \multicolumn{2}{|l|}{$1995 / 96$} & \multicolumn{2}{|l|}{$2002 / 03$} & \multicolumn{2}{|l|}{$2009 / 10$} \\
\hline & Product type in order & Share $(\%)$ & Product type in order & Share (\%) & Product type in order & Share (\%) \\
\hline 1 & malt liquors and malt & 9.46 & sugar and confectionery & 12.40 & sugar and confectionery & 8.89 \\
\hline 2 & spinning, weaving, and finishing & 9.42 & cement, lime, and plaster & 9.40 & cement, lime, and plaster & 8.37 \\
\hline 3 & sugar and confectionery & 8.86 & spinning, weaving, and finishing & 8.42 & malt liquors and malt & 7.88 \\
\hline 4 & tobacco & 7.65 & malt liquors and malt & 7.50 & flour & 6.95 \\
\hline 5 & tanning and dressing of leather & 7.41 & tanning and dressing of leather & 7.26 & plastics & 6.83 \\
\hline 6 & flour & 6.06 & flour & 5.15 & soft drinks & 5.85 \\
\hline 7 & basic iron and steel & 5.03 & soft drinks & 5.08 & structural metal products & 5.80 \\
\hline 8 & cement, lime, and plaster & 4.97 & basic iron and steel & 4.36 & spinning, weaving, and finishing & 4.98 \\
\hline 9 & soft drinks & 4.70 & publishing and printing & 3.35 & basic iron and steel & 4.05 \\
\hline 10 & bodies for motor vehicles & 4.50 & plastics & 3.33 & soap detergents, perfumes & 3.71 \\
\hline \multirow{2}{*}{\multicolumn{2}{|c|}{$\begin{array}{l}\text { Top } 10 \text { share (\%) sum } \\
\text { Total MLSM GVP (billion Birr) }\end{array}$}} & 68.07 & & 66.26 & & 63.31 \\
\hline & & 5.53 & & 8.95 & & 42.0 \\
\hline \multicolumn{7}{|c|}{ Top 10 products exported rank and share (\%) } \\
\hline & \multicolumn{2}{|l|}{$1995 / 96$} & \multicolumn{2}{|l|}{$2002 / 03$} & \multicolumn{2}{|l|}{$2009 / 10$} \\
\hline & Product type in order & Share $(\%)$ & Product type in order & Share (\%) & Product type in order & Share (\%) \\
\hline 1 & tanning and dressing of leather & 91.27 & tanning and dressing of leather & 59.20 & tanning and dressing of leather & 34.86 \\
\hline 2 & spinning, weaving, and finishing & 4.24 & sugar and confectionery & 20.17 & spinning, weaving, and finishing & 15.81 \\
\hline 3 & meat and fruit & 1.65 & spinning, weaving, and finishing & 14.27 & dairy & 10.28 \\
\hline 4 & sugar and confectionery & 1.27 & food NEC & 3.70 & wearing apparel except fur & 7.38 \\
\hline 5 & wearing apparel except fur & 0.92 & footwear & 0.95 & footwear & 7.01 \\
\hline 6 & wood and wood & 0.35 & non-metallic NEC & 0.66 & flour & 4.80 \\
\hline 7 & non-metallic NEC & 0.09 & meat, fruit & 0.52 & meat, fruit & 4.67 \\
\hline 8 & footwear & 0.06 & malt liquors and malt & 0.25 & basic iron and steel & 3.21 \\
\hline 9 & wine & 0.04 & edible oil & 0.18 & other fabricated metal prod. & 3.01 \\
\hline 10 & furniture & 0.02 & wine & 0.03 & soap detergents, perfumes & 2.16 \\
\hline \multirow{2}{*}{\multicolumn{2}{|c|}{$\begin{array}{l}\text { Top } 10 \text { export share (\%) sum } \\
\text { Total MLSM exports (billion Birr) }\end{array}$}} & 99.91 & & 99.94 & & 93.17 \\
\hline & & 0.401 & & 0.848 & & 1.19 \\
\hline
\end{tabular}

Source: CSA (various years), but own calculations. 
manufacturing of sugar, cement, liquors, flour, plastic, soft drinks, structural metal, textile, basic iron and steel, and detergent and soaps. In sum, they account for about 63 per cent of total MLSM production value. Emerging industries include the structural metal, detergent, and plastic sectors. There is some evidence that the textile industry and leather tanning are among the stagnant industries.

\subsubsection{Ownership Types}

The presence of foreign owned companies in Ethiopian manufacturing is generally limited. A recent (2011/12) sample based survey by the WB reveals that only 4 per cent of the sampled firms in Ethiopia are private and foreign owned (Geiger and Goh 2012). Table 2.5 reports the share of paid-up capital, by foreign and domestic private ownership. The foreign ownership share in terms of paid-up capital was only 7.6 per cent of the reported total in the MLSM sector. Foreign capital is relatively more visible in industries such as apparel (35.3 per cent), rubber and plastic (17.6 per cent), and food and beverage ( 8.8 per cent).

\subsubsection{Trade Orientation}

The volume of manufactured exports from Ethiopia is low. Only 4 per cent of manufacturing firms participate in export markets. The leather, textile, and

Table 2.5 Paid-up capital and value added by ownership and industry group (2009/10)

\begin{tabular}{|c|c|c|c|c|}
\hline & \multirow{2}{*}{$\frac{\text { Paid-up capital (mil. Birr) }}{\text { Total }}$} & \multicolumn{3}{|c|}{ Share in paid-up capital by ownership type (\%) } \\
\hline & & Public & Domestic private & Foreign \\
\hline Food and beverage & $5,192.3$ & 15.9 & 75.3 & 8.8 \\
\hline Tobacco product & 195.0 & 100.0 & 0.0 & 0.0 \\
\hline Textile & $1,897.4$ & 15.5 & 77.1 & 7.4 \\
\hline Apparel & 361.9 & 0.4 & 64.3 & 35.3 \\
\hline Tanning and leather products & 757.2 & 5.0 & 87.8 & 7.2 \\
\hline Wood products & $1,757.7$ & 93.0 & 6.7 & 0.3 \\
\hline Paper and printing & 902.7 & 17.1 & 81.3 & 1.6 \\
\hline Chemical products & $1,021.1$ & 22.5 & 72.3 & 5.1 \\
\hline Rubber and plastic & $1,673.0$ & 9.1 & 73.3 & 17.6 \\
\hline Non-metallic mineral products & $2,585.5$ & 13.7 & 79.0 & 7.3 \\
\hline Basic iron and steel & 710.6 & 13.8 & 83.7 & 2.5 \\
\hline Basic metal and engineering & $1,823.1$ & 22.2 & 72.6 & 5.2 \\
\hline Furniture & 296.0 & 7.8 & 91.6 & 0.6 \\
\hline Total & $19,173.5$ & 23.0 & 69.5 & 7.6 \\
\hline
\end{tabular}

Source: CSA survey 2009/10, but own calculations. Note that basic iron and engineering includes fabricated metal, machinery and equipment, and motor vehicle sectors. 
apparel sectors have the highest participation rates. The export to sales ratio is also correspondingly small (see Table 2.6). For example in 2010, the average share of export in total sales of the MLSM sector was only 3 per cent. This is much lower than in previous years. The export to sales ratio has also declined in the three most important export sectors-leather, apparel, and textile sectors-during this period.

Table 2.6 also reports raw material import dependence and export coverage of imported raw materials. In 2009/10 imported raw materials accounted for about 51 per cent of the total use of raw materials in the MLSM sector. The dependence on imported raw materials is relatively lower in the agroindustries. The chemical, plastic and rubber, basic iron, and engineering industries depend heavily on imported inputs, ranging from 70 per cent to 99 per cent of total cost of raw materials.

The overall dependence of the manufacturing sector on imported raw materials has increased in comparison to 2002/03. The apparel, leather, and non-metallic mineral products which are customarily among the less dependent have shown increasing dependence on imported raw materials over time. In contrast, import dependence of wood and paper industries has declined. The declining share of export sales and a simultaneous increase in import dependence means the export coverage of imported raw materials of the manufacturing sector has fallen over time.

\subsubsection{Geographic Distribution}

Historically, MLSM establishments have been concentrated in a few large towns. ${ }^{10}$ Table 2.7 gives the geographical distribution of the Ethiopian MLSM establishments. In 1995/96 the top ten towns accounted for about 85 per cent of the total number of establishments and 79 per cent employment in the MLSM sector. In the same year Addis Ababa (the capital city) alone accounted for about 67 per cent and 60 per cent respectively. This concentration has shown a modest decline and in 2009/10 the top ten towns share reached 60 per cent and 62 per cent of the total number of MLSM establishments and employment respectively. The share of Addis Ababa also correspondingly declined to 40 per cent and 46 per cent respectively in the same year. New industrial towns such as Burayu, Sululta, Sebeta, Mojo, and Ambo are emerging around the capital city. Four of these were among the top ten

\footnotetext{
10 For example in 1980/81 the two provinces, Shoa and Eritrea, in which the largest two cities Addis Ababa and Asmara respectively are located, accounted for more than 80 per cent of the MLSM sector in terms of number of establishments, employment, and value added (WB 1985).
} 
Table 2.6 Export sales and imported raw materials by sector MLSM (2009/10)

\begin{tabular}{|c|c|c|c|c|c|c|c|c|c|}
\hline & \multicolumn{3}{|c|}{ Exports' share in sales (\%) } & \multicolumn{3}{|c|}{ Imported raw materials share (\%) } & \multicolumn{3}{|c|}{ Exports coverage of imported raw materials (\%) } \\
\hline & $2002 / 03$ & $2007 / 08$ & $2009 / 10$ & $2002 / 03$ & $2007 / 08$ & $2009 / 10$ & $2002 / 03$ & $2007 / 08$ & $2009 / 10$ \\
\hline Food and beverage & 6.00 & 3.14 & 1.78 & 22.03 & 27.91 & 24.8 & 79.88 & 28.62 & 16.29 \\
\hline Tobacco & 0.00 & 0.31 & 0.45 & 79.84 & 13.8 & 5.5 & 0.00 & 8.61 & 12.41 \\
\hline Textile & 17.24 & 14.06 & 9.19 & 29.04 & 29.64 & 37.0 & 93.52 & 80.24 & 47.60 \\
\hline Apparel & 0.10 & 26.08 & 12.92 & 25.66 & 37.28 & 50.3 & 0.79 & 138.06 & 55.10 \\
\hline Leather & 69.11 & 61.26 & 36.27 & 21.64 & 23.56 & 34.4 & 423.96 & 382.35 & 172.86 \\
\hline Wood products & 0.00 & 0 & 0.05 & 54.63 & 23.87 & 21.1 & 0.00 & 0 & 0.39 \\
\hline Paper and paper products & 0.00 & 0 & 0.00 & 75.36 & 81.54 & 59.5 & 0.00 & 0 & 0.00 \\
\hline Chemical & 0.00 & 1.58 & 1.02 & 72.33 & 87.06 & 70.5 & 0.00 & 2.92 & 2.30 \\
\hline Rubber and plastic & 0.00 & 0 & 0.13 & 85.00 & 77.22 & 92.3 & 0.00 & 0 & 0.27 \\
\hline Other non-metallic mineral products & 0.57 & 0.13 & 0.07 & 29.79 & 19.84 & 58.1 & 9.35 & 4.13 & 0.26 \\
\hline Basic iron and steel & 0.00 & 0 & 2.42 & 99.17 & 99.8 & 79.1 & 0.00 & 0 & 4.25 \\
\hline Fabricated metal & 0.00 & 0 & 1.53 & 88.97 & 80.19 & 84.6 & 0.00 & 0 & 2.92 \\
\hline Machinery and equipment & 0.00 & 0 & 2.04 & 92.32 & 97.68 & 85.1 & 0.00 & 0 & 4.25 \\
\hline Motor vehicles, etc. & 0.00 & 0 & 0.00 & 93.39 & 97.13 & 98.5 & 0.00 & 0 & 0.00 \\
\hline Furniture & 0.00 & 0.8 & 0.00 & 42.30 & 52.51 & 50.1 & 0.00 & 3.01 & 0.01 \\
\hline Total & 9.95 & 6.05 & 3.03 & 43.52 & 53.61 & 51.0 & 52.93 & 24.42 & 11.65 \\
\hline
\end{tabular}

Source: CSA (various years), but own calculations. 
Table 2.7 Geographical distribution of manufacturing enterprises

\begin{tabular}{|c|c|c|c|c|c|c|c|c|}
\hline \multicolumn{3}{|c|}{ Top 10 towns share (\%)1995/96 } & \multicolumn{3}{|c|}{ Top 10 towns share (\%) 2003/04 } & \multicolumn{3}{|c|}{ Top 10 towns share (\%) 2009/10 } \\
\hline Top 10 towns & \# of est. & Employment & Top 10 towns & \# of est. & Employment & Top 10 towns & \# of est. & Employment \\
\hline Addis Ababa & 67.2 & 60.4 & Addis Ababa & 55.8 & 53.6 & Addis Ababa & 40.3 & 45.9 \\
\hline Dire Dawa & 4.0 & 7.0 & Awassa & 3.3 & 2.8 & Awassa & 3.6 & 2.5 \\
\hline Bahr Dar & 2.6 & 3.3 & Mekelle & 3.0 & 1.7 & Dire Dawa & 2.8 & 1.9 \\
\hline Awassa & 2.4 & 3.2 & Bahr Dar & 2.3 & 2.6 & Mekelle & 2.8 & 1.9 \\
\hline Nazreth* & 2.3 & 1.5 & Burayu* & 2.2 & 1.4 & Nazreth* & 2.4 & 3.1 \\
\hline Jimma & 1.9 & 0.4 & Dire Dawa & 2.2 & 3.9 & Bahr Dar & 2.3 & 1.4 \\
\hline Mekelle & 1.6 & 0.3 & Nazreth* & 2.2 & 1.7 & Debrezeit* & 1.7 & 2.5 \\
\hline DebreZeit* & 1.1 & 1.2 & Debre Zeit* & 1.9 & 2.8 & Sebeta* & 1.7 & 1.5 \\
\hline Harar & 1.1 & 1.3 & Sebeta* & 1.7 & 1.7 & Burayu* & 1.6 & 1.3 \\
\hline Dessie & 1.0 & 0.3 & Dessie & 1.5 & 0.4 & Hosana & 1.1 & 0.3 \\
\hline Top 10 towns sum (\%) & 85.2 & 79.1 & & 76.3 & 72.6 & & 60.5 & 62 \\
\hline Total & 622 & 91,096 & & 982 & 104,681 & & 2,172 & 186,978 \\
\hline
\end{tabular}

Note: *Indicates towns fewer than $100 \mathrm{~km}$ from Addis Ababa.

Source: CSA (various years), but own calculations. 
industrial towns in both 2003/04 and 2009/10. This brings the concentration in Addis Ababa and the surrounding towns (in a $100 \mathrm{~km}$ radius), for example in 2009/10, to above 48 per cent (number of establishments) and 52 per cent (in terms of employment).

Some of the current regional capitals such as Awassa in the south, Dire Dawa in the east, Mekelle in the north, and Bahr Dar in the northwest are also among the top ten towns hosting a substantial number of industrial establishments. The gap between the first and the next top ranking towns is, however, very large. For example in 2009/10, the first top town (Addis Ababa) hosted about eleven times more manufacturing establishments than the second largest industrial concentration town (Awassa).

\subsection{Patterns of Industrial Productivity in the Ethiopian Manufacturing Sector}

\subsubsection{Productivity across Firm Size}

In this subsection we examine productivity difference by firm size. Table 2.8 gives the value added per labour across four broad size categories of the manufacturing enterprises for selected years between 1995/96 and 2007/08. The value added is adjusted for price change using a GDP deflator. The magnitude of the difference in labour productivity between the size groups is striking. For example in 2007/8, the value added per employee in large firms (employing 50+ workers) was about five times that of the micro-firms (employing fewer than ten workers), above four times that of the small size category (11-20 employees) and about double that of the medium sized enterprises category (21-50 employees).

The observed large difference in labour productivity is associated with differences in the proportion and quality of the input factors used in production. For example, large firms are more likely to use more capital than small

Table 2.8 Productivity by size category for selected years (1995/96-2008/09)

\begin{tabular}{|c|c|c|c|c|c|c|c|}
\hline \multirow[t]{2}{*}{ Year } & \multicolumn{4}{|c|}{$\begin{array}{l}\text { Value added per labour ( } 1000 \text { s Birr) } \\
\text { by employment size category }\end{array}$} & \multicolumn{3}{|c|}{$\begin{array}{l}\text { TFP by employment } \\
\text { size category }\end{array}$} \\
\hline & $<10$ & $10-19$ & $20-49$ & $50+$ & $10-19$ & $20-49$ & $50+$ \\
\hline $1995 / 96$ & & 9.44 & 16.96 & 28.25 & -0.10 & 0.02 & 0.25 \\
\hline $1999 / 2000$ & & 12.02 & 21.29 & 36.71 & -0.15 & 0.00 & 0.28 \\
\hline $2003 / 04$ & & 10.70 & 26.86 & 46.50 & -0.20 & -0.01 & 0.26 \\
\hline $2007 / 08$ & 8.2 & 10.84 & 21.63 & 42.59 & -0.16 & -0.03 & 0.17 \\
\hline $2008 / 09$ & & 16.44 & 28.05 & 45.88 & -0.15 & -0.06 & 0.18 \\
\hline Avg. 1995/96-2008/09 & & 12.85 & 34.02 & 42.63 & -0.2 & -0.016 & 0.22 \\
\hline
\end{tabular}

Source: CSA (various years), but own calculations. 
firms, and employ more skilled (and expensive) workers. ${ }^{11}$ To shed light on productivity differences while netting out the effects of input differences, we use total factor productivity (TFP) as an alternative productivity measure. The TFP is defined as the residual in a Cobb-Douglas production function for the MLSM sector. ${ }^{12}$ The estimation is based on firm level panel data covering 1996-2009. Similar to labour productivity, the TFP exhibits a big difference across the size categories in favour of the large size groups (see Table 2.8).

\subsubsection{Productivity across Sectors}

Table 2.9 reports average labour productivity and TFP in fourteen Ethiopian manufacturing industries based on the most recent three years average (2007/ 08-2009/10). There is a large difference in productivity across sectors. Industries such as basic iron and steel, other non-metallic minerals, food and beverage, and fabricated metals have relatively high levels of labour productivity and TFP. Furniture, paper and printing, textile, and apparel record low average productivity levels.

Table 2.9 Productivity and capital intensity in the MLSM, by industry

\begin{tabular}{lccr}
\hline & \multicolumn{3}{c}{ 3-years average (2007/08-2009/10) } \\
\cline { 2 - 4 } Industry & $\begin{array}{l}\text { Value added per labour } \\
\text { (000s Birr) }\end{array}$ & $\begin{array}{l}\text { Capital per labour } \\
\text { (000s Birr) }\end{array}$ & TFP \\
\hline Basic iron and steel & 126.97 & 102.19 & 0.64 \\
Non-metallic minerals & 85.35 & 82.15 & 0.44 \\
Food and beverage & 83.21 & 61.43 & 0.60 \\
Fabricated metal & 81.78 & 60.43 & 0.41 \\
Rubber and plastic & 76.75 & 42.94 & 0.53 \\
Leather & 73.13 & 26.74 & 0.61 \\
Machinery and equipment & 70.80 & 42.28 & 0.06 \\
Motor vehicles & 69.79 & 104.39 & 0.02 \\
Chemicals & 67.70 & 71.26 & 0.23 \\
Wood & 66.25 & 9.77 & 0.07 \\
Apparel & 56.75 & 12.87 & 0.57 \\
Textile & 50.71 & 21.31 & 0.30 \\
Paper and printing & 50.48 & 47.22 & -0.01 \\
Furniture & 29.16 & 30.47 & -0.33 \\
All industries (mean) & 72.3 & 52.5 & 0.30 \\
All industries (median) & 71.04 & 47.2 & 0.33 \\
\hline
\end{tabular}

Source: CSA (various years); author's calculations.

11 Other reasons why large firms might be more productive than small firms include the fact that they are more likely to use better technology and management. They are also relatively more favoured in the capital market than are small firms.

${ }^{12}$ Micro-enterprises with ten or fewer employees are excluded from the estimation as there is an absence of time series data for the specified period. 


\subsection{The Current Industrial Policy Framework}

In 2002/03 the EPRDF-led government formulated a comprehensive IDS. ${ }^{13}$ IDS is based on the government's broader development vision-Agricultural Development Led Industrialization (ADLI) — which was developed in the mid1990s and subsequently elaborated. The IDS maintains that sustainable and fast industrial development can only be ensured if the sector is competitive in international markets. Hence, the export oriented sectors should lead industrial development and be given preferential treatment. The strategy explicitly further argues for a strong role from the state. Inspired by the East Asian experience the government has recently introduced the language of 'developmental state' as its policy principle regarding the public-private relationship. The strategy cites two important mechanisms in which the government could engage and promote the private sector, thus creating an environment conducive to and providing direct support for identified sectors. With regard to the first of these headings, the strategy paper identified the following intervention areas: (1) maintaining macroeconomic stability; (2) building a functioning and well-regulated financial sector; (3) creating dependable infrastructure services; (4) developing skilled and effective human resources; (5) creating an efficient civil service and legal framework; (6) developing industrial zones in major cities and towns with all required infrastructure facilities. The working paper version of this chapter examines these interventions in further detail (Gebreeyesus 2013). In what follows, we focus on initiatives aiming to support the identified sectors more directly.

The 2003 IDS declared priority sectors for government direct support which included textile and garment; meat, leather, and leather products; other agroprocessing industries (e.g. sugar and sugar related industries); construction industry; and the micro- and small enterprises (MSEs). The list of priority sectors has been updated over time. For example the flower industry and some import substituting industries have been sequentially added. The targets and accompanying government supports were explicitly stated in the country's five-year development plans, the so-called PASDEP (2005/06-2009/10) and the ongoing Growth and Transformation Plan (GTP) covering the period 2010/11-2014/15. The focus of this study is mainly on the former. The overall target for the industrial sector during the period of the PASDEP was to register an average annual growth rate of 11.5 per cent and thereby increase the sector's share in overall GDP from 13.6 per cent in 2004/05 to 16.5 per cent by the end of 2009/10 (MoFED 2006). Targets were also set at sub-sector level with a particular focus on the selected export industries.

13 FDRE (2002). As far as we know the original industrial policy document is in the local language, Amharic; as yet there is no official English translation. 
In order to meet these targets the government provided extensive support, including economic incentives (credit, land, and duty and tax exemption), capacity building, and direct public investment. These support programmes have largely been directed at the exporting firms and industries. Exporters are eligible for various economic incentives. In addition to the efforts to boost the general human capital of the country the government has been involved in capacity building of the private sector particularly in the selected priority industries. In 2005, it launched an ambitious reform programme known as the Engineering Capacity Building Program (ECBP) with the aim of further enhancing the competitiveness of the private sector through improving workforce skills.

\subsection{Industrial Policy in Practice-Some Industry Cases}

Textile and leather are the two preferred industries receiving the most attention from Ethiopian policy makers for export promotion. The flower industry, which emerged spontaneously, is another celebrated industry. This section highlights the implementation and performance of industrial policy to date focusing on these sectors.

\subsubsection{The Textile and Leather Sectors}

According to the PASDEP five-year plan the textile and apparel sector was expected to generate foreign exchange of about US\$500 million by the end of the plan period, i.e. 2009/10. It was envisaged that continuous investment support and expansion activities would be carried out by the government for more than 191 investors, with investment worth US\$1.6 billion. Similarly, the leather industry was expected to generate US\$500 million by the end of the plan period and at the same time to change the mix of exports towards processed and finished goods. The shoes sub-sector alone was anticipated to produce twenty million pairs of shoes and generate US\$175 million and the other finished leather products to generate US\$43 million by the end of the plan period.

In order to meet these targets the government made sector specific capacity building efforts in addition to the general support programmes given to all exporters. Two sector specific institutions, namely, the Textile Industry Development Institute (TIDI) and the Leather Industry Development Institute (LIDI), were set up to support, coordinate, and guide the private sector in these areas. These institutions have been implementing jointly capacity building programmes aimed at enhancing the competitiveness of the industries in international markets. 
Sector special training institutions were established under the guidance of these institutions. In 1998, the Ethiopian Leather and Leather Products Technology Institute (ELLPTI) was established to support the leather industry. ELLPTI provides training, laboratory testing, technical support, and consultancy to the sector. From 2003/04 to 2007/08 the institute provided training on footwear, leather, and leather products for more than 1,800 trainees. Another training centre, the Textile and Apparel Institute with facilities similar to those of ELLPTI, is also under establishment in support of the textile sector. At the time of writing, the scope of training is limited to basic tailoring skills but there are plans to expand the scope when complete implementation of the project is realized. To improve the international competitiveness of these industries the government introduced various additional support programmes, including benchmarking, institutional twinning, market research, and kaizen. In what follows we assess the implementation of these programmes with a focus on the textile and leather industries.

Benchmarking: In 2009, the government launched a programme called benchmarking with a view to upgrading technology and raising the capacity of the prioritized sectors, thereby increasing their competitiveness in the international arena. Under this programme selected textile and leather enterprises, both public and privately owned, will receive comprehensive direct support from internationally renowned firms sponsored by the government to alleviate their constraints in the areas of management, productivity, input supply networking, marketing of products, human resource development, and product quality.

Twinning programmes: The idea of the twinning programme is to establish long-term knowledge and experience sharing between the TIDI and the LIDI on the one hand, and other international and selected domestic and similarly renowned institutes on the other. In the leather sub-sector, a network has been established between the LIDI, Engineering Capacity Building, and selected foreign counterpart institutes (e.g. the Indian Leather and Leather Products Technology Institute). At the time of writing, this networking has enabled the LIDI to provide short-term training in the fields of leather technology and leather science.

Marketing and other support activities: Marketing products internationally is expensive and out of reach for many of the local industries. Moreover, whenever markets are available, the scale of operation of local firms is so limited that they cannot individually meet the order size from big companies. Realizing this constraint, the Ethiopian Embassies are endeavouring to promote the products and establish market links internationally; while at the same time the MoTI (Ministry of Trade and Industry) is coordinating and facilitating domestic firms to establish market networks for products and inputs among themselves through sub-contracting and other arrangements. 
In this regard, domestic firms are linked with potential international buyers such as ARA of Germany, ADELCHI of Italy, ANNABELA of Italy, and the Brown Shoe Company of America.

Kaizen: The Kaizen scheme is a cross-sector initiative which was introduced in 2009 in Ethiopia as a two-year pilot project in thirty selected companies located in Addis Ababa and its environs. It is a Japanese management philosophy which aims at bringing incremental and continuous change. Encouraged by the results achieved in the selected companies in terms of increased productivity and improved quality, the government is envisaging a scale-up of its implementation to other companies. To this effect a Kaizen Training Institute was established by a regulation in October 2011.

Despite these efforts the textile and leather sectors' export performance in the PASDEP period has been unsatisfactory. For example, the government envisaged US\$500 million from exports from textile and garment industries by the end of the PASDEP period, but only about 8 per cent of this target (US $\$ 40.3$ million) was actually achieved. Similarly, the plan for the leather industry was to generate US\$500 million of which US\$221 million was to come from shoe and other leather product sub-sectors. But only US\$65 million worth of hides and skins and US\$8.3 million worth of leather articles and footwear had been exported by the end of the plan period, respectively 23 per cent and 3.7 per cent of target.

\subsubsection{The Flower Industry}

In contrast to the textile and leather industries, the Ethiopian cut-flower industry represents an extraordinarily successful export diversification. In the mid-1990s two private domestic entrepreneurs started the experimentation by producing summer flowers and exporting to the EU market. A modern and large-scale floriculture industry began to emerge in the early 2000s. By 2008 , the sector consisted of eighty-one farms that had created more than 50,000 jobs and generated more than US\$100 million in foreign exchange. As a result the country became the fifth-largest non-EU exporter to the EU market of cut flowers and the second largest exporter in SSA, after Kenya. The sector continues to grow even further whereby the foreign exchange earnings from this sector have reached about US\$189 million. ${ }^{14}$

The dynamics of the public-private interaction in the flower industry is different from other priority sectors. The flower industry was not even on the list of priority sectors at inception of the industrial policy document. Government was only lately aware about the export potential of this sector through

\footnotetext{
14 Gebreeyesus and Iizuka (2011) have an excellent discussion of the emergence of the floriculture industry in Ethiopia. The discussion that follows relies heavily on that.
} 
the experimentation of the private entrepreneurs and their effort to acquire government support. The early entrants faced a number of difficulties particularly related to logistics, land, and finance. In 2002, they formed an association and started to seek government support. The government responded quickly and positively, and finally at the end of 2002, the Prime Minister's Office requested the MoTI to draw up a five-year plan of action for the sector, outlining the sector's constraints and possible solutions. Based on the MoTI report, targets were set to put 1,000 ha under flower production by the end of five years. ${ }^{15}$

To meet these targets, the government came in with multi-faceted support starting from 2003, particularly focusing on: access to land, access to longterm credit, infrastructure, and air transport coordination. Prior to 2003, private investors in the flower sector were able to obtain land by leasing it from small farmers. With the government decision to engage in promotion of the sector, land held by the government was increasingly made available for flower farms within the vicinity of the airport in Addis Ababa, leading to the creation of flower enterprise clusters. The land was offered very cheaply with longer leases and payment periods. A survey carried out by this author in 2008 shows that the majority ( 83 per cent) of the source of farmland was by government lease. The government also made available cheaper loans with easier access for investors in the floriculture sector through the Development Bank of Ethiopia. Other forms of support include advocacy and capacity building.

\subsection{Remaining and Emerging Challenges}

The first decade of the EPRDF regime (1991-9) was marked by a series of reforms under the SAP to reverse the command economic system. In 2002/ 03, after a decade in power, the government formulated comprehensive IDS, which has been concretized into action by subsequent development plans and various sub-sector strategies. The government made notable efforts to implement the IDS. It particularly promoted selected export industries through setting targets and providing comprehensive support in meeting their targets.

Unlike many other reform policies that had to be agreed on with international financial institutions, the IDS was designed by the Ethiopian Government and based on its broad development vision, known as ADLI. The government has shown firm commitment and exerted maximum efforts in implementing it.

15 These targets were updated in the PASDEP five-year plan. 
The strategy relies on the state playing a central role in guiding the private sector through the development process.

The industrial policy-making process in Ethiopia is characterized by more flexibility and scope for policy learning. In 1998, the government formulated an export promotion strategy which was narrowly defined as industrial policy. In 2002/03, a comprehensive industrial policy was designed, which has a list of several sectors for support including meat, leather and leather products, apparel and textile, other agro-processing sectors, construction, and small and medium enterprises (SMEs), and a package of incentives. Later, floriculture was added to the priority list after it emerged largely through entrepreneurial experiment from the private sector. The list of priority sectors has recently been adjusted to include import substituting sectors such as metal and engineering, chemical, and pharmaceutical industries. Over time, the government has also expanded its policy instruments to promote the selected industries.

The performance so far has been mixed and manufacturing export performance so far has not been satisfactory. Recent studies highlighted poor trade logistics and lack of quality inputs in the domestic market to be among the major constraints reducing global competitiveness of the textile and leather sectors in Ethiopia. The government has taken different measures to address these problems. For example, it implemented a wide range of reforms to modernize the civil service and in particular the customs administration. It invested in infrastructure in order to reduce the cost of doing business. Still, the poor trade logistics and lack of quality inputs continue to be a drag on the export sectors.

In contrast to the textile and leather, the Ethiopian flower export is booming and has become one of the major export sectors. Why has the flower industry, which was not even in the original government priority list, emerged to be so successful but not the leather and textile industries that long before received the most attention? This leads to the identification of potential products, an issue as prominent as the industrial policy itself. The Ethiopian case study suggests that although governments might have their own list of priority sectors a priori, they should allow for flexibility and revise their choices over time. To do so one needs to introduce a mechanism to elicit valuable information through continuous consultation with the private sector on potential industries. This is consistent with the Hausmann and Rodrik (2003) view that there is large element of uncertainty as to what a country will be good at producing, once we move beyond the broad aggregates (e.g. labour-intensive or natural resource-based) that are predicted by factor endowment models.

Several other issues arise regarding the effectiveness of the support programmes and the implementation of industrial policy. How much rent and how long should the private sector in the selected areas be given to bear fruit? 
What form of relationship should be instituted between the government and the private sector? How do you create an environment that maximizes the social benefits while limiting rent-seeking? In this regard, Ethiopian industrial policy made a distinction between 'developmental' and 'rent-seeking' private sector; and vows to support the former and curtail the latter. It provides generous incentives and support programmes to build the private sector capacity and has also created public-private consultation forums (carrots). At times (particularly recently) it has introduced a number of measures (sticks) alleging to 'discipline' the 'rogue' private sector, which have resulted in increasing tension and policy uncertainties around the private sector. There are critics that maintain that these instruments (carrot and stick) are not transparent and policy makers tend to 'patronize' the private sector instead of encouraging competition and innovation. Failing to address these concerns might also damage the efficacy of industrial policy.

\section{References}

Central Statistical Agency (CSA) (various years[a]). 'Report on Small-Scale Manufacturing Industries Survey'. Addis Ababa: CSA.

Central Statistical Agency (CSA) (various years[b]). 'Report on Medium and Large Manufacturing and Electricity Industries Survey'. Addis Ababa: CSA.

Central Statistical Agency (CSA) (2003). 'Report on Cottage/Handicraft Manufacturing Industries Survey'. Addis Ababa: CSA.

Federal Democratic Republic of Ethiopia (FDRE) (2002). 'Ethiopian Industrial Development Strategy'. Ethiopia (Amharic version). Addis Ababa: FDRE.

Gebreeyesus, M. (2013). 'Industrial Policy and Development in Ethiopia: Evolution and Present Experimentation'. WIDER Working Paper 2013/125. Helsinki: UNU-WIDER.

Gebreeyesus, M. and Iizuka, M. (2011). 'Discovery of the Flower Industry in Ethiopia: Experimentation and Coordination'. Journal of Globalization and Development 2(2): 1-27. Geiger, M. and Goh, C. (2012). Chinese FDI in Ethiopia: A World Bank Survey. Washington, DC: World Bank. Available at: <http://documents.worldbank.org/curated/en/2012/ 11/17073974/chinese-fdi-ethiopia-world-bank-survey>, accessed 10 July 2013.

Hausmann R. and Rodrik, D. (2003). 'Economic Development as Self-discovery'. Journal of Development Economics 72: 603-33.

Imperial Ethiopian Government (IEG) (1957). First Five Year Development Plan (1958-1962). Addis Ababa: IEG.

Imperial Ethiopian Government (IEG) (1962). Second Five Year Development Plan (1963-1967). Addis Ababa: IEG.

Imperial Ethiopian Government (IEG) (1968). Third Five Year Development Plan (1969-1973). Addis Ababa: IEG.

Ministry of Finance and Economic Cooperation (MoFED) (2006). 'Ethiopia: Building on Progress: A Plan for Accelerated and Sustained Development to End Poverty 
(PASDEP) (2005/06-2009/10)' Addis Ababa: MoFED. National Bank of Ethiopia (NBE) (2010), Annual Report 2009/10, available at: <http://www.nbe.gov.et/publications/ annualreport.html>, accessed 10 July 2013.

Provisional Military Administrative Council (PMAC) (1975). Declaration of Economic Policy of Socialist Ethiopia. Addis Ababa: PMAC.

United Nations Industrial Development Organization (UNIDO) (1991). Ethiopia: New Directions of Industrial Policy. Industrial Development Review Series, Regional and Country Branch. Vienna: UNIDO.

World Bank (1985). Ethiopia: Industrial Sector Review, 1985. Washington, DC: World Bank.

World Bank (2010). World Development Indicators. Washington, DC: World Bank, available at: <http://databank.worldbank.org/ddp/home.do>, accessed 10 July 2013. 


\title{
3
}

\section{Industrial Policy in Ghana}

\author{
Its Evolution and Impact
}

Charles Ackah, Charles Adjasi, and Festus Turkson

\subsection{The Evolution of Industry}

\subsubsection{Historical Developments since 1965}

Ghana has since independence undergone three major episodes of industrialization namely an inward overprotected ISI (import substitution industrialization) strategy (1965-83), an outward liberalized industrialization strategy (1984-2000), and since 2001 industrial architecture based on valueadded processing of Ghana's natural resource endowments through a private sector-led accelerated industrial development strategy. In Section 3.1 we describe in detail the dominating policies during the two first episodes and in subsequent sections we zoom in on the post-2000 episode.

\subsubsection{PRE-ECONOMIC RECOVERY PROGRAMME, 1965-83}

Ghana's industrial development post-independence has evolved from an ISI strategy to the current private sector-led industrialization programme. Prior to Ghana's attainment of political independence in 1957, the industrial sector, a corollary of the colonial economic system, was a small sector (mainly made up of a domestic manufacturing sector) that contributed very little to economic growth. The industrial sector that was inherited from the colonial rulers was one that had been underdeveloped mainly because the regime was more interested in extracting raw materials from the Gold Coast (Ghana) while at the same time creating an economic system heavily dependent on manufactured products from Britain.

At the time that Ghana gained political independence from Britain, the Nkrumah led Convention Peoples Party (CPP) government viewed industrialization 
as a key factor for modernization and development. The extensive industrialization programme, which emphasized import substitution, was pursued to transform the industrial structure and reduce the Ghanaian economy's dependence for goods on colonial powers and other foreign economies. According to Killick (2010), the CPP government gave priority to import substitution because it was believed that it would help dispense with the distorting effect of the colonial system, escape from dependence on primary exports, and break the vicious circle of poverty.

At the centre of the ISI strategy was the development of large-scale, capital intensive state owned manufacturing industries. Government invested heavily in infrastructure and was involved in domestic production of previously imported consumer goods, processing of exports of primary products (agricultural and mining), and the expansion and development of building materials and electrical, electronic, and machinery industries. According to Steel (1972), the development of these industries was intended to serve as one that would provide the necessary inputs needed to expand the industrial sector in the near future. As noted by Steel (1972), it seemed that Nkrumah's industrialization programme had been entwined with socialism and macroeconomic policy within the broader development plan of Ghana.

From the mid-1960s the ISI strategy was characterized by a strong reliance on import substitution through high levels of effective protection, to reduce economic dependence on imported goods and to resolve balance of payment difficulties arising from increasing import bills and stagnant export earnings. In addition, the government resorted to administrative controls in the form of import tariffs and licensing. As indicated by the World Bank (WB 1985), these direct controls were not successful in achieving their intended objectives but instead formed incentives that created excess capacity and inadequate linkages with other growth enhancing sectors.

The initiative to create a state managed ISI strategy through the development of large-scale, state owned capital intensive manufacturing industries did have the intended impact. From a contribution of 19 per cent to gross manufacturing output in 1962, SOEs (state owned enterprises) produced 32 per cent and 42 per cent of gross manufacturing output in 1966 and 1967 respectively. As indicated by Steel (1972), output in both the wholly state and state-private joint venture companies (JVCs) grew at rates over 250 per cent faster than the average for privately owned between 1962 and 1966. Over the same period there was a dwindling contribution from the predominantly nonGhanaian privately owned enterprises to gross manufacturing output. This significant decline in privately led manufacturing was a direct result of the government strategy to take over the domain of many private enterprises, and as a result led to an uncertain climate for private investments (WB 1985). 
By the beginning of the 1970s, the ISI strategy began to face structural bottlenecks against the backdrop of a shift from a centrally planned to a market-based economy during the Busia-led government in 1969. ${ }^{1}$ However, as a result of the liberalization of imports and interest rates, high public expenditure, and a huge surge of imports which led the economy into severe balance of payment problems and to a 90 per cent devaluation of the cedi in 1971, the National Redemption Council, led by General Acheampong, overthrew the Busia regime in 1972, denounced its laissez faire policies, and reintroduced comprehensive import controls, price controls, a rent freeze, and a revaluation of the cedi (reversing the devaluation of 1971).

As indicated by the World Bank (WB 1985), by its nature the ISI strategy was self-limiting in two ways. By discouraging growth of exports and agriculture, the ISI strategy ensured that foreign exchange earned by Ghana could not keep pace with the need to import raw materials and spares for the many import substituting industries that had been set up. Second, the effective protection granted to the industries under the ISI strategy made such import dependent industries inefficient in utilizing domestic resources.

As a result of external shocks and inappropriate domestic policies during the period from the mid-1970s to 1983, the industrial sector and the Ghanaian economy as a whole suffered a severe worsening in economic and financial performance. According to the World Bank (WB 1985), the period 1975-83 was characterized by a decline in Ghana's export earnings (estimated to be about two-thirds of imports), a significant reduction in capital flows, official aid, and lack of creditworthiness. In addition to these external shocks, there were a number of inappropriate macroeconomic policies pursued by various governments that negatively impacted on the industrial sector and the economy, including large fiscal deficits financed primarily by borrowing from the domestic financial sector leading to sharp increases in money supply and resultant inflationary pressures, an increasingly overvalued exchange rate, a high lending rate, and the crowding out of private investment.

These structural bottlenecks resulted in a decline in the growth of the economy throughout the late 1970s, with real GDP declining by an average of 2 per cent per annum between 1979 and 1982. Over this period the structure of production shifted away from industry to services and trade, while agriculture maintained its importance by contributing over half of real GDP.

\footnotetext{
1 At the beginning of the Busia administration in October 1969, the National Liberation Council (NLC), which had overthrown Nkrumah's CPP government in 1966, claimed that Ghana had achieved economic stability and restored the necessary conditions for economic growth (Killick 2010: 62).
} 
3.1.1.2 POST-ECONOMIC RECOVERY PROGRAMME, 1983-2000

The initiation of the Economic Recovery Programme (ERP) as part of the Structural Adjustment Programme (SAP) in April 1983 was intended to arrest and reverse the decline in all sectors of the Ghanaian economy and also to rehabilitate ruined productive and social infrastructure. The SAP/ERP sought to correct the structural macroeconomic imbalances that the Ghanaian economy faced by restructuring almost all sectors of the economy including the industrial sector. ${ }^{2}$ Important economic policy reforms under the SAP included: introduction of a market-determined exchange rate with minimal interventions; removal of price and distribution controls; liberalization of the financial sector and interest rates; abolition of the import licensing system; rationalization of import tariffs and the taxation system; promulgation of a new investment code (PNDC Law 116); establishment of the Ghana Investment Centre (GIC); and the privatization of the SOEs (Nyanteng 1993). In addition the SAP sought to initiate the SOEs' reform programme in order to introduce more competition into state dominated industrial sectors. All these policy objectives had impact on the structure and development of the industrial sector.

Soon after the initiation of the ERP, the industrial sector in general and the manufacturing sector in particular responded positively to the reforms and this laid the foundation for Ghana's industrial recovery after a decade of decline. Over the initial five-year period after the launch of the ERP (i.e. 1984-8), the industrial sector grew on average by 11.2 per cent annually, this coming from a negative growth spell three years prior to the launch of the ERP in 1984. This remarkable performance by the industrial sector was largely accounted for by the encouraging recovery of manufacturing and improved performance of the electricity and water sub-sectors. These improvements were largely due to reforms in trade policies, the provision of financial and technical assistance in the rehabilitation, modernization, and expansion of potentially productive and efficient industries, the improved utilization of installed capacity, and correction of price distortions that served as a disincentive to industrial production and the initiation of reforms in allied sectors.

Growth in the industrial sector, however, slowed down from the late 1980s (Figure 3.1). The decline in growth rates was attributed to the slow response of the private sector (dominant in the industrial sector) to the economic reforms in the face of institutional and structural constraints, the adverse effects of

2 According to Killick (2010) it is conventional to split the SAP/ERP into two periods: 1984-6 and 1987-9, the former concentrating on macroeconomic stabilization and the latter on longer term and structural developmental issues. Specifically the latter phase involved restoring the infrastructural base of the economy, eliminating/reducing the remaining price distortions, and encouraging private sector development. 


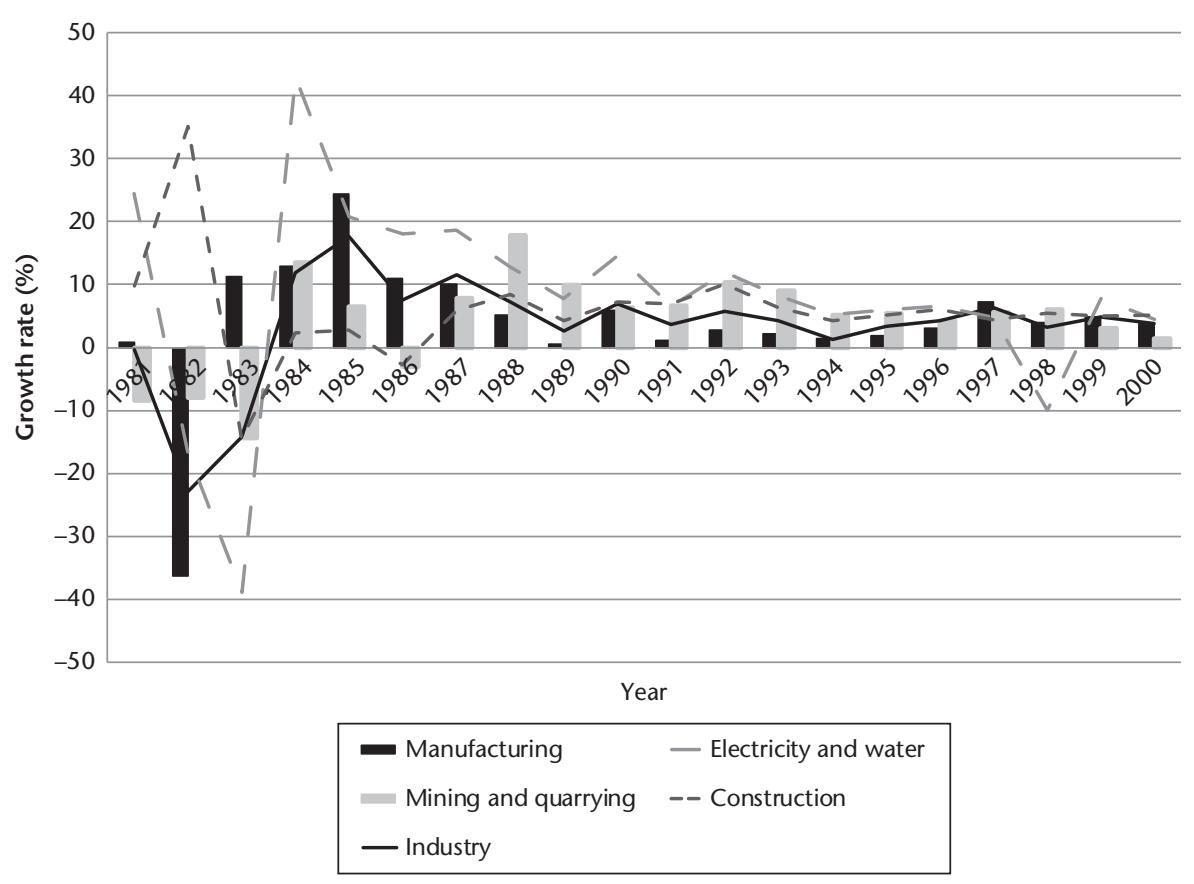

Figure 3.1 Growth rate of industry and sub-sectors, 1981-2000

Source: Authors' illustration based on National Accounts, GSS (2002) and State of the Ghana Economy (SGER) (ISSER 1911-2011) data.

trade, exchange rate, and financial sector liberalization, the lack of effective linkages between manufacturing and other major sectors, especially agriculture, and increased investment in the other sectors at the expense of the industrial sector. Structural constraints including unreliable water and power supply, infrastructural bottlenecks, problems of land acquisition, an unstable industrial relations environment, and perverse bureaucracies at the ports combined to impede manufacturing and overall industrial sector growth. The lack of expansion within the electricity and water sectors, coupled with the overreliance on nature to assure generation of electric power, led to a reduction in power supply and this adversely affected the manufacturing sector.

As a result of sluggish growth over the period 1989-94, the government in 1994 set up a committee to examine the constraints facing the domestic industries resulting from the ERP. The result was an identification of three ways in which the economic reforms had negatively impacted the industrial sector. First, it overexposed protected domestic industries to competition from imported manufactured inputs. Second, financial liberalization and exchange rate reform (which resulted in the rapid depreciation of the cedi and high costs of credit) led to increased production costs and production cuts within the 
industrial sector. Third, the reforms did not allow most industries enough time to adjust and build the necessary restructuring that was needed after a comprehensive reform.

Based upon the committee's recommendations the government introduced a number of measures to help the distressed but potentially viable industries to recover from the shock of the economic reforms. This included the setting up of the Business Assistance Fund (BAF), the Private Enterprise and Export Development Fund (PEED), the Trade and Investment Programme (TIP), the Fund for Small and Medium Enterprises Development, the Export Processing Zone (EPZ), and the Ghana Trade and Investment Gateway project (GHATIG). Although the industrial sector responded positively to the measures, there was only a marginal increase in growth rates.

One of the most remarkable features after the launch of the economic reforms was the change in the relative contribution of industry to GDP. Although the manufacturing sector remained dominant in the industrial sector its contribution declined over time following the launch of the ERP (Table 3.1). Over the same period, contributions from the construction and mining sector increased significantly. Especially the mining sector benefited immensely from exchange rate liberalization and inflows of loans to the economy in response to the comparably favourable investment climate. Various investment legislations passed during the period under consideration provided a clear framework for mining investment and contributed to the inflow of foreign direct investment (FDI) into the sector. The inflow of resources enabled the sub-sector to acquire the much-needed equipment and spare parts to boost mining production.

\subsubsection{THE NEW MILLENNIUM, 2000-5}

During the first half of the 2000s, there was a shift in the focus of Ghana's industrialization strategy. The government's broad policy objective was aimed at creating wealth by transforming the nature of the economy to achieve growth, accelerated poverty reduction, and the protection of the vulnerable/ excluded within a decentralized, democratic environment. The emphasis over

Table 3.1 Relative contributions of industry to GDP, 1984-2000 (\%), period averages

\begin{tabular}{|c|c|c|c|c|c|}
\hline \multirow[t]{2}{*}{ Year } & \multirow{2}{*}{$\begin{array}{l}\text { Industry } \\
\text { (\% of total GDP) }\end{array}$} & \multicolumn{4}{|c|}{ Relative contribution of industrial sub-sectors (\%) } \\
\hline & & $\begin{array}{l}\text { Manufacturing/ } \\
\text { quarrying }\end{array}$ & Mining & $\begin{array}{l}\text { Electricity/ } \\
\text { water }\end{array}$ & Construction \\
\hline 1984-90 & 13.6 & 64.6 & 8.7 & 7.8 & 18.9 \\
\hline $1991-5$ & 16.5 & 55.0 & 12.4 & 10.2 & 22.4 \\
\hline 1996-2000 & 25.2 & 36.2 & 22.6 & 10.5 & 30.7 \\
\hline
\end{tabular}

Source: National Accounts and State of the Ghana Economy (SGER) (ISSER 1991-2011). 
that period was to stabilize the economy and lay the foundation for sustainable, accelerated, and job creation agro-based industrial growth. The focus of the WB-IMF sponsored Interim Poverty Reduction Strategy Programme (PRSP) (2000-2) and the Growth and Poverty Reduction Strategies, GPRS I (2003-5) and GPRS II (2006-9) was private sector-led industrial production through the application of science and technology.

The policy strategies within the industrial sector were aimed at promoting agro-processing, facilitating the development of commercially viable export and domestic market-oriented enterprises in the rural areas, improving agricultural marketing and enhancing access to export markets, and improving the competitiveness of domestic industrial products, among others. The industrial sector responded positively to these initiatives (see Table 3.2).

The construction sector recorded relatively higher growth than the other subsectors. Notable developments within the construction sector that contributed to growth success were the government's real estate developments in low-cost housing at various service barracks and selected communities in Ghana, road infrastructure developments (Accra-Kumasi corridor road, Weija-Cape Coast Road, Ofankor-Nsawan, etc.), the construction of the West African Gas Pipeline, and development of the Osagyefo Power Barge Plant. Interestingly, the strong growth experience did not transform into a higher industry contribution to GDP.

Despite improved performance, the industrial sector by 2005 continued to face challenges expected to continue to endanger its growth prospects in the future. High costs of credit (high lending rates), unreliable power supplies, and rising fuel prices continued to compel especially import dependent manufacturing firms to cut back production. In addition, the liberalization of external

Table 3.2 Industry share of GDP and sub-sector growth rates, 2001-5 (\%)

\begin{tabular}{lccccc}
\hline \multirow{2}{*}{ Year } & Industry growth & \multicolumn{4}{c}{ Industry sub-sectors } \\
\cline { 3 - 6 } & & Manufacturing & $\begin{array}{l}\text { Mining/ } \\
\text { quarrying }\end{array}$ & $\begin{array}{l}\text { Electricity/ } \\
\text { water }\end{array}$ & Construction \\
\hline 2001 & 2.9 & 3.7 & -1.6 & 4.0 & 4.8 \\
2002 & 4.7 & 4.8 & 4.5 & 4.1 & 5.1 \\
2003 & 5.1 & 4.6 & 4.7 & 4.2 & 6.1 \\
2004 & 5.1 & 4.7 & 4.5 & 3.7 & 6.6 \\
2005 & 7.6 & 5.0 & 6.3 & 12.3 & 9.9 \\
\hline & 24.9 & & Share of total industry & \\
\hline 2001 & 24.9 & 36.7 & 21.1 & 10.3 & 31.9 \\
2002 & 24.9 & 36.7 & 21.0 & 10.3 & 32.0 \\
2003 & 24.7 & 36.6 & 21.0 & 10.2 & 32.3 \\
2004 & 24.7 & 36.4 & 20.9 & 10.1 & 32.7 \\
2005 & Industry (\% of total GDP) & 36.3 & 20.4 & 10.2 & 33.2 \\
\hline
\end{tabular}

Source: National Accounts and State of the Ghana Economy (SGER) (ISSER 1991-2011). 
trade continued to expose many vulnerable domestic manufacturing firms to severe competition from imported manufactured goods making the sector less attractive to potential investors.

\subsubsection{Policies for Industrial Development (Historical Evolution)}

\subsubsection{POST-INDEPENDENCE, PRE-ERP: INWARD OVERPROTECTED} ISI STRATEGY, 1965-83

Post-independence industrial policies were based on an ISI strategy through high levels of effective protection in the form of a highly restrictive trade policy regime. At the centre of the ISI strategy was the development of largescale public sector investments as the leading edge in Ghana's industrial development. The ISI strategy (introduced in 1962) relied on administrative controls rather than market mechanisms to determine incentives and resource allocations. The policies put in place to achieve government objectives were supported by (1) quantitative import restrictions; (2) foreign exchange rationing; (3) import licensing (despite high tariffs on imported consumer goods and domestic price controls in the form of administrative fixing of minimum wages, rents, and interest rates).

\subsubsection{POST-ERP: OUTWARD LIBERALIZED INDUSTRIALIZATION STRATEGY, 1983/84-2000}

The ERP introduced a paradigm shift in the industrial policy of Ghana from the traditional import substitution and overprotected industrial strategy to an outward liberalized private sector-led industrial strategy. The ERP industrial policies sought to develop a more internationally competitive industrial sector with emphasis on local resource based industries with capacity for export and efficient import substitution. A significant feature of the industrial strategy under the ERP was the shift from government as the main vehicle for industrial development to the private sector as the prime mover of industrialization. It also sought to generate employment with emphasis on job creation in small- and medium-scale enterprises. It was expected that this would contribute to the absorption of redeployed labour from the public sector and new labour market entrants.

Some of the specific initial ERP policies to achieve these objectives included: (1) introduction of a market-determined exchange rate with minimal interventions; (2) removal of price and distribution controls; (3) liberalization of the financial sector and interest rates; (4) abolition of the import licensing system and the rationalization of import tariffs; (5) privatization of the SOEs under the Divestiture Implementation Programme.

By the mid-1990s, additional policies were designed to assist the distressed but potentially viable enterprises that were finding it difficult to survive under 
the economic reforms. These policies included: (1) the launch of the TIP in 1993; (2) tariff policy reforms in 1994; (3) the establishment of the Business Assistance Fund (BAF) in 1993, PEED policy in 1994, and the investment policy Fund for Small and Medium Scale Enterprises Development (FUSMED) in 1990 to provide the needed funds to boost industrial production; (4) the promulgation of a new investment code (GIPC Act of 1994 to PNDC Law 116) and the establishment of the GIC; (5) the Ghana Trade and Investment Gateway Programme (GHATIG) in 1996; (6) establishment of the Ghana Free Zones Board (GFZB) in 1995; (7) institutional and regulatory reforms in general.

\subsection{The Current Structure of the Industrial Sector}

\subsubsection{Sector Composition}

Industry currently contributes to around 28 per cent of GDP, and is therefore the second largest sector after services (49 per cent). The recent improvement in the contribution of industry to GDP (see Table 3.3) can alone be attributed to the commencement of crude oil mining in 2010 that has resulted in the mining and quarrying sub-sectors' contribution to GDP quadrupling from about 2 per cent to over 8 per cent since 2011 .

Industrial sub-sector growth rates have been highly volatile recently, which reflects the fact that the industrial sector continues to be very event sensitive. For example improvement in the industrial sector's performance in 2008 was driven by strong growth in the construction sub-sector in 2007 and 2008 due to massive infrastructural developments. Similarly, the downturn in 2009 was significantly affected by unreliable power supplies and rising fuel prices, and the 2011 surge was a direct result of increased production of crude oil and the commercial production of petroleum from the Jubilee Fields.

Table 3.3 Relative contribution of sub-sectors to industrial GDP, 2006-12 (\%)

\begin{tabular}{|c|c|c|c|c|c|c|}
\hline \multirow[t]{2}{*}{ Year } & \multirow{2}{*}{$\begin{array}{l}\text { Industry } \\
\text { (\% of GDP) }\end{array}$} & \multicolumn{5}{|c|}{ Industrial sub-sectors (\%) } \\
\hline & & Manufacturing & $\begin{array}{l}\text { Mining and } \\
\text { quarrying }\end{array}$ & Electricity & $\begin{array}{l}\text { Water and } \\
\text { sewerage }\end{array}$ & Construction \\
\hline 2006 & 20.8 & 49.0 & 13.5 & 3.8 & 6.3 & 27.4 \\
\hline 2007 & 20.7 & 44.0 & 13.5 & 2.9 & 4.8 & 34.8 \\
\hline 2008 & 20.4 & 38.9 & 11.8 & 2.6 & 3.9 & 42.7 \\
\hline 2009 & 19.0 & 36.6 & 10.9 & 2.5 & 3.6 & 46.4 \\
\hline 2010 & 19.1 & 35.5 & 12.2 & 3.2 & 4.4 & 44.7 \\
\hline 2011 & 25.9 & 25.9 & 32.8 & 2.3 & 3.3 & 35.7 \\
\hline $2012^{*}$ & 27.6 & 24.2 & 32.0 & 1.8 & 2.7 & 39.4 \\
\hline
\end{tabular}

Source: State of the Ghana Economy (SGER) (ISSER 2010); GSS (2012). 
In terms of the relative contribution from sub-sectors to total industrial sector output, since 2008 the construction sub-sector has overtaken the manufacturing sub-sector. The contribution from the construction sub-sector since the beginning of 2006 has increased consistently from 27 per cent in 2006 to 45 per cent in 2010. Over the same period the manufacturing sub-sector's contribution has dipped consistently from 49 per cent in 2006 to 36 per cent in 2010. The massive infrastructural developments that have taken place since the mid-2000s as part of Ghana's development agenda and the high production costs are challenges that confront the manufacturing sub-sector and can help explain this development.

\subsubsection{Size Distribution}

The number of establishments within the industrial sector has increased significantly from 8,640 firms registered in 1987 to 26,493 firms in 2003. Some 90 per cent of these were in manufacturing. This dominance by the manufacturing sub-sector in the distribution of firms may explain why industrial policies that have been pursued since independence have concentrated mainly on the manufacturing sub-sector.

For the purpose of this analysis, the size classification adopted considers an establishment that employs fewer than five people to be a microestablishment; from 5-20 employees to be small establishments; from 21-50 employees to be medium establishments; and over 50 employees as large establishments. By this classification, the Ghanaian industrial sector appears to be primarily comprised of micro- ( 55 per cent) and small (39 per cent) firms who make up 94 per cent of the total number of firms. Medium firms on the other hand make up only 4 per cent with the remaining 2 per cent being large firms. As expected, within the manufacturing sub-sector, the size distribution follows more or less the same structure as the overall industrial sector. On the other hand, the size distribution in the more capital-intensive mining and quarrying, and electricity and water sub-sectors is skewed more towards larger firms.

\subsubsection{Employment}

The industrial sector provides employment and income for around 15 per cent of the country's labour force. With respect to the distribution of employment across sub-sectors, evidence from Table 3.4 indicates that between 2000 and 2006, there was a significant increase in the proportion of total industry employment accounted for by the manufacturing sector. From a proportion of 69 per cent in 2000, the manufacturing sub-sector employed about 80 per cent of the total industrial sector in 2006. This was mainly as a result 
Table 3.4 Employment in industry and sub-sectors, 2000, 2006, and 2012

\begin{tabular}{lccc}
\hline Industry/sub-sectors & 2000 & 2006 & 2012 \\
\hline Total number employed & $1,151,394$ & $1,296,407$ & $1,733,717$ \\
Share of industry in total employment (\%) & 15.5 & 14.2 & 14.4 \\
Sub-sector share of total industry employment (\%) & & & \\
Manufacturing & 69.0 & 80.1 & 63.2 \\
Mining and quarrying & 9.0 & 5.2 & 11.1 \\
Electricity and water & 2.6 & 1.5 & 2.8 \\
Construction & 19.4 & 13.2 & 22.9 \\
Total & 100.0 & 100.0 & 100.0 \\
\hline
\end{tabular}

Source: Ghana Living Standards Survey (GLSS) IV, V, and VI (GSS 2000, 2008, 2014).

of a decline in the shares of total industry employment by the mining and quarrying, electricity and water, and the construction sub-sectors. However, with the boom of the oil industry in 2010 and its related/linked sub-sectors the share of total industry employment by mining and quarrying increased to 11.1 per cent in 2012 .

However, manufacturing remains the largest job creation industry subsector, and the recent low manufacturing growth rates signals that it is a sector whose policy should have continued to receive high priority.

\subsubsection{Ownership}

With respect to ownership, around 6 per cent of employees in the industrial sector are working in SOEs and 7 per cent are employed in joint ventures. The remaining 88 per cent are employed by privately owned firms. Not surprisingly a larger share of firms (41 per cent-2003 census numbers) within mining and quarrying are joint ventures, whereas most firms (97 per cent) within electricity and water are SOEs.

\subsubsection{Spatial Distribution}

The regional distribution of establishments in Ghana as of 2003 reveals that the Greater Accra region has the largest number of establishments, followed by Ashanti. The two regions accounted for 50 per cent of the total number of establishments in industry. The Eastern (11 per cent), Central (10 per cent), and Western (8 per cent) regions together accounted for about 30 per cent of the total number of establishments (GSS 2012). This implies a concentration of establishments (about 80 per cent) in the major cities/urban areas of five out of the ten regions of Ghana. By their very nature these clusters are populated by establishments/enterprises that are engaged in similar productive or 
Table 3.5 Selected clusters in Ghana

\begin{tabular}{|c|c|c|c|}
\hline Location & Group & Firm size range & Industrial sector \\
\hline \multirow{4}{*}{$\begin{array}{l}\text { Kumasi- } \\
\text { Ashanti } \\
\text { Tema-Greater } \\
\text { Accra }\end{array}$} & Furniture cluster & Micro-small & Furniture \\
\hline & Suame-Magazine & Micro-small & Metalwork and machinery \\
\hline & $\begin{array}{l}\text { Tema industrial area } \\
\text { Free zones enclave }\end{array}$ & Small-medium-large & All sectors \\
\hline & $\begin{array}{l}\text { Spintex industrial area/ } \\
\text { Free zones enclave }\end{array}$ & Small-medium-large & All sectors \\
\hline \multirow{2}{*}{$\begin{array}{l}\text { Accra-Greater } \\
\text { Accra }\end{array}$} & North industrial area & Small-medium & Manufacturing \\
\hline & South industrial area & Small-medium & Manufacturing and garages \\
\hline \multirow{3}{*}{$\begin{array}{l}\text { Sekondi/ } \\
\text { Takoradi- } \\
\text { Western }\end{array}$} & Light industrial area & Small-medium-large & $\begin{array}{l}\text { Manufacturing (mainly food } \\
\text { processing and wood exporters) }\end{array}$ \\
\hline & Light industrial area & Micro-small & Garages-metalwork and machinery \\
\hline & Heavy industrial EPZ & Small-medium-large & Mineral processing for exports \\
\hline $\begin{array}{l}\text { Shama- } \\
\text { Western }\end{array}$ & Shama EPZ & Small-medium-large & Petroleum, petrochemical \\
\hline
\end{tabular}

Source: Authors' research.

commercial activities. Table 3.5 shows a list of some selected industrial clusters in Ghana.

Industrial clusters in Ghana have either grown spontaneously or have arisen in response to government/public interventions or policies. The Suame-Magazine and furniture cluster in Kumasi are examples of the spontaneous agglomeration of micro- and small enterprises that are confined in small areas as in many other places in Africa. Suame-Magazine, located in the Suame area of Kumasi, the second largest city in Ghana, is possibly the largest light manufacturing cluster in Africa with approximately 10,000 micro- and small enterprises and workshops. These enterprises and workshops are mainly engaged in automobile repair services (i.e. garages), automobile parts production and retail, and metalworking. Originating from the 1930s, it currently employs over 100,000 workers and spans an area of approximately 900,000 square metres.

In addition to the industrial clusters, there are four industrial zones that have been set up by the GFZB as EPZs. These include the Tema, Sekondi, and Shama EPZs and the Ashanti technology park.

Currently there are about 300 enterprises operating within Ghana's free zone enclaves within the various sub-sectors of the industrial sector. Mainly within the manufacturing sub-sectors, these enterprises are involved in food processing, wood and veneer processing, production of consumable goods, processing of shea nuts/oil seeds, lubricants and biofuels, garment processing, food processing machines and spare parts, plastic waste recycling, data processing, telecommunication, software development, jewellery and furniture making, etc.

With the production and exploration of oil in the western region, the Shama EPZ is expected to attract petroleum/petrochemical sector enterprises 
to the enclave. The GFZB has already indicated its intention to sustain its participation in Ghana's oil sector by licensing and monitoring growing businesses in all the downstream and support services segments; the Shama EPZ will serve as the ideal industrial zone for those operations.

\subsubsection{Sunrise and Sunset Industries}

\subsubsection{SUNRISE SECTORS}

Sunrise industries can be found mainly in the manufacturing and construction sub-sectors. This partly explains why the greater proportion of investment inflows have been directed towards these two sub-sectors. Information from the Ghana Investment Promotion Centre indicates that the manufacturing and construction sub-sectors attracted a total of US\$10,179 million worth of FDI (about 72 per cent of total investment) between 1994 and 2010. Out of a total number of 413,603 jobs that were expected to have been created between 2001 and 2010, the manufacturing and construction sub-sectors were expected to create about 28 per cent. This has been as a result of the discovery and exploration of oil and gas in Ghana as well as the current industrialization strategy of encouraging agro-processed exports within the industrial sector.

Within the manufacturing sub-sector there has been an increase in the firms engaged in energy-related activities such as producing petrochemicals, fertilizer, and LPG (liquid petroleum gas) cylinders. Within the construction sub-sector, industries producing energy (oil and gas, and power) related infrastructure and real estate developments are expected to benefit largely from the expected increased real GDP growth because of oil exploration.

\subsubsection{SUNSET SECTORS}

As a result of the ISI that was pursued after independence, Ghana established many light industries to produce imported goods locally. Some of the industries already established manufactured textiles and garments, soap, woodwork, aluminium, and metal, among others. According to Quartey (2006), for over two decades after ISI began, the textile sub-sector dominated the manufacturing sector and contributed significantly to livelihood. It employed about 25,000 of the labour force, accounted for 27 per cent of total manufacturing employment, and operated at about 60 per cent of plant capacity.

By 1982, the dominance of the textile and garments sub-sector within manufacturing had begun to dwindle as it began to operate at low capacity. This was as a result of a shortage of foreign exchange for importing raw materials. This situation was further exacerbated by the negative impact of trade liberation which formed part of the SAPs pursued in the 1980s and 1990s. The trade reforms led to increased importation of textiles and other used apparel, which facilitated the death and closure of many textile 
industries in Ghana. As at 2002, there were only four major companies that had survived the turbulence in the sub-sector, namely, the Ghana Textile Manufacturing Company (GTMC), Akosombo Textile Limited (ATL), Ghana Textile Product (GTP), and Printex, with GTP maintaining the lead in the industry.

The decline in textile and garment sub-sector activity levels was also evident in the output and employment levels within the sub-sector. Although in 1977, Ghana's textile industry had accounted for 27 per cent of total manufacturing, employing 25,000 people, by 1995, employment within the subsector had declined to 7,000, further declining to 5,000 by the year 2000 . As at March 2005 the four major textile companies in Ghana employed 2,961 persons, and this accounted for less than a fifth of the employment level of 1977.

Major reasons accounting for the decline include: low demand for local textile products and influx of second hand clothing; lack of competitiveness of local textiles against imported textiles due to the high cost of local textiles and smuggling. Local producers of textiles and garments experience increased production costs due to obsolete plant and machinery, the high cost of local cotton and utilities, an unreliable supply of utilities, high interest rates/cost of finance, and overstaffing.

Given the decline in output, employment, and number of firms operating in the industry, the textile and garments sub-sector of manufacturing remains the major sunset sector within the industrial sector of Ghana. As indicated by Quartey (2006), the outlook for the textile and garments sector remains bleak, and therefore calls for pragmatic policies that will lead to both local and global restructuring of the industry. Locally, Quartey (2006) recommends that concrete steps are taken to address the problem of cheap imports, under-declared imports, wrongly described textile imports, and copied brands, markings, tickets, and labels including those of the Ghana Standards Board.

\subsubsection{Patterns of Industrial Productivity}

Figures 3.2 and 3.3 show the growth of labour productivity and employment across firms which were subject of the World Bank Enterprise SurveyInvestment Climate Assessment 2013. The food sub-sector is the most productive and textiles the least productive. In addition, the recent 2013 survey shows that annual labour productivity growth rates are much higher in food processing (11 per cent) as compared to textiles and other manufacturing ( 2 per cent). Older firms are also found to be increasing productivity faster than younger firms, while foreign owned firms compared to domestic firms are increasing their labour productivity faster. Exporting firms are likewise improving productivity faster than firms only selling to the local domestic 
A: Sector

Annual labour productivity growth (\%)

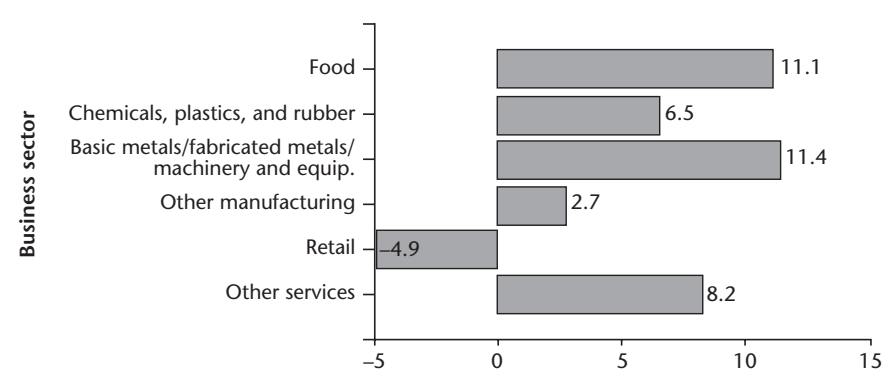

C: Location

Annual labour productivity growth (\%)

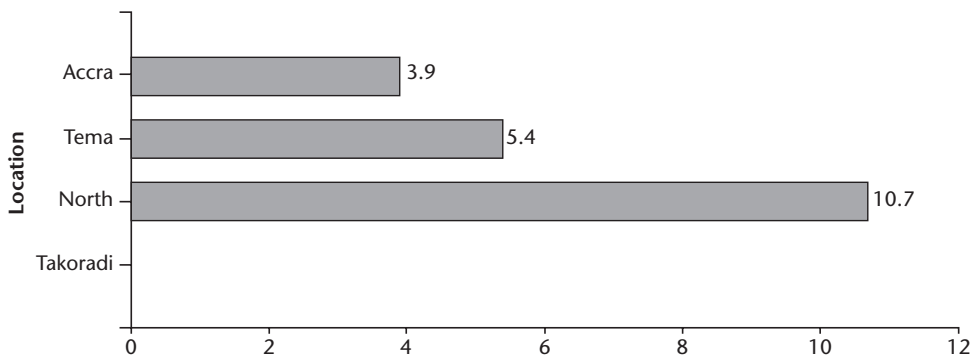

B. Firm size

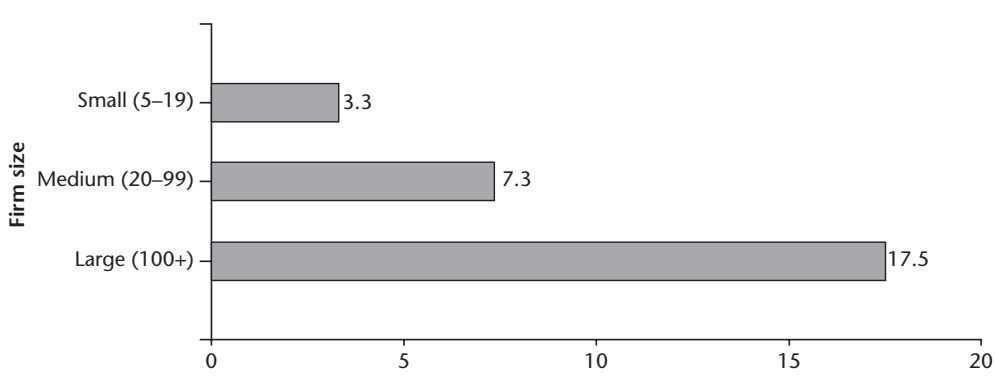

D: Export status

Annual labour productivity growth (\%)

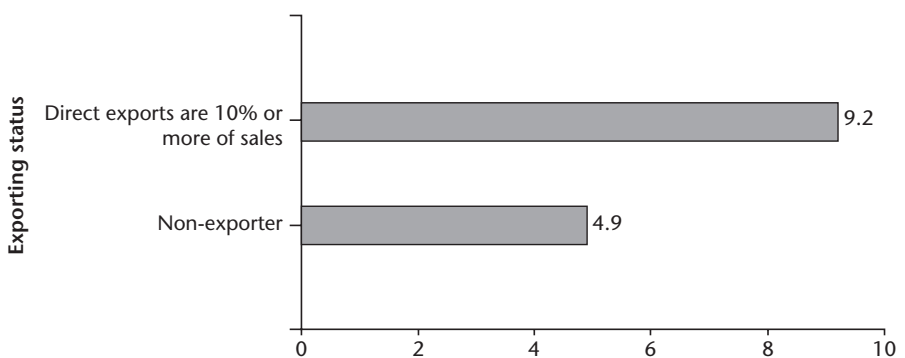

Figure 3.2 Annual labour productivity growth, 2013

Source: World Bank 2014. 
A: Sector

Annual employment growth (\%)

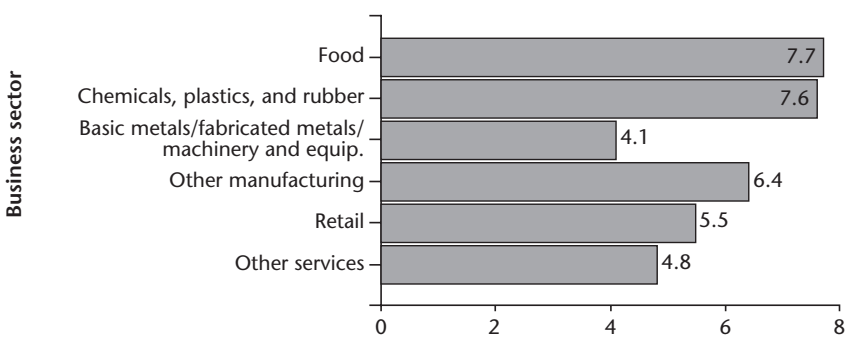

C: Location

Annual employment growth (\%)

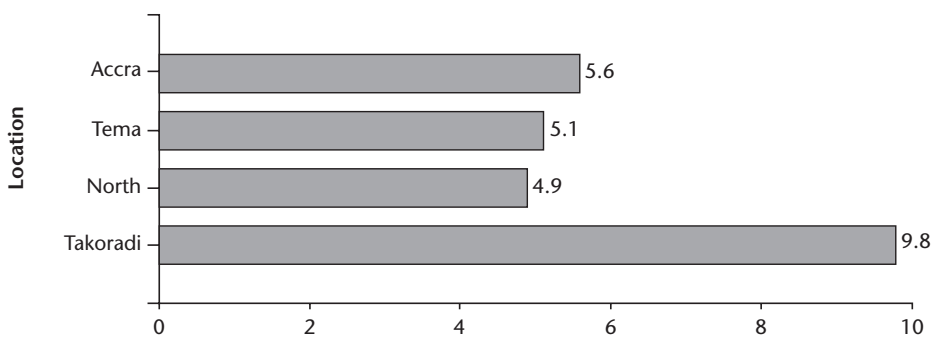

B. Firm size

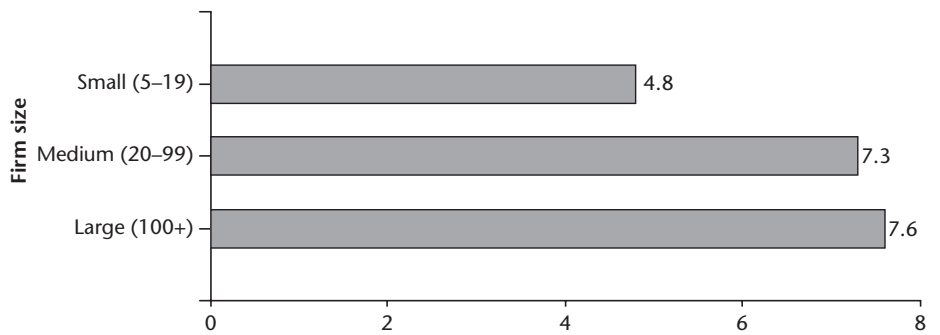

D: Export status

Annual employment growth (\%)

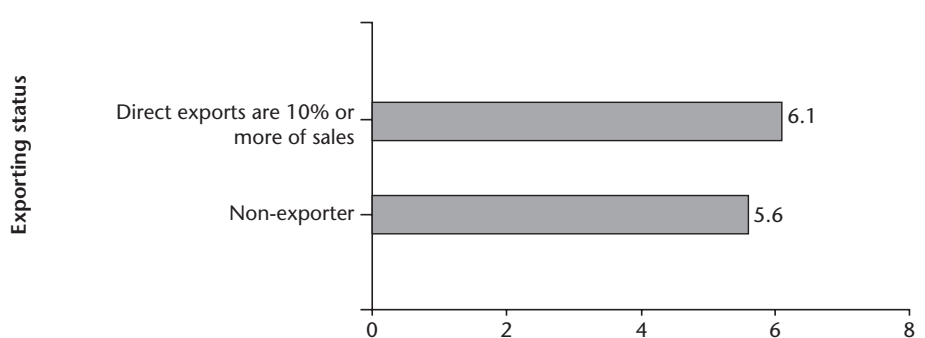

Figure 3.3 Annual employment growth, 2013

Source: World Bank 2014; GSS 2012. 
markets. Whether this is due to self-selection of high productivity firms into exporting or learning by exporting is beyond the scope of this chapter. Figure 3.2 also shows that average annual labour productivity growth was higher in larger firms and surprisingly in the northern part of Ghana.

As expected, annual labour productivity is strongly correlated with average wages for individual workers (not reported). Moreover, Figure 3.3 shows that most of the differences between groups in annual labour productivity growth are not driven by differences in employment growth rates. As an example food processing in 2013 experienced very high labour productivity growth rates and at the same time the sector recorded the highest employment growth rates in the manufacturing sector.

\subsection{The Industrial Policy Framework}

Currently, Ghana's new industrialization strategy is aimed at creating an industrial architecture based on value-added processing of Ghana's natural resource endowments through the private sector-led accelerated industrial development strategy. Set within the context of Ghana's long-term strategic vision of achieving middle-income status by 2020 the key development objectives of the industrial policy are to: (1) expand productive employment in the manufacturing sector; (2) create a modern productive economy with high levels of value added; (3) expand technological capacity in the manufacturing sector; (4) promote agro-based industrial development; (5) promote spatial distribution of industries in order to achieve reduction in poverty and income inequalities; (6) provide consumers with fairly priced, better quality products and services; (7) make firms within the industrial sector-especially manufacturing firms-competitive on both domestic and international markets (Government of Ghana, 2011).

Derived from the key development planning frameworks of the Government of Ghana, the industrial policy framework represents the set of specific policy instruments and measures to be applied to improve access to competitive factors of production within the economy, and to enhance the productivity, efficiency, and growth of Ghana's industrial sector, especially the manufacturing sub-sector.

Although the full spectrum of industrial policy initiatives which cut across twenty-one policy thematic areas have been categorized into four main components, namely Production and Distribution; Technology and Innovation; Incentives and Regulatory Regime; and Cross-cutting Issues, this report discusses these policy initiatives under the following headings: (1) Macroeconomic Policies; (2) Trade Policies; (3) Institutional and Regulatory Framework; (4) Industry Sector specific policies. 


\subsubsection{Macroeconomic Policies}

Ghana's economic growth over the last decade has been among the most rapid in Africa and faster than in some high investment emerging market economies. The economy of Ghana has experienced moderate but consistent growth over the past twenty-five years, with the growth rate between 1990 and 2010 averaging 5 per cent. With oil and gas coming on stream, Ghana is well positioned to become one of Africa's leading 'commodities powerhouses'. Oil revenue is expected to eventually contribute an equivalent of about 20 per cent of total national revenue. The contribution of gold and other minerals, cocoa, and oil provides a diversified commodity backbone that will underpin the country's rapid industrialization and sustained economic growth (Government of Ghana 2010).

The macroeconomic policies that have continued and continue to be pursued to ensure macroeconomic stability include: (1) rationalization of government sector expenditure and enhanced revenue mobilization to ensure fiscal consolidation so as to lower fiscal deficits and tone down the inflationary impact of unsustainable fiscal deficits; (2) reforms in public financial management with the aim of ensuring fiscal sustainability; (3) maintenance of a flexible exchange rate regime to enhance competitiveness of domestic firms; 4) continuous operationalization of the inflation targeting framework which aims at creating an enabling environment (keeping inflation low and easing access to low-cost credit) for the private sector to flourish.

\subsubsection{Trade Policies}

With respect to the industrial policy framework, the policy thrust of the external trade sector within the framework of trade liberalization is to use trade policy to promote the international competitiveness of domestic enterprises; improve export competitiveness of such enterprises; diversify markets and increase exports; and accelerate economic integration with other regional and/or sub-regional countries/states. The major trade policy initiatives include: (1) maintaining competitive real exchange rates; (2) improving the import/export regime; (3) establishment of the Ghana Competition Commission to deal with unfair international trade practices; (4) establishment of a National Agency for the Protection of Consumers; (5) promoting new goods and services; (6) taking full advantage of Preferential Access to markets such as Africa Growth and Opportunity Act (AGOA), European Union-African Caribbean and Pacific (EU-ACP), and sub-Saharan Africa (SSA) sub-regional trading blocs; (7) engaging fully in multilateral trade negotiations; (8) strengthening links between industrial and trade policies. 


\subsubsection{The Institutional and Regulatory Framework}

In order to build a vibrant, competitive private sector strongly positioned for international and domestic competition, the institutional and regulatory policy effort seeks to tackle the core constraints inhibiting private-sector growth. The many barriers that confront investors and investments are being removed to make Ghana a more attractive investment destination necessary for enhanced industrial production.

The various business registration requirements, levies for business registration, and several investment legislations, are being rationalized while ministries, departments, and agencies (MDAs) that administer business regulations are being made to be more responsive to the needs and imperatives of the private sector. To enhance productivity and efficiency, and to reduce the cost of doing business, the government has put in place measures to remove value chain constraints to improve service delivery through urgent and aggressive investment in both physical and social infrastructure as a national priority to improve efficiency and reliability in the production chain.

A proactive local content policy is required for industrial development to translate into job creation at the level needed to change the economic fortunes of Ghanaians. This can be achieved only if the natural resources are applied locally along the industrial value chain. That means most of the valueadded processing must be done in Ghana. Without a specific policy strategy to compel the direct participation and involvement of Ghanaians there will be little job creation.

The institutional and regulatory policies to boost industrial production include: (1) ensuring easy access to business registration and acquisition of permits; (2) strengthening the capacity of relevant institutions to deliver efficient services countrywide; (3) promoting harmonious labour and industrial relations in the manufacturing sector to increase productivity; (4) formulating and implementing appropriate laws to ensure that Ghanaians at all levels directly benefit from the industrialization process.

A key role in promoting industrialization in Ghana is the development and effective use of national standards (both voluntary and mandatory), based on relevant international standards. This assures consumers of the safety and suitability of products. While voluntary standards developed by consensus among relevant stakeholders essentially provide the basis for assessing the quality of products, processes, and systems, Technical Regulations (mandatory standards) are applied to protect the health and safety of consumers and the environment.

In view of the importance of standards, regulatory and institutional policies geared towards the development and use of standards in industry include government efforts to: (1) facilitate the strengthening of the links between 
Ghana Standards Board and industry associations in the development of voluntary standards; (2) encourage the application of national standards in manufacturing; (3) support initiatives to improve institutional capacity of associations to develop standards of interest to their members; (4) facilitate coordination among the regulatory bodies in the development of Technical Regulations; (5) improve the institutional capacity of regulatory bodies to enforce the application of Technical Regulations in industry.

\subsubsection{Sector Specific Policies}

For the attainment of economic transformation as envisaged under the government's medium-term agenda, the industrial sector, which is expected to play a pivotal role, is projected to grow at an average annual rate of over 20 per cent over the medium term. The main drivers expected to help achieve this target include: enhanced growth from the construction sector; infrastructure development in the oil sector; energy and water sub-sector growth in 2011 and beyond resulting mainly from the Bui Dam's operations; production of gas to power thermal generation; and an increase in output from the mining sector, especially in salt production to meet industrial demand.

Under the National Industrial Policy, the industrial sector specific policies include measures to:

- strengthen the links between industry, and research and development institutions;

- decentralize industrial development to exploit the resource endowments of districts;

- establish new and emerging industries such as petrochemicals, fertilizer, and LPG cylinders production on the back of the new oil and gas industry;

- establish manufacturing enterprises to process agricultural produce, especially beans, fruits, and shea nuts;

- exploit the limestone deposits in northern Ghana for the production of cement and for industry, as well as utilization of the significant clay deposits in the country for the production of bricks and other building materials to support the programme for the construction of affordable housing units;

- rejuvenate the textile industry in an integrated manner, from seed production to spinning to ginning, and printing;

- establish integrated shea butter processing factories in the three northern regions, targeting the processing of 50,000 tons of shea butter per annum for both local and international markets; 
- rehabilitate abandoned but viable manufacturing enterprises, including the jute factory, tomato cannery, gold refinery, and ceramics production;

- establish a second oil refinery in the western region to boost the production of petroleum products for exports and for national energy security;

- review and implement plans for an integrated iron and steel industry;

- establish Industry Support Centres to assist firms become internationally competitive;

- seed and facilitate the creation of industrial anchors, and deploy the full benefits of existing free zone, export zone, and related investment laws to accelerate industrial development.

\subsection{Emerging Policy Issues}

The 'top three' issues that emerge from the industrial policy debate relate to the key developmental objectives of the current industrial policy. These include:

- first, and most importantly, how to empower the private sector, especially small and medium enterprises to expand productive employment and technological capacity within a highly competitive manufacturing sector;

- second, beyond expansion in a productive and technological capacity, how to promote agro-based industrial development to ensure value-added to manufactures and Ghana's traditional and non-traditional exports;

- third, to achieve poverty reduction and reduce income inequalities; how to promote the spatial distribution of industries away from the current situation of over-concentration of industries within urban areas.

These three issues are important because ultimately the success of Ghana's industry policy will be measured by the extent to which it empowers the private sector (especially small and medium enterprises) within a highly competitive manufacturing sector to expand and create opportunities for employment and reduce poverty and spatial inequalities in Ghana.

\section{Acknowledgements}

We should like to thank John Rand, John Page, and Finn Tarp for valuable comments on earlier drafts of the chapter. 


\section{References}

Ghana Statistical Service (GSS) (2000). Ghana Living Standards Survey: Fourth (IV) Round, v. 2 Oct. 2008. Accra: Ghana Statistical Service.

Ghana Statistical Service (GSS) (2002). Population and Housing Census, Summary Report of Final Results. Accra: Ghana Statistical Service.

Ghana Statistical Service (GSS) (2008). Ghana Living Standards Survey: Fifth (V) Round, Sep. 2008. Accra: Ghana Statistical Service.

Ghana Statistical Service (GSS) (2012). 'Provisional GDP 2012'. Accra: Ghana Statistical Service.

Ghana Statistical Service (GSS) (2014). Ghana Living Standards Survey: Sixth (VI) Round, Aug. 2014. Accra: Ghana Statistical Service.

Ghana Statistical Service (GSS) (various years) 'Quarterly Digest of Statistics'. Accra: Ghana Statistical Service.

Government of Ghana (2010). 'The Coordinated Programme of Economic and Social Development Policies, 2010-2016. Statement on the "Agenda for Shared Growth and Accelerated Development for a Better Ghana"'. Presented to Parliament by the President, Accra, December.

Government of Ghana (2011). 'Industrial Sector Support Programme'. Accra: Ministry of Trade and Industry.

ISSER (1991-2011). 'The State of the Ghanaian Economy'. Accra: University of Ghana, Legon.

Killick, T. (2010). Development Economics in Action: A Study of Economic Policies in Ghana, 2nd edn. New York, NY and Abingdon: Routledge.

Nyanteng, V. K. (1993). 'Policies and Options of Ghanaian Economic Development'. Accra: University of Ghana, Legon.

Quartey, P. (2006). 'The Textile and Clothing Industry in Ghana', in H. Jauch and R. Traub-Merz (eds) The Future of the Textile and Clothing Industry in sub-Saharan Africa. Bonn: Bub Bonner Universitats-Buckdruckerei, 135-46.

Steel, W. F. (1972). 'Import Substitution and Excess Capacity in Ghana'. Oxford Economic Papers 24(2): 212-40.

World Bank (WB) (1985). 'Ghana: Industrial Policy, Performance and Recovery'. West Africa Region and Industry Department of the World Bank, Report 5716-GH. Washington, DC: World Bank.

World Bank (2014). World Bank Enterprise Survey data sets, available at: <http://www. enterprisesurveys.org/Custom-Query/ghana\#hReprtpreview>, accessed December 2014. 


\title{
4
}

\section{Kenya's Industrial Development}

\author{
Policies, Performance, and Prospects
}

Dianah Ngui, Jacob Chege, and Peter Kimuyu

\subsection{Introduction}

This chapter reviews the history of manufacturing in Kenya, starting with the period immediately before independence in 1963, discussing industrial policies pursued by different regimes and their impact on Kenyan manufacturing. There are also discussions on the structure of the industrial sector and its contribution to employment, and the different sectors' future prospects; and on size distribution and factor productivity structured around ownership, legal status, and export participation. The chapter concludes by reflecting on the factors that have shaped industrial development in Kenya.

\subsection{Evolution of Industrial Policies since Independence}

\subsubsection{Import Substitution Hangover, 1963-70}

Like many developing countries, Kenya's early years of independence pursued an import substitution (IS) strategy in which the government provided both direct support and tariff protection for the industrial sector. This strategy was a carryover from colonial policies, and its objectives were the rapid growth of industry, reduced balance of payment pressure, more indigenous participation in the sector, higher productivity, and high-income employment. However, the IS policy failed to create much needed employment and its high import content caused major balance of payment problems. 
Eventually, the IS phase and the policies that sustained it had mixed results. On the positive side, the country enjoyed a considerably higher rate of industrial growth during the first decade of independence with the manufacturing sector growing at an average of 8.0 per cent and was second only to agriculture in terms of employment creation during this period. Manufacturing output grew not only faster than the rest of the Kenyan economy but also faster than other industrial sectors in sub-Saharan Africa. Light industries accounted for the lion's share of gross industrial production followed by intermediate industries (Kinyanjui 2013). Some industries expanded from a few establishments into industries with a wide range of products and a large number of employees. These included paper, textiles and garment manufacturing, food processing, leather tanning and footwear (Coughlin 1988; KAM 1989). The IS strategy was successful in establishing industries in textile and garments, and food, beverages, and tobacco (FBT) which are still dominant industries today. The strategy was implemented in an environment of generalized optimism that created a climate supportive of widespread economic performance.

\subsubsection{Policies during External Shocks, 1970s}

The 1970s were turbulent years in Kenya's history, and were marked by a general deterioration in the country's overall economic performance. The government increased its participation in the economy under the strategy of IS, promoting and financing new industrial projects. Industrial production for export markets slowed down substantially because the incentive structure favoured production for domestic markets, so creating an inward-looking industrial sector whose potential was severely limited by the size of the domestic market. The situation was compounded by the collapse in 1977 of the East African Community (EAC). In addition, there was erosion of fiscal discipline after the coffee boom of the late 1970s, which was aggravated by a deterioration in the country's external terms of trade following the second oil shock in 1977 (Foroutan 1993). Under these circumstances, Kenyan products could not compete in export markets. Industries found it more profitable to produce for the highly protected domestic market resulting in an 'anti-export bias' (KNBS 1994).

Of particular importance to manufacturing in this period was the emergence of the informal sector supported by official recognition and pro-informal sector policies. The manufacturing outcomes of such policies were however eroded by selective implementation which made provision for exploitation of linkages between the informal sector and other sectors. Overall, the IS strategy penalized certain sectors such as the agricultural sector which suffered high input costs. But government continued to subsidize and guarantee industrial 
expansion through foreign capital in ways that made it possible for African industrialists to penetrate large-scale manufacturing (Kinyanjui 2013).

\subsubsection{Structural Adjustment and Liberalization, 1980 s and 1990s}

During the 1980s, the government introduced a structural adjustment programmes (SAP) in order to, inter alia, strengthen competitiveness and reduce excess capacity in the industrial sector. Major restructuring of policies and institutional frameworks was initiated through the publication of a session paper on Economic Management for Renewed Growth (KNBS 1986). The policy measures in this study were aimed at removing the 'anti-export bias' inherent in past policies. The government also undertook to completely remove restrictive import licensing and tariffs. In 1993, import licensing schedules were abolished and in 1994 the capital and current transactions were liberalized. In the same year, Kenya joined the World Trade Organization (WTO) and the Kenyan economy was declared 'open'. However, even though the SAP led to liberalization of the domestic economy and opened it up to international competition (Chirwa 2000), the industrial sector continued to be inwardoriented, excessively import dependent, capital intensive, and incapable of absorbing an adequate proportion of the rapidly increasing labour force (KNBS 1994; Swamy 1994).

The institutional and market oriented initiatives taken to redirect the economy away from the IS strategy to export promotion comprised the creation of a series of export platforms. Included were the Export Promotion Council established in 1993, the Export Compensation Scheme, Manufacturing under Bond (MUB), Export Processing Zones (EPZ), and import duty and VAT remission schemes that were intended to improve export producers' access to imported inputs at world prices (Bigsten et al. 2010). These export platforms aimed to promote export oriented manufacturing through a systematic process of tariff reduction and through a variety of market incentives. ${ }^{1}$ For example the Export Compensation Scheme was designed to compensate exporters for government taxes on inputs, while the MUB programme was meant to encourage manufacturing for world markets. Other changes relevant to the manufacturing sector included the introduction of an Essential Goods Production Support Programme and the abolition of price controls in 1994. In the 1993/94 budget, the government also abolished the Export Compensation Scheme because of inherent problems in its implementation (ibid). ${ }^{2}$

\footnotetext{
${ }^{1}$ For a detailed description of the incentives, see Gerdin (1997: 30); Bigsten (2002: 17).

2 It was opportunistic implementation of the Export Compensation Scheme that led to the hugely infamous Goldenberg scam.
} 


\subsubsection{New Millennium Policies}

Further policy changes have occurred since the year 2000 that have had significant implications for industrial development and trade in Kenya. In that year, the United States government enacted the African Growth and Opportunities Act (AGOA), which allowed African countries to export textile and garments duty free and without import quota restrictions. Kenya signed up to AGOA soon after it was enacted, giving the EPZ a fresh impetus. The rise in exports of garments and apparel from Kenya from US\$30 million to US\$249 million between 2000 and 2005 has been attributed to export opportunities in the US fabric market.

The Kenyan Government's efforts to improve the sector's performance culminated in the drafting of the National Industrial Policy (NIP) that was finalized in 2007. The document takes stock of non-implementation of industrial strategies outlined in Sessional Paper No. 2 of 1997. The lack of harmonized and coherent industrial policy hindered the implementation of the policies in the sessional paper. The NIP proposed creation of institutions to coordinate and facilitate industrial development with clear targets and benchmarks.

Policy reforms since 2000 have been spelt out in three blueprints namely, the Poverty Reduction Strategy Paper, the Economic Recovery for Wealth Creation, and Kenya Vision 2030. Contained in these documents are many proposals targeting the productivity and general performance of Kenyan industry (Bigsten et al. 2010). Under Vision 2030, the objective is to develop a diversified, robust, and competitive manufacturing sector. This objective is to be realized through emphasis on local production, expansion in the regional markets, and identification of Kenya's niche in global markets (Republic of Kenya 2007).

The building of a self-sustaining export oriented industrial sector has been the central focus of the country's industrial development policy. Despite the structural reforms undertaken, a close analysis of the manufacturing sector shows that supply responses to the policies have been poor. In particular, the manufacturing sector has been experiencing poor total factor productivity growth rates. Lack of success in achieving significant export volumes as per expectations has been blamed largely on government failure to appreciate that there is a need to address other factors that hinder exports, such as inadequate infrastructure, increased crime, the spread of contraband, and rising trade costs due to corruption (Asanuma et al. 2008).

\subsection{Key Industrialization Episodes and Turning Points}

Although Kenya's manufacturing enjoyed relatively rapid growth in early post-independence years, it has generally been sluggish without dramatic 
shifts in performance. However, its performance has been shaped by some notable developments. The first of these is the carry forward of the IS policy that was begun during colonial rule and adopted by the independent government. This policy served the purpose of ensuring availability of basic products in the domestic market. However, such products were overpriced and the policy distorted the evolution of industry by encouraging the excess capacity and generalized inefficiency that undermined the ability of Kenyan products to penetrate external markets. A change came when in the mid-1980s the government eventually recognized the need to shift focus towards export promotion. However, immediate efforts to encourage exports were overshadowed by macroeconomic challenges and externally driven SAPs that were implemented half-heartedly and opportunistically.

The recognition in 1972 of the importance of the informal sector following the International Labour Organization (ILO) led not only to a reduction in the harassment of informal firms by state organs but also the enactment of policies and administration interventions supportive of the sector. Since then, the informal sector has grown to become an important contributor to entrepreneurship, employment, and wealth creation (ILO 1972). Informal firms are ubiquitous in Kenya and provide a base for the country's private sector. Although these are often dismissed in the development literature, research has shown some growth and formalization opportunities for informal manufacturing firms in Kenya (Kimuyu 2010).

The liberalization of the Kenyan economy in the early 1990s through the dismantling of foreign exchange allocations and price controls was a turning point for the overall economy and for industrial development. Although this policy played havoc with inefficient industries, those that survived were more able to participate in export markets. Manufacturers relying on imported material were better able to plan their import and production plans, maintain product export schedules, and pursue their entrepreneurial dreams.

Since publication of the Economic Recovery Strategy by the National Rainbow Coalition (NARC) government in 2004 (Republic of Kenya 2003) and Vision 2030 which was its successor, there was more focus on improving the performance of the manufacturing sector. There was also a focus on improving the overall business climate including the rationalization of business licences. The enactment of the AGOA, revival of the EAC, and deeper participation in the common market for eastern and southern Africa (COMESA) opened up new opportunities for Kenyan capital and exports. Kenya is currently the most important source of foreign direct investment (FDI) in Uganda and Rwanda. The region, particularly Uganda, is the main important export destination for Kenyan products. 


\subsection{Structure of the Industrial Sector}

\subsubsection{Sectoral Composition}

Industrial activity, concentrated around the three largest urban centres, Nairobi, Mombasa, and Kisumu, is dominated by food-processing industries such as grain milling, beer production, and sugarcane crushing, and the fabrication of consumer goods, e.g. vehicles from kits. Kenya also has had an oil refinery that processed imported crude petroleum into petroleum products, mainly for the domestic market till 2015 when it became uneconomical to run. A distinctive feature of the manufacturing sector in Kenya is the coexistence of the modern sector alongside a rapidly expanding informal sector. While the former comprises mainly small, medium, and large enterprises, the latter covers all small-scale activities that are normally semi-organized, unregulated, and use low and simple technologies while employing few persons. A large proportion of industrial output is directed towards satisfying basics needs, namely the provision of low-income consumer goods and services. Such items include clothing, furniture, foodstuffs, and motor vehicle repairs. While data on this sub-sector are inadequate, it is one of the fastest growing sectors and a major source of employment in Kenya.

The small and medium-size enterprises (SMEs), which form part of the formal economy, are characterized by some degree of specialization. These enterprises manufacture a wide range of items including wood and furniture, metal products, glass and pottery, clothing, and leather products. The items are generally designed to meet the domestic needs of low-income households although some are exported to neighbouring countries.

The structure of Kenya's manufacturing sector has undergone minimal change despite shifts in policies. Production is still largely geared towards consumer goods. Table 4.1 shows the share of total manufacturing (at the International Standard Industrial Classification (ISIC) three-digit level) value added by sectors from 2005 .

Although the manufacturing sector in Kenya is diversified in terms of manufacturing activities, processing of food and other agricultural goods still contributes the largest share of manufacturing GDP, followed by textile and garment, and the refining of crude petroleum, respectively. For instance, in 2006 the contribution from the agro-processing of food commodities and refining of petroleum products to manufacturing value added to GDP was 21 per cent and 15 per cent respectively. The single most important industrial sub-sector is FBT which forms over 30 per cent of the total manufacturing output in recent years (Table 4.2). In 2009 food manufacturing contributed relatively about 22 per cent of manufacturing output, followed by other nonmetallic mineral products at about 19 per cent (see Table 4.2). Food, printing and publishing, rubber and plastic products, and metal product sub-sectors 
Table 4.1 Policies, institutions, and laws enacted to promote industry in Kenya

\begin{tabular}{ll}
\hline Year & Policy/act/institution \\
\hline 1954 & $\begin{array}{l}\text { Industrial and Commercial } \\
\text { Development Corporation }\end{array}$ \\
1958 & $\begin{array}{l}\text { Protective tariff regime } \\
\text { Development Finance Company } \\
\text { of Kenya }\end{array}$
\end{tabular}

1964 Foreign Direct Investment Act

1967 Trade Licensing Act

Kenya Industrial Estates

1968 New Projects' Committee

1971 Capital Issues Committee

1973 Industrial Development Bank

1974 Export Compensation

Manufacturer's Act

Kenya Bureau of Standards

1979 Kenya Industrial Research Institute

1981-2 Replacement of quantitative restrictions with equivalent tariffs, tariff reduction, and rationalization

1983 Establishment of the Investment Advisory Centre

1986 Manufacturing under Bond Investment Promotion Centre

1990 Export Processing Zones

1992 Export Promotion Centre

To increase industrial capability by encouraging participation of indigenous Kenyans in industry and commerce

To support import substitution industrialization

A government owned investment company established to promote post-independence industrialization

To permit issuance to foreign owned firms with a 'Certificate of Approved Enterprise' which permitted repatriation of profits, loans, and interest on loans as well as 'an approved proportion of the net proceeds of sale of all or part of the approved enterprise'

To secure specific types of trade and trading zones for retail and wholesale for African businesses;

to encourage the entry of indigenous firms into manufacturing

To serve as a bargaining forum between the government and multinational enterprises on investments

To deal with all issues of capital stocks in order to stamp out potential capital flight occasioned by the threat of nationalization

To advance industrial and overall economic development by promoting, establishing, expanding, and modernizing medium- and large-scale enterprises

To promote export of non-traditional products under the industrialization strategy; to promote the competitiveness of manufactured goods, both locally and internationally, by increasing their quality

To promote industrial innovativeness through the development of a sufficiently national capacity in embodied and disembodied industrial capabilities for self-sustaining industrialization

To promote freer movement of manufactured goods

To replace the 1968 New Projects Committee and attract FDI

To promote exports;

to promote investment in Kenya and replace the Investment Advisory Centre

To promote export oriented industrial development

To formulate market strategies, promote an export culture, and identify regional and global export opportunities; 
Export Programme Office

1993-4 Dismantling of import licensing and price control

2000 The (American approved) Africa Growth and Opportunities Act

2001 Kenya Industrial Property Institute

2004 Kenya Investment Authority

2008 Vision 2030

2013 Jubilee Manifesto to operate a form of duty drawback scheme administered by the national treasury

To liberalize the Kenyan market and make it more competitive and give Kenyan products a chance to compete in external markets

To promote export of textiles from Africa to America

To grant and enforce property rights and trade marks

To replace the Investment Promotion Centre and introduce mandatory investment thresholds and restrictive screening procedures for foreign investments

To make Kenya globally competitive and prosperous. The economic pillar on which Vision 2030 is founded pays special attention to manufacturing and proposes important flagship projects in support of the sector including development of integrated iron and steel mills that will lead to local supply of machines and equipment

To implement the blueprint to be used by the Jubilee government to implement its agenda of transforming Kenya;

to include the transformation of the industrial conversion, building on Vision 2030

Source: Based on Kinyanjui (2013).

Table 4.2 Percentage share of total manufacturing value added by sub-sector

\begin{tabular}{|c|c|c|c|c|c|}
\hline Manufacturing activity (at current prices) & 2005 & 2006 & 2007 & 2008 & 2009 \\
\hline Manufacture of food products & 20.61 & 20.37 & 20.93 & 19.71 & 22.42 \\
\hline Tobacco and beverages & 8.37 & 9.03 & 9.45 & 10.28 & 10.48 \\
\hline Textiles & 1.87 & 1.80 & 1.73 & 1.51 & 1.19 \\
\hline Clothing & 1.27 & 1.45 & 1.37 & 1.55 & 1.81 \\
\hline Leather and footwear & 1.76 & 1.75 & 1.83 & 1.87 & 1.66 \\
\hline Wood and cork products & 0.82 & 0.77 & 0.73 & 0.80 & 0.74 \\
\hline Furniture & 0.78 & 0.74 & 0.79 & 0.95 & 1.01 \\
\hline Paper and paper products & 4.42 & 3.98 & 3.92 & 5.27 & 3.15 \\
\hline Printing and publishing & 2.86 & 2.52 & 2.58 & 1.89 & 2.42 \\
\hline Industrial chemicals, paint, and soap & 1.42 & 1.37 & 1.35 & 1.49 & 1.56 \\
\hline Petroleum refineries & 15.87 & 15.43 & 15.37 & 9.54 & 4.75 \\
\hline Rubber and plastic products & 3.29 & 3.27 & 3.02 & 2.62 & 2.83 \\
\hline Other non-metallic mineral products & 11.72 & 12.54 & 12.92 & 16.94 & 19.42 \\
\hline Metal products & 4.24 & 4.58 & 4.60 & 4.56 & 4.76 \\
\hline Non-electrical machinery & 0.61 & 0.53 & 0.38 & 0.32 & 0.31 \\
\hline Electrical machinery & 2.05 & 1.79 & 1.29 & 1.08 & 1.05 \\
\hline Transport equipment & 1.50 & 1.76 & 1.61 & 1.72 & 1.74 \\
\hline Miscellaneous manufacturing & 0.54 & 0.52 & 0.55 & 0.66 & 0.71 \\
\hline Micro- and small enterprises & 11.94 & 12.01 & 11.66 & 13.32 & 14.94 \\
\hline Export Processing Zones & 4.05 & 3.79 & 3.93 & 3.90 & 3.07 \\
\hline
\end{tabular}

Source: KNBS (2006-10); authors' calculations. 
recorded negative growth in 2008 but picked up in 2009. Growth theory suggests that nations tend to move from agrarian-led development towards manufacturing or technological development. Thus, the contribution from manufacturing would rise relative to that of agriculture. However, Kenya's manufacturing sector share to GDP is fairly stagnant although the share from agriculture has itself declined. However, significant complementarity between the two sectors can be noted. The manufacturing output potential may lie in exploiting the valued addition of agricultural products.

The manufacturing sector in Kenya is the third largest by sectoral contribution to GDP (10.3 per cent) after transport and communication (11.3 per cent) and agriculture and forestry (23.4 per cent) (KNBS 2008: Table 28). The average annual growth rate of real GDP for the manufacturing sector declined from 10 per cent in the period $1974-9$ to 4.8 per cent, 2.5 per cent, and 3.8 per cent in the periods 1980-9, 1990-9, and 2000-7 respectively.

The manufacturing sector's share of GDP has increased only marginally in the last three decades, contributing only 10 per cent in the 1964-73 period and 13.6 per cent in the $1990-5$ period. It reverted back to 10 per cent and has stagnated at that level for most of the past decade. A combination of factors including the IS strategy, poor weather conditions, import liberalization, and deteriorating infrastructure could explain the slack. Although there has been a slight upswing in more recent years, the contribution from manufacturing to GDP has remained low, contributing 11.5 per cent and 12.8 per cent in the second quarters of 2009 and 2010 respectively. The manufacturing sector in general suffers from low value added compared to Malaysia, Singapore, Mauritius, and South Africa but higher than that of Uganda and Tanzania (Table 4.3).

Table 4.3 Manufacturing value added (\% GDP)

\begin{tabular}{lcrrrr}
\hline & 2004 & 2005 & 2006 & 2007 & 2008 \\
\hline Brazil & 19.2 & 18.1 & 17.4 & 17.4 & \multicolumn{1}{c}{16} \\
China & 32.4 & 32.8 & 33.6 & 34.1 & 34.4 \\
Egypt, Arab Rep. & 18 & 17.3 & 16.6 & 15.7 & 16.9 \\
Botswana & 4.1 & 3.7 & 3.7 & 3.3 & 3.2 \\
Kenya & 11.3 & 11.8 & 11.6 & 11 & 9.1 \\
Mauritius & 21.1 & 20.2 & 19.1 & 19.9 & 19.4 \\
Malaysia & 30.4 & 29.6 & 29.6 & 28 & \\
Singapore & 27.5 & 26.9 & 26.9 & 24.9 & 20.8 \\
South Africa & 19 & 18.5 & 18.4 & 18.1 & 18.5 \\
Uganda & 7.6 & 7.6 & 7.7 & 7.7 & 7.6 \\
Tanzania & 7 & 6.8 & 6.9 & & \\
Korea, Rep. & 27.7 & 27.5 & 27.1 & 27.3 & 28.1 \\
\hline
\end{tabular}

Source: World Development Indicators (WB 2011). 


\subsubsection{Manufacturing Employment}

Kenya's manufacturing sector has been the main conduit for the country's integration into regional and world markets. The sector is a major source of employment in urban areas and possesses substantial backward and forward linkages to the rest of the economy. It is critical to achieving the country's vision of becoming prosperous and globally competitive by 2030. Available data show that casual employment as a proportion of total formal sector employment has risen markedly since 1994. Informal and precarious forms of employment have gained momentum, as the system evolves towards employment of a diverse pool of irregular, flexible, or casual workers ${ }^{3}$ with no formal labour contracts and employment benefits. Most of these employment effects have been witnessed during a period of intense trade liberalization and openness. This may have been largely undertaken as a cost-cutting strategy, since the latter types of workers do not usually enjoy fringe and other employment benefits such as severance pay, medical allowances, and so on. The proportion of part-time and casual workers increased to 36 per cent in 2003 from 28 per cent in 1993.

Employment growth averaged 1.43 per cent per annum over the period 2005-9. The average annual growth rate declined from 3.34 per cent in 2007 to -0.75 per cent in 2008 . This was followed by a growth rate of 0.44 per cent in 2009. Employment growth seems to have largely followed the decline in manufacturing output growth and hence economic growth. Growth between 2008 and 2009 is probably due to an increase in the number of employees rather than an increase in the number of establishments, since these too declined during this period (see Table 4.6 (size distribution)). Informal sector economic manufacturing activities provided employment for 1,801.1 workers in 2010, up from 1,711.2 in 2009, an increase of 5.3 per cent.

The FBT sub-sector was significantly affected in 2009 by post-election violence and dry weather. Even as the FBT manufacturing sub-sector actually recorded negative growth in the 2008-9 period the performance of other manufacturing in 2008 was not only positive but had increased. This may be a pointer to low linkages between the two sub-sectors, meaning that they neither support nor reinforce each other. Table 4.4 shows the trend in percentage share of employment by sector.

Table 4.4 reveals notable differences in terms of employment within the sub-sectors. Out of the total wage employment in the manufacturing sector in 2009, FBT contributed 34.25 per cent whereas textile and garments

\footnotetext{
${ }^{3}$ In the literature, such forms of employment are also referred to as 'non-standard forms of employment' or 'precarious employment'. Part-time workers in the context of this paper work under conditions similar to those of casual workers but for relatively shorter periods-periods of three months or fewer. In both cases, payment is often at the end of the day/week, or piece rate.
} 
Table 4.4 Trend in percentage share of employment by sector

\begin{tabular}{|c|c|c|c|c|c|}
\hline Manufacturing activity & 2005 & 2006 & 2007 & 2008 & 2009 \\
\hline Manufacture of food products & 31.37 & 31.16 & 30.73 & 30.68 & 30.89 \\
\hline Tobacco and beverages & 3.09 & 2.95 & 3.34 & 3.31 & 3.36 \\
\hline Textiles & 17.59 & 17.73 & 17.49 & 17.59 & 17.12 \\
\hline Clothing & 6.41 & 6.26 & 6.11 & 5.61 & 5.61 \\
\hline Leather and footwear & 0.77 & 0.72 & 0.67 & 1.14 & 1.01 \\
\hline Wood and cork products & 3.93 & 3.83 & 3.70 & 3.70 & 3.78 \\
\hline Furniture & 1.78 & 1.75 & 1.71 & 1.64 & 1.69 \\
\hline Paper and paper products & 3.38 & 3.33 & 3.25 & 3.28 & 3.34 \\
\hline Printing and publishing & 3.46 & 3.48 & 3.45 & 3.34 & 3.32 \\
\hline Industrial chemicals, paint, and soap & 6.04 & 6.03 & 6.02 & 5.75 & 5.84 \\
\hline Petroleum refineries & 0.10 & 0.09 & 0.08 & 0.09 & 0.10 \\
\hline Rubber and plastic products & 4.24 & 4.49 & 4.80 & 4.71 & 4.64 \\
\hline Other non-metallic mineral products & 3.14 & 3.39 & 3.80 & 3.99 & 4.08 \\
\hline Metal products & 4.36 & 4.31 & 4.40 & 4.45 & 4.51 \\
\hline Fabricated metal products & 3.50 & 3.44 & 3.36 & 3.28 & 3.35 \\
\hline Non-electrical machinery & 0.61 & 0.59 & 0.58 & 0.60 & 0.62 \\
\hline Electrical machinery & 1.23 & 1.19 & 1.15 & 1.15 & 1.14 \\
\hline Transport equipment & 2.75 & 2.58 & 2.39 & 2.96 & 2.92 \\
\hline Medical precision and optical instruments & 0.15 & 0.15 & 0.15 & 0.15 & 0.16 \\
\hline Other manufacturing & 2.11 & 2.51 & 2.80 & 2.56 & 2.52 \\
\hline Percentage employment growth & 1.6 & 2.52 & 3.34 & -0.75 & 0.44 \\
\hline
\end{tabular}

Source: KNBS (2006-10); authors' calculations.

contributed 22.73 per cent. In 2009, the manufacturing sector contributed 13.27 per cent of total formal employment in Kenya. Note that apart from the agriculture based sub-sectors offering a higher contribution to value added than all other manufacturing sub-sectors, these sub-sectors also absorb the largest share (about 13 per cent) of manufacturing contribution to overall formal employment.

\subsubsection{Size Distribution}

Table 4.5 shows trends in the distribution of employment by size. Firms are classified as follows: micro-establishments with fewer than five employees; small establishments (from 5-20 employees); medium establishments (21-50 employees); and large establishments (over 50 employees). ${ }^{4}$

As shown in Table 4.5, the share of employment across the years in the different size categories has been fluctuating, decreasing in 2008 probably due to post-election violence. The share has remained high in both medium and large enterprises over the years. Distribution in the sub-sectors indicates that FBT had the highest percentage share of the total medium and large

\footnotetext{
${ }^{4}$ Because there are insufficient data available, distribution in the World Bank (WB) survey disaggregates medium enterprises to comprise firms with between 51 and 100 workers, and large enterprises to comprise firms with 101 workers and above.
} 
Table 4.5 Percentage share in the distribution of employment by size/category

\begin{tabular}{lrrrr}
\hline Year/employees & $0-10$ & $11-50$ & $>50$ & \% growth \\
\hline 2005 & 1.65 & 9.89 & 88.46 & 1.60 \\
2006 & 1.65 & 9.88 & 88.47 & 2.52 \\
2007 & 3.42 & 25.70 & 70.88 & 3.34 \\
2008 & 3.28 & 25.22 & 71.50 & -0.75 \\
2009 & 3.29 & 25.01 & 71.70 & 0.44 \\
\hline
\end{tabular}

Source: KNBS (2006-10); authors' calculations.

Table 4.6 Percentage share in the number of establishments by size/category

\begin{tabular}{lrrrr}
\hline Year/category & $0-10$ & $11-50$ & $>50$ & \% growth \\
\hline 2005 & 32.62 & 34.24 & 33.17 & - \\
2006 & 32.94 & 34.16 & 32.878 & 0.82 \\
2007 & 32.92 & 34.21 & 32.875 & -0.73 \\
2008 & 32.98 & 34.25 & 32.775 & 1.68 \\
2009 & 32.96 & 34.25 & 32.782 & -0.02 \\
\hline
\end{tabular}

Source: KNBS (2006-10); authors' calculations.

enterprises, while clothing, fabricated metal products, furniture, industrial chemicals, paint, and soap, and electrical machinery had the highest percentage share of the total micro-enterprises. Table 4.6 shows trends in the number of establishments by size/categories.

Concentration of the number of establishments in large businesses declined over time. In particular, the percentage share of plants employing over 50 workers reduced at a decreasing rate up to 2009. In contrast, the percentage share of small plants employing 11 to 50 workers slowly increased up to 2008 while the percentage share of micro-plants fluctuated over the study period. Consequently, distribution of employment by number of establishment size indicates that the role of micro- and small enterprises (MSEs) in employment is increasingly important, while the role of medium and large business in employment weakened during 2005-9. Small-size enterprises maintain the largest share in number of establishments over time even when employment is declining.

Interestingly, a decline in the number of employees in MSEs is accompanied by an increase in the number of establishments indicating new firm creation rather than increases in sizes in these categories. This implies a high level of 'churning'; that is, new enterprises starting up and at the same time existing ones ceasing operations. This is in contrast to large enterprises where a decline in the number of employees is reflected in a reduction in the number of establishments, while an increase in the number of employees is not reflected in the number of establishments, indicating that large enterprises absorb employees into their existing enterprises. 


\subsubsection{Ownership}

In Kenya, there are two ethnically distinct groups of businesses, namely, those owned by Kenyans of Asian (largely Indian) origin and others owned by Kenyans of African origin. While the former group constitutes a small minority their presence in trade and manufacturing is substantial (Himbara 1994). There are possibly extensive flows of information among KenyanAsian entrepreneurs. For example, the formal or organized sector is relatively small with correspondingly few players, most of whom are Kenyan Asians. In addition, for various political and historical reasons, this immigrant entrepreneurial community is socially embedded. For example, its members tend to live in clusters of close proximity, participate vigorously in social clubs, and have numerous community activities both within and outside these clubs.

With regard to ownership and management of firms in Kenya's manufacturing industry, there have been significant changes in the years since independence. Currently, multinationals and parastatals dominate the large industries while Kenyans of African origin dominate the micro- and small establishments. Table 4.7 shows the enterprise ownership by ethnic origin.

Most of the micro- and small-scale enterprises are owned by Kenyans of African origin (Table 4.7). The share of African owned businesses falls sharply as those of Indian origin and other Asian origin ownership increase up the enterprise size scale. As a consequence, Asians own a majority of the medium and large-scale enterprises, a finding consistent with Ikiara et al. (2002). Europeans and entrepreneurs from the Middle East own a small proportion only of all size categories compared with other entrepreneurs. The concentration of African entrepreneurs in micro- and small businesses could be explained by Africa's limited ability to mobilize financial and human resources (Ikiara et al. 2002). Table 4.8 shows the legal status of firms by size category.

The majority of micro-establishments were owned by sole proprietors, with ownership declining with size category. Although the publicly listed companies' ownership was small across all size categories, they still held the largest

Table 4.7 Enterprise ownership by ethnic origin

\begin{tabular}{|c|c|c|c|c|c|c|c|c|c|c|c|c|c|c|}
\hline & \multicolumn{2}{|c|}{ African } & \multicolumn{2}{|c|}{$\begin{array}{l}\text { Indian } \\
\text { (Asian) }\end{array}$} & \multicolumn{2}{|c|}{$\begin{array}{l}\text { Middle } \\
\text { Eastern }\end{array}$} & \multicolumn{2}{|c|}{$\begin{array}{l}\text { Other } \\
\text { Asian }\end{array}$} & \multicolumn{2}{|c|}{ European } & \multicolumn{2}{|c|}{ Other } & \multicolumn{2}{|c|}{ Total } \\
\hline & No. & $\%$ & No. & $\%$ & No. & $\%$ & No. & $\%$ & No. & $\%$ & No. & $\%$ & $\%$ & No. \\
\hline Micro & 282 & 87.31 & 31 & 9.60 & 0 & 0.00 & 7 & 2.17 & 1 & 0.31 & 2 & 0.62 & 323 & 41.36 \\
\hline Small & 134 & 54.47 & 94 & 38.21 & 4 & 1.63 & 6 & 2.44 & 6 & 2.44 & 2 & 0.81 & 246 & 31.50 \\
\hline Medium & 20 & 22.47 & 49 & 55.06 & 1 & 1.12 & 6 & 6.74 & 9 & 10.11 & 4 & 4.49 & 89 & 11.40 \\
\hline Large & 14 & 11.38 & 76 & 61.79 & 5 & 4.07 & 15 & 12.20 & 10 & 8.13 & 3 & 2.44 & 123 & 15.75 \\
\hline Total & 450 & 57.62 & 250 & 32.01 & 10 & 1.28 & 34 & 4.35 & 26 & 3.33 & 11 & 1.41 & 781 & 100 \\
\hline
\end{tabular}

Source: Authors' calculations from Investment Climate Assessment Survey (WB 2007). 
Table 4.8 Legal status of firms by size category

\begin{tabular}{|c|c|c|c|c|c|c|c|c|c|c|c|c|}
\hline & \multicolumn{2}{|c|}{ Publicly listed } & \multicolumn{2}{|c|}{ Private Itd co. } & \multicolumn{2}{|c|}{ Sole proprietors } & \multicolumn{2}{|c|}{ Partnership } & \multicolumn{2}{|c|}{ Other } & \multicolumn{2}{|c|}{ Total } \\
\hline & No. & $\%$ & No. & $\%$ & No. & $\%$ & No. & $\%$ & No. & $\%$ & No. & $\%$ \\
\hline Micro & 0 & 0 & 51 & 14.1 & 213 & 72 & 64 & 55 & 0 & 0 & 328 & 42 \\
\hline Small & 1 & 14.28 & 125 & 34.63 & 70 & 23.89 & 46 & 39.66 & 3 & 75 & 245 & 31.37 \\
\hline Medium & 2 & 28.57 & 74 & 20.5 & 4 & 1.37 & 5 & 4.31 & 0 & 0 & 85 & 10.88 \\
\hline Large & 4 & 57.14 & 11 & 3.05 & 6 & 2.05 & 1 & 0.86 & 1 & 25 & 23 & 2.95 \\
\hline Total & 7 & 0.9 & 361 & 46 & 293 & 37.5 & 116 & 14.9 & 4 & 0.5 & 781 & 781 \\
\hline
\end{tabular}

Source: Authors' calculations from Investment Climate Assessment Survey (WB 2007).

percentage share in the large size category. Private limited companies held the highest percentage share in small enterprises. About 94 per cent of African owned firms were sole proprietorships compared to 5.34 per cent of Indian owned firms (Table 4.8).

\subsection{Sunrise and Sunset Industries}

The industrialization process in Kenya was, in the early post-independence period, clustered around three sub-sectors namely textile, food processing, and metal industries. Whereas the market liberalization policies from the 1980s led to the collapse of the textile industry, food processing and metal industries have withstood the vagaries of a changing macro- and policy environment and developed over time, albeit slowly. The AGOA in 2001 slightly changed the growth fortunes for the textile industry with exports of garments and apparel from Kenya increasing from US\$30 million in 2000 to nearly US\$250 million by 2005 (KIPPRA 2009). The growth in food processing and metal industries has largely been driven by expanding local and regional markets. However, growth in these sub-sectors was at its lowest ebb during 1990-2002 as the cost of doing business worsened during the period, occasioned by the near-collapse of infrastructure, declining local demand, and lack of clear policy direction.

Failure to create backward linkages to fully exploit the AGOA initiative, particularly in reviving the cotton industry, delayed the envisioned growth in the textile industry. Increasing input costs and uncoordinated cotton marketing have been a disincentive to cotton farmers. Similarly, local textile products are not sufficiently competitive to penetrate the local market which has largely become the domain of textile imports. For instance, Kenya's textile industry has relatively high labour costs when compared to textile producing countries such as China and India. 
The Economic Recovery Strategy (ERS) 2003-7 placed emphasis on revitalizing the infrastructure and was categorical about the direction in which the government wanted industry to go. Further, enhanced discourse between the government and the private sector, particularly through the Kenya Association of Manufactures, has been catalytic in raising government interest in addressing problems facing manufacturers. Indeed, there has been an increased trend for government to involve the private sector in the budget process, as well as in institutions responsible for prioritizing critical areas where the government should invest to improve the business environment.

Beyond textile, food processing, and metal industries, Kenya has diversified her manufacturing activities. Refining of petroleum products, rubber and plastics manufacturing, and paper and printing have increasingly contributed to manufacturing GDP. Similarly, manufacturing of construction products, particularly cement, have had phenomenal growth fuelled by increased demand in the real estate industry. This growth is expected to continue, given the many infrastructure projects planned under Vision 2030, with general growth in the real estate and construction sectors. The oil and steel industry and other industries that feed on iron ore petroleum products such as plastics are poised to grow phenomenally given recent discoveries in Kenya of fossil resources and iron ore.

\subsection{Labour and Total Factor Productivity}

Given the increasing openness of the economies of many countries, discussions on how competitive is a country are of special importance because a globalized market environment demands that products compete locally with imports while at the same time trying to have a competitive edge in world markets. A country or a firm can be either price- or quality-competitive in specific products. Productivity is important for competitiveness. Firms that are not productive have a poor chance of competing for domestic and export markets. This is particularly so considering recent developments in which countries have opened their economies by dismantling trade barriers and enacting policies for promoting trade. Not only does productivity performance have a bearing on competitiveness, it also has a bearing on profits and wages, and ultimately poverty reduction and overall welfare. Productivity growth permits sustained economic expansion, a greater demand for labour, and increased real wages.

Two broad categories of factors determine competitiveness (Urata 1994; Onjala 2002). One includes factors defining the operating environment and is therefore exogenous to the firm. Competitive pressure, indicated by market concentration and openness of an economy and buttressed by trade policies is 
an example of such factors. In an acutely competitive environment, firms either match up regarding efficient use of factors of production or are forced out of the market purely as a response to external forces. The other category includes those associated with the internal capability of firms. Such factors include managerial talent, reward systems, value-cost ratios, and technological fitness. An analysis of firm-level productivity is important in understanding the extent of preparedness by Kenyan manufacturers to compete in external markets. In this section, we attempt to assess the productivity of Kenya's manufacturing sector by exploring output per worker and total factor productivity. Parametric measures of productivity are sensitive to the models used. For that reason, results obtained from this level of our analysis need to be viewed as indicative only.

In order to generate estimates on output per worker and firm-level total factor productivity, we use the 2007 WB datasets on manufacturing. These datasets provide information on the value of sales, used in this report to proxy for output; expenditure on equipment and buildings, used to proxy for capital; wage bills, used to represent labour input; and the cost of raw materials. For growth in total factor productivity in manufacturing, we need time series information on aggregate manufacturing output, capital, and labour. Official statistical reports such as the Statistical Abstract and Economic Survey publish sufficiently disaggregated data on these variables. We were able to build a 1964-2010 series from these sources from which we applied a lag operator to generate the necessary changes in the variables in our estimation.

While it is quite easy to obtain direct information on the value of manufacturing output and manufacturing wage bills, capital is always difficult to measure. This is because it is the value of the flow of capital services rather than the actual capital stock that is desirable for purposes of modelling productivity. However, such a flow is difficult to track through time since it contains components such as dividends and interest charges that are not usually recorded on an annual basis. To circumvent this problem, the practice is normally to assume that capital services are proportional to the stock of capital. In addition, we use fixed capital formation in the manufacturing sector as a proxy for the flow of capital services. ${ }^{5}$ Information on the manufacturing sector's contribution to GDP and the aggregate manufacturing wage bill is also extracted directly from official statistical publications. Because of these data problems, our estimated productivity measures must be treated as initial approximations.

Official statistics on value added and employment, only available for firms with more than 50 employees, reveal that leather and footwear, industrial

5 This use of a proxy means that our results are at best provisional. 
chemicals, petroleum refineries, other non-metallic products, and electrical machinery have the highest levels of labour productivity, more than twice as high as levels in other sectors. Firm-level data obtained from a WB survey in 2007 indicate that productivity in the food sector is greater than that for garments and other sectors. ${ }^{6}$ This is true for both labour productivity and total factor productivity. The food sub-sector appears an outlier from a manufacturing sector labour productivity perspective. However, the distinction is less dramatic when total factor productivity (TFP) is taken into account, suggesting that there is more capital being utilized in the food sector relative to other sectors in Kenya's manufacturing sector. Overall, labour productivity is greater for medium and large firms than for small firms, and higher in privately owned firms than in firms under different forms of ownership.

\subsection{Conclusions}

\subsubsection{Factors Undermining Industrial Development in Kenya}

Industrial policies in Kenya have been inconsistent over time. Even when policy statements are potentially efficacious, the stated policies have not always been diligently implemented. For example there are many useful policies developed in the recent past which have not yet been implemented. Failure to implement has often led to loss of industrial development opportunities. For example, the NIP, which makes significant proposals, is yet to be implemented. While other countries have used the less technologically complicated textile sector to kick off rapid industrialization, Kenya allowed marketing boards to destroy the cotton value chain beginning with the destruction of cotton growing and ginning. Major joint venture investments in cotton mills were unable to survive the lack of cotton and opportunistic management. State involvement in other agro-processing industries such as the sugar sector and dairy and meat processing combined with the excesses of the cooperative movement to undermine what would have been huge industrial operations.

Many of the manufacturing enterprises are either micro- or small establishments. Studies have shown that firms in this size category face particular problems. First, they are under-capitalized and face very poor transformation prospects (Lundvall et al. 2002; Kimuyu 2010). Second, they have more limited access to financial services (Isaksson and Wihlborg 2002). Most of their start-up cost and upgrading is funded through borrowing from family and friends (Green et al. 2007). As a result, they invest very little if at all,

\footnotetext{
${ }^{6}$ See Chege et al. (2014) for further details.
} 
usually in used equipment (Söderbom 2002). MSEs are less productive and less able to participate in external markets: studies have established a strong positive association between size and propensity to export (Graner and Isaksson 2009). What all this means is that the dominance of small firms in Kenyan industry gets in the way of industrial development.

Generally, Kenyan manufacturing has suffered poor productivity growth. There are numerous reasons for this outcome. Very little investment takes place, either at firm or national level. The public sector emphasizes academic rather than technical education which tends to have greater impact on overall productivity. Kenya does not have an adequate supply of infrastructure and many firms are forced to self-provide for water, power, and security. Also, firms are not always able to focus on their core business because of failures in the market for such complementary services as transport. Most firms end up spending their resources on providing services which can be supplied more cost effectively through outsourcing. Finally, very little $R \& D$ takes place in Kenya. There are no mechanisms for linking industry with institutions of higher learning. The result is that there is neither obvious demand for nor beneficial application of results arising from research carried out by such institutions.

\section{References}

Asanuma, Shinji et al. (2008). Report of the Stocktaking Work on the Economic Development in Africa and the Asian Growth Experience. Tokyo: Japan International Cooperation Agency (JICA) and Japan Bank for International Cooperation (JBIC).

Bigsten, A. (2002). 'History and Policy of Manufacturing in Kenya', in A. Bigsten and P. Kimuyu (eds) Structure and Performance of Manufacturing in Kenya. New York: Palgrave, 7-30.

Bigsten A., Kimuyu, P., and Söderbom M. (2010). 'The Manufacturing Sector', in C. Adams, P. Collier, Ndungu and N. S. (eds) (2007) Kenya: Policies for Prosperity. Oxford: Oxford University Press.

Chege, Jacob, Ngui, Dianah, and Kimuyu, Peter (2014). 'Scoping Paper on Kenyan Manufacturing'. WIDER Working Paper 2014/136. Helsinki: UNU-WIDER.

Chirwa, E. W. (2000). 'Structural Adjustment Programmes and Technical Efficiency in the Malawian Manufacturing Sector'. African Development Review 12(1): 89-113.

Coughlin, P. (1988). 'Toward a New Industrialization Strategy in Kenya', in P. Coughlin and G. K. Ikiara (eds) Industrialization in Kenya: In Search of a Strategy. Nairobi: Heinemann, ch. 12.

Foroutan, F. (1993). 'Trade Reform in Ten sub-Saharan African Countries: Achievements and Failures'. World Bank Policy Research Paper 1222. Washington, DC: World Bank. 
Gerdin, A. (1997). On Productivity and Growth in Kenya, 1964-94, Ekonomiska Studier 72, PhD thesis, Göteborg University, Sweden.

Graner, M. and Isaksson, A. (2009). 'Firm Efficiency and the Destination of Exports: Evidence from Kenyan Plant Level Data'. The Developing Economies 47(3): 279-306.

Green, C. J., Kimuyu, P., Manos, R., and Murinde, V. (2007). 'How Do Small Firms in Developing Countries Raise Capital? Evidence from a Large-scale Survey of Kenyan Micro and Small Scale Enterprises (MSEs)', in M. Hirschey, K. John, and A. K. Makhija (eds) Issues in Corporate Governance and Finance vol. 12: Advances in Financial Economics. Amsterdam: Elsevier, 379-404.

Himbara, D. (1994). 'The Failed Africanization of Commerce and Industry in Kenya'. World Development 22: 3.

Ikiara, G. K., Kimuyu, P., Manundu, M., and Masai, W. (2002). 'Firm and Other Characteristics', in A. Bigsten and P. Kimuyu (eds) Structure and Performance of Manufacturing in Kenya. New York, NY: Palgrave, 151-72.

International Labour Organization (ILO) (1972). Employment, Income and Equality: A Strategy for Increasing Productive Employment in Kenya. Geneva: ILO.

Isaksson, A. and Wihlborg, C. (2002). 'Financial Constraint on Kenyan Manufacturing', in A. Bigsten and P. Kimuyu (eds) Structure and Performance of Manufacturing in Kenya. New York, NY: Palgrave, 93-115.

Kenya Association of Manufacturers (KAM) (1989). Rural Industrialization in Kenya: Opportunities and Constraints in Providing Basic Infrastructure. Nairobi: KAM.

Kenya Institute for Public Policy Research and Analysis (KIPPRA) (2009). Kenya Economic Report 2009: Building a Globally Competitive Economy. Nairobi: KIPPRA.

Kenya National Bureau of Statistics (KNBS) (1986). Sessional Paper No. 1 of 1986: Economic Management for Renewed Growth. Narobi: Government Printer.

Kenya National Bureau of Statistics (KNBS) (1994). National Development Plan 1994-1996. Nairobi: Government Printer.

Kenya National Bureau of Statistics (KNBS) (2006-2010). Statistical Abstract. Nairobi: Government Printer.

Kenya National Bureau of Statistics (KNBS) (2008). Economic Survey. Nairobi: Government Printer.

Kimuyu, P. (2010). 'Do Small Firms in Developing Countries Ever Transform?' Regional Development Studies 14: 11-28.

Kinyanjui, B. K. (2013). Reversed Fortunes in the South: A Comparison of the Role of FDI in Industrial Development in Kenya and Malaysia. Leiden: University of Leiden, African Studies Centre.

Lundvall, K., Ochoro, W., and Hjalmarsson, L. (2002). 'Productivity and Technical Efficiency', in A. Bigsten and P. Kimuyu (eds) Structure and Performance of Manufacturing in Kenya. New York, NY: Palgrave, 151-72.

Onjala, Joseph (2002). Total Factor Productivity in Kenya: The Links with Trade Policy. AERC Research Paper 118. Nairobi: African Economic Research Consortium.

Republic of Kenya (2003). Economic Recovery Strategy for Wealth Employment and Creation, 2003-2007. Nairobi: Government Printer.

Republic of Kenya (2007). Kenya Vision 2030: A Globally Competitive and Prosperous Kenya. Nairobi: Government Printer. 
Söderbom, M. (2002). 'Investment Behaviour', in A. Bigsten and P. Kimuyu (eds) Structure and Performance of Manufacturing in Kenya. New York: Palgrave, 119-48.

Swamy, G. (1994). 'Kenya: Patchy, Intermittent Commitment', in I. Husian and R. Farugee(eds) Adjustment in Africa: Lessons from Country Case Studies. World Bank Regional and Sectoral Studies. Washington, DC: World Bank, 193-237.

Urata, S. (1994). 'Trade Liberalization and Productivity Growth in Asia: Introduction and Major Findings'. The Developing Economies, XXXII(4): 363-72.

World Bank (WB) (2007). Investment Climate Assessment Survey. Washington, DC: World Bank.

World Bank (2011). World Development Indicators. Washington, DC: World Bank. 


\section{5}

\section{Mozambique's Industrial Policy}

\section{Sufficient to Face the Winds of Globalization?}

António Sousa Cruz, Dina Guambe, Constantino Pedro Marrengula, and Amosse Francisco Ubisse

\subsection{The Evolution of Industry}

The current Mozambican industrial development pattern, a mix of private sector initiative and public sector licensing mechanism, replaced the postindependence public sector-led industrialization of the central planning countries' tradition. The transition in the mid-1980s from a public-driven economy to a market-driven one followed an international trend with the collapse of the socialist bloc countries and the end of the Cold War era.

Before its independence from Portugal in 1975, Mozambique had a mixed industrialization pattern of a dual society. On one hand, there was a growing colonial, urban, and industrializing population, and on the other, a local majority population dedicated to low-productive agriculture and other manual activities, such as mining and public works. Although the rules of a market economy applied, the public sector was heavily present, distorting labour relations. This national discrimination within an international market economy system partially explained the choice of a socialist economic system post-independence.

Although Mozambique has undergone a series of social, political, and economic transformations since the end of the Second World War (WWII), it still is a predominantly agricultural country, with two-thirds of the population dedicated to agricultural, fishery, and related production, utilizing lowproductivity traditional technology.

Currently, the country faces the challenge of choosing the most adequate strategy to transform its economic structure from an agricultural country to an industrialized one with efficient services to achieve higher standards of living. 
This chapter discusses the evolution of industry in Mozambique since the colonial era in the first half of the twentieth century to date. Based on a literature review, it pays particular attention to four sectors: mining, manufacturing, electricity and water, and the construction sector.

The study describes the evolution of industry in Section 5.1, presents the structure of the industrial sector in Section 5.2, explains the current industrial policy framework in Section 5.3, and concludes in Section 5.4.

\subsubsection{Colonial Industrial Development, 1945-74}

Today's industrial development could also be understood within the framework of the colonial Portuguese development strategy. Initially the main tasks of the Mozambican economy were to be: (1) a source of raw material for Portuguese industries; (2) a supplier of cheap labour; (3) an export market for Portuguese manufactured goods; (4) a labour market for Portuguese unemployed. These elements shaped colonial government economic policies, in particular with regard to its industrialization strategy. While it promoted the production of agricultural goods such as cotton, sisal, cashew nuts, and palm oil, it also imposed restrictions on the local production of manufactured goods that posed an immediate threat to Portuguese exports to Mozambique. Because of the high rate of unemployment in mainland Portugal, Portuguese settlers were encouraged to establish themselves around the most productive areas in Mozambique and supportive measures were deliberately adopted to empower them.

In 1953, Mozambique experienced a shift in colonial industrial strategy from a colonial pact which encouraged transfer of cheap agricultural products and raw materials from the colony to the mainland to a foment plan where the colonial economy would become more integrated, with a larger proportion of the financing package coming from within the colony, coupled with an increase in supporting infrastructure investment (Wuyts 1983; Leite 1989).

The number of Portuguese settlers in Mozambique increased significantly following the first national development plan (Plano de Fomento 1953-8). Manufacturing output for domestic trade expanded significantly, creating a market for such new products as cotton articles and clothing in 1954, animal feed and shoes in 1955, paper, furniture, gas, metal works, machine repair, and transport vehicles in 1956, and glass articles in 1958 (Wield 1977). Besides diversifying the industrial base, the colonial government managed to support the emergence of a selected number of heavy industries such as metal work, vehicle maintenance, electricity, cement, gas, and water (Cruz 1994).

The national independence movements throughout Africa in the late 1950s and early 1960s put pressure on Portugal to reform its relations with the colonies. In 1961, the Angolan Liberation Popular Movement (MPLA) started 
its armed struggle in that colony. The Mozambique Liberation Front (Frelimo) was created in 1962 and in 1964 started waging a liberation war. To counteract mounting pressure, Portugal adopted a more interventionist economic policy, approving the Portuguese economic space integration law, creating the escudo zone, and approving the forced labour abolition law (Portugal 1961; Wuyts $1980,1983)$. These reforms and the implementation of foment plans contributed to continued industrial acceleration in the following period.

During this period, the colonial government implemented two additional development plans: Plano de Fomento II (1959-64) and Plano de Fomento III (1968-73), with an intermediate plan for 1965-7. A fourth plan was designed to be implemented from 1974 onwards. The objectives of both plans differed only slightly from each other; ultimate targets remained more or less similar.

The colonial government's sustained efforts for industrialization can be deemed a success story, with the combined industries being the largest sector contributor to GDP. Moreover, in 1964, industrial production for the domestic market became greater than industrial production for the external market (Leite 1989). In the 1960s, the financial system in Mozambique improved (Wuyts 1983), and industrial development benefited from the increase in capital flows and led to increased investment in more capital intensive industries, thereby creating (1) a laminated iron and steel sector; (2) a construction and assembly of railways transportation materials industry; (3) a petroleum refinery (Brum 1976).

By the end of the 1960s, external finances came under pressure (Wuyts 1983). Consequently, import substitution strategies were strengthened, leading in the 1970s to the creation of several new sub-industries (Brum 1976). Dominant sub-sectors remained within the industry processing of cashew, sugar, tea, timber, flowers, tobacco, cotton, textiles, refined oil, soap, different types of acids, and cement. In 1973, the textile, cashew, and sugar industries' share in total exports was over 50 per cent, and together they created over 85 per cent of manufactured exports (Castel-Branco 2002).

Following the 1973 international oil prices crisis, the 25 April 1974 military coup d'état in Portugal, and the negotiations on 7 September 1974 between the Portuguese Government and Frelimo, Mozambique entered a transitional period ending with independence on 25 June 1975. In the time to come significant structural changes would face the industrial sector in Mozambique, affecting the previous years of successful expansion.

\subsubsection{Post-independence Industrial Development, 1975-86: Central Planning Economy}

In 1975, Mozambique was the eighth largest industrial producer in subSaharan Africa (SSA) (Biggs et al. 1999). Manufacturing value added was above 10 per cent of GDP, and including mining, water, energy, and 
construction, the industrial sector was the main GDP contributor. Mozambique had developed one of the largest hydropower plants in Africa (the Cahora Bassa Dam), and the manufacturing sector had diversified within a context of highly effective protection.

Shortly after independence in 1975, the new Mozambican Government adopted a series of nationalist and socialist policies. Besides taking over top government positions, Mozambicans progressively occupied most of the medium-level positions in public administration and in major enterprises. There was basically a massive exodus of Portuguese settlers out of Mozambique, and these were replaced by Mozambicans and expatriates. The latter were called cooperantes, and came mainly from other socialist countries, African countries, and Western countries with a similar ideology.

The third and fourth Frelimo Congresses (Frelimo 1977, 1983) outlined the basic industrial strategies to be pursued by the new government of Mozambique. The congress resolution stated the following main objectives for the industrial sector, to:

- set up appropriate bureaucratic structures for steering industrialization, following a centrally planned model. This includes preparing a 10-year industrialization plan;

- turn abandoned private companies into state owned ones;

- ensure the satisfaction of people's needs in terms of food, hygiene products, and other household goods, clothes, footwear, and fuel/energy;

- provide raw materials, fuels, and means of production for all sectors, particularly for agriculture;

- contribute to balance of payments stability;

- improve skills and build a pool of technical manpower.

In line with Congress decisions, during 1980-3 the government allocated about 58 per cent of total investment funds for agriculture and industry, both defined as priority sectors for satisfying people's needs (DNE-CNP 1985).

The global social product (GSP), an indicator of the material product of a country, increased from 71.1 billion meticais in 1975 to 83.7 billion in 1981, at 1980 constant prices. During 1975-84 agriculture and industry contributed on average 76 per cent to GSP (DNE-CNP 1985). Hence, at a first glance initial investment strategies seemed to have paid off. Major contributors to growth of the manufacturing sector included: petrol, rubber, metal works, textiles, oil, soaps, and fisheries.

Gains from the third Frelimo congress were, however, short lived as in 1983 the country suffered a major drought. On top of this, the government failed to mobilize the much needed international funds for sustaining its ten-year development plan for 1980-90. Internal war was spreading throughout 
the country, besides increasing a rural-urban exodus and expanding the informal market.

The fourth Frelimo congress, in 1983, took place amid increased social tension and discontent. The congress resolution stressed the need to ensure provision of basic goods, again through investment in agriculture and industry as the main drivers for structural transformation. It called for greater emphasis on import substitution and the development of small and medium enterprises (SMEs). To open up space for other actors, in 1984 it introduced the first generation of liberalization measures in Mozambique, removing government control over prices of selected goods, including vegetables. It also encouraged government retreat from retail businesses.

The fourth Congress policy objective for the manufacturing sector aimed at '[i]ncreasing industrial production by 12-15 per cent from 1980 to 1985, focusing on growth within textiles, fisheries, metal works, mechanic constructions, metallurgic and ship maintenance'. Particular focus was set on improving capacity utilization. It was the first time since independence that the ruling party officially considered private investors a relevant partner.

The fourth Congress decisions and the significant state interventions turned out to be insufficient to circumvent the internal conflicts' destructive toll. By the mid-1980s the industrial sector was operating at 10 to 30 per cent of its capacity. Average labour productivity had declined by more than 60 per cent. The agricultural sector was reduced to subsistence level. Production of tea, cashew, cotton, and sugar, the country's main exports at independence, dropped to 30 per cent of the 1980s levels, while exports declined to one-third of pre-independence levels (Castel-Branco 2002).

The combined effects of a reduced supply of raw materials, limited demand for final goods, and the failure of the export oriented agricultural sector left the country near collapse. War and natural disasters added to the problem through the sabotage of infrastructure and disruption of road networks. Colonial era logistics, learning expertise as well as market intelligence broke down, after the massive exodus of skilled labour that followed independence and the destabilization from civil war. These factors and the collapse of the central planning economy led to a declining/stagnant economic performance, reaching in 1986 its lowest GDP level since the late 1960s.

\subsubsection{Transitional Industrial Development, 1987-96: Towards a Market Oriented Economy}

Mozambique introduced the Economic Rehabilitation Program (PRE) in 1987, the Social and Economic Rehabilitation Program (PRES) a few years later, and a more market oriented constitution in 1990. In 1992, Frelimo and Renamo signed a peace agreement, marking the end to sixteen years of destabilization 


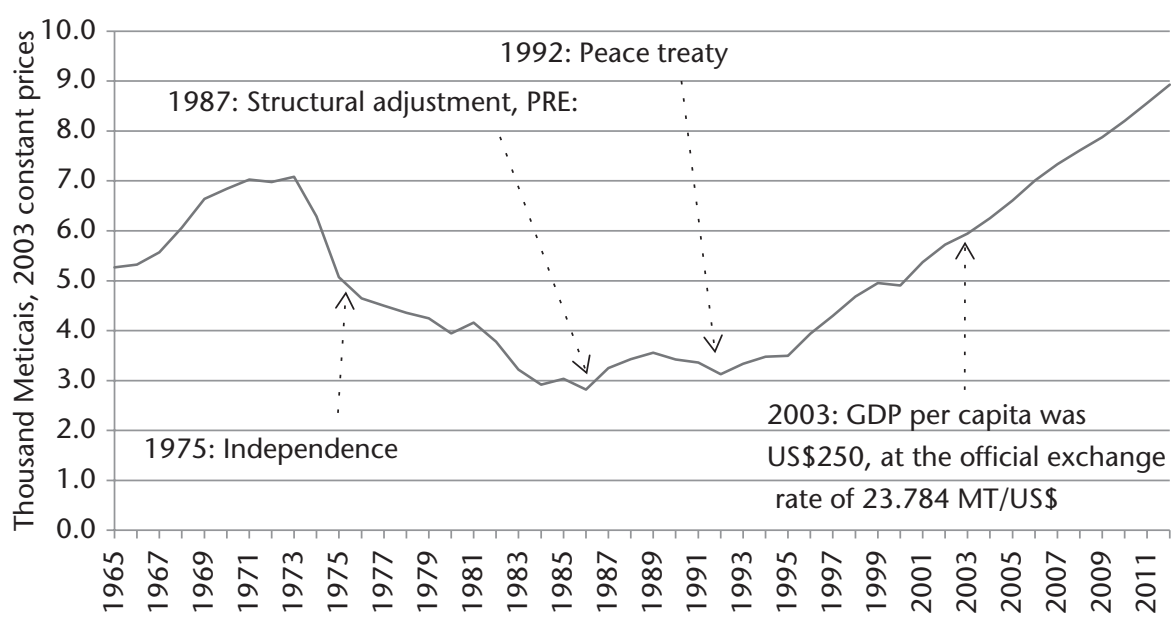

Figure 5.1 From 1992 onwards, the economy steadily increased its per capita GDP, with a Gini coefficient of around 0.42

Source: Authors' illustration based on Sulemane 2002; INE various years a (Anuário Estatístico 2008, 2010); INE 2012 (Serie de Contas Nacionais); MPD 2010.

and civil war. This removed the most important barrier to industrial development, and allowed the country to access much needed international funding. State-owned operated entities were no longer seen as the main driver for industrialization and economic development. Instead, emphasis was on developing the private sector as the main source for growth and market forces as the appropriate mechanism to guide resource allocation. From 1992 onwards, the country followed a long period of economic recovery and expansion (Figure 5.1).

When PRE was implemented, industry had been collapsing. The introduction of liberalization measures and the inflow of much needed donor funds were instrumental in launching industrialization. Interventions resulting from the PRE are reported in the policy matrix in Box 5.1.

After the peace agreement in 1992, the industrial sector resumed its postwar positive growth trend (Figure 5.2). The World Bank (WB) during the mid1990s confirmed the positive revenue growth episode of manufacturing firms (Biggs et al. 1999). The growth in employment was, however, limited, suggesting that the reported revenue growth was as a result of increased capacity utilization (increasing labour productivity), rather than a general expansion of existing firms.

With the structural adjustment programme (SAP) and the privatization process, in 1995 the share of manufacturing in total GDP reached its lowest point, with 7.4 per cent, increasing gradually afterwards. Besides better capacity utilization and productivity growth, liberalization increased the 
Box 5.1 POLICY MATRIX: INTERVENTION UNDER PRE

\begin{tabular}{|c|c|c|c|c|}
\hline \multicolumn{3}{|c|}{ Policy intervention } & \multicolumn{2}{|c|}{ Evaluation } \\
\hline & Instrument & Purpose of policy & Success & Failure \\
\hline \multirow{10}{*}{$\begin{array}{l}\text { Policy reforms: } \\
\text { PRE \& PRES }\end{array}$} & & & Economic growth & \\
\hline & Liberalization & $\begin{array}{l}\text { Stop economic } \\
\text { deterioration; } \\
\text { establish market } \\
\text { oriented } \\
\text { economy }\end{array}$ & $\begin{array}{l}\text { Highly technical } \\
\text { efficiency; } \\
\text { better access to } \\
\text { capital, modern } \\
\text { production } \\
\text { techniques, and } \\
\text { knowledge }\end{array}$ & $\begin{array}{l}\text { Efficiency not enough } \\
\text { to allow firms to } \\
\text { compete in world } \\
\text { markets }\end{array}$ \\
\hline & & & $\begin{array}{l}\text { Improved access to } \\
\text { strategic raw } \\
\text { materials }\end{array}$ & $\begin{array}{l}\text { Textiles sector loss of } \\
\text { clothing markets in } \\
\text { Eastern Europe }\end{array}$ \\
\hline & & & $\begin{array}{l}\text { Increase in demand } \\
\text { Appearance of new } \\
\text { manufacturing } \\
\text { firms owned by } \\
\text { foreigners }\end{array}$ & \\
\hline & Privatization & $\begin{array}{l}\text { Stop the economic } \\
\text { deterioration; } \\
\text { establish market- } \\
\text { oriented } \\
\text { economy }\end{array}$ & $\begin{array}{l}\text { Growth rate of sales } \\
\text { and job creation }\end{array}$ & $\begin{array}{l}\text { Non-exporters failed } \\
\text { to perform } \\
\text { comparatively } \\
\text { better in sales and } \\
\text { employment }\end{array}$ \\
\hline & & & $\begin{array}{l}\text { Increase capacity } \\
\text { utilization }\end{array}$ & $\begin{array}{l}\text { Workers less } \\
\text { productive }\end{array}$ \\
\hline & & & $\begin{array}{l}\text { Resource shift } \\
\text { towards efficient } \\
\text { firms }\end{array}$ & \\
\hline & & & $\begin{array}{l}\text { Increase in private } \\
\text { investment } \\
\text { mainly in capital } \\
\text { equipment }\end{array}$ & \\
\hline & & & $\begin{array}{l}\text { Increase in } \\
\text { manufacturing } \\
\text { productivity }\end{array}$ & \\
\hline & & & $\begin{array}{l}\text { High labour and } \\
\text { capital } \\
\text { productivity of } \\
\text { privatized firms }\end{array}$ & \\
\hline
\end{tabular}

availability of foreign exchange, improved access to strategic raw materials, and significantly reduced production bottlenecks. Moreover, new private investment (on average 2-3 per cent of GDP per annum over 1992-7) in manufacturing showed renewed trust and interest in the industrial sector. The period also saw a much needed shift/reallocation in resources towards more efficient firms, which contributed to aggregate productivity improvements (Biggs et al. 1999). However, the average efficiency of manufacturing 


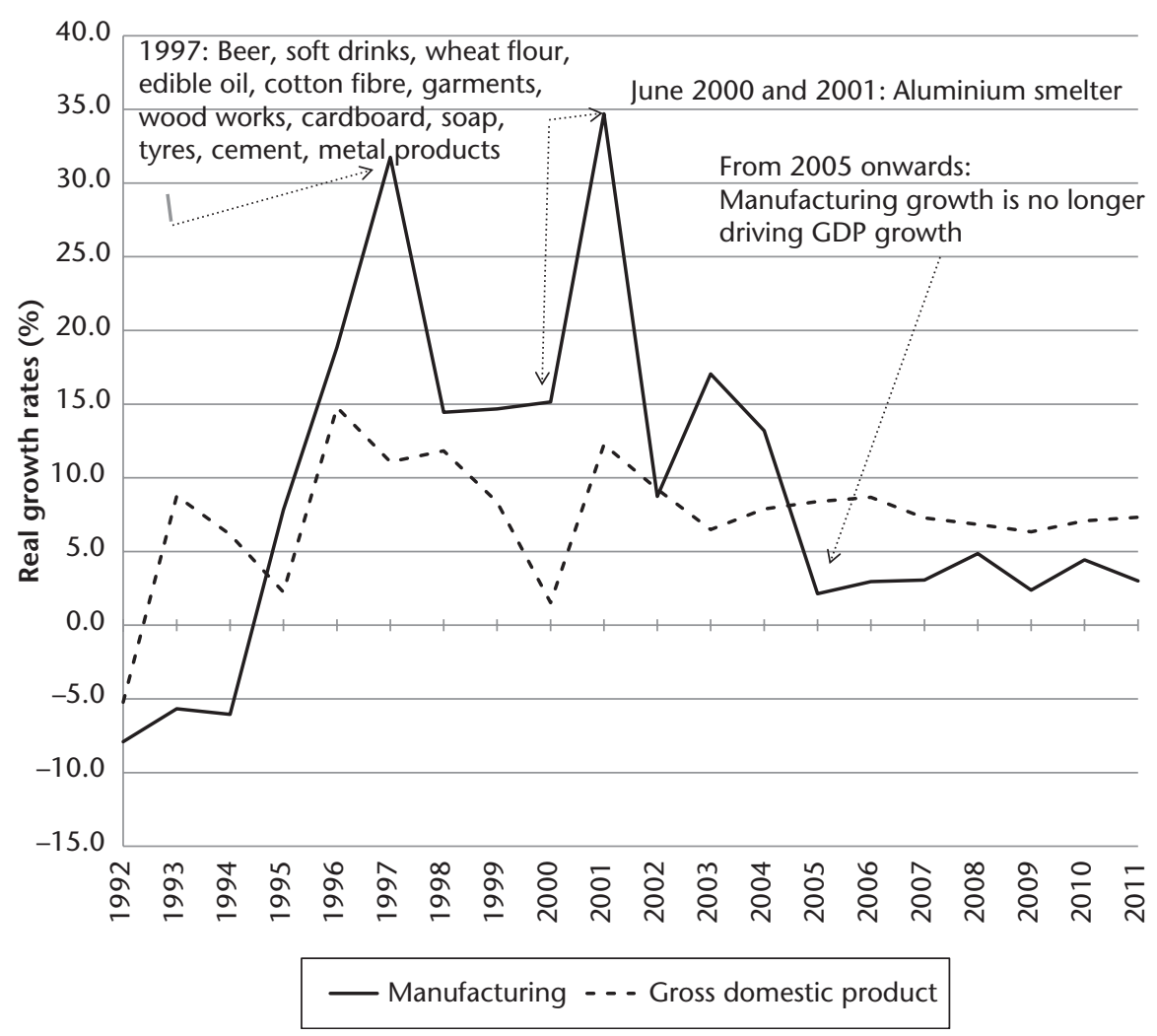

Figure 5.2 After its dynamic role in GDP growth between 1995 and 2004, from 2005 the manufacturing sector ceased to be the main driver of growth Source: Authors' illustration based on INE 2012 (Serie de Contas Nacionais).

firms in Mozambique remained below the average among South African Development Community (SADC) members, impairing the country's ability to compete with imported goods and in world export markets.

\subsubsection{Current Industrialization Pattern: IPS 1997 and IPS 2007}

Five years after the 1992 peace agreement and three years after the first multiparty and democratic elections, the government approved the 1997 Industrial Policy and Strategy (IPS97), (MIC 1997). Ten years later the 2007 IPS07 was developed from IPS97, but was now built upon a more articulated and multi-sectoral industrial dynamic approach (MIC 2007). As such it was an improvement over IPS97, as it promoted a more coordinated industrial system. 
The overall objectives of the IPS were to ensure the emergence and development of a modern and competitive industrial base that was less dependent on external resources, including factors of production. For this purpose, the government called for: (1) value addition to natural resources; (2) industry contribution to the balance of payments; (3) supply of basic goods; (4) promotion of labour-intensive technologies.

The IPSs followed a typically liberal approach to industrialization. The state was to orient, regulate, and supervise industrial development, while building appropriate conditions for robust industrial activity. The channel of intervention included the establishment of several different industrial policy instruments, ensuring promotion of an appropriate business environment for producers and investors. The IPS also maintained that the state had the responsibility to set up a system of transparent incentives, including complementary investment, in order to attract private (foreign) investors. However, central to the IPS was also ensuring a quick and painless privatization process (Campbell White and Bhatia 1998; Castel-Branco et al. 2001).

The government adopted several strategic approaches for implementation of the industrial policy including: (1) setting an enabling environment for private sector development; (2) development of micro, small, and medium enterprises (MSMEs); (3) creation of training and skill acquisition programmes; (4) establishing incentives for investment; (5) promotion of foreign investment with focus on industrial development and exports.

The implementation of IPS97 and IPS07 led the country to a new stage of industrial development. The policies managed to establish institutions for sustaining industrialization, including: (1) the Beluluane Export Processing Zone, hosting the Mozal Smelter Project and its suppliers with investment amounting to more than US\$2.3 billion; (2) the Nacala Rapid Development Zone; (3) the Institute for the Promotion of micro, small, and medium enterprises (IPEME); (4) the statute for MSME; (5) the district development fund; (6) the Maluana Technology Park; (7) a one-stop electronic window for clearing imports.

However, IPS97 and IPS07 left the manufacturing sector in a bipolar state. On the one hand, private manufacturing was left to liberalize market forces and on the other hand, state administration focused on supporting and ensuring joint ventures with local representatives operating especially within the mining sector (Castel-Branco et al. 2001).

Mega-projects (especially within the mining sector) have been under public scrutiny, owing to the low contribution to state revenues and the low degree of integration with the rest of the economy (Castel-Branco 2008, 2010; CIP 2013). However, these projects are also considered to have increased the country's visibility among international investors; to have exposed local institutions to large investing companies; to contribute to state revenues in the longer run, in particular since the 2007 law approval. Currently and in the 
near future, until mid- and end 2020s, the expected growth in coal and natural gas exports should continue to have an accumulated significant impact on GDP growth.

At the same time, light manufacturing, producing mostly for the domestic market, has been developing from 1995 onwards. Several types of these light manufacturing firms have emerged during this period. The first are larger-scale entities started with 100 per cent foreign capital, for example Coca-Cola and SABMiller. A second type, although smaller, were operating by exploring activities from thousands of cotton farmers, or through large sugar cane companies. A third category was feeding the construction industry which was booming on account of public investment in infrastructure and private housing investment. And finally, a fourth type were smaller-scale formal and informal manufacturing SMEs with very mixed production portfolios.

Evidence from two rounds of manufacturing enterprise surveys (Byiers and Rand 2006; MPD 2013) revealed an improvement in the business environment between 2002, 2006, and 2011 for these types of manufacturing SMEs. However, while employment growth rates between 2002 and 2006 were over 30 per cent (Byiers and Rand 2006), the period from 2006 to 2012 saw stagnating employment figures in surviving manufacturing firms (MPD 2013). Moreover, comparing census data for Nampula, Zambezia, Manica, Sofala, and Maputo Byiers and Rand (2006) and Schou and Cardoso (2014) document that the growth rate in the number of manufacturing firms between 2002 and 2012 was relatively limited: from 2,018 registered manufacturing firms in 2002 in the five provinces to 2,490 in 2012, corresponding to an annual increase of 1.9 per cent.

This weak role and growth of the private-led manufacturing industry is in line with evidence on the limited structural transformation taking place in Mozambique (Castel-Branco 2003; Jones and Tarp 2012; MPD 2013). Moreover, low levels of diversification and lack of inter-industrial linkages (Newman etal. 2014) are additional signs of an unsustainable industrial growth path. Despite this industrial trend, the domestic economy has revealed strong and persistent growth rates since 1993, which are not well explained in the literature. We look deeper into the current structure of the industrial sector in what follows.

\subsection{Current Structure of the Industrial Sector}

\subsubsection{Industrial Output}

The industrial sector is divided into four major sub-sectors: mining, manufacturing, electricity and water, and construction. Figure 5.3 shows each sub-sector's contribution to total industrial production post-civil conflict. Generally, the 


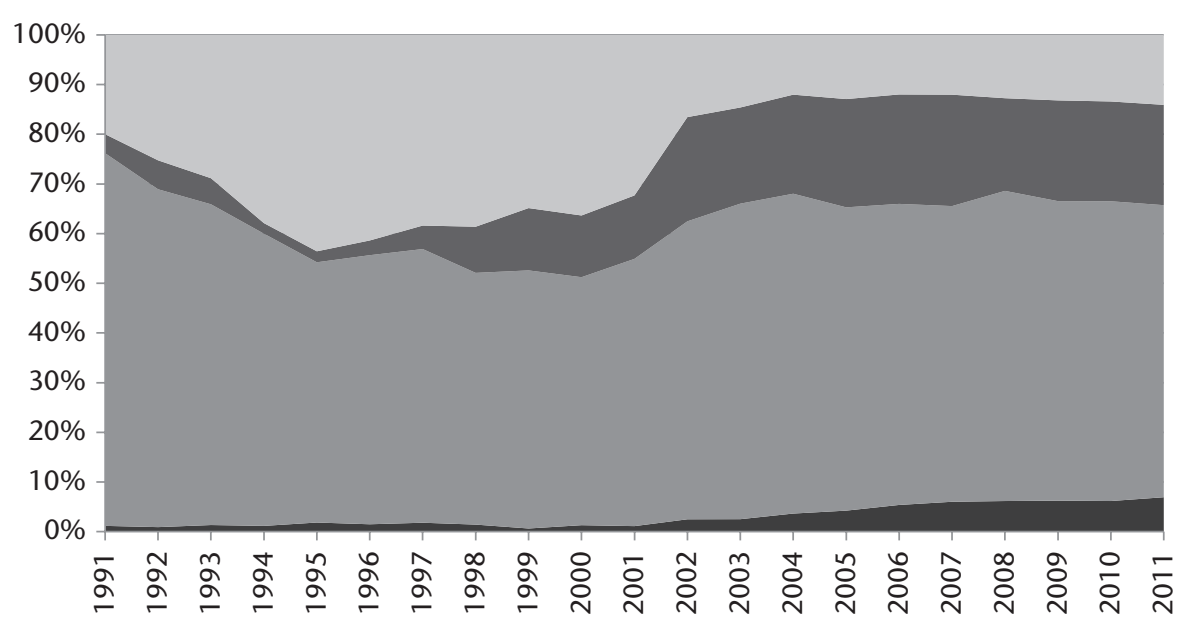

- Extractive industries $\square$ Manufacturing $\square$ Electricity and water $₫$ Construction

Figure 5.3 The intra-industrial structure stabilized between 2005 and 2011, although the mining industry is expected to increase significantly in the 2010s and 2020s Source: Authors' illustration based on INE 2012 (Serie de Contas Nacionais).

industrial sub-sector structure has stabilized since 2005: manufacturing is the largest sub-sector with a contribution of 60 per cent of total industry value added, followed by electricity and water ( 21 per cent), construction (13 per cent), and mining ( 6 per cent). However, this pattern is expected to change significantly in the future in favour of mining, given the recent coal and natural gas initiatives approved by the Mozambican Government.

Within the manufacturing sector, metal works (dominated by aluminium processing) generate the largest share of manufacturing value added (43 per cent), with the food and beverage industry currently coming second, generating around 36 per cent of manufacturing sector production. This means that manufacturing is relatively concentrated within two 2-digit International Standard Industrial Classification (ISIC) production sectors, making this sub-sector relatively vulnerable to international price fluctuations within a relatively narrow segment of goods.

\subsubsection{Firm Size in the Industrial Sector}

As already highlighted, the number of industrial firms in Mozambique is only modestly increasing. Moreover, the size distribution of firms has remained almost constant over time (Byiers and Rand 2006; MPD 2013). The Instituto Nacional de Estatística (INE)'s annual survey of companies revealed that firms with fewer than ten employees (micro-establishments) are in the majority 
(INE various years). Almost 80 per cent of enterprises in manufacturing (responsible for 88 per cent of industrial firms) are micro-enterprises; 12 per cent are small (between 10 and 30 employees); 5 per cent are medium (between 31 and 100 employees); and 3 per cent are large (more than 100 employees). Almost 90 per cent of the combined industrial sector is composed of micro- and small enterprises (MSEs). Most larger firms are found within the mining, and electricity and water sectors, as these tend to be capital intensive and demand high levels of recurrent investment.

MPD (2013) also documents that most Mozambican manufacturing companies produce relatively homogenous products using basic technology and sell almost exclusively to private individuals locally. Diversification of manufacturing production is very weak and the MPD (2013) found it questionable whether these small-scale craftsman-type firms can be drivers of industrialization.

\subsubsection{Contribution from the Industrial Sector to Employment}

Industrial sector contribution to total employment averages around 37 per cent (Table 5.1). Manufacturing is responsible for approximately 70 per cent of industrial employment, with construction being the second largest employer at around 22 per cent. The mining and electricity sectors are relatively unimportant in terms of direct job creation, with share averaging 3 per cent and 5 per cent, respectively.

\subsubsection{Ownership of Industrial Firms}

The largest share of employees are engaged in privately owned companies (76 per cent). Foreign owned firms comprise 21 per cent, whereas only 3 per cent of workers are employed in state-owned enterprises (SOEs).

Table 5.1 Employment in industry and its sub-sectors, 2006-9

\begin{tabular}{lcccc}
\hline Industry/sub-sectors & 2006 & 2007 & 2008 & 2009 \\
\hline Total employment in industry & 81,388 & 96,004 & 87,498 & 109,507 \\
Sector contribution as a percentage of total & 36.65 & 40.83 & 33.13 & 37.31 \\
$\quad$ employment & & & & \\
Sub-sector contribution to industrial sector (\%) & & & & 2.79 \\
Mining & 2.64 & 2.72 & 71.6 & 68.5 \\
Manufacturing & 66.9 & 71.3 & 3.0 & 6.2 \\
Electricity and water & 6.3 & 4.5 & 22.6 & 22.8 \\
Construction & 24.2 & 21.5 & 100 & 100 \\
Total & 100 & 100 & & \\
\hline
\end{tabular}

Source: INE various years b (Inquérito Anual as Empresas 2009-2011). 
The MPD (2013) found a positive relationship between foreign ownership and employment growth, even when controlling for firm size and other relevant firm attributes. This is in line with Ramachandran and Shah (1999), who found that minority (or non-indigenous) entrepreneurial companies grow significantly faster than indigenously owned firms in Mozambique.

\subsubsection{Sunset and Sunrise Industries}

The mining, energy, and construction sectors have been especially attractive in the 2000s. However, in terms of job creation potential it is clear from Subsection 5.2.3 that manufacturing should be given special policy priority.

The metal, machinery, furniture, and textiles/apparel sub-sectors have shown particularly adverse potential (MPD 2013). On the other hand, wood and paper, publishing and printing, and chemicals appeared to have done better than average. Especially, textiles have for some time been considered the main sunset industry of Mozambique. However, it still remains to be seen whether this sub-sector is overcoming its slump.

From the MPD (2013), 'sunrise' industries are found within food and beverages, and the non-metal minerals sectors, when evaluated in terms of employment generation, labour, productivity improvements, and increasing manufacturing revenue shares. However, it was noteworthy that while firms in the non-metal minerals sector have very high survival probabilities, firms in the food and beverages sector are among the least likely to stay in business. This clearly signals that the food and beverages sector is competitive and dynamic, and is a sector where creative destruction processes have been allowed to take their toll.

\subsection{Industrial Policy Framework}

After the introduction of the PRE in 1987, and the peace agreement in 1992, the government embarked on privatization and liberalization programmes aimed at enforcing the role of market forces as the main engine for growth. The degree to which the reported reforms were successful in putting the country on the right track towards industrialization remains a contentious issue. While market friendly reforms were successful in reopening the space for private sector development, a number of issues from a policy perspective remain unsolved.

\subsubsection{Macroeconomic Policies}

Mozambique's fiscal and monetary policies have followed the standard International Monetary Fund (IMF) and WB supported programmes. Since 1987, 
the government objective has been to ensure a sustained reduction in the government primary deficit, money supply, and inflation control. Initial fiscal policy instruments included privatization of state assets, removal of price controls and subsidies, and tax reforms such as the introduction of VAT in 1999. To ensure inflation control, the Central Bank (Bank of Mozambique) introduced direct monetary controls, besides privatization of the banking sector and liberalization of interest and exchange rates.

By the end of 1999 Mozambique had privatized more than 1,200 state companies (Andersson and Sjöö 2002), and at the beginning of the 2000s, Mozambique was regarded as one of the most appropriate economies for doing business in southern Africa. Real GDP growth averaged 8 per cent between 1992 and 2000. From 2001 it increased to 12 per cent per annum, setting the country among the fastest growing economies in the world. Inflation dropped from a level as high as 62 per cent between 1987 and 1996 to 14 per cent in 2003. In 2012, the average inflation and exchange rate depreciation were 7 per cent and 3 per cent, respectively.

Following fiscal reforms such as the introduction of a new personal income and corporate taxes in 2003, in 2006 the government set up the Mozambique Revenue Authority, merging in the same entity the tax collection activities of different units within the Ministry of Finance. The country's fiscal stance improved as a result. The tax to GDP ratio increased from around 11 per cent in 2000 to 23 per cent in 2012. Despite this improvement, the tax system is still considered inefficient for industrial development. Various discussions on the tax system report that it is not conducive to manufacturers because of the following problems: (1) uneven application of tax regime; (2) lack of guidelines to fully comply with tax requirements; (3) complicated and timeconsuming procedures; (4) delays in VAT refunds; (5) breaks in the VAT chain.

\subsubsection{Trade Policies}

Since the adoption of PRE in 1987, the government has taken measures to free international trade from unnecessary barriers. Export taxes have been removed and import duties for most goods were scheduled to drop to zero by the year 2015, when the SADC common market becomes operational. Currently the top tariff is 20 per cent, the average applied tariff rate is 12.1 per cent, and the trade weighted average tariff is only 9 per cent. ${ }^{1}$ Despite offering some form of protection in selected sectors, such as the sugar industry, the effective rate of protection in most sectors is lower than that of most other SADC members.

1 Mozambique uses ad valorem duties. 
For attracting investment, in 1994 the government established the Investment Promotion Centre. Through the investment code of 1998 and the subsequent amendment in 2004, the government created free export processing and rapid development zones, where investors enjoy generous tax incentives, including tax exemptions and profit repatriation.

Since the introduction of the first generation of reforms in 1987, trade and capital flows have been increasing as a result of the reported wave of reforms. However, the country is still lagging behind due to limitations associated to the way it manages its exports and imports: corruption, high rate of inspection of both export and import shipments, limitations of the duty drawback/duty suspension, and the VAT rebate system (FIAS 2008).

AIMO (2010) estimates that, on average, a typical industrial importer has to spend MT55,473 for each import made through the Maputo cargo terminal, in addition to the required expenditures. This adds to the average cost of inputs, reducing profit margins as well as the competitiveness and performance of local industry (ANEMM 2000; Marrengula et al. 2012).

\subsubsection{Institutional and Regulatory Framework}

Mozambique has introduced business environment reforms and as well as commercial law in order to improve the protection of property rights. Initiatives include: (1) opening a centre for arbitration; (2) establishing public risk evaluating bureaux; (3) introduction of modern regulation regarding industrial licensing and company insolvency.

For investors, besides being a member of the Multilateral Investment Guarantee Agency (MIGA), the Overseas Private Investment Corporation (OPIC), and the International Convention and Centre for settlement of investment disputes, Mozambique also offers a number of guarantees, including: (1) guarantees over security and legal protection of property rights; (2) rights to import own-equity capital or loans to carry out investment; (3) entitlement to just and equitable compensation in the event of expropriation based on absolute necessity and weight, reasons of public interest, health, and public order.

The introduction of a market based economy in the late 1980s and in the 1990s brought incentives for a more entrepreneurial society, but Mozambique continues to lag behind other SADC members in both Global Competitiveness and Doing Business rankings.

Focusing specifically on industrial development, a number of government bodies have been created to support specific industries, but their roles remain limited and it is not clear whether the government considers this approach a valuable asset for industrial development (Marrengula et al. 2012). 


\subsubsection{Current Constraints for Future Industrial Development}

\subsubsection{SKILLS AND EDUCATION}

Mozambique's labour force qualifications are limited, illustrated by the fact that 52 per cent of the population is illiterate. According to the National Institute of Professional Training and Employment, 80 per cent of illiterate Mozambicans have no professional qualifications (MITRAB 2006). Around 90 per cent of those applying for their first job have not completed basic education. Among them the majority (62 per cent) have no work experience or qualifications.

The situation is no different among those sectors with high growth potential (ANEMM 2000; AIMO 2010). For example, within the building materials industry, more than 60 per cent of employees hold only a primary school certificate (ANEMM 2000; AIMO 2010). The same percentage holds for employees among contractors and only 9 per cent have finished secondary school. While the supply of unskilled labour is in excess, contractors argue that there is a considerable scarcity of mid-level managers, project directors, supervisors, and headmasters for building, carpentry, metal work, electricity, welding, and water pumps (Marrengula et al. 2012).

The government has supported the emergence of mid-level and higher education institutions geared towards the study of business and management. Enrolment rates have as a result increased among higher education institutions. The average growth rate in enrolment among public institutions was close to 19 per cent between 2009 and 2012.

Towards the beginning of the implementation period of industrial policy, besides advocating reforms to the education system, the government and the donor community adopted a more proactive approach towards the development of the local private sector and entrepreneurship. Following this shift, three institutions were set up, namely: United Nations Development Programmes (UNDP)'s Enterprise Mozambique; UNIDO (United Nations Industrial Development Organization) and the Associação Industrial de Moçambique (AIMO)'s Industrial Development Advisory Centre (CADI); and the WB's Private Sector Development Program (PODE).

More recently, due to the high rate of unemployment, IPEME introduced the SME promotion strategy, paying particular attention to the entrepreneurship promotion programme, access to finance, business services, removal of regulatory constraints, and tax burdens. IPEME is currently working to set up its first network of incubators. The education ministry initiated two major entrepreneurship education programmes, including curriculum reforms aimed at developing entrepreneurship skills among teachers as well as primary and secondary school graduates.

At secondary school level, the education ministry is implementing an entrepreneurial programme financed by UNIDO for students to learn how to start 
and run a small-scale business. Since its inception in 2007, in a pilot phase, the programme has involved 255 schools and 1,521 teachers and created 52,309 secondary school graduates. This is by far the biggest entrepreneurship education programme in Mozambique.

\subsubsection{ACCESS TO ENERGY AND WATER}

The energy market in Mozambique follows a monopolistic structure in terms of both production and distribution. PETROMOC, a state owned company, remains the dominant player in the petroleum market, and in the electricity market the state owned company Electricidade de Moçambique (EDM) supplies more than 90 per cent of the electricity distributed in Mozambique. Recent reforms have allowed for concessions, public-private partnerships, and entry of private sector players within both production and distribution of energy. A significant increase in access to the public grid has been recorded between 2000 and 2010, but with the southern part of Mozambique benefiting more from the public grid expansions.

The long-term implication of these improvements for the industrial sector will depend on additional government policies and how the electricity market itself will evolve. So far the available conditions remain unfavourable for industry in terms of access, in comparison with other SADC countries (World Bank 2014). Close to 70 per cent of the members of the Federation of Industry (AIMO-FI) interviewed in 2011 considered lack of access to a reliable and regular supply of electricity a fundamental constraint against doing business. Businesses also experience frequent power cuts; on average five to ten times per week, lasting at times more than thirty minutes. This situation worsens when one moves from the Maputo metropolitan area to the north.

In terms of cost, van Eeden (2009) also reports that EDM charges a higher price for electricity as compared to equivalent charges in Malawi, Tanzania, Swaziland, Zambia, and South Africa. For small businesses, EDM recently charged a 38 per cent higher unit price for delivering electricity to small businesses than Eskom in South Africa. In Malawi and Tanzania electricity charges were even lower.

Turning to access to water for production purposes, van Eeden (2009) highlights that inefficient distribution is significantly constraining the productivity of water intensive industries. Moreover, water is not cheap. The payment for up to 50 cubic metres for industrial use is US\$35/month, almost the value charged for mines in South Africa. Following the water reform process initiated with the creation of the national fund for water (FIPAG) during the second half of the 1990s, water production and coverage have increased. However, the system is still considered inefficient and exposed to frequent interruptions. As a result, companies have to hire private water supply agents and invest in water distribution and conservation equipment. 


\subsubsection{FINANCIAL RESOURCE ACCESS}

Mozambique's financial system has made significant progress since the introduction of the PRE in 1987. The number of banks went from three at the beginning of the PRES to eighteen in 2012. The country obtained the first stock exchange in 1999, while the number of insurance and micro-finance institutions has also expanded. As a result, financial savings, captured by the volume of term deposits, tripled from 9 per cent as a percentage of broad money (M3) to 31 per cent in 2008 (Navalha 2009). However, the liberalization of the financial sector has increased demand for collateral and on average raised interest rates; and for local industries, the improvements in M3 did not expand access and the availability of funds, particularly for long-term investment (ANEMM 2000; AIMO 2010).

The availability and access to the necessary project finance is constrained by: (1) banking sector market concentration; (2) low levels of financial savings in the face of high public sector demand, with deposits to credit ratio reported to be below the average for SSA (IMF 2010; Banco de Moçambique 2007).

Recently, the Bank of Mozambique introduced policy measures meant to improve the state of economic conditions in Mozambique. In the last five years a reduction in the capital requirement ratio led to the emergence of new financial institutions, hence increasing financial inclusion. It also led to financial innovations, particularly within the micro-finance segment, with indirect effects on interest rates (which have resulted in a reduction in the gap between the deposit and credit interest rates, although they remain high by SSA standards) and the degree of competition. The challenge of more targeted intervention with a view to supporting the sustained growth of Mozambique entrepreneurs through long-term investment, however, still remains to be achieved (ANEMM 2000; AIMO 2010).

\subsubsection{ACCESS TO SUITABLE TECHNOLOGY}

The government's industrial strategies for 1997-2012 highlighted the technology gap as one of the main factors behind indigenous companies' inability to compete. The strategy called for urgent measures, but in a recent survey, AIMO (2010) found that the situation had not changed despite the fact that the implementation period of the industrial policy and strategy paper is reaching its end. Over 62 per cent of the companies surveyed in the course of the AIMO 2010 study had not made major acquisitions of new technologies since the 1990s; their machinery was over twenty years old and they were finding it hard to maintain the equipment and replace spare parts (ANEMM 2000; AIMO 2010).

Mozambique's poor performance in terms of industrial technology upgrading is a result of the following factors: (1) reduced degree of absorption of new technology associated with a lack of skills; (2) low levels of innovation; 
(3) weakness in protecting intellectual property rights; (4) reduced private sector investment in $R \& D$, due to the sector's relatively small size and undercapitalization (ANEMM 2000; AIMO 2010).

Around 42 per cent of companies complain about the lack of finance and the costs of acquiring new technology. Moreover, few companies report to having had access to new technology, unless often through ties with foreign investors and exposure to external markets through exports. It is this linkage that is believed to ensure access to new technologies and allows for constant upgrading and maintenance in a Mozambican context (AIMO 2010; Marrengula et al. 2012). This is supported by a recent finding in Cruz et al. (2014a) showing that firms in Mozambican manufacturing learn by exporting, but that this learning process is significantly limited by significant external market access constraints.

\subsection{Conclusion}

Mozambique's post-independence industrial development background can be divided into two phases. The first eleven years of the socialist experiment came with strong state activism, a destructive war, and a failed economy. This was indeed a lost decade for industrialization. The country failed to sustain and maximize the gains to industry that resulted from the colonial era's active industrial policies. The country lost export markets and the industrial base.

The introduction of liberalization measures, starting in 1987, a new constitution in 1990, and a peace agreement in 1992, brought new economic opportunities and access to donor funds. This was indeed the beginning of the second phase, with a growing economy and the emergence of new industries. Over the last twenty years the country's average growth rate is estimated at 7 per cent.

Recent government industrial policy interventions follow a typically liberal approach, relying on the private sector to steer economic growth, and until 2004 leaving the state with a hands-off stance, but more proactive thereafter. In both of these sub-periods, the public sector role has been perceived as provider of an enabling environment for the private sector, with both drawbacks and advantages.

The main drawbacks were a hands-off approach from 1994 onwards, and an oligopolistic approach that worsened after 2005. The extreme liberal approach regarding the industrial sector led to significant deindustrialization of the cashew nuts, food processing (tomato, fruit juices, milk products, wheat, and other cereal products), textile, construction materials, chemical, metallurgical, and equipment industries. At the same time, other processing 
branches were expanding, such as beverages, grain milling, sugar, tobacco, cement, and tyres.

Licensing procedures ensured that selected interests linked to the ruling government conditioned private investment. This tradition became severe and centralized to a limited number of interests even after 2004. At the same time, public companies or enterprises with public capital ensured management places for this oligopoly.

Two consequences came from this approach: there was marginalization of thousands of potential local entrepreneurs among young people and others, from business opportunities in industry; and after 2004 manufacturing expansion lost momentum. The construction sector developed, but failed to create larger local companies to participate in the booming infrastructure phase. Although most sectors were growing, the economy became dominated by a profitable financial sector of banks and insurance companies, as well as large public natural monopolies and opportunistic large construction and commercial companies.

On the advantages side, with the implementation of the first and second industrial policy and strategy papers from 1997 and 2007, the country moved to a new stage of pseudo-industrial development. The country has managed to establish some of the necessary institutions for sustaining industrial sector progress. There is also evidence of efforts to invest in developing the national standard and quality control framework as well as the country's skill and entrepreneurship profile. Liberalization, however, exposed the domestic industry to the winds of globalization. To be successful a number of challenges need to be addressed, including: (1) skills development; (2) improving access to financial resources; (3) improving access to technology; (4) improving access to cheaper and more reliable electricity and water; (5) fine tuning tax policy; (6) improving regulations and practices for both imports and exports; (7) maintaining macroeconomic stability, preventing unsustainable debt increases, and managing significant inflows of external revenues from natural resources; (8) promoting development and linkages between agriculture, industry, and services. However, global players are investing billions of dollars into exploitation of mineral resources, including coal, gas, iron, and gold. How income from these resources is used in future will be of the utmost importance for the success (or failure) of Mozambique's structural transformation.

\section{References}

Andersson, P.-Å., and Sjöö, B. (2002). 'O Sucesso Moçambicano no Controlo da Inflação durante a Transição para uma Economia de Mercado'. In A Economia Moçambicana Contemporanea: Ensaios. Maputo: Gabinete de Estudos, Ministério do Plano e Finanças. 
Associação Industrial de Moçambique (AIMO) (2010). Competitividade Industrial de Moçambique. Maputo: AIMO.

Association Nacional Das Empresas Metalúrgicas E Electromecânicas (ANEMM) (2000). Sectores de Destino da Produção da Metalurgia e Electromecânica: Moçambique, Vol. II. Lisboa: Associação Nacional das Empresas Metalúrgicas e Metalomecânicas.

Banco de Moçambique (2007). 'Custos de Intermediação Financeira Versus Rentabilidade das Instituições Financeiras'. Relatório ao XXXII. Conselho Consultivo do Banco de Moçambique.

Biggs, T., Naisr, J., and Fisman, R. (1999). 'Structure and Performance of Manufacturing in Mozambique'. RPED Paper No. 107. Washington, DC: World Bank.

Brum, J. M. (1976). Manufacturing Industries in Mozambique: Some Aspects. Maputo: Eduardo Mondlane University, School of Economics.

Byiers, B. and Rand, J. (2006). 'Enterprise Development in Mozambique: Results Based on Manufacturing Surveys Conducted in 2002 and 2006'. Discussion Papers No. 33 E, Oct. Maputo: Ministry of Planning and Development.

Campbell White, O. and Bhatia, A. (1998). Privatization in Africa. Washington, DC: World Bank.

Castel-Branco, C. N. (2002). Investigation into the Political Economy of Industrial Policy: The Case of Mozambique, PhD thesis, School of Oriental and African Studies, University of London.

Castel-Branco, C. N. (2003). 'Indústria e Industrialização em Moçambique: Análise da Situação Actual e Linhas Estratégicas de Desenvolvimento', available at <http:// www.iese.ac.mz/lib/cncb/AI\%202003c\%20QUADER_.PDF>, accessed 10 February 2016.

Castel-Branco, C. N. (2008). 'Alguns pontos que gostaria de ver abordados no discurso do Presidente sobre o estado da Nação', Comentários e Opiniões. Maputo: IESE, available at <http://www.iese.ac.mz/lib/publication/outras/Pontos_para_a_entrevista_ sobre_estado_da_nacao.pdf $>$, accessed 10 February 2014.

Castel-Branco, C. N. (2010). 'Economia extractiva e desafios de industrialização em Moçambique', in Economia extractiva e desafios de industrialização em Moçambique. Maputo: IESE, 19-128.

Castel-Branco, C. N., Cramer, C., and Hailu, D. (2001). 'Privatization and Economic Strategy in Mozambique'. WIDER Discussion Paper 64. Helsinki: UNU-WIDER.

Centro de Integridade Publica (CIP) (2013). 'Pande Temane Gas exports to South Africa: First major extractive sector projects fails Mozambique', Centro de Integridade Publica, available at <http://www.cip.org.mz/cipdoc/274_Pande\%20Temana\%20Gas\% 20exports\%20to\%20South\%20Africa\%20by\%20Sasol.pdf>, accessed 10 February 2016.

Cruz, A. (1994). 'Transformações da Indústria em Moçambique'. Tese de Licenciatura. Maputo: Universidade Eduardo Mondlane (UEM) - Faculdade de Economia (FE) (UEM-FE).

Cruz, A., Newman, C., Rand, J., and Tarp, F. (2014a). 'Learning by Exporting: The Case of Mozambique'. WIDER Working paper 66/2014. Helsinki: UNU-WIDER.

Cruz, A. S., Guambe, D., Marrengula, C. P., and Ubisse, A. F. (2014b). 'Mozambique's Industrialization'. WIDER Working Paper 2014/059. Helsinki: UNU-WIDER. 
Direcção Nacional de Estatística, Comissão Nacional do Plano (DNE-CNP) (1985). 'Informação Estatística 1975-1984'. Maputo: Direcção Nacional de Estatística, Comissão Nacional do Plano.

Foreign Investment Advisory Service (FIAS) (2008). 'Special Economic Zones: Performance, Lessons Learned, and Implications for Zone Development'. Washington, DC: World Bank, available at <https://www.wbginvestmentclimate.org/toolkits/investmentgeneration-toolkit/upload/SEZ-Report-April-2008.pdf>, and at <http://www-wds.wor ldbank.org/external/default/WDSContentServer/WDSP/IB/2008/10/07/000334955_ 20081007064814/Rendered/PDF/458690WP0Box331s0April200801PUBLIC1.pdf>, accessed 10 February 2016.

Frelimo (1977). Directivas Económicas e Sociais. Maputo: Colecção III Congresso.

Frelimo (1983). Directivas Económicas e Sociais. Maputo: Colecção IV Congresso.

Instituto Nacional de Estatística (INE) (various years a). 'Anuário Estatístico 1992' (1993-2011), Maputo: INE, Publicado em 1993-2012.

Instituto Nacional de Estatística (INE) (various years b). 'Inquérito Anual às Empresas, Principais Resultados', Maputo: INE, Publicado em 2009-2011.

Instituto Nacional de Estatística (INE) (2012). 'Serie de Contas Nacionais 1991-2011', Instituto Nacional de Estatística, available at www.ine.gov.mz, accessed 28 December 2015.

International Monetary Fund (IMF) (2010). 'Republic of Mozambique: Financial Sector Assessment Program - Financial System Stability Assessment'. IMF Country Report no. 10/12. Washington, DC: IMF.

Jones, E. S. and Tarp, F. (2012). 'Jobs and Welfare in Mozambique - Country Case Study for the 2013 World Development Report', available at <http://siteresources.worldbank. org/EXTNWDR2013/Resources/8258024-1320950747192/8260293-1320956 712276/ 8261091-1348683883703/WDR2013_bp_Jobs_and_Welfare_in_Mozambique.pdf>, accessed 10 February 2016.

Leite, J.H.M.F.P.P. (1989). Pacte colonial et industrialization: Du colonialism Portugais aux réseaux informell de sujétion marchande-1930/1974, PhD thesis, Paris, École des Hautes Études en Sciences Sociales.

Marrengula, C., Nhabinde, V., and Ubisse, A. (2012). 'The Challenges and the Way Forward for the Construction Industry in Mozambique'. Report to the International Growth Centre in Mozambique. London and Oxford: London School of Economics and Oxford University Press.

Ministério da Indústria e Comércio (MIC) (1997). 'Politica e Estratégia Industrial 1997'. Resolução no. 23 do Conselho de Ministros. Maputo: Ministério da Indústria e Comércio.

Ministério da Indústria e Comércio (MIC) (2007). 'Politica e Estratégia Industrial 2007'. Maputo: Ministério da Indústria e Comércio.

Ministerio do Trabalho (MITRAB) (2006). 'Estratégia de Emprego e Formação Profissional 2006-2015'. Maputo: Ministerio do Trabalho, Instituto Nacional de Emprego e Formação Profissional.

Ministério da Planificação e Desenvolvimento (MPD) (2010). 'Pobreza e Bem-estar em Moçambique: Terceira Avaliação Nacional'. Maputo: Direcção Nacional de Estudos e Analise de Politicas e Universidade de Copenhaga. 
Ministério da Planificação e Desenvolvimento (MPD) (2013). 'Inquérito às Indústrias Manufactureiras, 2012: Relatório Descritivo'. Maputo: DNEAP-MPD and Copenhaga: KU.

Navalha, F. (2009). 'Desafios de Financiamento às PME`s em Ambiente de Crise Financeira'. Maputo: Banco de Moçambique.

Newman, C., Page, J., Rand, J., Shimeles, A., Söderbom, M., and Tarp, F. (2014). 'Identifying Direct FDI Linkages through Triangulation'. UNU WIDER working paper 2015/001. Helsinki: UNU-WIDER.

Portugal (1961). 'Integração Económica Nacional'. Decreto-Lei no. 44016, 8 Nov., aprovado pela Presidência do Conselho.

Ramachandran, Vijaya and Shah, Manju K. (1999). 'Minority Entrepreneurs and Firm Performance in sub-Saharan Africa'. Journal of Development Studies 36(2): 71-87.

Schou, S. and Cardoso, J. (2014). 'How Many Manufacturing Firms are there in Mozambique?' UNU-WIDER Working Paper 2014/84. Helsinki: UNU-WIDER.

TradeMark Southern Africa (SourceWatch (2013a). 'Mozambique and Coal', Website accessed on 6 Feb. 2014: <http://www.sourcewatch.org/index.php/Mozambique and_coal>, 25 May.

SourceWatch (2013b). 'Benga Coal Mine', Website accessed on 6 Feb. 2014: <http:// www.sourcewatch.org/index.php/Benga_coal_mine28\%20June>, 16:37 h.

SourceWatch (2013c). 'Rio Tinto Coal Mozambique', Website accessed on 6 Feb. 2014: <http://www.sourcewatch.org/index.php/Rio_Tinto_Coal_Mozambique>, 28 June, 22:30 h.

Sulemane, J. (2002). 'Dados Básicos da Economia Moçambicana', in 'A Economia Moçambicana Contemporanea: Ensaios', Maputo: Gabinete de Estudos, Ministério do Plano e Finanças, pp. 45-70.

van Eeden, J. (2009). 'The Cost of Doing Business in Mozambique Relative to other SADC Countries'. Econex Research Note 10. Stellenbosch: Econex.

Wield, D. (1977). 'Some Characteristics of the Mozambican Economy, Particularly Relating to Industrialization'. Working paper. Maputo: Centro de Estudos Africanos, UEM.

World Bank (2014). 'Doing Business 2015: Mozambique'. Washington, DC: World Bank.

Wuyts, M. (1980). 'Economia Política do Colonialismo', Estudos Moçambicanos 1: Maputo: Centro de Estudos Africanos (CEA), Universidade Eduardo Mondlane (UEM), 99-122.

Wuyts, M. (1983). ‘A Organização das Finanças e o Desenvolvimento Económico em Moçambique: Do Sistema Capitalista Colonial ao Desenvolvimento Socialista'. Texto de Apoio no. 15. Maputo: Centro de Estudos Africanos, UEM. 


\section{6}

\section{Industrial Policy in Nigeria}

\section{Opportunities and Challenges in a Resource-rich Country}

Louis N. Chete, John O. Adeoti, Foluso M. Adeyinka, and Femi Oladapo Ogundele

\subsection{Introduction}

Nigeria is the largest economy in Africa; in 2013 its population was in excess of 170 million, with GDP of over US\$500 billion (World Bank 2014). The continent's biggest oil exporter is also home to large natural gas reserves. The economy has recorded considerable acceleration in growth; real GDP grew by 6.3 per cent, 7.6 per cent, and 7.4 per cent in 2009, 2010, and 2011 respectively. Despite this, poverty is persistently high, and the structure of the economy is that of a typically underdeveloped country.

Over half of GDP is accounted for by primary sectors, with agriculture continuing to play an important role. The oil and gas sector is the major driver of the economy, which in 2011 made up over 95 per cent of export earnings and about 85 per cent of government revenue. The sector contributed 14.8 per cent to GDP in 2011-in contrast, the industrial sector accounts for a tiny proportion of economic activity (6 per cent) while the manufacturing sector contributes only 4 per cent to GDP.

The political landscape since Nigeria gained independence from Britain in 1960 has, like that of much of the rest of Africa, been turbulent. This, coupled with the significant emphasis on the oil economy, has contributed to the meagre performance of the manufacturing sector over the last fifty years. Following independence, the first military regime took power in 1966, leading to a civil war which lasted until 1970 . The post-war economy was dominated by the oil sector, with industrial policy focused on import substitution (IS). 
The economy grew by 6.2 per cent annually between 1970 and 1978 . The year 1979 marked the beginning of the second attempt at democratic governance. However, following the oil crisis and global recession, the Nigerian economy entered into a period of negative growth in the first half of the 1980s. The year 1986 saw the introduction of the World Bank (WB)-International Monetary Fund (IMF) economic structural adjustment programme (SAP) and the economy began to recover, experiencing real GDP growth of 4 per cent annually during 1988-97. In 1999, democratic rule returned and has remained in place since. Recovery was slow, particularly for the manufacturing sector, whose contribution to GDP declined from 4.9 per cent in 1999 to only 4 per cent in 2005 (Adeoti 2010).

In this chapter we explore the evolution of the industrial sector in Nigeria over the last fifty years. Section 6.2 provides an overview of the policy framework for industrial development from the 1960s to the present day. Section 6.3 describes the structure of the manufacturing sector. Special attention is also placed on economic zones, given their emphasis in current industrial policy in Nigeria. In Section 6.4, the current industrial policy framework is described in detail. Focus is placed on macroeconomic policy, trade policy, and the institutional and regulatory framework. Section 6.5 concludes with a discussion of emerging industrial policy issues.

\subsection{Evolution of Industry: Historical Perspective}

At independence in 1960, and for much of that decade, agriculture was the mainstay of the Nigerian economy. The sector provided food and employment for the populace, raw materials for the nascent industrial sector, and generated the bulk of government revenue and foreign exchange earnings. Following the discovery of oil and its exploration and exportation in commercial quantities, the fortunes of agriculture gradually diminished.

Table 6.1 highlights the extreme dominance of the primary sector in GDP in Nigeria and the small contribution from the manufacturing sector. At independence, the contribution from the primary sector to GDP was about 70 per cent. The transition from primary production to secondary and tertiary activities was sluggish; in 2009 more than half of Nigeria's output was still generated by the primary sector. The secondary sector contributes the least to GDP in Nigeria.

The macroeconomic performance of the economy is divided into five distinct periods, characterized by significant shifts in economic policy management (Adeoti et al., 2010). These periods are:

1. immediate post-independence period starting from independence in 1960 to the advent of the first military regime in 1966; 
Table 6.1 Percentage distribution of real GDP by sectoral group, 1961-2009

\begin{tabular}{lrrrrrrr}
\hline Sectoral group & 1961 & 1970 & 1981 & 1990 & 2003 & 2007 & 2009 \\
\hline Primary sector & 70.54 & 66.99 & 58.40 & 55.68 & 68.36 & 61.92 & 58.44 \\
Agriculture & 68.88 & 49.45 & 28.37 & 22.99 & 34.62 & 42.02 & 41.69 \\
Mining and quarrying & 1.66 & 17.54 & 30.03 & 32.69 & 33.74 & 19.90 & 16.75 \\
Secondary sector & 9.67 & 16.15 & 12.14 & 9.04 & 10.51 & 9.24 & 9.05 \\
Manufacturing & 4.73 & 7.66 & 5.60 & 5.12 & 4.32 & 4.03 & 3.72 \\
Building and construction & 3.30 & 7.77 & 2.83 & 1.78 & 2.70 & 1.72 & 2.01 \\
Utilities & 1.63 & 0.60 & 3.71 & 2.14 & 3.49 & 3.49 & 3.32 \\
Tertiary sector & 19.79 & 16.86 & 29.46 & 35.28 & 21.13 & 28.84 & 32.51 \\
Wholesale and retail & 19.36 & 13.56 & 14.17 & 8.68 & 12.92 & 16.16 & 18.14 \\
Other services activities & 0.43 & 3.29 & 15.29 & 26.60 & 8.21 & 12.68 & 14.37 \\
Total (GDP) & 100.00 & 100.00 & 100.00 & 100.00 & 100.00 & 100.00 & 100.00 \\
\hline
\end{tabular}

Source: National Bureau of Statistics (NBS various years); authors' calculations.

2. post-civil war oil economy starting from the end of the 30-month civil war in 1970 to the handover of government by the military to civilians in 1979;

3. transition to an austere economy that emerged in the second republic and the subsequent adoption of the WB-IMF-led economic structural adjustment programme (SAP) in 1986;

4. era of SAP and guided economic liberalization starting from 1986 to the advent of the new democratic dispensation in 1999;

5. regime of further economic liberalization starting from 1999 and resulting in emergent macroeconomic stability in recent years.

\subsubsection{Post-independence}

Nigeria's first attempt at comprehensive and integrated planning took the form of the First National Development Plan (1962-8). The plan included an aggregate growth rate target of 4 per cent per annum, an increase in the rate of investment from 11 per cent to 15 per cent of GDP and an increase in the 'directly productive component' of government investment (Bevan et al. 1999: 30). To encourage industrial development and lessen dependence on foreign trade, import substitution industrialization (ISI) was introduced conserving foreign exchange by producing local products that were previously imported. Import duty relief, accelerated depreciation allowances, and easy remission of profits aimed to attract foreign investors. The period of this plan witnessed the commissioning of energy projects such as the Kanji Dam and the Ughelli Thermal Plants, which provided a vital infrastructural backbone for the emerging industrial sector. Other important industrial infrastructure included an oil refinery, a development bank, and a mint and security 
company. Clearly, the main objective of the ISI strategy was to stimulate the start-up and growth of industries, as well as enhance indigenous participation. However, it led to high technological dependence on foreign know-how, to the extent that the domestic factor endowments of the country were grossly neglected.

\subsubsection{Post-civil War Oil Economy}

Military intervention in Nigeria's governance in 1966 resulted in a 30-month civil war from July 1967 to January 1970. The post-war economy was dominated by the oil sector, arising from the unprecedented increase in the price of crude oil in the international market. Oil exports as a percentage of total exports rose from 58 per cent in 1970 to 83 per cent in 1973. The oil boom enabled public sector expansion in infrastructure and manufacturing, most of which was aimed at achieving IS of foreign consumer goods and consumer durables. These measures were encompassed in the Second National Development Plan (1970-4). The government embraced ambitious and costly industrial projects in sectors such as iron and steel, cement, salt, and paper (Oyelaran-Oyeyinka, 1997).

The period of the 1970-4 plan also witnessed a dramatic shift in policy from private to public sector-led industrialization. It was clear that there was a dearth of human capital and skills required for initiating, implementing, and managing industrial projects among Nigerian entrepreneurs. Foreign technical skills and services were heavily relied upon. The oil economy was characterized by 'Dutch Disease', signified by the diversion of productive resources away from agriculture into commercial activities that thrived on trade in imported manufacturing goods (Forrest 1993). The windfall in oil revenue affected the fiscal policy of government. Political pressures meant that the tax base remained narrow under the belief that oil revenue would always lead to surplus. Non-oil taxes were thus neglected and some taxes abolished.

The Third National Development Plan (1975-80) was launched at the height of the oil boom-emphasis remained on public sector investment in industry. Indigenization policy was implemented in 1973 and 1978, with the objectives of increasing the level of local managerial control, building local technological capability, and extending state ownership. Heavy subsidies were provided for public companies and corporations. The Nigerian Enterprises Promotion Act of 1977 aimed to further support Nigerian businesses.

It became apparent that the country had entered into industrial project agreements with very little concern for capabilities for technology acquisition. While each of these projects required the acquisition of key sector-specific skills, the agreements made by Nigerian planners were for the turnkey transplantation of technology. During the same period, the nation's oil sector had 
become vibrant and prosperous, and the gates of the economy had been opened up to all sorts of imports. This had a debilitating effect on real industrial growth. The period of the Third National Development Plan failed to advance the course of industrial development in Nigeria in a positive way.

\subsubsection{Austerity}

The Fourth National Development Plan (1981-5) coincided with a global economic recession which sparked declining foreign exchange earnings, balance of payment disequilibrium, unemployment, and accelerating inflation in the Nigerian economy. This prompted emergency stabilization measures in 1982. These measures included advance deposits for imports; increases in import duties; review of import licences; a 40 per cent across the board cut in public expenditure without any prioritization; and an upward review of excise duties, interest rates, and prices of petroleum products. In the agricultural sector, exports became highly constrained by the overvalued naira and production declined. This included the production of labour-intensive export crops (e.g. cocoa, palm oil, cotton). The decline in output was most apparent in the manufacturing sector, resulting in gross losses in employment. This demonstrated the vulnerability of the high cost, import-dependent industrialization that had been encouraged by the pattern of incentives in the 1970s. A decline in the aggregate index of manufacturing was observed from 1982, falling by 26 per cent in 1983 (Forrest 1993). Plant closures were common in consumer goods sectors, especially in textiles. Average capacity utilization in industry declined from 73.3 per cent in 1981 to 38.2 per cent in 1986 (Fashoyin et al. 1994). The stabilization measures achieved some reduction in the volume of imports, however, the inability to effectively control the allocation of import licences and foreign exchange aggravated the pace of decline. The experience in the first half of the 1980s exposed profound weaknesses in Nigeria's industrial structure and planning.

\subsubsection{Structural Adjustment}

The introduction of the WB-IMF-packaged economic SAP in July 1986 was aimed at addressing the inherent weaknesses of the economy. The SAP generated an intense debate between proponents of a liberalized economy and advocates of state-led development. The SAP was a medium-term programme, with the twin objectives of revamping an economy under persistent recession and setting it on the path of sustainable growth. It consisted of the stabilization policies of the IMF (to reduce budget and balance of payment deficits and reduce inflation) and the structural adjustment policies of the $\mathrm{WB}$. The salient features included: 
- currency devaluations;

- real cuts and reorientation towards agriculture in the government budget;

- reorientation of public expenditures in the productive sectors towards rehabilitation and maintenance;

- increased taxes on consumer goods;

- holding nominal wages fixed and/or raising them by significantly less than required to make up the effects of inflation;

- liberalization of the import regime;

- substantially raising nominal producer prices for agricultural cash crops to limit real declines;

- reduced price controls;

- increased competition and flexibility in agricultural marketing;

- privatization of government-owned assets and concentrated efforts to raise efficiency in remaining government institutions.

All of these policy instruments were applied between 1986 and 1993. The implementation had controversial economic and social consequences. While the conditions imposed by the IMF caused a sharp deterioration in living standards, the developmental impacts of the SAP were slow. With the introduction of the Second-tier Foreign Exchange Market in September 1986, devaluation of the naira was put on course, and demand management became an important feature of monetary and fiscal policy. In order to avoid a mutually reinforcing currency depreciation and inflation, the SAP reduced liquidity in the economy and compressed consumer incomes, through a wage freeze and significant cuts in public expenditure.

The impact of SAP on the productive sectors of the economy was mixed. Industry had to cope with the new regime as well as a slump in effective demand. Tariffs were cut on finished goods more than on intermediate inputs and raw materials, thereby reducing rates of protection and increasing competition with foreign producers. Industries with less dependence on imports (e.g. textiles) were less adversely affected. There were new investments in industries that relied on local raw materials such as the tanning of hides and skins and soya milk processing. Ogun (1995) reported that an increase in the cost of imports and pressure by government had resulted in the rise of local raw material sourcing by industry from 38 per cent in 1985 to 50 per cent in 1988. The impact of the SAP on the export of agricultural produce was also remarkable. Cocoa exports rose significantly as producer prices soared. The tanning industry in Kano received new export-oriented investment, and the export of rubber also increased.

A national science and technology (S\&T) policy was formulated and launched in 1986 with the aim of placing S\&T at the centre of national development. Measures included the establishment in 1986 of the Raw 
Materials Research and Development Council (RMRDC) and the Standards Organisation of Nigeria (SON). The S\&T policy emphasized the transfer of foreign technology to local firms. There is little evidence, however, that this was successful. Bamiro (1994) and Oyelaran-Oyeyinka (1997) suggested that the main reason was that S\&T institutions operated independently of each other, with little or no interaction; they also criticized the isolation of the manufacturing sector from $R \& D$ activities and the resultant non-commercialization of ideas. In essence, innovation was absent in this era of industrial development.

In 1989, the trade and financial liberalization policy was enacted to stimulate competition among domestic firms and between domestic import-competing firms and foreign firms. The policy involved a reduction in both tariff and non-tariff barriers, scrapping the commodity marketing boards and market determination of the exchange rate, as well as the deregulation of interest rates. The National Economic Reconstruction Fund (NERFUND) was set up in the same year, with the objectives of reversing some of the provisions of the Nigerian Indigenization Policy and opening up the economy for foreign investors. NERFUND sought to address the financial constraints experienced by small and medium-scale entrepreneurs, provide the required resources to merchant and commercial banks to lend to small and medium-scale firms, and provide naira or foreign-denominated loans to firms.

The decade of the 1990s was mostly a period of economic and political crisis in Nigeria, largely on account of authoritarian military rule. The pains of the SAP deepened, and with no evidence of a reversal of the economic recession, in the mid-1990s the government adopted a policy of guided deregulation. Under this programme, attempts were made to curtail the extent of liberalization under the SAP. A dual exchange rate emerged (one for government essential transactions, the other serving as the inter-market exchange rate). The privatization and commercialization of public sector companies which was intensely debated under the SAP proceeded with measured pace.

\subsubsection{Economic Liberalization}

The return to democratic governance in 1999 introduced a new opportunity for political and economic freedom. The Bank of Industry (BoI), established in 2000, was introduced to accelerate industrial development through the provision of long-term loans, equity finances, and technical assistance to industrial enterprises. As a complement to this, a Small and Medium Industries Equity Investment Scheme was also set up. The role of S\&T featured prominently in the economic reform agenda between 1999 and 2007, specifically within the rubric of the National Economic Empowerment and Development Strategy (NEEDS) (NPC 2004; 2007). Similarly, the current economic policy 
Table 6.2 Structure of industry by age of firms

\begin{tabular}{lrlllrrr}
\hline Sector & $\begin{array}{l}\text { \% of } \\
\text { firms }\end{array}$ & $\begin{array}{l}\text { Of which: } \\
\text { 0-5 yrs }\end{array}$ & $\begin{array}{l}6-10 \\
\text { yrs }\end{array}$ & $\begin{array}{l}11-20 \\
\text { yrs }\end{array}$ & $\begin{array}{l}\text { 20+ } \\
\text { yrs }\end{array}$ & $\begin{array}{l}\text { Foreign } \\
\text { owned }\end{array}$ & Exporting \\
\hline Textiles & 1.40 & 28.57 & 28.57 & 21.43 & 21.43 & 0.00 & 14.29 \\
Garments & 22.28 & 24.22 & 43.95 & 26.01 & 5.83 & 0.00 & 4.93 \\
Food & 30.17 & 27.15 & 43.71 & 20.20 & 8.94 & 0.99 & 0.66 \\
Wood and furniture & 13.59 & 22.79 & 32.35 & 33.82 & 11.03 & 0.00 & 1.47 \\
Other man. & 27.27 & 20.51 & 42.12 & 28.21 & 9.16 & 1.47 & 5.13 \\
Construction & 5.29 & 24.53 & 26.42 & 28.30 & 20.75 & 0.00 & 1.89 \\
All sectors* & 100.00 & 23.98 & 40.66 & 25.97 & 9.39 & 0.70 & 3.20 \\
\hline
\end{tabular}

${ }^{*} n=1,001$

Source: World Bank Investment Climate Survey (WB 2006).

blueprint—Nigeria Vision 2020 (NV20:2020) (NPC 2009)—embraces elements of science, technology, and innovation (STI).

The macroeconomic policy regime that had emerged by the late 2000s showed a keenness for economic liberalization and an ardent commitment to private enterprise-led development. Despite these efforts, the manufacturing sector in Nigeria remains small, accounting for only 3.7 per cent of GDP in 2009 (Table 6.1). In what follows, we describe in detail the characteristics of the sector.

\subsection{The Structure of Industry}

The analysis presented in this section utilizes data from the WB Investment Climate Survey (WB 2006) and Nigeria's National Bureau of Statistics (NBS various years). The WB survey covered manufacturing firms, microenterprises, retail, and residual businesses. The manufacturing survey addressed a wide range of issues pertinent to the industrial sector. Among the 2,387 firms surveyed, only 42 per cent fell within the industrial sector.

\subsubsection{Structural Composition and Firm Characteristics}

The distribution of firms across, age, ownership, and export status is presented in Table 6.2. The Nigerian manufacturing sector is dominated by firms in the food (30.17 per cent) and garment (22.28 per cent) sub-sectors-firms in the dominant sub-sectors over twenty years old have a relatively smaller percentage. Most of the firms are owned by domestic investors, but all sectors participate in some exporting activities. The highest proportion of exporting firms is in the textiles industry, representing 14.29 per cent of firms. 
Table 6.3 Average firm size

\begin{tabular}{lccccccc}
\hline Sector & All firms & 0-5 yrs & $6-10$ yrs & 11-20 yrs & 20+ yrs & Foreign owned & Exporting \\
\hline Textiles & 70 & 30 & 18 & 10 & 254 & & 35 \\
Garments & 15 & 14 & 13 & 20 & 12 & & 24 \\
Food & 31 & 23 & 29 & 30 & 64 & 54 & 69 \\
Wood and furniture & 22 & 17 & 21 & 22 & 33 & & 47 \\
Other man. & 34 & 23 & 27 & 28 & 114 & 84 & 74 \\
Construction & 29 & 19 & 39 & 28 & 29 & & 13 \\
All sectors* & 27 & 20 & 24 & 25 & 67 & 70 & 50 \\
\hline
\end{tabular}

${ }^{*} n=1,001$

Source: World Bank Investment Climate Survey (WB 2006).

Table 6.4 Wages per employee

\begin{tabular}{lrrrrrrr}
\hline Sector & All firms & 0-5 yrs & $6-10$ yrs & $11-20$ yrs & 20+ yrs & Foreign owned & Exporting \\
\hline Textiles & $1,691.97$ & $1,881.54$ & $1,319.69$ & $2,278.50$ & $1,349.04$ & - & $1,693.92$ \\
Garments & 934.76 & 972.16 & 885.97 & 960.50 & $1,032.41$ & - & $1,105.17$ \\
Food & $1,199.82$ & $1,137.31$ & $1,182.59$ & $1,197.41$ & $1,479.28$ & $2,415.93$ & $1,039.20$ \\
Wood and furniture & $1,002.90$ & 863.56 & $1,091.45$ & $1,008.76$ & $1,013.16$ & - & $1,335.44$ \\
Other man. & $1,354.82$ & $1,098.84$ & $1,360.93$ & $1,307.25$ & $2,046.63$ & $2,606.72$ & $2,354.94$ \\
Construction & $2,420.01$ & $1,059.84$ & $2,217.87$ & $3,158.54$ & $3,277.67$ & - & $1,609.61$ \\
All sectors* & $1,227.78$ & 1,064 & $1,188.66$ & $1,269.33$ & $1,700.28$ & $2,524.96$ & $1,714.78$ \\
\hline
\end{tabular}

${ }^{*} n=1,001$; Wages are total annual salary costs of the firm divided by the total number of employees (full-time + part-time). Source: World Bank Investment Climate Survey (WB 2006).

The proportion of sales accounted for by exporting firms is also high-10.81 per cent for the garments sector and 27.84 per cent for other manufacturing.

The average size of firms is reported in Table 6.3 (measured as the total number of employees engaged by the firm). Firms in the textile industry engage the highest number of employees on average at 79 . The smallest firms are in the garment sector, with only 15 employees on average. Table 6.3 also reveals a positive relationship between firm size and survival, as is consistent with manufacturing in other countries.

Wages per employee (Table 6.4) are highest in the construction sector, followed by textiles. Average wages per employee show a rising trend with years of operation for firms in the construction and food sectors, but this pattern is not as clear-cut for other sectors. Significantly, foreign owned firms pay high wages per employee compared to exporting firms.

\subsubsection{Technology and Skills}

In relation to the technology underlying firms' production processes, capacity utilization averages 67.5 per cent while only 22.38 per cent of firms have email facilities and only 7.58 per cent have websites (Table 6.5). The ratio of 
Table 6.5 Technology

\begin{tabular}{lcrr}
\hline Sector & Capacity utilization & Email & Website \\
\hline Textiles & 67.29 & 21.43 & 14.29 \\
Garments & 66.75 & 14.00 & 1.79 \\
Food & 68.99 & 24.50 & 8.29 \\
Wood and furn. & 66.14 & 15.44 & 5.15 \\
Other man. & 67.18 & 29.67 & 12.09 \\
Construction & & 26.42 & 9.43 \\
All sectors & 67.50 & 22.38 & 7.59 \\
$\mathrm{~N}$ & 947 & 1,001 & 1,001 \\
\hline
\end{tabular}

Source: World Bank Investment Climate Survey (WB 2006).

Table 6.6 Skills

\begin{tabular}{lcc}
\hline Sector & $\begin{array}{l}\text { Ratio of temporary } \\
\text { to full-time staff }\end{array}$ & $\begin{array}{l}\text { Number of years of } \\
\text { experience of top manager }\end{array}$ \\
\hline Textiles & 0.08 & 12.43 \\
Garments & 0.25 & 11.05 \\
Food & 0.14 & 10.06 \\
Wood and furniture & 0.28 & 12.53 \\
Other man. & 0.20 & 11.59 \\
Construction & 0.25 & 12.26 \\
All sectors & 0.20 & 11.18 \\
$\mathrm{~N}$ & 1,001 & 1,001 \\
\hline
\end{tabular}

Source: World Bank Investment Climate Survey (WB 2006).

temporary to full-time staff averages 0.20 per cent while the number of years of experience of managers averages 11.18 per cent (Table 6.6).

\subsubsection{Constraints}

Table 6.7 describes the constraints to growth as reported by the firms in the sample. Electricity outages, transport bottlenecks, crime, and corruption are all key factors. Nigerian manufacturers suffer acute shortages of infrastructure such as good roads, piped water, and, in particular, power supply. Electricity outages and voltage fluctuations are commonplace, causing damage to machinery and equipment. Consequently, most firms rely on self-supply of electricity by using generators, escalating costs of production and eroding competitiveness relative to foreign firms.

Only 3.7 per cent of firms surveyed have access to formal credit and a phenomenal 38.9 per cent pay bribes. ${ }^{1}$ Corruption, rent-seeking, and patron-client

\footnotetext{
${ }^{1}$ See Chete et al. 2014: Table 9.
} 
Table 6.7 Constraints to firm growth

\begin{tabular}{lccccc}
\hline Sector & Telecomm. & Transport & Electricity & Crime & Corruption \\
\hline Textiles & 0.57 & 1.43 & 3.36 & 1.57 & 1.64 \\
Garments & 0.60 & 1.60 & 3.45 & 1.40 & 1.49 \\
Food & 0.63 & 1.97 & 3.17 & 1.47 & 1.42 \\
Wood and furniture & 0.62 & 2.10 & 3.15 & 1.29 & 1.46 \\
Other man. & 0.58 & 2.02 & 3 & 1.45 & 1.35 \\
Construction & 0.94 & 1.94 & 1.72 & 2.53 & 2.13 \\
All sectors & 0.62 & 1.91 & 3.11 & 1.50 & 1.46 \\
$\mathrm{~N}$ & 1,001 & 1,001 & 1,001 & 1,001 & 1,001 \\
\hline
\end{tabular}

Source: World Bank Investment Climate Survey (WB 2006).

Table 6.8 Labour productivity

\begin{tabular}{lrrrrrrrr}
\hline Sector & All firms & $0-5$ yrs & $6-10$ yrs & $11-20$ yrs & $20+$ yrs & Foreign owned Exporting \\
\hline Textiles & $6,875.42$ & $5,300.88$ & $5,804.72$ & $12,133.06$ & $5,144.80$ & - & $7,750.00$ \\
Garments & $4,057.15$ & $4,332.93$ & $3,770.24$ & $4,203.23$ & $4,422.74$ & - & $7,776.41$ \\
Food & $8,195.12$ & $9,064.70$ & $7,790.77$ & $7,369.25$ & $9,443.14$ & $9,319.74$ & $4,148.01$ \\
Wood and & $5,509.95$ & $3,516.15$ & $4,687.69$ & $7,121.76$ & $7,213.07$ & - & $14,358.5$ \\
$\quad$ furniture & & & & & & & & \\
Other man. & $8,547.93$ & $6,544.65$ & $8,251.15$ & $9,664.62$ & $11,290.19$ & $22,063.1$ & $17,745.99$ \\
Construction & $15,058.42$ & $9,969.51$ & $19,219.17$ & $10,636.61$ & $21,806.84$ & - & $30,046.15$ \\
All sectors* & $7,347.00$ & $6,681.63$ & $6,996.89$ & $7,542.45$ & $10,198.81$ & $17,815.31$ & $12,701.72$ \\
\hline
\end{tabular}

${ }^{*} n=996$

Source: World Bank Investment Climate Survey (WB 2006).

relationships impinge on the cost of doing business and contribute to a poor investment climate in Nigeria. Many firms are forced to offer gratifications to public officials for sundry purposes such as accessing public utilities, clearing goods at the ports, and obtaining licences and permits. Credit delivery from the financial system circumscribes smaller and medium-sized firms. To bridge the gap, the government provides subsidized credit to favoured sectors and firms. Implementation of these initiatives is typically faulty, with funds failing to get to the intended beneficiaries.

\subsubsection{Productivity}

Several recent policy measures in Nigeria have placed emphasis on productivity enhancement. Using the World Bank Investment Climate Data (WB 2006), a labour productivity measure can be constructed by dividing the total annual sales of firms by the total number of employees (both full- and part-time). Labour productivity is presented in Table 6.8. The average across all sectors is N7,347 per worker (approximately US $\$ 45$ ). The highest labour productivity of *15,058 per worker was recorded in the construction industry. The lowest 
labour productivity, with an average of $\$ 4,057$ per worker, was recorded in the garment industry.

An average productivity of $\$ 10,198$ per worker is recorded among firms above twenty years of age and increases with the firm's age. The average among foreign owned firms is $\$ 17,815$ per worker-among exporting firms, it stands at $\$ 12,701$ per worker.

Capital productivity is measured using total assets divided by the number of employees, reported by Chete et al. (2014: Table 11) alongside value added by sector. The highest capital productivity was recorded in the food, beverages, and tobacco (FBT) sectors. The highest value added was recorded in the electrical and electronics sectors (over $400 \mathrm{~m}$ ), followed by machinery and equipment; the lowest was recorded in the garment sector.

\subsubsection{SPACIAL DISTRIBUTION}

A prominent feature of the industrial sector in Nigeria is the existence of a number of special economic zones. There are approximately twenty-five free trade zones (FTZ) licensed by the federal government. However, fewer than thirteen of these are currently operational. Some are under construction and in the early phases of development. Two types of free trade arrangement operate in Nigeria-specialized and general-purpose. These are managed by two bodies-the Oil \& Gas Free Zone Authority for the oil and gas zone and the Nigerian Export Processing Zone Authority (NEPZA) for the generalpurpose zones.

Economic activity is clustered in this way to create a controlled environment for industrialization to flourish, especially in the presence of poor infrastructure. The localization of firms allows for infrastructural provisions to be prioritized, and it gives firms a competitive edge while offering access to raw materials, skilled labour, technology, and materials. Nigeria has a number of large industrial estates and complexes, but has also witnessed the spontaneous development of small clusters across the country. The latter include the computer village in Otigba, Lagos; the auto and industrial spare parts fabricators in Nnewi; and the footwear, leatherworks, and garment cluster in Aba.

\subsubsection{Sunrise and Sunset Industries}

Information and communications technology (ICT) is an emerging sector in Nigeria. A key example is the Otigba Computer Village which started in 1995, involving over 392 small and medium enterprises (SMEs) and employing more than 3,000 workers (Oyelaran-Oyeyinka 1997). ${ }^{2}$ The formation of this

\footnotetext{
${ }^{2}$ Data presented in this section are from Oyelaran-Oyeyinka (2004).
} 
cluster has given Nigeria a foothold in skills-intensive computer repair and 'clone' production. The village is located in Lagos and covers an area of some $325 \mathrm{~km}^{2}$.

On the other side of the spectrum, the textile industry is an example of a sunset industry and illustrates the deindustrialization process that Nigeria has experienced in the last decade. Over 820 companies shut down or suspended production between 2000 and 2008 (MAN 2009). At its peak, the textile industry employed close to 700,000 people (making it the second largest employer after the government) and generated a turnover of over US\$8.95 billion. The industry witnessed a catastrophic collapse, from 175 firms in the mid-1980s to ten factories in stable condition in 2004, while employment in the industry plunged from 350,000 to 40,000 .

\subsection{Industrial Policy Framework}

\subsubsection{Policy Management and Coordination}

At the apex of Nigeria's economic policy-making architecture is the National Economic Council (NEC). The NEC has the vice-president of the country as chairman and the National Planning Commission as its secretariat. Membership of this body includes the Governors of Nigeria's thirty-six states, the Governor of the Central Bank of Nigeria (CBN), the Minister of National Planning and the Minister of Finance, Attorney General of the Federation, and Minister of Justice and Chief Economic Adviser to the President. The three tiers of government-federal, state, local-implement, monitor, and evaluate policies approved by the body through their respective executive councils which meet on a monthly basis.

There is also a twenty-four-member National Economic Management Team headed by the president, and a fifteen-member Economic Implementation Team headed by the finance minister. The mandate of these teams includes achieving macroeconomic stability and developing critical sectors such as infrastructure, agriculture, manufacturing, education, health, and housing. The Federal Ministry of Industry, Trade and Investment has the operational mandate of promoting increased production and export of non-oil and gas products, fostering industrialization, attracting investment, and developing enterprise.

There are other agencies which play important roles in the trade and industrial sectors in Nigeria. For instance, the BoI, Small \& Medium Enterprises Development Agency of Nigeria (SMEDAN), NEPZA, Nigeria Export Promotion Council, and Nigerian Investment Promotion Commission (NIPC) are parastatals of the Federal Ministry of Industry, Trade and Investment. The RMRDC is an agency of the Federal Ministry of Science and Technology and the 
Nigerian Customs Service is a parastatal of the Federal Ministry of Finance. The setting-up of these teams and the designation of the finance minister as coordinator of economic policy have improved the implementation of economic policy in the country. It is typical for private sector groups such as the National Association of Small-Scale Industrialists to be invited to talks on draft policy.

\subsubsection{Macroeconomic Policies}

In the 2000s the main policies for economic development in Nigeria were encompassed in the NEEDS (NPC 2004). The key objectives were to:

- sustain a rapid, broad-based GDP growth rate;

- diversify the production structure away from oil and mineral resources;

- make the productive sector internationally competitive;

- reduce the role of government in the direct production of goods and strengthen its regulatory functions;

- adopt policies that are consistent with raising domestic savings and increasing private investments;

- promote exports and diversify exports away from oil;

- liberalize imports, harmonize tariffs with Economic Community of West African States (ECOWAS)' common external tariffs, and use import levies and prohibitions to protect local industries;

- maintain a competitive but stable exchange rate regime by establishing a market-determined nominal exchange rate and avoiding overvaluation of the real exchange rate;

- maintain low real lending interest rates.

These policy measures have led to a relatively stable exchange rate, a fairly predictable macroeconomic environment, and good prospects for growth. A review of the performance of NEEDS showed that the GDP growth rate, which was 3.3 per cent in 1999, was an average of 6.0 per cent during 2004-7, with oil and non-oil sectors having GDP growth rates of 0 per cent and 8.3 per cent respectively. The external reserve rose from US $\$ 4$ billion in 1999 to US $\$ 43$ billion in 2007. There was an average inflation rate of 9.5 per cent. Furthermore, noticeable achievements were recorded in the liberalization of the telecommunication industry, which became one of the fastest growing in the world. The privatization of publicly owned enterprises also progressed, with about 110 privatization transactions effected between 2000 and 2006 (NPC 2007).

Efforts under NEEDS have been complemented by the Seven Point Agenda (SPA) introduced in 2007. The SPA involves seven sectoral-specific targets to which the principles of NEEDS are applied. The aim is to make Nigeria one of the 
twenty largest economies by the year 2020 (NV20:2020). The SPA encompasses seven key areas of development (FGN 2008):

- critical infrastructure

- Niger delta region

- food security

- human capital

- land tenure changes and home ownership

- national security

- wealth creation.

The current and future vision for economic development in Nigeria is set out in NV20:2020. The macroeconomic policy thrusts of the NV20:2020 are as follows (NPC 2009: 22-3):

- achieving double-digit growth rates and maintaining strong economic fundamentals, including inflation, exchange rate, interest rates, and other monetary aggregates;

- achieving significant progress in economic diversification, such as to achieve an economic structure that is robust and consistent with the goals of the NV20:2020;

- stimulating the manufacturing sector and strengthening its linkage to the agricultural and oil and gas sectors, in order to realize its growth potential and serve effectively as a strong driver of growth;

- raising the relative competitiveness of the real sector, to increase the demand for Nigeria's non-oil products and services;

- deepening the financial sector and sustaining its stability to enable it to finance the real sector;

- encouraging massive investment in infrastructure and human capital and creating an enabling environment for domestic and private investment;

- adopting pragmatic fiscal management and implementing appropriate monetary, trade, and debt management policies to support domestic economic activities.

\subsubsection{Industrial Policy}

The NV20:2020 industrialization strategy aims at achieving greater global competitiveness in the production of manufactured goods by linking industrial activity with primary sector activity, domestic and foreign trade, and service activity. A key component is the promotion of a comprehensive policy of cluster development in the manufacturing and processing industries. This 
includes the development of industrial parks, industrial clusters and enterprise zones, and incubator facilities.

Industrial parks, aimed at large manufacturers, are expected to cover areas of more than $3,050 \mathrm{~km}^{2}$. The parks will be based on the comparative and competitive advantage of each geographical zone. The following business activities have been identified for each of the zones (Nigeria Vision 20:2020).

- North East: agriculture and solid minerals e.g. gypsum, biomass, ethanol, biodiesel, tropical fruits, etc.;

- North West: gum arabic, livestock and meat processing, tanneries, biofuel, etc.;

- North Central: fruit processing, cotton, quarries, furniture and minerals, boards, plastic processing, leather goods, garments, etc.;

- South East: palm oil-refining and palm tree-processing into biomass particle boards, plastic processing, leather goods, and garments;

- South West: manufacturing (especially garments, methanol, etc.), distributive trade, general goods, plastic, etc.;

- South Central: petrochemicals, manufacturing (plastic, fertilizer, and fabrications, etc.), oil services, and distributive trade (TINAPA).

The industrial clusters, which will be established with the participation and assistance of states and local governments, will cover areas of between 100 and $1,000 \mathrm{ha}$. They will be exclusively devoted to the organized private sector. The location of the clusters will take into account access to roads, railways, sea ports, cargo airports, and proximity to a city, and management will be through a private cluster company. Industrial incentives similar to those in industrial parks will also be provided, while each cluster will have a skill acquisition/training centre.

Enterprise zones are platforms of 5-30 ha, targeted at incorporating the informal sector into the organized private sector. Located in state capitals and local government areas, they will enable farmers and SMEs to feed their products into the value chain of large-scale industries. These centres will accommodate mechanics, block makers, small-scale furniture manufacturers, timber merchants, and other vocational workers who constitute over 70 per cent of Nigeria's private sector. Skills acquisition/training centres will also be located in each enterprise zone, while management will be handled by the private sector.

The incubators will be start-up centres for new and inexperienced entrepreneurs, graduates of tertiary institutions, investors, and vocational workers wishing to set up their own businesses. In these centres, prospective start-up companies will be equipped with entrepreneurial skills and resources aimed at nurturing them from formation to maturity. 


\subsubsection{Trade Policies}

Recent economic policy reforms (from NEEDS to date) have sought to reduce the unpredictability of the trade policy regime, establish a schedule to adopt the ECOWAS common external tariff (CET), and respect obligations under multilateral trading systems (Adenikinju 2005).

Nigeria has several incentives for export promotion, but still uses import prohibition to protect its manufacturing and agricultural sectors. The rationale is that the production base is relatively weak, import-dependent, and limited in technological capability. The import prohibition list includes a wide range of manufactured consumer goods that were often dumped in Nigeria's relatively large market. A few agricultural products (e.g. fresh fruits, pork, and frozen poultry) that are produced locally in large quantities are also included in the list to protect the local industry and encourage job creation. On the export prohibition list are staple foods/crops that are important for food security, commodities that could serve as raw materials to local industries, and living organisms that are becoming rare. Such commodities include maize, hides and skin, scrap metals, and wildlife animals classified as endangered species.

There are also elaborate export incentives including: the Manufacture-inBond Scheme, which allows exporting manufacturers to import intermediate products duty-free; the Duty Drawback Scheme, which provides refunds for duties/surcharges on raw materials; the Export Development Fund Scheme, which provides financial assistance to exporting companies to cover part of their initial expenses; and the Trade Liberalization Scheme of ECOWAS, which involves the removal of barriers to trade in goods originating from ECOWAS countries. In addition, the government has established the Oil and Gas Export Free Zone (1996) and Export Processing Zones (EPZs), which offer preferential tax treatment and other incentives for firms. Moreover, foreign investors are free to repatriate their profits and dividends net of taxes. The government, through the NIPC Act, has guaranteed that no enterprise shall be nationalized or expropriated.

\subsubsection{The Institutional and Regulatory Framework}

In recent years, the institutional framework for the implementation of macroeconomic and industrial policies has been strengthened or established where necessary. Some improvements include the following:

- The CBN has been reformed and is now relatively more autonomous and powerful. A major achievement of the $\mathrm{CBN}$ is the consolidation of the Nigerian banking institutions, which reduced the number of 
banks from eighty-nine to twenty-five by the end of 2005; the banks are arguably considerably stronger and able to provide better financial services.

- The Customs and Excise Department has improved infrastructure, especially in the area of ICT.

- The Bureau of Public Enterprises (BPE) has increased the pace of privatization of publicly owned enterprises.

- The National Communication Commission has successfully liberalized the telecommunications sector.

- The National Agency for Food, Drug Administration and Control has improved Nigeria's food and drug products.

- The SON has improved standardization of industrial products.

- The Nigerian Export Promotion Council has improved the implementation of export incentives.

Some of the new institutions which have contributed to policy implementation include:

- the BoI, formed through the merger of the former Nigerian Industrial Development Bank and the Nigerian Bank for Commerce and Industry;

- the Nigerian Agricultural, Cooperatives and Rural Development Bank formed through the merger of the former Nigerian Agricultural and Cooperative Bank and the Peoples Bank;

- SMEDAN;

- The National Information Technology Development Agency (NITDA);

- The Economic and Financial Crimes Commission (EFCC);

- The Independent Corrupt Practices and other related offences Commission.

\subsubsection{Sector Specific Policies}

With the exception of the oil and gas industry, sectoral policies are not prevalent in Nigerian industrial policy. However, the NIPC shows sectoral policies aimed at stimulating investment in areas considered to have potential.

For the manufacturing sector, companies with turnover of under $\$ 1$ million are taxed at a low rate of 20 per cent for the first five years of operationdividends are also tax-free for this period. Dividends derived from manufacturing companies in petrol, chemical, and liquefied natural gas sub-sectors are exempt from tax.

In the agro-industry, incentives include a 100 per cent tax-free period for five years in processing, favourable duties, and capital allowances, and an 
Agricultural Credit Guarantee Scheme Fund (ACGSF), where the CBN provides a partial guarantee for all loans granted by commercial banks.

An arguably disproportionate range of incentives also applies to the solid minerals sector (where firms enjoy a 3-5-year tax holiday) and the oil and gas industry. Firms are also subject to a low income tax rate of between 20 and 30 per cent, royalty payments are deferred, and holders of a mining lease are entitled to a range of capital allowances and tax reliefs. In the oil and gas industry significant incentives are granted to joint ventures with the Nigerian National Petroleum Corporation.

\subsection{Conclusion}

Despite the size and fast pace of economic growth in the Nigerian economy over the last decade, the manufacturing sector remains weak. Past policy efforts aimed at improving the performance of the sector have failed, and the focus has shifted towards more targeted policies aimed at specific sectors, as set out in NV20:2020. A key aim is economic diversification, with a focus on stimulating the manufacturing sector and strengthening its link with the agricultural and services sectors.

A number of challenges exist that will be critical to the success or failure of this strategy. Key among these are infrastructure, corruption, and national security. The current infrastructure base in Nigeria is grossly inadequate in terms of capacity and quality. Power generation capacity is less than 2,000 MW-about 20 per cent of estimated national demand. A key challenge for government and the private sector is to build a modern, efficient, and effective infrastructure network within the next five to ten years.

Nigeria ranks highly in the Corruption Perception Index. This has implications for investment and foreign direct investment (FDI) flows into the country. Previous anti-corruption policies implemented in Nigeria have been targeted at enforcement measures rather than addressing the root causes, which include social insecurity and over-centralization of resources.

The internal security of Nigeria has become a major challenge. Internal conflicts, including religious, ethnic, and economic, have had debilitating effects on the economy. The insecurity of lives and properties became noticeable following the civil war and the subsequent military regimes, and the recent upsurge of violence and insurgency in the country heightens the need to address the persistent causes of social tension.

Addressing these concerns will require private sector collaboration. Business coordination efforts in Nigeria have been largely successful, but future cooperation will require the development of efficient, accountable, transparent, and participatory governance. Strong public service institutions can engender 
government effectiveness, and success will depend on the establishment of a competitive business environment characterized by sustained microeconomic stability and the enhancement of national security and justice.

\section{References}

Adenikinju, A. F. (2005). 'African Imperatives in the New World Order: Country Case Study of the Manufacturing Sector in Nigeria', in O. E. Ogunkola and A. Bankole (eds) Nigeria's Imperatives in the New World Trade Order. Nairobi: African Economic Research Consortium and Ibadan: Trade Policy Research and Training Programme, 101-58.

Adeoti, J. O. (2010). 'Investment in Technology and Export Potential of Firms in Southwest Nigeria'. AERC Research Paper No.231. Nairobi: African Economic Research Consortium.

Adeoti, J. O., Odekunle, S. O., and Adeyinka, F. M. (2010). Tackling Innovation Deficit: An Analysis of University-Firm Interaction in Nigeria. Ibadan: Evergreen.

Bamiro, O. A. (1994). 'National Technology Policy for Development: The Role of Research and Development Institutions'. Paper Presented at the National Workshop on Technology Management, Policy and Planning, NISER, October, Ibadan, 18-21.

Bevan, D., Collier, P., and Gunning, J. W. (1999). The Political Economy of Poverty, Equity, and Growth: Nigeria and Indonesia. Washington, DC: World Bank and Oxford: Oxford University Press.

Chete, L. N., Adeoti, J. O., Adeyinka, F. M., and Ogundele, O. (2014). 'Industrial Development and Growth in Nigeria: Lessons and Challenges'. WIDER Working Paper 2014/019. Helsinki: UNU-WIDER.

Fashoyin, T., Matanmi, S., and Tawose, A. (1994). 'Reform Measures, Employment and Labour Market Processes in the Nigerian Economy: Empirical Findings', in T. Fashoyin (ed.) Economic Reform Policies and the Labour Market in Nigeria. Lagos: Friedrich Ebert Foundation, 5-13.

Federal Government of Nigeria (FGN) (2008). Yar' Adua's Seven Point Agenda. Abuja: Federal Ministry of Information and Communications.

Forrest, T. (1993). Politics and Economic Development in Nigeria. Oxford: Westview Press. Manufacturers Association of Nigeria (MAN) (2009). 'Sustaining Nigeria's Manufacturing Sector in the Face of the Current Global Economic Recession'. Speech by the President of the Association, Alhaji Bashir Borodo, at its 37th Annual General Meeting, March, Lagos, available at <http://www.vanguardngr.co./2009/07/820manufacturing-companies-close-down>, accessed 22 February 2016.

National Bureau of Statistics (NBS) (various years). Nigeria Gross Domestic Product Report. Abuja: Federal Republic of Nigeria.

National Planning Commission (NPC) (2004). Nigeria: National Economic Empowerment and Development Strategy. Abuja: National Planning Commission.

National Planning Commission (NPC) (2007). Nigeria: National Economic Empowerment Development Strategy (NEEDS2). Abuja: National Planning Commission. 
National Planning Commission (NPC) (2009). Nigeria Vision 20:2020: Economic Transformation Blueprint. Abuja: National Planning Commission.

Ogun, O. (1995). 'Country Studies: Nigeria', in S. M. Wangwe (ed.) Exporting Africa: Technology, Trade and Industrialisation in sub-Saharan Africa, UNU-INTECH Studies in New Technology and Development. London: Routledge, 246-95.

Oyelaran-Oyeyinka, B. (1997). 'Industrial Technology Policy: Making and Implementation in Nigeria: An Assessment'. NISER Occasional Paper. Ibadan: NISER.

Oyelaran-Oyeyinka, B. (2004). 'Networking Technical Change and Industrialization: The Case of Small and Medium Firms in Nigeria'. ATPS Special Paper Series No. 20. Nairobi: African Technology Policy Studies Network.

World Bank (WB) (2006). Nigeria Investment Climate Survey. Washington DC: World Bank.

World Bank (WB) (2014). Nigeria Country Overview, available at www.worldbank.org, accessed 25 June 2015. 


\title{
7
}

\section{Industrial Policy in Senegal}

\author{
Then and Now
}

Fatou Cissé, Ji Eun Choi, and Mathilde Maurel

\subsection{Introduction}

Senegal is the fourth largest economy in West Africa after Nigeria, Ivory Coast, and Ghana, with a real GDP and GDP per capita estimated respectively at US $\$ 760$ and US\$11.26 billion (AEO 2014). The economy underwent prolonged decline until 1995, but has since recovered steadily. As a result per capita GDP has more or less stagnated since independence. The Senegalese economy is mainly driven by the service sector, which since 1980 contributed more than 55 per cent of GDP, while agriculture and industry accounted for less than 20 per cent each (Figure 7.1). Since 1990 there has been a noticeable improvement in the share of industry in the composition of GDP, exceeding that of agriculture.

Unlike its resource-rich neighbours, Senegal's economy is largely driven by public investment and private consumption, with share of exports remaining unchanged over the years. It is not surprising therefore that policy makers in Senegal strived to nurture the manufacturing sector in the decades following independence.

It is indeed in the manufacturing sector that learning effects, technological innovation, and diversification are most likely to occur. While small economies cannot benefit from scale economies because of the small size of their internal market, trade openness is a powerful driver of industrial development. The strategy of openness is successful when it is based upon high competitiveness, which reinforces the profitability of the manufacturing sector.

The aim of this chapter is to review policies that have been put in place during the last decades to promote the Senegalese manufacturing sector. Section 7.2 depicts the structure of the industrial sector-sectoral composition 


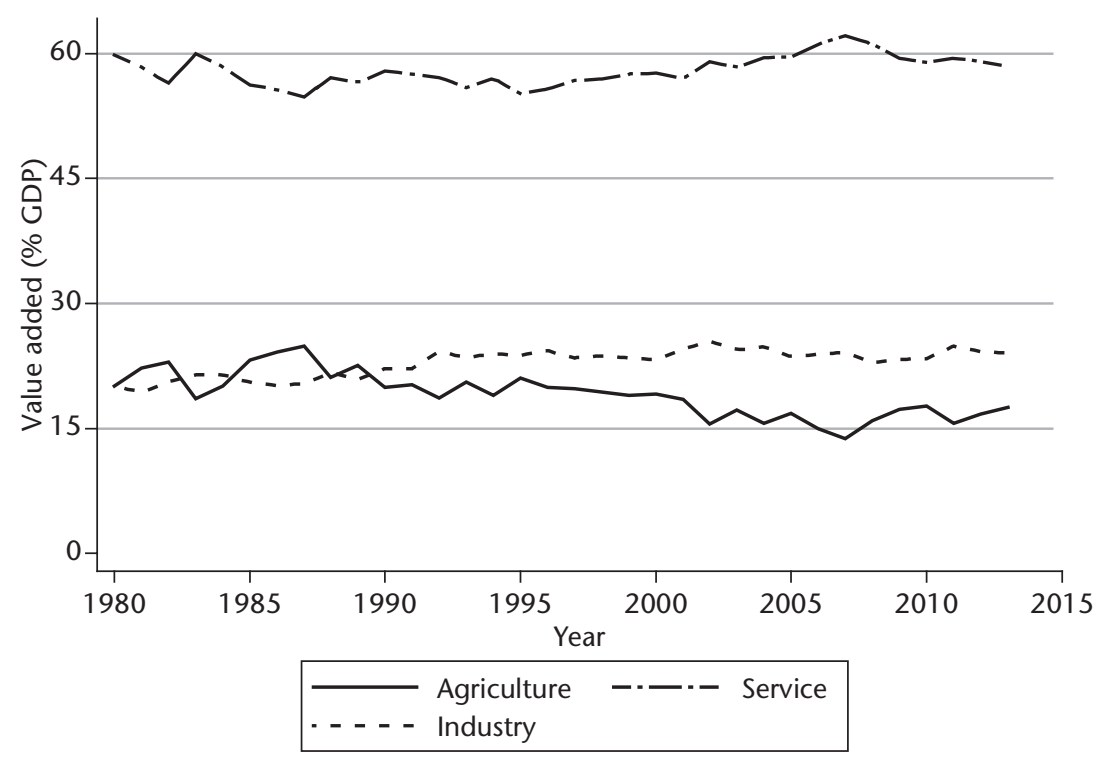

Figure 7.1 Sectoral decomposition of GDP in Senegal

Source: Authors' computation using data from World Development Indicators (World Bank 2014).

at the 2-digit International Standard Industrial Classification (ISIC) level, size distribution, employment, ownership, share of foreign direct investment (FDI), and export contribution as well as sunrise and sunset industries. Section 7.3 analyses total factor productivity (TFP), its features across industries, as well as the patterns of productivity change. It aims at relating TFP with 'fundamentals' for industrial development: availability of electricity (both in terms of quantity and quality), education level of a production worker, and trade policy, among others. Section 7.4 explores the evolution of the policies of industrial development since 1965. It also discusses the emerging policy issues and sums up the major current problems that industrial development faces in Senegal.

\subsection{The Evolution of Senegal's Industrial Policy}

Nearly all of the newly independent countries in the region started with an import substitution (IS) approach to industrialization, where nascent industries received protection. Senegal applied these policy instruments during the 1960s primarily to preserve the industrial base inherited from the colonial era.

\subsubsection{From Import Substitution to Economic Liberalization}

Senegal's first two development plans which were implemented during the period 1961 to 1969 focused primarily on promoting industrial development 
to substitute for manufacturing imports. Tariff and non-tariff barriers protected large enterprises which were created through this strategy. In the 1970s, an alternative policy emphasized the development of small and medium businesses through the creation of the National Company for Industrial Research and Development (SONEPI), followed by the Dakar Industrial Free Trade Zone (ZFID), in 1969 and 1974 respectively. SONEPI is primarily responsible for technical support for private initiatives and gives substance to state industrial policy, particularly by developing industrial areas in regional capitals.

\subsubsection{TARIFF PROTECTION}

Prior to the 1979 tax reform, taxes on imports included customs duties, statistical taxes, and flat-rate taxes, making the tax system complex, benefiting firms that process primary products such as peanuts, imported wheat, textile fibres, and fish for consumption. This tariff system is intended to procure resources for the state and protect domestic firms.

\subsubsection{QUANTITATIVE RESTRICTIONS}

Quotas, prior authorizations, and prohibitions against the import of certain goods provided quasi-monopoly status to some firms. Moreover, domestic producers in certain sectors benefited from additional protection that restricted imports through special conventions and memoranda of understanding and administrative pricing (initially used to address undervaluation of declared imports). However, exporting firms had to pay a statutory tax, a transaction tax, a statistical tax, and a market research and packaging tax (only for peanuts), thus increasing the anti-export bias in import protection measures.

\subsubsection{THE INVESTMENT CODE}

Senegal introduced its first investment code in 1962 to help domestic firms that were set up to promote the objectives of the strongly IS-oriented development plan. Beneficiary firms had major tariff and tax exemptions that remained unchanged for a full twenty-five years. The code was amended in 1965, lowering the required investment from 1 billion FCFA to 500 million FCFA and expanding tariff and tax exemptions on replacement parts, in addition to deferred taxes on imported inputs. In 1977, a new law came into force with the goal of broadening the industrial base through promotion of small and medium enterprises (SME). With this law, there were now two tax codes: the grand code for large firms and the petit code for businessmen with initial investments under 20 million CFA francs (FCFA).

\subsubsection{DAKAR INDUSTRIAL FREE TRADE ZONE}

The ZFID was established in 1974 to accommodate firms engaged in manufacturing, assemblies, and processing for export, as well as complementary 
service firms. Authorized firms were exempted from taxes on corporate profits, wages, and all indirect domestic taxes on production. In terms of tariffs, they did not pay tariffs and taxes on imports of capital goods, equipment, primary materials, and other semi-finished inputs. Free trade zones were introduced in 1991, and firms benefited from all the advantages conferred upon those in the ZFID without having to set up there. Exporting firms benefiting from the free trade zone or ZFID frameworks had to face a corporate tax of only 15 per cent, starting in 1995.

\subsubsection{INDUSTRIAL ZONES}

The idea of industrial zones appeared in 1965, but was not the object of any financing scheme until the 1975 agreement between the governments of Senegal and Germany, which led to creation of the Dakar Industrial Zone Corporation in 1978. The government also created industrial zones in other regional capitals, albeit with varying success. SMEs operating in these industrial zones received assistance from management firms in addition to major tax advantages. In particular, they benefited from a five-year exemption from corporate taxes in Dakar and a seven-year exemption in other regions, and from other taxes on equipment and materials not manufactured or otherwise produced in Senegal, as well as from taxes on replacement parts for this equipment, activities relating to training or the expansion of firms, and services offered by management firms.

The industrial zones typically provided technical, legal, administrative, and marketing assistance to firms operating in the area. By the early 1980s, the process of industrialization had begun to show several weaknesses: (1) the IS policy had reached its limits in a small and overprotected market; (2) the process weakened benefits from natural resources and the export crisis left traditional export sectors (peanuts, phosphates, fish) with no prospects for recovery; (3) highly effective tariffs (25-300 per cent) had perverse effects through lost competitiveness and high rigidities against adaptation; (4) state intervention proved excessive and costly. Industrial growth after 1980 generally ranged from 0-2 per cent, as opposed to 4-5 per cent in the preceding decade.

\subsubsection{Adjustment Policies and Liberalization of the Economy}

In 1979, Senegal was hit by a major macroeconomic crisis which was exacerbated by the return of the drought cycle. Faced with a growing deficit, inflation, and growth collapse, the government sought the support of the Bretton Woods Institution who in return demanded the implementation of structural adjustment programmes. The adjustment policies were based on four pillars: (1) management of aggregate demand with the twin objectives of 
controlling inflation and reducing the balance of payments deficit; (2) restoration of market forces in determining allocations and prices of resources; (3) opening up the economy; (4) withdrawal of the state and consolidation of public finances.

In 1979, the year of the first stabilization programme, the state sought to simplify and reduce import tariffs and taxes, while export taxes were eliminated except on peanuts and phosphates. By 1984, after progress to stabilize the economy was deemed satisfactory, a new agricultural policy (NPA) was launched to organize the withdrawal of the state from the agricultural sector. By 1986, the new industrial policy (NPI) made substantial progress in dismantling tariff barriers. In 1986 another major decision was taken to abandon administrative pricing (used to address undervaluation of declared imports) to calculate tariffs on imports.

The NPI action plan comprised four components: revised protection for domestic industrial sectors, export promotion, revival of investment, and improvement of the environment for industrial activities. The tariff code was revised, with rates cut from 65 per cent to 30-40 per cent over two years and by reducing the number and range of applicable rates. The resulting reduction in the anti-export bias was supplemented by introducing an export subsidy amounting to 10 per cent of the free on board (FOB) value of exports over 1980-3. Eventually the rate rose to 15 per cent of the FOB value over 1984-6 and 25 per cent of value added in export activities after 1986.

The third and fourth components of the NPI provided revisions of the investment code. An industrial restructuring fund was created and assistance to investors was expanded. To improve the business environment in the industrial sector, measures aimed at liberalizing prices and simplifying administrative formalities were taken. However, these measures took place during a period of persistent domestic currency appreciation and the declining competitiveness of Senegalese firms. In 1989, in the face of pressure from firms and declining tax receipts, the government was forced to postpone implementation of the second phase of NPI. The 1989 reform plan was not implemented until 1994 and only as part of the overall adjustment initiated by devaluation of the CFA franc. The NPI remains a painful failure in the history of economic reform in Senegal, with the closure of uncompetitive firms causing significant job losses (7 per cent of permanent staff between mid-1987 and mid-1988).

\subsubsection{Implementation of a Common External Tariff}

The period preceding the 1994 devaluation witnessed a heated debate on the future of the West African Monetary Union (WAMU). Preservation of the 
union remained a priority and ultimately provided the basis upon which an economic union was created with the goal of accelerating integration and convergence among economies in the CFA franc zone. Following this, the goal of not creating a West African Economic and Monetary Union (WAEMU) 'fortress' was upheld and the union proceeded with tariff reductions and established a common external tariff (CET) system. The 50 per cent reduction in the FCFA exchange rate had already made possible the substantial 1994 reduction in tariff rates and simplification of import taxes which remained up to the initiative of each member state.

A customs union made possible the movement of raw materials and goods from small-scale producers, free of tariffs or taxes among WAEMU member states. The WAEMU CET was implemented during 1996-2000 with four categories of products, subject to the following rules: public goods, the import of which was only charged a statistical tax (RS) of 1 per cent and a community solidarity levy (PCS) of 1 per cent; basic necessities, primary raw materials, equipment goods, and other specific inputs levied with a 5 per cent customs tariff plus the RS and PCS upon import; other inputs and intermediate products were levied a 10 per cent tariff plus the RS and PCS; finally, consumption goods and other products not listed elsewhere were levied at a 20 per cent tariff rate plus the RS and PCS. Two exceptional taxes, which were temporary and digressive, are the digressive protection tax (TDP) and a special import tax (TCI) which were introduced to compensate for major declines in tariff protections associated with the CET (in the case of the TDP) or with erratic variations in world prices (in the case of the TCI).

Implementation of the CET is considered a productivity shock comparable to the National Industrial Policy (NIP) except that it came in the wake of the major productivity gains associated with devaluation of the CFA franc. Between 1995 and 2005, industrial activities grew by an annual average of 3.8 per cent (International Monetary Fund (IMF) report 12/337, November 2012).

\subsubsection{Deepening Economic Liberalization and Other Measures to Promote the Private Sector}

In the first couple of decades following independence, price control, the predominance of public and mixed enterprises, and the prevalence of a restrictive regulatory environment all severely hindered the development of private enterprise with the exception of a certain number of privileged entrepreneurs. But price control was eased following the privatization programme initiated during the 1980s which extended to sectors previously considered as strategic, such as infrastructure services and the financial sector. Notable examples are the disappearance of the first public banks and the 25 per cent 
limit on the state's share of bank capital (Programme d'ajustement du secteur financier, 1989-91, Ministère de l'Économie et des Finances, 1988). Concerning the labour market, the reforms carried out over 1994-7 allowed firms to resort to economic lay-offs and also reduced restrictions on fixed-term labour contracts. The dynamics of reform and consultation with employer organizations accelerated following devaluation of the FCFA in 1994, culminating in a private sector development strategy adopted between parties in April 1999.

Implementation of this strategy began in 2000 with the creation of the Investment Promotion and Major Projects Agency (APIX), and in 2001 of the Agency for the Development and Supervision of SMEs (ADEPME). This was followed in 2002 by the transformation of the Senegalese Standards Institute into an association in order to encourage professionals to be more accountable in product quality certification. In 2003 the creation of the Modernization Office and in 2005 creation of the Senegalese Export Creation Agency (ASEPEX) and the introduction of the Accelerated Growth Strategy (SCA) also helped this process.

The SCA offers a common framework to establish an environment conducive to business with international standards to benefit all sectors. The SCA action plan also includes development of special economic zones and other dedicated sites such as incubators and community agriculture areas as well as tourism zones. The industrial redeployment strategy launched in July 2005 is perfectly consistent with the SCA by aiming to rebalance industrial sites to correct for regional disparities and to reorient the productive apparatus of the country towards sectors with high value added.

However, real GDP growth slowed considerably during 2006-11; the economy has proven rather vulnerable to the exogenous shocks of the energy, food, and financial crises of 2007-9-industrial activity growth rate fell to 3.2 per cent during this period. ${ }^{1}$

\subsubsection{The Industrial Policy Framework and Emerging Questions}

The industrial sector is entrusted to a department which is also responsible for trade, SMEs, and the informal sector. The industrial zones are key features of the industrial sector policy validated in 2005. The objectives are: a rebalancing of industrial facilities across the country, which continue to be concentrated in the Dakar region; reorientation of the productive base towards new promising sectors; and strengthening of managerial capacities required to promote highly productive competitive industries.

\footnotetext{
1 Rapport du FMI 12/337, November 2012.
} 
The industrial redeployment policy (PRI) is thus part of the orientations and objectives of the SCA which, in turn, is part of the action plan to reach the productivity and growth objectives of the National Social and Economic Development Strategy (SNDES), which is Senegal's third generation poverty reduction strategy document. Thus, the PRI rests on the stability of the macroeconomic environment, the policy of external openness and regional integration, the option to establish a business environment with international standards, and the development of economic zones. ${ }^{2}$ The competitiveness cluster approach is symbolic of opportunities for innovation within the SCA as well as for collaboration between actors along the value chain, which create the conditions for better positioning of Senegalese products in both domestic and foreign markets.

The observed advantages of an effective industrial redeployment policy are: (1) the presence of important measures to increase value added in industrial sectors; (2) increased accountability in the private sector; (3) the ongoing process to develop infrastructure; (4) access to foreign markets. Complicating factors include: (1) the strong concentration of industrial activity and population in Dakar, which may be a source of agglomeration effects and positive external economies of scale but could make the redeployment less beneficial; (2) the lack of synergies between the industrial sector and small-scale producers; (3) backwardness in entrepreneurial spirit and technological innovation; (4) the cost of developing industrial sites.

With respect to industrial policy in Senegal, emerging issues involve: (1) the lack of adequate infrastructure, notably energy; (2) limited human resources, including entrepreneurial spirit; (3) overvaluation of the real exchange rate which hindered competition.

\subsection{The Structure of the Industrial Sector}

Despite relatively early industrialization, Senegal is characterized by a poorly developed industrial sector with the majority of firms concentrated in Dakar. The industrial sector is very heterogeneous in terms of age and firm size. Besides a small number of large firms established before or during the first years of independence and controlled by foreign interests or by the state, there are numerous small-scale firms. While large firms made up only 10 per cent of firms operating between 1992 and 1995, they contributed almost three-quarters of total investment, jobs, and revenue. Small firms

\footnotetext{
${ }^{2}$ Loi d'Orientation 2008-03 du 08 janvier 2008 sur la Stratégie de Croissance Accélérée, article 2.
} 
count for three-fifths of the total number of industrial firms, and less than one-tenth of jobs and revenue (Republic of Senegal-UNDP 1997).

Furthermore, the industrial sector contributed 30 per cent of the value added of Senegalese business enterprises. This has declined from 46.4 per cent in 1999 to 28.35 per cent in 2010. However, in 2011 its value registered a slight increase to 30 per cent. On the other hand, the contribution from trade and services increased from 44.8 per cent to 63.54 per cent over the same period. In 2011 its value stood at 62.2 per cent (see Cissé et al. 2014: Figure 2).

The industrial sector was mainly made up of electricity and water (22.4 per cent) and construction (22.4 per cent) sectors in 2011, followed by the chemical industry which accounted for 10.38 per cent and the glass and pottery sector accounting for 8.16 per cent of the industrial value added. These four sectors accounted for more than 65 per cent of the total industrial value added.

The 1980s showed a slightly different picture, with the dominant role played by electricity and water (30 per cent), manufacturing (13.8 per cent), construction (12 per cent), and the chemical industry ( 7 per cent). The first four sectors accounted for 63 per cent of the total industrial value added.

One can conclude that over the last thirty years the production structure of the industrial sector in Senegal has been concentrated in a few sectors with little diversification. While some sectors diminished, others have grown in importance (see Table 7.1 for details).

It is also interesting to note that despite the limited role of the manufacturing sector in overall value added, the share of the formal modern industrial sector in total industrial value added has remained more or less stable at 45 per cent (see Table 7.2).

\subsubsection{Employment}

According to Table 7.3, at the beginning of the 1980s a significant share of the labour force was employed in the manufacturing and processing of sugar (19 per cent), followed by the production of rubber products (about 10 per cent), utilities, and production of machines (about 8.5 per cent each). In 2010 the distribution of the labour force among the industrial sectors changed significantly. Over a third of the active labour force worked in the construction sector (almost 36 per cent), while 10 per cent worked in utilities. The manufacturing sector, including fisheries, sugar processing, and others together accounted for only 15 per cent of the active labour force.

In past years, the most significant increase in the number of employees over the last thirty years was recorded in the leather processing and manufacturing sectors, followed by the glassware and pottery sector and the building sector. The fourth sector in terms of the number of employees was the manufacture of other foods. These sectors have also seen the most important growth rates in 
Table 7.1 Share of industrial sectors in total industrial value added on a five-year basis, 1980-2010

\begin{tabular}{|c|c|c|c|c|c|c|}
\hline Industrial sectors & $1980-5$ & 1986-93 & 1994-9 & $2000-4$ & $2005-10$ & 1980-2010 \\
\hline $\begin{array}{l}\text { Processing and preservation of meat } \\
\text { and fish }\end{array}$ & 7.29 & 8.31 & 7.47 & 4.79 & 2.59 & 6.27 \\
\hline Edible fats & 2.87 & 1.90 & 2.60 & -0.21 & 0.56 & 1.62 \\
\hline $\begin{array}{l}\text { Grain milling and manufacture of grain } \\
\text { products }\end{array}$ & 1.91 & 2.80 & 2.73 & 1.32 & 1.57 & 2.14 \\
\hline Manufacturing of cereal foods & 0.35 & 0.47 & 0.51 & 0.28 & 0.34 & 0.40 \\
\hline $\begin{array}{l}\text { Manufacturing and processing } \\
\text { of sugar }\end{array}$ & 12.51 & 8.18 & 5.52 & 4.92 & 3.88 & 7.15 \\
\hline Manufacturing of other foods & 0.99 & 1.80 & 2.19 & 1.44 & 1.71 & 1.64 \\
\hline Manufacturing of beverages & 2.23 & 1.99 & 2.16 & 2.01 & 3.81 & 2.43 \\
\hline Manufacturing of tobacco products & 1.34 & 1.19 & 1.29 & 1.62 & 1.35 & 1.34 \\
\hline Cotton and textiles manufacturing & 3.52 & 3.29 & 3.28 & 2.32 & 1.45 & 2.82 \\
\hline $\begin{array}{l}\text { Leather processing and } \\
\text { manufacturing }\end{array}$ & 0.20 & 0.23 & 0.27 & 0.28 & 0.12 & 0.22 \\
\hline $\begin{array}{l}\text { Woodworking and manufacturing of } \\
\text { wooden products }\end{array}$ & 0.38 & 0.53 & 0.62 & 0.34 & 0.06 & 0.40 \\
\hline Paper and stationery & 3.33 & 3.92 & 4.20 & 4.82 & 5.82 & 4.37 \\
\hline Petroleum processing and coking & 0.28 & 0.22 & 1.21 & 3.21 & 2.66 & 1.38 \\
\hline Chemical industry & 7.24 & 8.79 & 13.99 & 14.75 & 11.09 & 10.90 \\
\hline Production of rubber products & 2.70 & 2.73 & 2.44 & 3.54 & 3.55 & 2.96 \\
\hline $\begin{array}{l}\text { Glassware and pottery } \\
\text { manufacturing }\end{array}$ & 4.10 & 3.41 & 3.95 & 6.21 & 9.10 & 5.20 \\
\hline $\begin{array}{l}\text { Metallurgy, foundry, and foundry } \\
\text { services }\end{array}$ & 3.66 & 4.07 & 4.57 & 4.81 & 5.22 & 4.43 \\
\hline Manufacturing of machines & 0.48 & 0.56 & 0.64 & 0.88 & 0.81 & 0.66 \\
\hline $\begin{array}{l}\text { Manufacturing of equipment and } \\
\text { devices (appliances) }\end{array}$ & 0.00 & 0.00 & 0.00 & 0.00 & 0.00 & 0.00 \\
\hline $\begin{array}{l}\text { Manufacturing of transportation } \\
\text { equipment }\end{array}$ & 0.33 & 0.41 & 0.30 & 0.32 & 0.50 & 0.38 \\
\hline Manufacturing of various products & 1.72 & 1.70 & 1.58 & 1.40 & 1.07 & 1.51 \\
\hline Electricity, water, and gas & 29.30 & 26.86 & 20.34 & 19.12 & 22.09 & 23.90 \\
\hline Building industry & 13.27 & 16.64 & 18.15 & 21.84 & 20.62 & 17.89 \\
\hline Total & 100.00 & 100.00 & 100.00 & 100.00 & 100.00 & 100.00 \\
\hline
\end{tabular}

Source: Authors' calculations based on data from Agence Nationale de la Statistique et de la Démographie (ANSD various years).

Table 7.2 Share of the modern industrial sector and the informal sector of the total industrial value added on a five-year basis, 1980-2010

\begin{tabular}{lccc}
\hline Period & Modern & Informal & Total \\
\hline $1980-5$ & 44.79 & 55.21 & 100.00 \\
$1986-93$ & 44.28 & 55.72 & 100.00 \\
$1994-9$ & 44.22 & 55.78 & 100.00 \\
$2000-4$ & 44.45 & 55.55 & 100.00 \\
$2005-10$ & 46.22 & 53.78 & 100.00 \\
$1980-2010$ & 44.77 & 55.23 & 100.00 \\
\hline
\end{tabular}

Source: Authors'calculations based on data from Agence Nationale de la Statistique et de la Démographie (ANSD various years). 
Table 7.3 Employment rates by sector on a five-year basis, 1980-2010

\begin{tabular}{|c|c|c|c|c|c|c|}
\hline & $1980-5$ & $1986-93$ & $1994-9$ & $2000-4$ & 2005-10 & 1980-2010 \\
\hline $\begin{array}{l}\text { Processing and preservation of meat } \\
\text { and fish }\end{array}$ & 7.96 & 6.95 & 8.06 & 6.75 & 7.32 & 7.40 \\
\hline Edible fats & 5.72 & 6.91 & 4.96 & 7.36 & 6.80 & 6.35 \\
\hline $\begin{array}{l}\text { Grain milling and manufacture of grain } \\
\text { products }\end{array}$ & 0.92 & 1.17 & 1.31 & 1.41 & 1.33 & 1.22 \\
\hline Manufacturing of cereal foods & 2.01 & 1.74 & 1.46 & 1.00 & 0.70 & 1.42 \\
\hline Manufacturing and processing of sugar & 18.85 & 17.34 & 11.80 & 11.84 & 8.69 & 14.00 \\
\hline Manufacturing of other foods & 1.42 & 2.59 & 2.95 & 3.59 & 4.74 & 3.01 \\
\hline Manufacturing of beverages & 0.93 & 1.23 & 1.15 & 1.19 & 1.64 & 1.23 \\
\hline Manufacturing of tobacco products & 1.32 & 1.08 & 0.66 & 0.50 & 0.42 & 0.82 \\
\hline Cotton and textiles manufacturing & 5.62 & 6.30 & 5.95 & 5.06 & 5.38 & 5.72 \\
\hline Leather processing and manufacturing & 0.11 & 0.20 & 0.44 & 0.60 & 0.90 & 0.43 \\
\hline $\begin{array}{l}\text { Woodworking and manufacturing of } \\
\text { wooden products }\end{array}$ & 0.24 & 0.29 & 0.43 & 0.38 & 0.26 & 0.32 \\
\hline Paper and stationery & 5.24 & 5.05 & 4.32 & 3.45 & 2.65 & 4.22 \\
\hline Petroleum processing and coking & 3.38 & 2.00 & 1.19 & 1.34 & 0.31 & 1.68 \\
\hline Chemical industry & 8.02 & 8.73 & 7.92 & 7.33 & 6.81 & 7.84 \\
\hline Production of rubber & 8.34 & 5.37 & 4.98 & 4.19 & 1.05 & 4.84 \\
\hline ery manufacturing & 0.49 & 0.88 & 1.00 & 1.71 & 2.48 & 1.27 \\
\hline $\begin{array}{l}\text { Metallurgy, foundry, and foundry } \\
\text { services }\end{array}$ & 4.45 & 3.37 & 5.43 & 4.22 & 1.04 & 3.66 \\
\hline Manufacturing of machines & 6. & 2.37 & 1.16 & 0.84 & 0.12 & 2.17 \\
\hline $\begin{array}{l}\text { Manufacturing of equipment and } \\
\text { devices }\end{array}$ & 0.00 & 0.00 & 0.00 & 0.03 & 0.15 & 0.04 \\
\hline $\begin{array}{l}\text { Manufacturing of transportation } \\
\text { equipment }\end{array}$ & 1.50 & 1.83 & 0.96 & 1.89 & 1.88 & 1.62 \\
\hline Manufacturing of various products & 1.01 & 1.45 & 1.48 & 1.97 & 2.34 & 1.63 \\
\hline Electricity, water, and gas & 9.12 & 10.76 & 11.84 & 11.29 & 10.10 & 10.61 \\
\hline Building industry & 7.31 & 12.39 & 20.55 & 22.05 & 32.87 & 18.51 \\
\hline Total & 100.00 & 100.00 & 100.00 & 100.00 & 100.00 & 100.00 \\
\hline
\end{tabular}

Source: Authors' calculations based on data from Agence Nationale de la Statistique et de la Démographie (ANSD various years).

number of employees during the last decade (between 2000 and 2010). However, except for the construction sector, the contribution from other sectors to the total industrial value added was quite low, amounting to 7 per cent for all three sectors over the thirty-year period. Out of the three sectors the glassware and pottery producing sector was the most important accounting for 5.2 per cent of the total industrial value added.

\subsubsection{Foreign Direct Investment}

In the case of Senegal, the flow of FDI originates mainly from Europe, with France being a leading source. While the share of FDI to GDP in Senegal was low in early 2000 (about 1 per cent), recently it has shown remarkable growth reaching an average of 2.5 per cent of GDP in 2010. The impact of FDI on growth varied greatly from country-to-country, because of the existence of 
technological spillover contingent on the absorptive capacity of the recipient countries.

\subsubsection{Profile of Firms}

According to a firm survey conducted in 2011, close to 28 per cent of firms were engaged in construction related activities, 8 per cent in the paper production industry, 8 per cent in the chemical industry, and about 5 per cent in agro-processing industries.

Between 1998 and 2011, the number of firms operating in the country decreased by 50 per cent, with the largest number recorded in 2006 reaching 594. The evolution of the number of firms during the period has been highly variable with many firms appearing and disappearing over the years. For example, in 2006 over one hundred firms were set up, but in 2007 the number of firms that exited was higher than the number of firms set up in the preceding year.

\subsection{Patterns of Industrial Productivity}

A simple way to assess the return on investment is to analyse TFP. The level of aggregate TFP is generally low and also declined steadily up to 1994 then rose slightly up to 2006, the year which marked the beginning of the crisis. TFP growth rate does not reflect any stable improvement. On the contrary, it is very uneven, a characteristic that could be explained by fluctuations in rainfall.

The contribution from each factor to growth is computed on the basis of the average growth rates of labour and capital. Thus over 1995-2004, 38 per cent of growth was due to the accumulation of physical capital, 43 per cent to labour, and 16 per cent to an improvement in TFP. Between 1995 and 2009, these figures were respectively 49 per cent, 47 per cent, and only 3 per cent for TFP.

Therefore we can conclude that the Senegalese growth model is evolving towards a change in the respective weights of labour and capital in growth, with a significantly more important role played by capital than in the previous period (1960-90). By applying the same methodology, Berthélémy et al. (1996) found the following percentages: 22 per cent attributable to capital, 58 per cent to labour, and 20 per cent to TFP. TFP contribution to growth remains therefore stable and small. The computation of the Syrquin effect suggests that 16 per cent of growth due to improved TFP mainly stems from the reallocation of labour from the agricultural sector to the secondary and tertiary sectors, characterized by higher labour productivity (Figure 7.2). The 


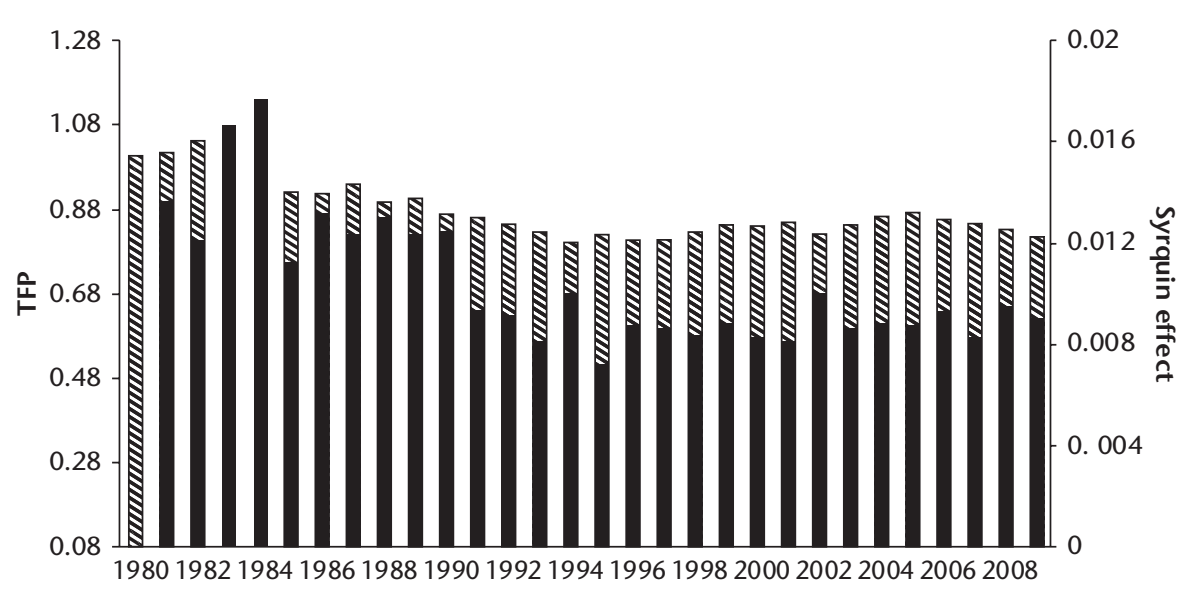

$\mathbf{D}$ TFP Syrquin Effect

Figure 7.2 Contribution of labour reallocation to TFP

Source: AfDB 2012 report.

Note: The effect of the impact of labour mobility is estimated as the sum of the growth rates of the sectoral share of total employment weighted by the sectoral share of total value added. The contribution of labour is calculated by multiplying the Syrquin effect by the output elasticity of labour, i.e. 0.65 .

slow progress of TFP can only partially be attributed to technical progress or to the streamlining of production. These patterns stem from the simple mechanical impact of the migration of labour, which leads to the conclusion that the Senegalese growth model still remains highly fragile.

We utilize a database from annual surveys conducted by the CUCI (Centre Unique de Collecte de Information) of the National Agency of Statistics and Demography (ANSD) of Senegal. The surveys record the information, which is needed for the collection and calculation of taxes. Registration is mandatory for firms in the formal sector, with sales above 50 million FCFA. However, firms can choose to pay a flat tax and in that case they are not required to complete and return the CUCI questionnaire. Therefore, there are biases in the CUCI database, which does not contain information about all companies in the manufacturing sector. Major Senegal firms are registered.

The database gathers information about 1,599 firms in the Senegalese manufacturing industry between 1997 and 2010, including sales, output, value added, revenues of capital, staff load, consumption of intermediate inputs, the identification of the sector in which the firm operates, and the classification code that allows large, medium, and small businesses to be distinguished from each other. However, this size categorization may change over time. Thus, a firm listed as small in a given year may change its status over the following years. The data cover all the major two-digit 
manufacturing industries according to ISIC. Maurel and Seghir (2014) estimate a Cobb Douglas production function. Imposing constant returns to scale, the estimated elasticity of output with respect to capital is statistically significant and ranging at 0.46 .

The sectors that had the highest TFP in 2011 were manufacturing of other foods, various products, and processing of sugar, as well as metallurgy, foundry, and foundry services. It is interesting to note that the most dynamic sectors do not play an important part either in terms of number of employees or in terms of value added. At the beginning of 1998, the highest TFP was recorded in manufacturing of other foods, various products, production of rubber products, and processing and preservation of meat and fish.

During 1998-2011 the highest average TFP was registered in the manufacturing of other foods (16.84), various products (16.63), production of rubber products (16.12), and metallurgy, foundry, and foundry services (15.79). The sectors prominent in value added and number of employees do not fare very well in terms of TFP. The average TFP over the same period was only 13.87 for the construction sector, 14.40 for the energy producing sector, and 14.25 for the chemical industry.

\subsubsection{Factors Affecting Firm Productivity in Senegal}

\subsubsection{LACK OF SKILLED LABOUR}

According to the 2001 Senegalese Household Survey (ESAM II), 68 per cent of migrants are between 15 and 34 years old and 94 per cent between 15 and 54 years old. Skilled workers represent 24.1 per cent of the migrant stock (Dia 2006). Also in 2001, 17.7 per cent of the population with a higher education level emigrated (Docquier and Marfouk 2005). Clemens and Pettersson (2007) confirm the brain drain feature: 51 per cent of Senegalese doctors and 27 per cent of nurses emigrated over the 1995-2005 period, mainly to France.

Literacy levels of the adult population remain low especially among the rural population, despite a significant achievement between 1988 and 2009, a period during which the literacy rate rose from 26.9 per cent to 49.7 per cent for the adult population. Illiteracy continued to affect half of the population in 2009 and women in particular are affected by this phenomenon (61 per cent). Special efforts should be made to improve literacy levels for women in rural areas.

The percentage of annual sales lost as a result of a power outage by sector of activity is given in Cissé et al. (2014: Figure 20). The average loss is 4.6 per cent with 7.5 per cent for small enterprises and 7 per cent for large enterprises. The worst affected firms are in the electronics sector. Successive power outages and cuts lead to the installation of electric generators by firms. These are much more expensive than grid-supplied electricity. Thus, to offset the shortfall in 
Table 7.4 Average electricity rates in West Africa

\begin{tabular}{|c|c|c|c|c|c|c|c|c|c|c|c|}
\hline & $\begin{array}{l}\text { Côte } \\
\text { d'Ivoire }\end{array}$ & Togo & $\begin{array}{l}\text { Burkina } \\
\text { Faso }\end{array}$ & Mali & Niger & Senegal & Nigeria & Benin & $\begin{array}{l}\text { The } \\
\text { Gambia }\end{array}$ & Liberia & Ghana \\
\hline $\begin{array}{l}\text { Price } \\
\text { (US cents: } \\
\text { KWh) }\end{array}$ & 13.11 & 14.92 & 30 & 19.9 & 14.07 & 22.7 & 4.2 & 14.28 & 27.33 & 43 & 8.93 \\
\hline
\end{tabular}

Source: Authors' calculations based on Africa Infrastructure Country Diagnostic (AICD various years).

electricity, over 61 per cent of manufacturing enterprises in Senegal (35.3 per cent in Uganda and 38.2 per cent in Zambia) have had to acquire generators to offset this shortfall.

\subsubsection{POOR INFRASTRUCTURE}

Between 2000 and 2009, electricity generation capacity grew from $365 \mathrm{MW}$ to $510 \mathrm{MW}$, while demand kept growing at a rate of 25-30 MW per year. This was undoubtedly a significant increase in generation achieved by Senegal National Electricity Company (SENELEC) but it still does not meet the ever-rising demand. SENELEC is faced with other problems in addition to the high demand for electricity which it is unable to meet. Its power generation and transmission facilities are obsolete and consequently this prevents the company from effectively meeting the growing demand and power disruptions. To solve this, electricity rates rose in 2006 to the highest levels in West Africa (Table 7.4) and sub-Saharan Africa (SSA): almost 60 per cent higher than in Côte d'Ivoire: CFAF 46/KWh in high voltage compared to CFAF 29 in Côte d'Ivoire.

Filling Senegal's infrastructure gap would require US\$1.8 billion per year over the next ten years-about 20 per cent of GDP. The highest allocations should be to electric power generation infrastructure (Torres et al. 2011). These needs are high in relation to those of other countries in the region (see Cissé et al. 2014: Figure 24). At present, Senegal allocates US\$911 million per year to its infrastructure (11 per cent of GDP). The control over electric power wastage because of frequent power outages (representing US\$312 million per year) would certainly enable the country to improve the infrastructure situation. In this respect, cost recovery in the electricity sector is one of the challenges to be taken up.

\subsection{Industrial Policy}

\subsubsection{Trade Policy Reforms and Manufacturing Performance}

Industrial policy in Senegal following independence has been marked by the state's strong desire to counter divestment pressures associated with the 
shrinking domestic market. In fact, ex-French colonies were engaged in processes to industrialize their economy. Typical IS industrialization policy instruments (tariff and non-tariff barriers) were established, along with complementary measures (creation of free trade zones and investment codes) to step up the still-nascent private sector.

Starting in the mid-1980s, the arrival of structural adjustment programmes (SAPs) led to economic liberalization processes, which resulted in the closure of many firms that faced competition pressures in the environment of an overvalued FCFA. The liberalization process stalled in 1989 and did not pick up significantly until 1994, following a 50 per cent devaluation of the FCFA. However, this massive devaluation occurred after a long period of currency overvaluation and thus cannot be explicitly interpreted as part of a programme to implement an export promotion policy.

The second half of the 1990s saw the establishment of a new economic and monetary union with the goal of accelerating the convergence and integration of West African countries, with the FCFA serving as a common currency. In summary, Senegal implemented an IS policy during 1960-86, followed by a policy of private sector development in a liberalized economy.

\subsection{Sunrise and Sunset Industries}

In this section we present an estimation of the Imbs and Wacziarg (2003) equation. This equation consists of a non-linear model that links diversification indicators like the Herfindahl Index and the level of development as measured by GDP per capita. According to this model, poor countries tend to diversify only after reaching a certain income threshold and specialization dominates once again in the development process. The estimation proposed below (AfDB 2012) covers a sample of fifty-three African countries between 1980 and 2010. The dependent variable is the Herfindhal Index, which varies between 0 and 1 ; lower values indicate greater diversification of exports of goods.

The negative (positive) sign of GDP per capita (GDP per capita squared) indicates that the Herfindahl Index initially falls to a critical threshold of GDP per capita of US\$6,313 in constant 2005 US dollars and increases from that threshold. The computations give a result very close to that of Imbs and Wacziarg (2003: 74), where the threshold is estimated at US\$9,000 in 1985 dollars, i.e. US\$10,500 in 2000 US dollars.

Furthermore, Imbs and Wacziarg (2003) compute a theoretical or potential specialization indicator as well as the effective specialization to potential ratio. It stood at about 20 per cent between 2000 and 2006 (dates for which data are available), which means that Senegal is above its natural diversification 
potential, and not much can be expected of a proactive policy. This result illustrates the non-linearity between growth and specialization in an African context: first there is an increase in diversification; then a specialization process sets in for the most advanced countries. Whereas Botswana, Mauritius, the Seychelles, South Africa, and Tunisia are beyond the critical threshold, Senegal with a GDP per capita in 2010 of US $\$ 1,700$ in 2000 US dollars is below the threshold from which growth leads to specialization. It is situated in the area where growth leads to continuing diversification.

The trend of the indicator in Cissé et al. (2014: Figure 6) shows a slight fall which is increased export diversification. There was an 80 per cent drop for the first ten products in 2004 and 60 per cent in 2010. The figure shows that there was not a real diversification trend over 1980-2010, and that exports remain highly concentrated.

The main exporting industries have seen many fluctuations over the last thirteen years, with the share of the processing and preservation of meat and fish diminishing from 34 per cent in 1997 to only 9.85 per cent in 2011. The lowest share of this branch of exports fell below 8 per cent in 2008. The share of the main exporting branch, the chemical industry, was over 33 per cent in 1998 and reached only 14 per cent in 2006, while petroleum processing and coking attained the highest level at 47 per cent of exports in 2000, before dropping and growing again. The most impressive evolution over the period was registered by the glassware and pottery industry, which accounted for only 0.5 per cent of exports in 1997 to reach almost 12 per cent in 2010. However, one can conclude that Senegalese exports are unstable and volatile. They are also poorly diversified with three sectors accounting for more than 55 per cent of exports and another three for more than a quarter of the remaining exports.

Following our analysis we identified three sunrise industries: building, chemical, and glassware and pottery. By contrast, the processing and preservation of meat and fish and other food industries constitute sunset industries.

\subsection{Conclusion and Emerging Policy Issues}

Senegal registered persistently slow growth rates, including during periods of major policy shifts including the deregulation of the 1990s, the 1994 devaluation of the CFA franc, and the recent debt relief programmes. The TFP trend shows the dependence of Senegalese growth on agriculture, which employs the vast majority of the population. Dualism in the economy is perpetuated by inadequate economic diversification, institutions that are too weak and do not motivate workers to leave the informal sector.

A key policy intervention that follows from our analysis is the much needed improvement of infrastructure and particularly the improvement of electricity 
supply. Frequent power outages impose significant costs on doing business. While infrastructure spending has grown recently reaching 11 per cent of GDP, the share allocated to the electricity sector is insignificant. Industry is largely concentrated in Dakar and close to consumer markets that are not lacking in transport infrastructure. Weak supply and frequent outages are, however, immediate obstacles to the development of the country's industrial growth and require immediate attention.

Privatization might be a possible solution provided that electricity rates are sufficiently attractive for investors. Improving the supply and financial performance of SENELEC, whose costs are too high, should be a main issue. The increase in private management in the infrastructure sector has appeared as a logical response to several constraints: search for enhanced efficiency, limited public resources, and the desire to attract foreign investors. This strategy has experienced considerable success especially in the transport and water supply sectors. For the time being, partial privatization of the electricity sector has not produced the expected results. The reasons need to be analysed before undertaking further privatization.

Another key issue is the educational drive. Its focus should be on primary education, and technical training, the returns to which are higher. The returns to higher education are, on the other hand, low. The job market in Senegal is more open to job seekers with primary, secondary, and technical levels of education than to university graduates: the job market seems to favour labour with low or intermediate qualifications, such as a primary school certificate or a technical diploma.

The mismatch between supply and demand (too many overqualified graduates) resulted in a high unemployment rate and a brain drain. The Senegalese educational system is suboptimal as it offers training that does not meet the requirements of the labour market.

Considerable efforts are required in order to improve Senegalese human capital, especially in the areas of secondary and university education, in order for Senegal to rapidly achieve a quality of human capital comparable to that existing in emerging countries. Also, human capital in Senegal would improve faster if the large increase in the number of young dependents slowed down.

\section{References}

Africa Infrastructure Country Diagnostic (AICD) (various years). 'Africa Electricity Transmission Network', available at <https://worldmap.harvard.edu/data/geonode: africa_electricity_transmission_network_o7k>, accessed 15 February 2016. 
African Development Bank (AfDB) (2012). Senegal Country Growth Diagnostic. Tunisa: AfDB.

African Economic Outlook (AEO) (2014). 'Global Value Chains and Africa's Industrialisation', available at <http://www.africaneconomicoutlook.org/fileadmin/uploads/ aeo/2014/PDF/E-Book_African_Economic_Outlook_2014.pdf $>$, accessed 10 February 2016.

Agence Nationale de la Statistique et de la Démographie (National Agency of Statistics and Demography) (ANSD) (various years). 'Rapports publics', available at <http:// www.gouv.sn/6-Agence-Nationale-de-la.html>, accessed 15 February 2016.

Berthélémy, J-C., Seck, Abdoulaye, and Vourc'h, Ann (1996). 'La croissance économique au Sénégal: un pari perdu?' Études du Centre de Développement, Série ‘Croissance à Long Terme'. Paris: OECD.

Cissé, Fatou, Eun Choi, Ji, and Maurel, Mathilde (2014). 'Scoping Paper on Industry in Senegal'. WIDER Working Paper No. 2014/157. Helsinki: UNU-WIDER.

Clemens, M. and Pettersson, G. (2007). 'New Data on African Health Professionals Abroad'. Washington, DC: Center for Global Development.

Dia, I.A. (2006). 'Profile of International Migration from Senegal', for the MRF Regional Office for West and Central Africa. Dakar: International Organization for Migration.

Docquier, F. and Marfouk, A. (2005). 'International Migration by Educational Attainment: 1990-2000'. Brighton: University of Sussex Centre for Migration, Globalization and Poverty.

Imbs, J. and Wacziarg, R. (2003). 'Stages of Diversification'. The American Economic Review 93(1): 63-86.

Maurel, M. and Seghir, M. (2014). 'The Main Obstacles to Firm Growth in Senegal'. African Development Bank Group Working Paper Series, no. 208.

Republic of Senegal-UNDP (1997). 'L'industrie Sénégalaise de 1992 à 1995'. Dakar: Republic of Senegal-UNDP.

Torres, C., Briceño-Garmendia, C., and Dominguez, C. (2011). 'Senegal's Infrastructure: A Continental Perspective'. Africa Infrastructure Country Diagnostic, Country Report. Washington, DC: World Bank.

World Bank (2014). World Development Indicators. Washington, DC: World Bank. 


\title{
8
}

\section{Industrial Development in Tanzania}

\author{
Jamal Msami and Samuel Wangwe
}

\subsection{Introduction}

Policy debates on various economic development theories have argued for the gradual transformation from primary production to tertiary production as essential both in the allocation of limited resources and in the realization of gains from trade. Relative to Africa, such debates have often pointed out the inadequacy of industrialization on the continent.

The performance of Africa's industrial sector in terms of growth, structural change, and absorptive capacity has historically lagged behind that of other regions. Subsequently, Africa's terms of trade have fared no better relative to the rest of the world (the Prebisch-Singer hypothesis).

In Tanzania, industrialization has been characterized by shifts in roles of the state and private sector: starting with largely private sector driven industrial development up to the mid-1960s as reflected in the First Five-year Development Plan (1964-9), shifting to largely state driven industrial development from 1967 to the mid-1980s as reflected in the Second and Third Five-year Plans (1969-74 and 1976-81). It shifted back to private sector driven industrialization after 1986 as reflected in the Economic Recovery Programme (ERP) of 1986-9 and the Economic and Social Action Programme of 1989-92 in which liberalization and privatization were practised followed by initiatives to revert back to industrialization as a development agenda from the mid-1990s as indicated in the Sustainable Industrial Development Programme of 1996-2020 and the Integrated Industrial Development of 2011.

\subsection{Historical Developments: Pre-independence Period}

In the colonial era, the primary focus of manufacturing in Tanzania was on primary, low value, labour-intensive agricultural goods. Before the First World 
War (WWI) German colonizers established a company called the German East Africa Company in mainland Tanzania. The economic performance of the colony was awash with potential and prior to the beginning of WWI the company's exports were twice as high as those of British East Africa which operated in the neighbouring British colony of Kenya. As a result of constraints posed by the financing of the war and the associated production and trade interruption, the German East African company performance suffered, as the colony could not produce for outside markets. Consequently, there were no imports, and industries which produced goods for military purposes experienced higher growth levels.

Following the signing of the treaty of Versailles in 1918, Tanganyika (now a British dominion) saw pronounced structural changes in domestic production in favour of capital, intermediate, and consumer goods from abroad. Under the British, local investment in the manufacturing sector was further discouraged in spite of its already low levels. In the latter years of British dominionship, particularly after the Second World War (WWII), the industrial sector began to receive concerted attention from the then administrators; efforts started to be put into the production of primary products such as cotton, sisal, and tobacco for export and replacing imported ones. However, in the absence of developed supply chains and networks, partly a deliberate mechanism designed to impose foreign rule over Tanganyika, local peasants did not reap the benefits of these changes in public policy.

The Tanzanian industrial sector continued to operate poorly and slowly because most foreign investors preferred investing in Kenya where there was better capital and physical and administrative infrastructure. In addition, the nature of the common external tariff policy (whose structure favoured the interests of Kenyan industrialists) for the then East African countries (Tanzania, Kenya, Uganda) was instrumental in marginalizing the development of local industries via the promotion of centre-periphery relations between the British colony of Kenya and the Tanganyika dominion.

The pervasive lack of indigenous investors (and 'captains of industry') further exacerbated the lack of growth and expansion of the industrial base. Other marginalizing traits of the local economy at the time such as small market size, low agricultural productivity, high illiteracy, and continued focus on low-skill labour-intensive agricultural production, contrived to undermine the development of an industrial base in the country. However, in the late 1950s there was an increase in the pace of industrialization in the country because of unstable political conditions in Uganda and Kenya which encouraged some investors to divert their attention to Tanzania. In spite of this, growth of the local industrial base failed to match Kenya's (RPED 1994).

As a consequence of policies under British dominionship, production activities at independence in 1961 in Tanganyika (now Tanzania) were extensively 
rooted in labour-intensive primary commodities. There were 220 manufacturing industries which employed 200,000 out of 9 million people (Skarstein and Wangwe 1986) which could meet just about 1 per cent of families. The industrial sector contributed about 4 per cent to GDP. Productive factories in drinks, agro-processing, and consumables such as Coca-Cola, East African Breweries, Tanganyika Packers, British American Tobacco, Metal Box, and Bata shoes, and even smaller companies, which existed at the time of independence, were under foreign ownership. Many of these large-scale companies produced either for urban consumption or for export while small-scale ones catered for rural markets.

A nationwide census of industries in 1961 established that 62 per cent of the seventy-six large-scale enterprises operating at the time in the then Tanganyika worked below full capacity on account of insufficient demand, unfavourable weather conditions, poor infrastructure, breakdown, shortage of skilled labour, and inefficient utilization of raw materials (Szirmai and Lapperre 2001). It is thus conceivable that the colonial era institutional set-up coupled with unreliable infrastructure, a high degree of unskilled citizens, poor technical skills and human capital, poor managerial capabilities, insufficient energy, lack of indigenous entrepreneurship, and a small domestic market for industrial goods hampered growth of the industrial sector in Tanzania.

From a policy setting, industrial development in Tanzania can be grouped into five distinct policy periods: 1961-9, 1969-81, 1981-6, 1986-95, and 1995 to date. Section 8.3 will systematically explore these periods in chronological sequence.

\subsection{Industrial Development, 1961-85}

In the early 1960s, the national economic agenda focused on growth with little attention to structural change or ownership. The colonial pattern of import substitution industrialization (ISI) was continued (largely processing and simple consumer goods). The Foreign Investment Protection Act of 1963 was designed to attract foreign direct investment (FDI) to fill the capital gap. Response was not encouraging and as a result the Arusha declaration was formulated: socialism and self-reliance from 1967.

\subsubsection{Industrial Development in the Early Post-independence Period, 1961-7}

Between 1961 and 1967, industrial development in Tanzania was defined by the introduction of the three-year development plan (TYP) for 1961-4 and the First Five-year Plan (FFYP) for 1964-9. The TYP aimed at promoting growth 
mainly through increasing investment in those activities that were expected to bring quick and high returns. A relatively low degree of regulatory control was exercised to promote private domestic and international investment in the economy. Against the tide of recently independent countries espousing left leaning economic and political ideology, the government of the young nation of Tanganyika moved to allay foreign and private investors' concerns on property nationalization during the TYP. Tax incentives were provided and existing investment opportunities published in a bid to expand the pool of capital flows. The TYP was successful in promoting basic consumer goods processing industries through the incentives outlined as well as providing a public injection of funds from the government through the Tanganyika Development Corporation. This period also saw the first active state promotion of the ISI strategy.

Under the TYP manufacturing units started to increase in numbers as did the level of output. In 1965, there were 569 manufacturing establishments employing ten persons or more of which over one-third came into existence after independence. Elements of ISI and diversity were noticed in some activities, for instance, in the metal and products industry which up to late 1958 produced only metal containers; diversification of the products portfolio was introduced in 1965. These included aluminium sheets, screws, nails, wire, enamelware, and razor blades (Rweyemamu 1973). In addition, ISI took place in paper, glass, printing, and wood products.

However, despite commensurate gains in manufacturing, the level of industrial output remained comparatively low. In 1966, the industrial output share in total production was only 6.6 per cent, below the expected level of 10 per cent (Rweyemamu 1973) despite the exceptionally high growth rate of the industry. The country's terms of trade with its East African neighbours remained unimpressive with recorded episodes of current account deficits between 1962 and 1964.

Regional trade imbalances (as seen in Table 8.1) led to negotiations between Tanzania and its neighbours and the eventual signing of the Kampala agreement in 1964 aimed at restructuring the distribution of industries across the

Table 8.1 Inter-East Africa trade, 1962-4

\begin{tabular}{lccccc}
\hline Year & \multicolumn{2}{c}{ Exports from Tanzania to } & & \multicolumn{2}{l}{ Imports of Tanzania from } \\
\cline { 2 - 3 } \cline { 5 - 6 } & Kenya & Uganda & & Kenya & Uganda \\
\hline 1962 & 56 & 9 & & 207 & 35 \\
1963 & 62 & 10 & & 216 & 42 \\
1964 & 87 & 20 & & 271 & 49 \\
\hline
\end{tabular}

Note: In Tsh. millions.

Source: Adapted from Rweyemamu (1973). 
East African region to attain a degree of equity among the nations. Ownership of means of production however remained firmly entrenched in foreign hands such that by 1965, an overwhelming majority of the industries set up prior to and during the TYP remained in foreign hands (Rweyemamu 1973). During the TYP employment fell, with gradual transformation of the structure of industries from labour to capital intensity. Foreign owned companies concentrated on the capital intensive production of such items as nonmetallic mineral products, repair of machinery and manufacture of metals and metal products, tobacco, textile, cement, radio assembly, diamond cutting, etc.

The FFYP succeeded the TYP in 1964 and provided the roadmap for shaping the industrialization of Tanzania for the next five years. The FFYP aimed at increasing the relative importance of the manufacturing sector through placing greater emphasis on production of substitutes for already imported goods. In the grand scheme of things, the FFYP was an extension of the TYP with a shared outcome. Under the FFYP, market size (economies of scale) and availability of capital were identified as major constraints hindering the expansion of the industrial sector. An amendment to clauses in the East African common market soon followed as states attempted to gain more independence on trade policy and regulation. This allowed the government to set conditions for investment in its industries which did not depend on the regional market by introducing a transfer tax system aimed at protecting weak industries.

The TYP and FFYP shared a similar focus for their goals. Both shared the broad perspective objective altogether by 1980 of raising per capita incomes from TShs 392 to over TShs 900, attaining full self-sufficiency in trained manpower in all economic fields and at professional levels, to increase the number of wage earners from 340,000 in 1960-2 to 800,000, and raising life expectancy from thirty-five to fifty years.

Success of the FFYP plan can be seen from the changes that took place within its duration. The gradual success of these two industrial policies achieved a 50 per cent increase in the number of manufacturing establishments between 1961 and 1965 in addition to increasing the ratio of manufacturing value added to GDP and labour productivity. Official statistics indicate that the GDP share of manufacturing value added increased from around 8.4 per cent in 1964 to 10.2 per cent in 1967 (BoT 1982; Bureau of Statistics 1978). This was also accompanied by an increase in comparative and general labour productivity between 1965 and 1967.

Tanzania's ideological shifts in the latter half of the 1960s led to an adverse appraisal of both the TYP and FFYP over their failure to promote local ownership of means of production. This led to criticism from party stalwarts over the distributive effects of the two policies. The failure to promote a product mix 
under the TYP and FFYP had hindered diversification and slowed down broadening of the domestic industrial base. This, along with the low degree of direct regulatory control which defined the economy and the conflicted political ambitions of the ruling elite, prompted a revision of policy.

\subsubsection{State-led Industrial Development, 1967-85}

The period from 1967 saw the inauguration of the national policy for nationalization and self-reliance: the Arusha declaration. Promulgation of the Arusha declaration in 1967 fired the fight for principles of socialism and self-reliance on major means of production. The Arusha declaration advocated utilization of local resources as primary endowments in production, and in effect signalled the end of low level direct regulatory control and the reliance on foreign private investors. Nationalization of large foreign owned enterprises ensued as did the expansion of the public sector. Increased state control in manufacturing saw the introduction of an industrial licensing procedure under the National Industries Licensing and Registration Act of 1967. The Arusha declaration introduced state-led ISI, state-led expansion of manufacturing, and a revision of ownership and management of established entities in favour of direct ownership and management of state organizations. Foreign ownership of production was subsequently limited to joint ventures with the government. Foreign investors participated through management agreements and as suppliers of equipment for industries. Direct regulatory control in manufacturing was then consolidated through establishment of the National Development Corporation while trade was largely operating under the State Trading Corporation (STC).

The Second Five-year Plan (SFYP) of 1969-74 attempted to bridge the disconnection between industrial development and rural development through nationalization of the internal wholesale trade in 1971. This forced manufacturers to sell specified goods to and purchase inputs from the STC.

This led to a decline in the size of the private sector and an increase in the number of publicly owned establishments. By 1973, the public sector's contribution to GDP had risen to 32 per cent from 5 per cent in 1966 (Szirmai and Lapperre 2001) and in 1973 accounted for 46.7 per cent (up from 15.5 per cent in 1967) of all total manufacturing employment (Skarstein and Wangwe 1986). Overall, industrial production increased between 1963 and 1969 (Table 8.2).

The increased role of the state in this era was accompanied by an increase in GDP share of manufacturing as well as gross manufacturing value added. Between 1967 and 1973, Tanzania recorded the most rapid growth of manufacturing value added (for enterprises employing ten or more personnel) in its history. It is worth noting that this increase in the contribution of 
Table 8.2 Production by selected industries

\begin{tabular}{llrrrrrr}
\hline Industry & \multicolumn{1}{c}{ Units } & 1963 & 1964 & 1965 & 1966 & 1967 & 1968 \\
\hline Textiles & '000 sq yds & 6,225 & 8,930 & 12,126 & 17,121 & 18,277 & 34,519 \\
Beer & '000 gallons & 1,962 & 2,249 & 2,673 & 4,139 & 5,120 & 5,413 \\
Cigarettes & millions & 1,144 & 1,535 & 1,869 & 2,049 & 2,044 & 2,137 \\
Paints & gallons & 95,357 & 96,981 & 162,573 & 221,020 & 274,623 & 317,948 \\
Plywood & '000 sq. ft & 2,004 & 6,573 & 7,794 & 10,247 & 8,808 & 10,658 \\
Sisal twine & tons & - & 658 & 5,778 & 10,138 & 14,887 & 16,454 \\
Saw milling & '000 cu. ft & 3,676 & 4,675 & 5,029 & 5,026 & 4,585 & 5,029 \\
Wheat flour & tons & 28,378 & 29,818 & 38,433 & 39,714 & 41,159 & 42,238 \\
Pyrethrum extract & tons & 99 & 107 & 174 & 200 & 287 & 187 \\
Canned meat & tons & $\mathrm{n} / \mathrm{a}$ & $\mathrm{n} / \mathrm{a}$ & 11,109 & 9,162 & 9,520 & 6,716 \\
Cement & tons & - & - & - & 49,324 & 144,612 & 153,894 \\
\hline
\end{tabular}

Source: Adapted from Rweyemamu (1973).

manufacturing also coincided with an increase in both absolute and relative labour productivity. ${ }^{1}$

The Arusha declaration also saw an increased role of government in setting, implementing, and monitoring monetary and exchange rate policies. In 1971, the National Price Control Advisory Board was created to set and oversee prices initially of a limited number of manufactured products (Maliyamkono and Bagachwa 1990). The Price Control Act of 1973, aimed at limiting the monopoly pricing power of domestic producers, allowed the government to exercise full price control in the manufacturing sector (Mongi 1980). Stringent regulations were introduced to monitor the flow of capital in and out of the country. The 1973 Finance Act gave the government carte blanche in administration of the foreign exchange market and led to an appreciation of the real exchange rate vis-à-vis that of Tanzania's trading partners as a result of rising domestic inflation and exchange rate rigidity. The artificial overvaluation of the nominal exchange rate precipitated by controls established by this act led to the proliferation of the parallel exchange market characterized by rates roughly double the nominal rate between 1971 and 1973. With insufficient foreign earnings from trade in goods and services, this led to a shortage of foreign currency (Lipumba and Kasekende 1991) a feature symptomatic of Tanzania's economic woes of the era.

The global oil crisis of 1973 further exacerbated the shortage of foreign exchange necessary for the importation of capital and intermediate goods. Declining productivity levels and consumption contributed to a fall in consumer goods to 30 per cent of output in 1973 compared to a peak figure of 43 per cent in 1963. The country experienced deteriorating balance of payments

\footnotetext{
${ }^{1}$ In 1973, labour productivity was 44 per cent higher than in 1967.
} 
which adversely affected industrial production between 1973 and 1974 (Skarstein and Wangwe 1986).

By the early 1970s, the increase in manufacturing had succeeded in meeting 70 per cent of domestic demand for consumer goods and improved clothing exports, but failed to improve the absorption capacity of technology transfers. These shortcomings prompted the launch of discussions to chart a long-term industrial strategy covering twenty years (1975-95). The twenty-year basic industry strategy was devised to improve the nation's industrial base to implement plans towards achieving national goals. The guiding national goals were growth, structural change, employment, income distribution, regional distribution, worker participation, and self-reliance. This long-term strategy ${ }^{2}$ aimed between 1975 and 1995 at increasing the relative importance of the manufacturing sector and reducing dependence on imports so as to achieve the seven national goals which were identified as relating to increasing industrial growth, structural changes, employment generation, income distribution, regional distribution, workers' participation, and self-reliance. The basic industry strategy was adopted for its score on structural change and self-reliance. Industrial goods were to meet the basic needs of the population and intermediate and capital goods in the economy. The latter was to be achieved through efficient utilization of domestic natural resources to produce a wide range of intermediate and capital goods. Industrial production was primarily meant to meet domestic demand. Exports were to result from an expansion of the domestic market. Manufacturing was projected to grow from 8 per cent of GDP in early 1975 to 18.8 per cent in 1995.

Meanwhile, the economy was experiencing an accelerated pattern of diverse industrialization. Records show that in 1977 the share of consumer goods in manufacturing value added fell to 74 per cent from 54.2 per cent in 1961, while intermediate and capital goods had increased from 23 per cent to 34.5 per cent and from 3 per cent to 11.8 per cent respectively (Skarstein and Wangwe 1986).

\footnotetext{
2 For implementation purposes, this twenty-year strategy was subdivided into several sub-strategies namely BIS, MGS, EAS, SSRS, and MS. The Basic Industrial Strategy (BIS) was for bringing about structural change and reducing the degree of the manufacturing sector's dependence on foreign aid. Production was centred on consumer, intermediate, and capital goods for the domestic market. Maximum Growth Strategy (MGS) was for maximizing industrial growth through incorporating in production those industries which could give highest value added out of investment. Small-scale Rural Strategy (SSRS) was for increasing the spread of small-scale units in most parts of rural areas. With this strategy large-scale industries would be established and put into operation only for those activities which would not be feasible when produced in small operations. The East African Strategy (EAS) proposed that the government should choose to specialize in production of some commodities to supply to the East African market while leaving alternative commodities' production in the hands of other member states. The Mixed Strategy (MS) went wider than others by opting to reach out for a larger part of national goals than focusing solely on specific ones such as growth.
} 
This marked a gradual evolution of industrial activity under the ISI strategy from the production of simple consumer goods to intermediate and capital goods. Unfortunately, the aftershocks of the 1973 oil crisis and a subsequent recovery of world coffee output (following a bout of frost in Brazil in 1976) led to a fall in international commodity prices and increased the price of domestic consumer goods and inputs. The government was then required to spend more to procure goods from outside, exerting additional pressure on foreign exchange reserves already affected by falling export receipts. Consequently, in the early 1980s, labour productivity was reduced and the economy continued to deteriorate as agricultural production failed to cater for domestic food demand.

The 1973 crisis increased the current account deficit relative to GDP to 14.3 per cent in 1974 from 6.5 per cent in 1973. Worsening balance of payment accounts were further compounded by a simultaneous rise in inflation from 7.6 per cent in 1972 to 27 per cent in 1975. A brief respite in 1976 and $1977^{3}$ brought about by a combination of policy responses and the coffee boom of 1977 was however short lived, as the 1977 collapse of the East African Community (EAC), the second oil crisis of 1979, the Kagera war with Uganda (1978-9), severe droughts, and deteriorating terms of trade resulted in an upshot of current account deficit to 12.7 per cent of GDP (Bigsten et al. 1999).

An acute shortage of foreign exchange and consumer goods contributed to a thriving parallel market with inflation increasing to 30.3 per cent in 1980 . Overall, macroeconomic growth came to a halt in 1981 with a negative real rate of growth recorded at -0.5 per cent by the end of the year, followed by a close to zero rate in 1982, and another year of negative growth in 1983 (Table 8.3).

In 1981, an Export Rebate System (ERS) was introduced to serve as an export subsidy for producers of horticultural goods, alongside a General Retention Scheme (GRS) for exporters to deposit part of their foreign exchange earnings for the purpose of importing inputs. The conditions were still not satisfactory and the mid-1980s marked the period of economic deregulation for Tanzania. The National Economic Survival Programme (NESP) came into existence in 1981-2 with the aim of reviving the economy using the nation's internally generated resources. It did not achieve its goals and the economic malaise continued well into the 1980s.

Later the government adopted a structural adjustment programme (SAP) for the period 1982/83-1984/85 to improve the availability of foreign capital inflows but again was unsuccessful because the government could not agree with International Monetary Fund (IMF) conditions. The decline in output

\footnotetext{
${ }^{3}$ Inflation decreased to 6.9 per cent in 1976, and current account deficit declined to 9.5 per cent of GDP in 1975 and 1.3 per cent in 1976.
} 
Table 8.3 Macroeconomic indicators in Tanzania, 1970-92

\begin{tabular}{lccccc}
\hline Year & $\begin{array}{l}\text { Annual GDP } \\
\text { growth }\end{array}$ & Inflation $^{\mathrm{b}}$ & $\begin{array}{l}\text { Current account } \\
\text { ratio to GDP }\end{array}$ & $\begin{array}{l}\text { Terms of trade } \\
(1987=100)^{\mathrm{c}}\end{array}$ & $\begin{array}{c}\text { Debt/GDP } \\
(\% \mathrm{~s})^{\mathrm{c}}\end{array}$ \\
\hline 1970 & 4.0 & 3.1 & -3.1 & $\mathrm{n} / \mathrm{a}$ & $\mathrm{n} / \mathrm{a}$ \\
1971 & 3.5 & 5.0 & -8.0 & $\mathrm{n} / \mathrm{a}$ & $\mathrm{n} / \mathrm{a}$ \\
1972 & 6.3 & 7.6 & -4.6 & $\mathrm{n} / \mathrm{a}$ & $\mathrm{n} / \mathrm{a}$ \\
1973 & 2.8 & 10.6 & -6.5 & 145.7 & 34.2 \\
1974 & 1.3 & 18.4 & -14.3 & 173.6 & 43.1 \\
1975 & 5.1 & 27.0 & -9.5 & 142.0 & 48.3 \\
1976 & 6.1 & 6.9 & -1.3 & 151.7 & 56.2 \\
1977 & 0.4 & 11.4 & -2.3 & 182.0 & 60.5 \\
1978 & 2.1 & 6.6 & -12.7 & 151.9 & 62.2 \\
1979 & 2.4 & 12.9 & -8.8 & 138.7 & 64.3 \\
1980 & 3.0 & 30.3 & -11.4 & 142.0 & 65.0 \\
1981 & -0.5 & 25.7 & -7.7 & 129.0 & 58.3 \\
1982 & 0.6 & 28.9 & -8.7 & 127.1 & 55.4 \\
1983 & -2.4 & 27.1 & -5.5 & 128.0 & 64.1 \\
1984 & 3.4 & 36.1 & -7.4 & 131.0 & 77.2 \\
1985 & 4.6 & 33.3 & -6.6 & 126.1 & 74.0 \\
1986 & 6.6 & 32.4 & -8.1 & 140.5 & 123.6 \\
1987 & 5.9 & 30.0 & -16.1 & 100.0 & 211.4 \\
1988 & 4.8 & 31.2 & -11.6 & 107.2 & 188.0 \\
1989 & 2.2 & 30.4 & -10.5 & 103.2 & 171.1 \\
1990 & 7.1 & 35.9 & -12.5 & 92.6 & 202.1 \\
1991 & 2.8 & 28.8 & -11.9 & 93.8 & 188.5 \\
1992 & 1.6 & 21.9 & -12.2 & 84.7 & 210.9 \\
\hline
\end{tabular}

Source: ${ }^{a}$ Bureau of Statistics (1978); ${ }^{\mathrm{b}}$ BoT $(1982) ;{ }^{\mathrm{c}}$ Bigsten and Danielsson (1999); Edwards (2012)

and productivity was arrested in 1984 and later stabilized between 1984 and 1989. However, the comparative levels of labour productivity continued to fall in Tanzania relative to those of developing economies in Asia such as China, India, and Indonesia (Timmer and Szirmai 2000). ${ }^{4}$

Several factors can explain this decline in productivity and output. First, protection through import licensing, exchange controls, and price controls based on the cost-plus principle did not create a business environment that could induce industries to build capabilities to compete. Second, foreign exchange earnings were overestimated, the rate artificially sustained at high levels, and actual production was constrained by a shortage of foreign exchange especially that associated with importing intermediate goods. A corollary of this was widespread capacity underutilization and shortages of foreign exchange leading to the shortage of intermediate inputs. Third, human resource skills fell below requirements, a direct consequence of failure of the industrial strategy to fully encapsulate them.

\footnotetext{
4 From 5.8 per cent of US manufacturing labour in 1984 to 3.9 per cent in 1990 . At the same time developing Asian economies recorded comparative labour productivity levels in medium- and large-scale manufacturing of between 5.7 and 10 per cent of the US level in 1987 .
} 


\subsection{Industrial Development under Structural Adjustment, 1986-95}

The coming into force of the ERP in 1986 ushered in a transformation of the economy from one being wholly state-owned to one involving private ownership of production processes. ERP was adopted with the objective of restoring economic stability and accelerating structural reforms in order to create a sustainable position of the country's balance of payments, correcting budget deficits, cutting down inflation, reforming the microeconomic framework of policies, and increasing incentives to agricultural producers. The government focused on linking agriculture and the private sector by improving agricultural production and encouraging private sector participation in agricultural marketing and to increase reliance on market forces in order to improve investment in agriculture. To support the functioning of ERP to reach its goal, the government established in 1987 the Tanzania Industrial Research Development Organization (TIRDO), with the intention of conducting industrial research and offering consultancy services to industry. TIRDO was formed with expectations to promote technology utilization and use of local resources.

Trade sector reforms, based on adjusting the exchange rate to promote exports, adjusting tariffs, and liberalizing internal trade, soon followed under ERP. The ERP included various other reform packages aimed at promoting output and facilitating trade including agricultural policy reforms, ${ }^{5}$ monetary, credit, and financial policy reforms, civil service reform, social services sector reform, Parastatal restructuring, and privatization. During programme implementation, the government adopted a crawling peg exchange rate regime (1986) in an attempt to depreciate the overvalued domestic currency (Ndulu 1987). ${ }^{6}$ This caused the nominal exchange rate to depreciate over the next years. A relaxation of exchange controls increased access by import starved manufacturers through the availability of the raw materials and spare parts necessary for improving capacity utilization.

Although the reforms were defined and well understood there were arguments against them. It was believed that they were a threat to many activities that were run by the government as well as to their employees. The reforms were also opposed because they were suspected of benefiting few capitalists thereby creating big differences among people in society. The World Bank carried out a Formal Sector Industrial Survey in 1989 to evaluate the impact of

\footnotetext{
5 These included increasing producer prices, improving agricultural marketing and distribution, and restructuring cooperative unions.

${ }^{6}$ By 1984 the overvalued exchange rate and excessive price controls had resulted in extremely high effective rates of protection. The effective rate of protection for the entire manufacturing sector was no less than 470 per cent in 1984 while overall industrial protection had risen to 526 per cent in the same year from 134 per cent in 1966.
} 
Table 8.4 Average capacity utilization rates in the textile industry in Tanzania: A comparison of public and private firms

\begin{tabular}{lcc}
\hline Year & Public & Private \\
\hline 1980 & 57.6 & 16.9 \\
1981 & 55.6 & 27.8 \\
1982 & 47.4 & 31.3 \\
1983 & 34.4 & 18.2 \\
1984 & 33.0 & 16.5 \\
1985 & 27.1 & 25.0 \\
1986 & 23.3 & 28.2 \\
1987 & 15.9 & 63.7 \\
1988 & 13.7 & 71.1 \\
1989 & 16.2 & 72.8 \\
1990 & 16.3 & 58.1 \\
\hline
\end{tabular}

Source: Adapted from Bagachwa et al. (1992).

the reforms on the growth of output and structure of the industrial sector since the mid-1980s; findings showed that overall industrial performance had improved during the ERP period. The 7 per cent (p.a.) decline in manufacturing GDP between 1979 and 1986 had been reversed so that it grew by 5 per cent (p.a.) between 1986 and 1989 (World Bank 1991).

The ERP was marked with an increasing trend in capacity utilization of the private sector in the textile industry which was accompanied by a reduction in the level of activities sponsored by the state. This postulates that the economy was really shifting from public to welcome private investment.

Table 8.4 reveals that up until 1985, textile establishments that were publicly owned performed better than those which were privately owned. This could have been as a result of the government's emphasis on use of the economy's own resources to bring growth into the industrial sector while putting restrictions on elements of private ownership.

In 1990, the ERP was replaced by the Economic and Social Action Programme (ESAP). The ESAP, unlike the ERP, placed an emphasis on the social costs of adjustment. To facilitate an increased flow of private investment the government set a priority to eliminate trade restrictions in order to accelerate economic activities and widen the tax base. In addition, a tax holiday was accorded to new firms while levels of corporate profit taxes and taxes on dividends were lowered.

All five industrial sub-strategies exhibited a shift from consumer to intermediate and capital goods. During the period the SSRS and EAS created about 596,000 jobs, MGS about 296,000 jobs, MS about 243,000 jobs, and BIS about 193,000 jobs (Skarstein and Wangwe 1986). The Tanzanian economy marked a decline in the balance of payments deficit in the 1988/89 budget; between 1984 and 1989 the level of labour productivity was stable and value added in GDP increased. The adjustments succeeded in devaluing the currency from 
TShs 16 (1986) to TShs 230 (1991) per US dollar. More land was put under cultivation and the country was able to experience an increase in the annual GDP growth rate and agricultural and industrial production in the period 1986-92. This package of reforms carried out in the early 1990s reduced and/or eliminated distortive barriers to production. In manufacturing, the level of capacity utilization which had declined to 5 per cent in the late 1980s increased to 34 per cent in 1994.

On balance, however, the long-term industrial strategy failed to improve the country's export performance. By 1990, the level of recorded merchandise exports had increased but at a decreasing rate which was far below that of 1981. In addition, the nation still suffered from worse unemployment conditions and the public sector was still dominating the economy. There seemed to be a drop in the level of GDP per capita by about 6 per cent from that of the year 1976 (RPED 1994) with a poor performance from the textile industry being one of the reasons. Macroeconomic reforms, privatization, and trade liberalization led to deindustrialization (by 1990, twenty-two out of twentyfour textile factories had closed). In terms of technology development and growing industrial complexity there seems to have been a reversal characterized by industrial shallowing e.g. in textiles (producing grey material instead of printed products) and in engineering industries. Furthermore, the programme did not succeed in reducing the supply of money as was aimed at, largely because of unpaid loans to cooperative unions and marketing boards to finance crop purchases. As a result, the rate of inflation (which had declined from 32.4 per cent in 1986 to 28.9 per cent in 1989) had increased between 1990 and 1994. This hurt domestic purchasing power and led to higher nominal interest rates and affected the market for domestic manufactures.

\subsection{The Return to Industrial Development as a Development Agenda, 1995-2011}

In 1996, a twenty-five-year Sustainable Industrial Development Policy for Tanzania (SIDP2020) began to be implemented with the aim of enhancing sustainable development of the industrial sector. For the period 1996-2020 the government aimed at achieving sustainable industrial sector growth in order to create favourable levels of employment, economic transformation, equitable development, ISI, and export promotion. SIDP accorded priority to employment creation, economic transformation, and equitable development and sought to strike an appropriate balance between ISI and export orientation. The private sector was recognized as the main vehicle for making direct investment in the sector while the government would provide an enabling environment. The government may make direct investment in industries 
(those which the private sector may not find it profitable to invest in) to encourage activities of critical importance for overall development.

The strategy had to be implemented in three phases. Phase I (1996-2000) was for a short-term programme to rehabilitate and consolidate existing industrial capacities. Phase II (2000-10) was for a medium-term programme to create new capacities in areas with potential for creating competitive advantage through use of efficient technology and learning processes. In this phase emphasis had to be placed on initiating the production of intermediate goods and light capital. Phase III (2010-20) is for a long-term programme to achieve major investment in basic capital goods industries to ensure consolidation of the industrial structures developed in the first two phases.

SIDP recognized the importance of the private sector in bringing such changes to the economy and suggested that what the government ought to do is create favourable conditions for the former to function efficiently. However, between 1996 and 1999, export earnings declined by 31 per cent while the overall trade deficit increased by 6.1 per cent (Bigsten and Danielsson 1999). In 1999 the economy adopted the development vision 2025 with emphasis on the role of the industrial sector for development and aiming at the nation to be semi-industrialized by 2025. Vision 2025 recognized the leading role of industry in transforming the economy.

Additional efforts to establish an environment for accelerating industrialization were put into the formation of the EAC in 2000 and into the adoption of common tariffs as well as elimination of intra-regional restrictions. An improving macroeconomic framework saw a reduction in the level of inflation to 5.2 per cent in June 2000 from 21 per cent in 1996, further creating an operating environment conducive to the nascent development policy. In the third quarter of 2000, commodity exports accounted for 50 per cent of total exports. The economy recorded increases in exports of fish, minerals, and other manufactured goods. Further, in 2004 UNIDO reported that by the third quarter of 2002, the total value of commodity exports increased by 16.2 per cent over and above the recorded level of 2001, with exports of non-traditional commodities contributing about 50 per cent of the increase by the end of 2002 .

To augment efforts required to attain SIDP goals, the Export Processing Zones (EPZ) Act was established in April 2002 and its implementation effectively started in March 2003. The objectives of EPZ were to attract and promote investment for an export-led industrialization, to increase foreign exchange earnings, to create and increase employment opportunities, to attract and encourage transfer of new technology, and to promote the processing of local raw materials for export (value addition). Incentives offered by the act included a ten-year exemption from corporate taxes, remission from customs duty, VAT, and other taxes on raw materials and goods of a capital nature 
which are related to production in EPZs, allowances to sell 20 per cent of goods in domestic markets, access to an export guarantee scheme, and unconditional transferability of profits, dividends, loyalties, etc. The vision of EPZ lies in the desire for the Tanzanian economy to export at least 80 per cent of goods/processes and to achieve at least US\$100,000 annual rate of turnover.

In 2002 the economy experienced improved performance in the export sector through an increase in the value of export commodities. Merchandise exports decreased in the early 2000s compared to the 1970s. There has however been a marked growth in the share of exports from specific individual sectors, led by improvements in mining and manufactured goods. The manufacturing sector maintained improvements, which continued in an upward trajectory with an annual growth rate of approximately 5 per cent in 2001, a 0.1 per cent increase on the level estimated two years before. Exports of food, beverages, and tobacco increased between the 1970s and 1990s but then started to fall.

Increasing levels of individual sectors' merchandise exports are partly due to the higher rates of capital growth over time. Capital is a crucial aspect for any economy to prosper as it facilitates effectiveness in production. Fifteen years of implementing SIDP have seen a boost in the economy's capital accumulation which has in return facilitated improvements in the productivity of labour and output.

In 2009, export manufactured goods declined due to the drop in demand for those goods in neighbouring countries as a result of the 2008 economic crisis. Total value of the country's traditional exports was reportedly 22.4 per cent greater in 2011 than during the previous year as a result of a significant increase in both the volume of exports as well as the price per unit of tobacco and cashew nuts. ${ }^{7}$

Currently, industries have been confronted by a series of interrelated external shocks, such as hikes in food prices, increases in energy prices, electricity cut-offs, and financial crises. These have implications for real output. Recent studies suggest that economic development requires structural change from low to high productivity activities. This underscores the need for upgrading and diversifying the industrial base (Lin 2011).

In June 2010 an Integrated Industrial Development Strategy (IIDS) 2025 was also adopted for the purpose of promoting efforts to achieve the SIDP goal of bringing the economy to a state of sustainable industrial development. The IIDS 2025 (June 2010) was formulated with a view to providing concrete strategies to implement SIDP 2020 and build a competitive industry by putting in place a competitive business environment and improving existing

7 (BoT Economic Review, Jan. 2011). 
development corridors-concentrated infrastructure development and promoting agriculture-led industrialization. Manufactured value added was projected to grow at 15 per cent p.a. The IIDS envisages a gateway port improvement for the region and the promotion of Economic Development Zones for growth and infrastructure development. It also articulates an industrial village concept whereby opportunities are created for the growth of micro- and small enterprises. The strategy targeted six sub-sectors: agroprocessing, textiles, leather, fertilizer and chemicals, light machinery, and iron and steel.

\subsection{Conclusion and Way Forward}

When traced over time, industrial development in Tanzania can be seen to have gone through several different evolutionary phases. Between 1961 and 1967 an ISI industrialization policy with relative little state participation was favoured. This was later supplanted by principles of the 1967 Arusha declaration which advocated a more pronounced role in the economy for the state. The nationalization of means of production and distribution soon followed. Policies that were adopted aimed at achieving high levels of growth while ensuring social transformation, increased worker's participation, and equitable distribution of national revenue. There was an increase in public ownership of industry and in state-led regulatory control on the flow of foreign investments, prices, and exchange rates. Less dependence was put on foreign aid and the government suggested utilizing local resources and producing intermediate goods for local industries. SIDO was created in 1973 for this purpose and two groups of industries were formed: one for production of consumables and other for intermediate goods.

In 1975, the BIS (and four others) was adopted to achieve growth by using the country's own resources. Performance of the BIS was hampered by a combination of non-market measures, notably price controls, import licences, and the overvaluation of the exchange rate. The global economic crises of the 1970s and the Kagera war, as well as declining productivity and relative terms of trade led to an acute shortage of manufacturing inputs and goods. Following two unsuccessful episodes of the NESP and the SAP, the ERP came into effect in 1986 and sought to redress the balance. In 1986, price controls were abolished, overall state regulatory control further reduced, the rate of protection was decreased, and active engagement of the private sector sought. To promote export production, some schemes were further introduced one of which was the New Retention Scheme which replaced the GRS.

In the 1990s the government passed the National Investment Act 1997 to promote and protect private investment by providing tax holidays, subsidies, 
and low taxes on corporate profits. This was later followed by the privatization of industries in the mid-1990s. In the same period the nation adopted the SIDP to last until 2020 for the purpose of achieving sustainable industrial development in order to increase employment, economic transformation, equitable development, ISI, and export promotion. However, implementation was derailed by a lack of effective allocation and utilization resources as well as a pronounced focus of the latter years' poverty reduction strategies on social sectors characterized by longer maturity periods.

The output of the economy has been fluctuating and in fewer periods the targeted levels were attained. In recent times, the industrial sector-especially the service and construction sub-sectors-has been showing positive growth and accounts for an increasing share of total employment.

The manufacturing sector in Tanzania remains relatively small, with most activities concentrating on the creation of simple consumer products such as foods, beverages, tobacco, textiles, furniture, and wood allied products. In spite of its declining size, however, the sector continues to be of considerable importance to the Tanzanian economy and is still one of the most reliable sources of government revenue in terms of import sales as well as for both corporate and income taxes, accounting for over half of the annual government revenue collection.

The contribution from the manufacturing sector to overall GDP of the country has averaged 8 per cent over the last decade; however, activities within the sector have been registering an annual growth of over 4 per cent and the sector is currently the third most important to the Tanzanian economy behind agriculture and tourism.

What is the way forward? Expanding the manufacturing sectors of African economies, Tanzania in particular, as a means of stimulating their growth and diversification has long been a preoccupation of many of the region's governments. In spite of this concern, most African countries have not been able to achieve the required threshold levels of manufacturing sector size, structure, and dynamism to help them escape from the vicious cycle that has restricted their significant and sustained entry in to foreign markets (Lyakurwa 2008).

Inherently isolated markets of African products create obstacles for manufacturing industries because of insulation from external market disciplines through trade and competition, thereby being denied the promotion of economies of scale in manufacturing on the continent.

Manufacturing has strategic importance in technology and innovation for economic development since it explores new ideas and is a leading sector for technological diffusion, which has strong linkages and spillover effects associated with manufacturing. However, high production costs continue to frustrate industries across Africa. In Tanzania, much like the rest of sub-Saharan Africa, infrastructure bottlenecks such as disjointed road networks and power 
shortages continue to define the manufacturing landscape. This in turn lowers the productive capabilities of nations with multiple reverberations, for example through increases in unemployment, shortage of goods and services, rise in price levels, and general increase in continental uncompetitiveness.

In positioning the region in the context of open regionalism, globalization, and competitiveness, the acquisition of comparative advantage remains important in strategizing how to take advantage of the continent's resource endowments. However, Tanzania and Africa are awash with impressively written strategies, with effective implementation remaining by far the weakest link. There is a need to take monitoring and evaluation (M\&E seriously: a progress marker might be: How to tell whether progress in the desired direction is being made or not. Priority needs to be placed on mechanisms for monitoring progress and learning over time from feedback. There is a need to plan carefully round what it takes to make it work e.g. human resources, financial resources, infrastructure, and other forms of commitment. Finally, investing in technology and innovation is key, considering that knowledge is the basis of sustainable competitiveness. Incentives are to promote knowledge creation and accumulation and to facilitate access to knowledge and human resource skills.

\section{References}

Bagachwa, M. S. D., Mbelle, A. V. Y., and Arkadie, B. V. (1992). Market Reforms and Parastatal Restructuring in Tanzania. Dar es Salaam: University of Dar es Salaam.

Bank of Tanzania (BoT) (1982). Twenty Years of Independence (1961-1981), a Review of Political and Economic Performance. Dar es Salaam: Bank of Tanzania.

Bigsten, A. and Danielsson, A. (1999). Is Tanzania an Emerging Economy? Göteborg: A Report for the OECD Project 'Emerging Africa'.

Bigsten, A., Mutalemwa, D., Tsikata, Y., and Wangwe, S. (1999). Aid and Reform in Tanzania. Washington, DC: World Bank, available at: <http://documents.worldbank. org/curated/en/1999/08/6705641/aid-reform-tanzania>, accessed 10 February 2016.

Bureau of Statistics (1978). Hali ya Uchumi wa Taifa katika Mwaka 1977-78. Dar es Salaam: Ministry of Finance and Economic Affairs. Government Printer, United Republic of Tanzania.

Edwards, S. (2012). 'Is Tanzania a Success Story? A Long Term Analysis'. National Bureau of Economic Research Working Paper Series, No. 17764.

Lin, J. Y. (2011). 'New Structural Economics: A Framework for Rethinking Development'. World Bank Policy Research Working Paper Series, available at: <http://ssrn.com/ abstract $=1547636>$, accessed 30 August 2012.

Lipumba, N. H. and Kasekende, L. (1991). 'The Record and Prospects of the Preferential Trade Area for Eastern and Southern American States', in A. Chibber, and S. Fisher (eds) Economic Reform in Sub-Saharan Africa. Washington, DC: World Bank. 
Lyakurwa, T. A. (2008). African Imperatives in the New World Trade. Nairobi: Africa Economic Research Consortium.

Maliyamkono, T. L. and Bagachwa, M. S. D. (1990). The Second Economy in Tanzania. London: James Currey.

Mongi, J. F. (1980). 'The Development of Price Controls in Tanzania', in S. Rwegasira (ed.) Inflation in Tanzania. Dar es Salaam: Institute of Finance Management.

Ndulu, B. (1987). Stabilization and Adjustment Policies and Programmes, Country Study 17. Helsinki: UNU-WIDER.

Research Programme on Enterprise Development (RPED) (1994). Development and Growth of Industrial Enterprises in Tanzania. Helsinki: Centre for International Business Studies.

Rweyemamu, J. (1973). Underdevelopment and Industrialisation in Tanzania: A Study of Perverse Capitalist Industrial Development. Oxford: Oxford University Press.

Skarstein, R. and Wangwe, S. M. (1986). Industrial Development in Tanzania: Some Critical Issues. Dar es Salaam: Tanzania Publishing House.

Szirmai, A. and Lapperre, P. (2001). The Industrial Experience in Tanzania. New York: Palgrave.

Timmer, M. P. and Szirmai, A. (2000). 'Productivity Growth in Asian Manufacturing: The Structural Bonus Hypothesis Examined'. Structural Change and Economic Dynamics 11(4): 371-92.

UN Industrial Development Organization (UNIDO) (2004). Tanzania Review of Industrial and Trade Performance; Macro-economy Commodities; Industrial Subsectors; Export Processing Zones. Vienna: UNIDO.

World Bank (1991). Tanzania Economic Report: Towards Sustainable Development in the 1990s, Report no. 9352-TA. Washington, DC: World Bank. 


\title{
9
}

\section{Tunisia}

\section{Industrial Policy in the Transition to Middle-income Status}

\author{
Mohamed Ayadi and Wided Mattoussi
}

\subsection{Introduction}

After independence in 1956, most French civil servants withdrew from Tunisia, leaving a large vacuum in the civil service. The primary goal of the incoming government was therefore to rebuild institutions and the civil service. At the time Tunisia's manufacturing was artisanal, and depended on agriculture, food processing, and mining. Breaking free of this mould at the beginning of the 1960s required adoption of a corporatist structure. The economy was left to depend excessively on the public sector, which advanced import substitution (IS). The eventual failure of this unsustainable model of collectivism led in 1969 to a strategy of combining IS, private sector development, and export promotion. Heavy industry, transport, water, and electricity were, however, left to the state and opportunities for the private sector were limited to the textiles and tourism sectors.

In the 1970 s the country adopted a semi-liberal infitâh policy that constituted a peculiar combination of IS and export promotion and coexistence of the public and private sectors. The private sector was involved in quick return manufacturing activities that are less capital intensive, while the state controlled the heavy industries that were believed to be beyond the capability and interest of the private sector (Bellin 1994). The infitâh policy opened up foreign trade and provided incentives aimed at encouraging the private sector to assume a more active role. These included extensive institutional and technical support deployed through new state bodies such as the API and CEPEX. In the 1970s the economy was characterized by an offshore sector 
dominated by foreign investors and geared towards exports targeting external markets and dominated by foreign players; an onshore sector that was shielded from competition and regulated by the state; a public sector composed of large firms, monopolized strategic sectors; and a private sector which primarily consisted of small business units that focused on simple assembling activities.

Later, in the early 1980s, the Tunisian economy experienced a slowdown in growth and productivity. To remedy the maladies caused by economic mismanagement and the political instability of the mid-1980s, the government put in place the Economic Recovery and Structural Adjustment Programme (ERSAP) which focused on tariff reduction, facilitating quantitative restrictions on imports, the introduction of a value added tax, the reduction of personal income taxes, the devaluation of the Tunisian dinar, and negotiations with creditors that extended the maturity on the country's foreign debt. The moderation of political instability following regime change in 1987 improved the business climate and encouraged the private sector to be more active, in particular for export-oriented activities.

During the 1990s Tunisian authorities promoted liberalizing measures through a legislative framework that encouraged foreign investment, accelerating privatization and deepening integration into the European market (UNIDO 2001). Trade remained protectionist throughout the first half of the 1990s. Since the mid-1990s, however, domestic industries have been liberalized, especially vis-à-vis 'preferential' trading partners. The government created several trade supports with the view to establishing a free trade agreement (FTA). At the time Tunisia was part of several trade agreements including GATT (General Agreement on Tariffs and Trade) in 1994, and subsequently became a member of the WTO (World Trade Organization) in March 1995. Tunisia became signatory to the European Union Association Agreement in July 1995 and a 1997 convention targeting the creation of an Arab free-trade zone over a period of ten years. Also, the country fostered bilateral ties with Morocco, Jordan, and Egypt further reducing tariffs. The government encouraged modernization of the industrial sector with the upgrading programme Programme de mise à niveau which was launched in 1996 and the Industrial Modernization Programme (PMI). These programmes were intended to provide firms with technical assistance, training, subsidies, and infrastructure upgrades to help them face international competition and survive in an open-market economy.

Economic policies in the 2000s provided conditions for improving the performance of the economy, developing its structure, enhancing its competitiveness, and ensuring openness requirements. These policies upgraded service companies and especially restructured hotel units, provided skills upgrading, and facilitated access to new technologies. Special programmes were put in place focusing on the development of industrial and tourist zones. Also the 
quality of roads was improved and communication infrastructures modernized. More measures were put in place to support entrepreneurs in the areas of simplifying new business creation procedures, and the creation of a network of business centres of excellence. Reforms aiming at trade liberalization focused on assisting in operations of export market prospecting, and forging a partnership agreement with the EU. Tunisian authorities developed the tax system, modernized monetary policy through the implementation of open-market instruments, optimized liquidity control operations, and adopted a flexible exchange rate policy thereby reinforcing financial liberalization and facilitating transactions of national companies.

The reforms set the stage for a marked growth in GDP, domestic and foreign investment, and exports during 2002-6. The service sectors led the way, while emerging industrial activities such as the mechanical and electrical industries followed closely. Export of goods and services expanded at an average rate of 8.5 per cent, mainly due to the emergence of new export sectors such as mechanical and electrical industries, automotive components, and textile and tourism exports. Until 2010, the Tunisian economy had masked inequitable growth and high unemployment rates-particularity among educated youth. Consequently, growing youth unemployment, corruption, and political repression led to the Arab Spring and the fall of the regime.

The study outlines historical developments that informed the structure of the Tunisian industrial sector, challenges to its development, and future prospects. The remaining sections are structured as follows. Section 9.2 presents a historical background of the Tunisian economy since independence (1956). The past five decades are divided into four milestones: the period of liberalization (1956-60); the collectivism experiment (1961-9); transition to a protectionist market economy (1970-85); and a period of private investment boom, competitiveness, and openness (1986-2010). Section 9.3 evaluates the performance of the manufacturing industry over the past five decades in terms of export. Section 9.4 discusses the evolution of Tunisian industries in terms of production, exports, and foreign direct investment (FDI). Section 9.5 presents major industrial policies undertaken by the Tunisian government since independence. Section 9.6 concludes.

\subsection{Evolution of Industry: Historical Perspectives}

\subsubsection{Initial Conditions}

Following independence in 1956, most French civil servants went back home leaving a large civil service vacuum. Between 1956 and 1960, almost all 12,000 French public servants working for the Tunisian administration were obliged to repatriate. In 1960, Tunisia signed an agreement with the French government 
to recover land annexed by the French government (UNIDO 2001). During the first few years following independence, the main goal of the new government was to rebuild institutions and the civil service in order to fill the institutional vacuum. At the beginning of the 1960s, Tunisia faced high illiteracy rates, and the standard of living of the majority of Tunisians was low. In 1966 poverty incidence rates were estimated at 33 per cent. Agriculture generated the largest employment and there was very little industry or tourism. The Tunisian government, naturally, put more emphasis on major dimensions of human development: education, family planning through birth control, women's rights, and 'eradication' of poverty (see Ayadi et al. 2005).

\subsubsection{The 1960s: 'Collectivism' Experiment}

The 1960s were years of policy experimentation: agricultural cooperatives, ${ }^{1}$ collectivism, and state-led IS. Industrialization was state-led with the private sector playing a marginal role. These industries reduced Tunisia's dependence on imported products, but did not create new employment in industry (Findlay 1984; Baker et al. 1999). Capital ${ }^{2}$ accumulation was by far the main source of growth in the 1960s (around 60 per cent). Investment went into capital intensive projects such as steel mills, an oil refinery, a paper plant, a couple of large textile factories, and an automobile assembly plant. Although these projects absorbed a large share of investment resources, they barely contributed to job creation.

\subsubsection{The 1970s: Private Sector Development and Export Industry Promotion}

Collectivism did not generate the dynamism that the government had hoped for, and eventually gave way to a strategy of combining IS, private sector development, and export promotion. The public sector nevertheless kept its grip on key sectors such as heavy industry, transport, water, and electricity; while the private sector focused on textiles and tourism. Windfalls from oil revenue, a budding private manufacturing industry, and tourism featured prominently in economic growth in the 1970s. Government helped by creating an enabling environment, setting up new institutions and new laws that promoted private sector development and foreign and domestic investment.

An Industry Promotion Agency (API) assisted investors and promoters with the administrative and legal formalities necessary for company incorporation in Tunisia. Supporting business information was provided to foreign importers

\footnotetext{
1 Cooperatives were also promoted in other economic sectors: all traders and several craftsmen were forced to join the cooperatives (Morrison and Talbi 1996; UNIDO 2001).

${ }^{2}$ In turn, labour barely contributed to growth with a rate almost equal to 10 per cent.
} 
by an Export Promotion Centre (CEPEX)-both institutions were created in 1973. An investment law (Law 72-38) was adopted in (1972) offering special advantages to exporting manufacturing companies. Incentives consisted of partial or total tax exemption for periods of 10-20 years and 50 per cent reduction thereafter (granted also to partially exporting firms), full tax exemption on reinvested profits and income, total exemption from customs duties on imported capital goods, raw materials, semi-finished goods, and services. A similar law was enacted in 1974 which encouraged investment in industries producing for local markets and which was later amended in 1981. Such firms were required by law to be owned by Tunisians (at least partially) which provided them with a wide range of tax concessions (e.g. exemption from corporate income tax during the first ten years of operation and repatriation of profits free of tax). Industrial zones were managed by a new Industrial Land Agency (AFI).

These policy packages contributed to a turnaround in labour productivity. Light manufacturing and tourism grew at rates exceeding 13 per cent per annum on average. GDP growth averaged 7.5 per cent per year during the 1970s. The private sector grew rapidly under the protection of import restrictions. Between 1972 and 1977 private investment exceeded public investment and 85,500 new jobs were created in light manufacturing industries (Findlay 1984; King 1988). However, the industrial structure remained concentrated in a few sectors and regions. In 1977, 54 per cent of new investment and 87 per cent of employment were concentrated in textiles, clothing, and leather (TCL) sectors. Almost all new industries were concentrated in the northeastern region, strengthening regional disparities and encouraging further migration towards this region (UNIDO 2001).

\subsubsection{Economic Mismanagement, 1977-86}

At the end of the 1970s, Tunisia's foreign debt ballooned while the economy showed no stable productive base capable of absorbing an excess labour force and exporting a diversified and competitive range of goods (Morrison and Talbi 1996). The Tunisian economy experienced further slowdown in the period between 1981 and 1986, reaching the lowest growth performance (2.8 per cent per annum) and productivity decline (around 1.5 per cent per year). The poor performance was mainly attributed to economic mismanagement and political instability. Despite low growth performance, the government instituted a public sector wage raise that inflated the wage bill. At the same time, food subsidies were maintained at record levels, representing more than 5 per cent of GDP. Inflation rose sharply to over 8 per cent while the current account deficit grew to over 10 per cent of GDP. In 1986 Tunisia registered negative growth, amid growing social unrest and labour strikes (Morrison and Talbi 1996; Baker et al. 1999; UNIDO 2001). Faced with internal imbalances 
and external debt, Tunisia negotiated its first economic adjustment programme (ERSAP) in 1986 (King 1988).

\subsubsection{Economic Recovery and Structural Adjustment Programme, 1986-90}

The ERSAP led to tariff reductions, quantitative restrictions on imports, introduction of a value added tax, reduction in personal income taxes, devaluation of the Tunisian dinar, and negotiations with creditors to extend the maturity on the country's US\$10 billion foreign debt. The privatization programme led to the full or partial privatization of nearly 160 state-owned companies. While public investment declined, the ensuing slowdown in growth was moderate (going from 3.7 per cent during 1980-5 to 3.0 per cent per annum during 1985-90). Macroeconomic stability was restored and the external debt burden fell. In addition, there was a sharp fall in inflation (below 5 per cent in less than ten years) and a reduction in the current account deficit from 7.8 per cent of GDP in 1986 to 2.4 per cent in 1996. Fiscal discipline and the realignment of the exchange rate were instrumental in reducing public and external deficits and placing the economy on a sustainable growth trajectory. The reduction in political instability following regime change in 1987 improved the business climate creating a vibrant private sector-especially in export-oriented activities.

\subsubsection{The 1990s: Global Competition}

Tunisian authorities played a crucial role in influencing the private sector to cope with increased competition in global markets. A legislative framework encouraged foreign investment, while privatization measures facilitated deepening integration into European markets (UNIDO 2001). The government encouraged modernization of the industrial sector through the Programme de mise à niveau launched in 1996 and the PMI that subsequently followed. The government created several trade initiatives with a view to establishing an FTA with the EU to improve the manufacturing sector's productivity and to increase the export share of manufacturing products. Trade remained protectionist throughout the 1980s and the first half of the 1990s. Since 1996, however, the government has gradually liberalized trade in manufacturing. Economic policies in the $1990 \mathrm{~s}$ contributed to a steady decline in capital. During the same period, labour productivity gains became important sources of growth - real GDP grew faster than in the previous period.

\subsubsection{Development of Services and Innovative Projects, Early 2000s-2011}

During the period 2002-6, economic indicators including GDP, investment, FDI, and export volumes of goods and services showed steady growth. Real 
GDP grew at an average rate of 4.5 per cent, despite agricultural sector stagnation on account of unfavourable climatic conditions.

The 2000s are characterized by the development of service sectors, which exhibited an average growth rate of 7.2 per cent. The mechanical and electronics industries showed promise with growth rates averaging 8.9 per cent. During the same period, the contribution from technologically intensive sectors to GDP grew to 20.4 per cent in 2006 against 16.8 per cent in 2001 . Overall investment grew at an average rate of 5.1 per cent to reach TND 41.2 billion. Favourable investment policies encouraged the participation of foreign firms leading to substantial growth of FDI over the period (close to 884 joint-venture firms were established during the period).

The private sector became the dominant force in the Tunisian economy, contributing towards totals of 57.1 per cent of total investment, 85 per cent of exports, and 91 per cent of job creation. Export of goods and services grew at an average rate of 8.5 per cent, because of the emergence of new export sectors such as mechanical and electronics industries, automotive components, and textiles and tourism. Economic performance during the period relied on the preservation of internal and external financial stability-most importantly a favourable current account deficit at 2.4 per cent of GDP; a reduction in the rate of external debt to 47.9 per cent of net income; consolidation of monetary reserves; control of budget deficit, excluding donations; and privatization return to an average rate of 3.1 per cent of GDP (Republic of Tunisia 2010).

\subsubsection{The Arab Spring: Tunisian Revolution of 14 January 2011}

Several factors including youth unemployment, corruption, human rights violations, extreme poverty, and regional disparities sparked the Arab Spring that unseated the ruling government. Even though the Tunisian economy had exhibited strong competitiveness prior to these events, it had also masked the inequitable growth and high unemployment rates among educated youth.

\subsubsection{YOUTH UNEMPLOYMENT}

In Tunisia unemployment is concentrated in younger age cohorts. In 2008 the unemployment rate for individuals under thirty years of age was nearly 30 per cent-twice the overall unemployment rate (Haouas et al. 2012). Unemployment rates among 25-29-year-olds increased from 12.6 per cent in 1984 to 25.2 per cent in 2008 (Haouas et al. 2012).

Young university graduates were particularly disadvantaged by the deterioration of job creation. Unemployment levels among youth completing higher education grew from 3.8 per cent in 1994 to 21.6 per cent in 2008 (Haouas et al. 2012). Search friction in an environment where the education system and training are not related to the structure of the economy culminated in these 
large unemployment rates. Private sector job creation remains concentrated on low-skill employment, while private investment is relatively low and tightly controlled by government.

\subsubsection{REGIONAL DISPARITIES}

Regional disparities in Tunisia are structural and institutional. Overall, coastal regions (such as Cap Bon, Sousse, Sfax, Mehdia) tend to be wealthier than inland regions (western, central, and southern regions); but these disparities are much more severe in Tunis, largely due to the political dominance of networks centred on the political regime. Factories (and employment prospects) have long been concentrated along Tunisia's coast, while the interior regions were isolated from these hubs of economic activity not only by distance but, more significantly, by lack of infrastructure, transportation, and information networks. Population and economic activities are mainly concentrated in the northeast (governorate of Tunis) and the mid-east (governorate of Sfax) with coastal regions accounting for 75 per cent of non-agricultural jobs. This has been the source of a significant gap in average consumption and poverty across costal and interior regions.

In 2010, while the poverty headcount (national average) stood around 15.5 per cent, regional disparities in poverty levels were much more significant. Considerable disparity in employment opportunities across regions has persisted for decades. For instance, on average, since 2004 the unemployment rate has exceeded 22.6 per cent in the regions of Jendouba, Le Kef, Kasserine, and Gafsa. Patterns of government spending have largely failed to address these persistent regional disparities in development. Close to 65 per cent of public investment is allocated to coastal areas. As a consequence, healthcare needs in the mid-west region are largely unmet and youth illiteracy remains significantly high.

A recent World Bank study ${ }^{3}$ on inequality across the Middle East and North Africa regions suggests that marginal improvements in transportation and digital connectivity networks entail significant welfare gains for disadvantaged regions.

\subsubsection{ECONOMIC COSTS OF THE ARAB SPRING}

In the wake of the revolution, investment sharply declined in almost all sectors, except the electronics sector, which saw uninterrupted growth (APII 2012). FDI flows decreased by 29.2 per cent during 2011 compared to 2010. Consequently, 182 foreign firms closed their doors (sixty-four Italian firms, sixty-one French firms, ten German firms) leading to the loss of 10,930 jobs. The decline of FDI was particularly severe in the tourism sector where losses were estimated at 83.3 per cent, while manufacturing and energy exhibited losses amounting to 42.4 per cent and 19 per cent, respectively.

\footnotetext{
3 Brisson and Krontiris (2012).
} 


\subsubsection{GOVERNMENT MEASURES}

The government took steps to limit losses in affected firms. Some of these measures included:

- reduction in firms' contributions to social security by 50 per cent

- reduction or even abolition of firms' tax dues for 2011

- reduction in credit fees by two points.

The government adopted an economic and social enhancement plan (FIPA 2012), through which more investment is devoted to less developed regions. The plan provided more incentives for investment through the Tunisian financial market, allowed totally exporting firms to operate in the local market, and facilitated firm level access to liquidity.

\subsubsection{ECONOMIC RECOVERY, 2012}

FDI flows recovered by as much as 44 per cent, from 775.3 MTD during the first half of 2011 to $1,121.2$ MTD in the first half of 2012. Compared to the same period in 2010, FDI amounts rebounded to 1,090.6 MTD, surpassing 2010 levels by about 2.8 per cent (APII 2012). During the first few months of 2012, seventy-one foreign firms were created giving rise to 6,731 new jobs. FDI was mainly concentrated in energy and manufacturing sectors (APII 2012).

\subsection{The Structure of Industry}

After a half century of rapid growth, the structure of the Tunisian economy changed. While industry and services shares in output have increased, that of agriculture has gradually decreased. Manufacturing was the fastest growing sector (particularly textile and garment). Excluding the agro-food industry, manufacturing value added grew at 11 per cent annually over about four decades, until 2000. By the year 2000 the textile and garment sector accounted for almost half of total manufacturing employment and 14 per cent of total employment. The rapid growth of this made it easier to absorb a large portion of low-skilled, active female population from neighbouring rural areas (Ayadi et al. 2005). During the period 2000-7, the contribution from industry to GDP stood at 29.2 per cent and its growth rate averaged 4.2 per cent (Chemingui and Sánchez 2011).

\subsubsection{Three Pillars of the Tunisian Manufacturing Industry}

In 2007, three sectors accounted for 87 per cent of exports, close to 62 per cent of FDI, and more than 83 per cent of jobs in the manufacturing sector-textile and footwear, agro-food processing, and the electronics industry. 
9.3.1.1 TEXTILE/CLOTHING AND LEATHER/FOOTWEAR INDUSTRIES The Tunisian textile industry gradually evolved from subcontracting ${ }^{4}$ to cocontracting, and subsequently to finished goods, to become the fifth largest supplier to the EU. The majority of businesses making up the sector produces for export markets. This includes more than 1,700 textile firms and more than 200 leather/footwear firms. There are 1,500 ready-to-wear garment manufacturers and 200 hosiery concerns, accounting for more than 70 per cent of exports by the sector. The leather and footwear industry is dominated by shoes-and-uppers producers. More than 220 firms out of a total of 300 businesses are engaged in the production of shoes and leather uppers.

\subsubsection{AGRO-FOOD INDUSTRIES}

Exports increased by almost 300 per cent during 2002-7 to TND 1,616 million, up from TND 557 million in the previous period. Firms in the agro-food sector employing at least ten or more people number over 1,000. One hundred and fifty-six of these firms are full exporters while close to 104 are financed partially by foreign holdings. Firms producing oils and fats, and cereals, and handling cold storage represent almost 70 per cent of the overall number of businesses in this sector.

\subsubsection{MECHANICAL/ELECTRICAL/ELECTRONIC INDUSTRIES}

These industries accounted for more than 30 per cent of industrial exports in 2007. During 2002-7, exports were growing at an annual rate of more than 20 per cent.

\subsubsection{Evolution of Manufacturing Industry: More Competitiveness and Openness}

The share of industry in GDP and total employment stood at 30 per cent and 32.5 per cent respectively in 2007. TCL industries benefited greatly from export promotion strategies which had been instituted in the 1970s with the aim of strengthening light industry beyond traditional food processing activities.

The decades following independence were dominated by an importoriented industrial strategy. At the beginning of the 1980s, the manufacturing sector accounted for 15 per cent of GDP. Over five decades, the structure of the industry changed significantly with the growth of the chemical and textile

\footnotetext{
${ }^{4}$ Industrial initiatives in Tunisia up until the late 1990s often handled just a limited part of the production process (task-based production). Companies today are no longer interested in handling only isolated portions of production, even if they are productive and profitable. Interest lies in coordinating links between various sites, leading to total immersion of Tunisian industry in other research, production, and service or distribution entities.
} 
sectors. The relative importance of exports continued as a result of the structural adjustment policy instituted in 1986 and later, with the Barcelona Declaration (1995). ${ }^{5}$

The progressive elimination of import tariffs and ensuing global competition provided an incentive for Tunisian firms to raise productivity. During 1983-7, the effects of the second oil crisis were still being felt and Tunisia faced severe economic and financial crises resulting from the decline in oil export earnings and net remittances (Morrison and Talbi 1996). A more restrictive external trade policy was instituted to stem the balance of payments crisis and the sharp fall in external reserves.

During 1987-95, and consequent to the adoption of structural adjustment policies, Tunisia joined GATT and became a signatory to the WTO. In addition to the multilateral approach to trade policy, a stronger Euro-Mediterranean partnership grew out of the Barcelona Declaration (1995).

Gradually, domestic demand became a key driver of real GDP growth especially during periods of global recession. During the past two decades, private consumption has contributed to growth and compensated for the decline in foreign demand during global recessions. Private consumption remains one of the main drivers of growth and occupies a central place in Tunisia's development strategy (Chemingui and Sánchez 2011).

\subsubsection{EXPORT AND OFFSHORING}

More recently, close to 70 per cent of manufacturing exports have come from firms that have benefited from offshore status since 1972. The major trading partners are France, Italy, Spain, and Germany. Up until the mid-1980s, export products exhibited high dependence on factor endowments, primarily natural resources (such as petroleum and derived products). Between 2000 and 2003, manufactured exports accounted for 80 per cent of the total exported. In June 2010, there were 5,840 industrial companies registered with the Industrial Agency Centre (API), 48 per cent of which exported all of their production (offshore sector). During the same period, Tunisia's exports of machinery and electrical products became the largest export sector. More than 80 per cent of industrial exports are shipped to European markets and close to 2,200 industrial European firms operate in Tunisia. Exports to EU countries have expanded more than 10 per cent annually since 1996.

Tunisia's exports are concentrated on a few products. For instance, the textile and agro-food sectors represent 50 per cent of production and 60 per cent of

\footnotetext{
${ }^{5}$ In November 1995, the Barcelona Declaration established a global framework geared towards strengthening a multidimensional partnership between the EU and twelve South and East Mediterranean (SEM) countries, including Tunisia. The main objective of this declaration was to promote shared prosperity on both sides of the Mediterranean Sea, mainly through the development of regional trade-liberalization of trade in goods by both parties by 2008 .
} 
employment. Export destinations are limited to a handful of EU countries (France, Germany, and Italy) and face strong competition from Asian exporters-China and India and Eastern European countries-that have higher productive costs and face lower labour costs.

Tunisian exports of manufactured products are mainly concentrated on textile and clothing, which constitute almost 70 per cent of manufactured products. However, a number of new products have emerged strongly from EU countries. For instance beam wire exports have targeted European massproduced vehicles, electronic components, certain plastic products, essential oils, and detergents.

Several modernization and upgrading programmes (mise à niveau) were implemented to enhance the competitiveness of Tunisian firms including the upgrading programme launched in 1996 and supported by the PMI partially funded by the EU. These programmes aided firms in their efforts to modernize equipment, resources, and governance strategies. This has improved the competitiveness of Tunisian firms, now consequently leading the expansion of industrial exports to 84 per cent of overall exports in 2007, up from 40 per cent in 1995.

The textile sector which accounted for 40 per cent of exports and 46 per cent of employment in 2005 faces persistent competition from lower cost and efficient Asian producers and exports including China. Tunisian wages in the sector are relatively high compared to other exporters such as China. On average, a Tunisian worker earns a monthly salary of €115-130 (40-48-hour working week), while a Chinese worker receives between 50 and 60 per cent less.

Tunisia is the fourth largest exporter of textiles to the EU. Current estimates by the World Bank indicate that one-third of the 250,000 jobs in the sector are threatened. The economy's continued dependence on low-cost production and traditional export sectors make it vulnerable to low-cost competitors. Export-oriented sectors, textile, and electromechanical equipment industries, in particular, have been weakly integrated into the rest of the economy (Chemingui and Sánchez 2011). Thus, only growth in high technology products is bound to absorb highly skilled unemployed Tunisians.

\subsection{Industrial Policy}

\subsubsection{Foreign Direct Investment}

Tunisian policy makers have instituted many measures over the past decades in a bid to spur on modern technology, enhance productivity, and stimulate 
export-led growth by attracting FDI. The government provided a wide range of incentives including:

- tax relief up to 35 per cent on reinvested revenues and profits (30 per cent beginning in 2007);

- exemptions from customs duties and a 10 per cent reduction in VAT for imported capital goods having no Tunisian manufacturing equivalent;

- suspension of VAT and sales tax on locally produced equipment at company start-up and an optional depreciation schedule for capital equipment older than seven years.

In 1972, an investment law provided special benefits for manufacturing companies producing for export. The regulation has been successful in attracting foreign involvement, particularly in the textile industry. The investment laws provided incentives consisting of:

- partial or total tax exemption for periods of 10-20 years and 50 per cent reduction thereafter (granted also to partially exporting firms);

- full tax exemption on reinvested profits and income;

- total exemption from customs duties on imported capital goods, raw materials, semi-finished goods, and services necessary for business.

A similar law was enacted in 1974 (amended in 1981) with the aim of encouraging investment in industries producing for local markets.

- The statute required firms eligible for benefits to be partially owned by a Tunisian (in many cases conditional on majority ownership).

- An amendment to the law in 1981 offered incentives for investment in less developed regions.

In the 1990s, the ratio of net FDI flows to GDP reached 2.2 per cent. FDI distribution by sector revealed that until the first half of the 1990s, FDI was mainly directed towards the petroleum and gas sector (about 80 per cent against 8 per cent for the manufacturing sector). By 1998, and following a successful privatization programme, the share of total FDI in the manufacturing sector grew substantially compared to the petroleum and gas sector (35 per cent and 58 per cent respectively).

The annual investment flow of FDI to Tunisia peaked at US\$778.8 million in 2000, up from US\$368 million in 1999. The annual investment flow fell following the global economic slowdown of 2001 and the September 2001 terrorist attacks in the United States. FDI flow to Tunisia fell from US\$486 million in 2001 to US\$402 million in 2002. Nevertheless, in 2002, the manufacturing sector accounted for 84 per cent of foreign owned firms in the country and 90 per cent of new jobs created. 
The Tunisian government has been relatively successful in creating an attractive environment for export-oriented foreign investors. The country is rapidly becoming an attractive destination for European investment due to geographical and cultural proximity. But even firms from the BRIC countries (Brazil, Russia, India, and China) and North America have expanded investment. Kearney's Global Services Location Index (GSLI), ranked Tunisia as the seventeenth most attractive offshoring ${ }^{6}$ destination in the world. The GSLI, which analyses and ranks the top fifty countries worldwide for locating outsourcing activities, bases its index on forty-three measurements, grouped into three categories: financial attractiveness, people and skills, and availability and business environment.

The report indicates that the geography of offshoring is rapidly shifting, with the Middle East and North Africa emerging as key offshoring destinations because of their size, high literacy rates, and proximity to Europe. Currently, 3,000 foreign companies are operating in Tunisia. The country has earmarked 7.5 per cent of its GDP for the education sector and 1.25 per cent for scientific research and innovation.

\subsection{2 $R \& D$ and Innovation Policies in Tunisia}

The mise à niveau is an industrial upgrading programme instituted in $1996^{7}$ targeting strategic sectors of the national economy. Launched in a pilot in 1996, the programme was supported in part by EU grants and consisted of technical assistance, training, subsidies, and infrastructure upgrades with the aim of restructuring and modernizing Tunisia's private sector.

During 1997-2006, the Ministry of Higher Education Scientific Research and Technology (MHESRT) reported the value of credits allocated to research and development (R\&D) to have reached TND 430 million in 2006 from TND 89 million in 1997. According to the office of planning and programming studies, the number of researchers in full-time positions reached 15,833 individuals in 2006 against 6,563 in 1998. During the period 1998-2006, the number of researchers per million inhabitants more than doubled, from 2.14 to 4.52 .

The number of national patents filed has significantly increased, from 160 in 1990 to 338 in 2005. Foreign investors own a majority of the patents (MHESRT). Between 1996 and 2005, only ten patents were filed by Tunisian companies in the United States Patent and Trademark Office (USPTO)—a very

\footnotetext{
${ }^{6}$ Offshoring defines the delocalization of service or production activities of certain firms towards countries exhibiting low wages or other advantages. This phenomenon was started after 1970 by American firms. After avoiding it for a long period, European firms became progressively more conscious of the advantage of reducing costs by delocalizing their firms. Firms could find the necessary competencies for their development by dealing with specialized subcontractors from other countries: in such a case, we speak of outsourcing offshore. If these firms are filial, we then talk about foreign direct investment.

${ }^{7}$ The programme was first adopted in 1995 and successively revised over time.
} 
small number as compared to other European and Mediterranean countries. The number of patents filed in the USPTO by partner countries between 1996 and 2005 stood at 42,464 for France, 19,334 for Italy, 3,651 for Spain, twentysix for Jordan, thirty-one for Morocco, and ninety-one for Egypt.

\subsection{Sunrise and Sunset Industries}

In this section the sunrise and sunset industries are presented in terms of production, exports, and FDI.

\subsubsection{Production, Investment, and Exports: Overview}

During 2004-8, the manufacturing sector grew at an annual rate of 14 per cent. However, not all sectors have experienced similar growth. While the textile and garment production sub-sector stagnated, with annual growth limited to 1 per cent during 2004-8, the electronics and chemical sub-sectors grew at annual rates of 21 per cent and 33 per cent, respectively (Table 9.1).

The growth in investment accounted for much of the growth in the manufacturing sector. Investment is still more concentrated on old industries, notably textile and garment (TND 1,364 million in 2008) rather than technology intensive sectors such as the electronics industry (TND 146 million in 2008).

Manufacturing exports represent 80 per cent of total national exports. Their levels have shown a steady rise with annual growth averaging around 16 per cent (during 2004-8). However, export growth rates differ by sub-sector. For instance, chemical product exports grew at an annual rate of around 33 per cent, while mechanical products exports and electronics exports grew at annual rates of 29 per cent and 22 per cent, respectively. In turn, the textile and garment exports have experienced a low growth rate which barely reaches 4 per cent per year (Table 9.2).

Table 9.1 Industrial production trend, 2004-8

\begin{tabular}{lrrrrrr}
\hline Sector & 2004 & 2005 & 2006 & 2007 & 2008 & $\begin{array}{l}\text { Annual growth } \\
\text { rate (\%) }\end{array}$ \\
\hline Chemical and rubber & 2,857 & 3,041 & 3,179 & 3,564 & 8,958 & 33 \\
Leather and shoes & 2,095 & 2,520 & 3,010 & 3,864 & 4,536 & 21 \\
Electrical and electronic & 3,051 & 1,280 & 3,271 & 4,611 & 5,681 & 17 \\
Mechanical & 2,169 & 2,305 & 2,851 & 3,254 & 3,706 & 14 \\
Agro-food & 6,784 & 7,060 & 7,888 & 8,615 & 9,927 & 10 \\
Building materials & 1,832 & 1,963 & 2,211 & 2,350 & 2,584 & 9 \\
Miscellaneous industries & 2,312 & 2,477 & 2,616 & 2,805 & 3,009 & 7 \\
Textile and clothing & 5,191 & 5,120 & 4,876 & 5,341 & 5,364 & 1 \\
Total & 26,291 & 25,766 & 29,902 & 34,404 & 43,765 & 14 \\
\hline
\end{tabular}

Source: Based on data from Ministère du développement et de la coopération internationale (MDCI 2012). 
Table 9.2 Industrial exports trend, 2004-8

\begin{tabular}{lrrrrrr}
\hline Sector & 2004 & 2005 & 2006 & 2007 & 2008 & $\begin{array}{l}\text { Annual growth } \\
\text { rate (\%) }\end{array}$ \\
\hline Agro-food & 1,227 & 1,233 & 1,599 & 1,616 & 1,850 & 11 \\
Building materials & 172 & 204 & 272 & 302 & 375 & 22 \\
Mechanical & 694 & 806 & 1,022 & 1,554 & 1,928 & 29 \\
Electrical and electronic & 1,861 & 2,184 & 2,661 & 3,464 & 4,217 & 23 \\
Chemical and rubber & 1,113 & 1,307 & 1,430 & 1,731 & 3,499 & 33 \\
Textile and clothing & 4,481 & 4,452 & 4,422 & 5,185 & 5,183 & 4 \\
Leather and shoes & 621 & 685 & 726 & 875 & 894 & 10 \\
Miscellaneous industries & 477 & 475 & 622 & 836 & 1,005 & 20 \\
Total & 10,646 & 11,346 & 12,754 & 15,563 & 18,951 & 16 \\
\hline
\end{tabular}

Source: Based on data from Ministère du développement et de la coopération international (MDCI 2012).

\subsection{Conclusions}

The Tunisian economy has undergone substantial structural change since independence in 1956. The economy has transited from liberalism, through a brief stint of collectivism, to a full-fledged market economy. The relatively closed and inward-oriented state-driven economy, heavily dependent on the public sector and insulated from foreign competition, has given way to an increasingly outward-oriented and export-oriented market economy. Currently, a modern and competitive manufacturing industry is at the centre of economic growth and holds the key to future economic prosperity. Past records of consistent growth have often masked inequality, regional disparities, and high unemployment rates among educated youth.

However, the gradual transformation of the economy towards technologically sophisticated manufactured exports is expected to absorb portions of the educated youth by creating opportunities for highly skilled jobs. More measures are being taken by the government to make sure that regional disparities are addressed. The government has expressed intentions to channel public investment to improve infrastructure projects in marginalized regions with the aim of attracting private investment. Statutory frameworks are being revised to accommodate objective criteria for selecting investment projects.

\section{References}

Agency for the Promotion of Industry and Innovation (APII) (2012). Agency for the Promotion of Industry and Innovation, available at <http://www.tunisieindustrie. nat.tn/en/home.asp>, accessed 12 February 2016. 
Ayadi, M., Boulila, G., Lahouel, M., and Montigny, P. (2005). 'Pro-Poor Growth in Tunisia'. International Development and Strategy. Paris, available at <http://siteresources. worldbank.org/INTPGI/Resources/342674-1115051237044/oppgtunisia11.pdf>, accessed 12 February 2016.

Baker, G., Gibbons, R., and Murphy, K. J. (1999). 'Informal Authority in Organizations'. Journal of Law Economics and Organization 15(1): 56-73.

Bellin, E. (1994). 'Tunisian Industrialists and the State'. World Development 22(8): 1211-21.

Brisson, Z. and Krontiris, K. (2012).'Tunisia from Revolutions to Institutions'. A Report by the World Bank and Reboot. Washington, DC: World Bank.

CEPEX (2015).'Tunisia Export news', available at <http://www.cepex.nat.tn/actualites/ actualit\%C3\%A9s-du-cepex>, accessed 12 February 2016).

Chemingui, M. and Sánchez, M. (2011). 'Assessing Development Strategies to Achieve the MDGs in the Republic of Tunisia'. A Report by the United Nations Department for Social and Economic Affairs (UNDESA). New York, NY: UNDESA.

Findlay, R. (1984). 'A Comment on North-South Trade and Export-led Policies'. Journal of Development Economics 15(1-3): 161-7.

Foreign Investment Promotion Agency (FIPA) (2012). 'Invest in Tunisia', available at $<$ http://www.investintunisia.tn>, accessed 13 February 2016.

Haouas, I., Sayre, E., and Yagoubi, M. (2012). 'Youth Unemployment Tunisia: Characteristics and Policy Responses'. Topics in Middle Eastern and African Economies 14 (September): 395-415.

King, R. (1988). 'Production, Growth and Business Cycles: II. New Directions'. Journal of Monetary Economics 21(2-3): 309-41.

Ministère du développement et de la coopération international (MDCI) (2012). 'Economic Indicators', available at <www.mdci.gov.tn/index.php/2012-05-05-09-36-04/indicateurseconomiques>, accessed 25 October 2015.

Morrison, C. and Talbi, B. (1996). Long-term Growth in Tunisia. Paris: OECD.

Republic of Tunisia (2010). Economic and Social Development in Tunisia, 2010-2014: Towards an Innovation and Creation Based Growth. Tunis: Republic of Tunisia, available at <http://www.mdrp.gov.tn/fileadmin/publications/publication_ang/Economic_Social_ Development_2010_2014.pdf>, accessed 13 February 2016.

UN Industrial Development Organization (UNIDO) (2001). 'Support to SMEs in the Arab Region: The Case of Tunisia'. Project coordinated by Stefano Giovannelli. UNIDO/UNDP edition. Vienna: UNIDO. 


\title{
10
}

\section{The Evolution of Industry in Uganda}

\author{
Isaac Shinyekwa, Julius Kiiza, Eria Hisali, and Marios Obwona
}

\subsection{Introduction}

Uganda obtained independence from Britain in 1962, emerging as a poor agrarian economy dominated by agriculture. After a decade of economic and political stability, in 1971 Idi Amin led a military coup, initiating a period of political and economic chaos lasting until 1986. The National Resistance Movement led by Yoweri Museveni took power, and has remained the ruling political organization since. During the first two decades of rule, economic development was significantly hampered by civil war in the North. A period of relative peace has followed, even though improvements in peace and stability mask substantial governance concerns-such as rising inequality, youth unemployment, and corruption in public office.

Against this background the recent performance of the Ugandan economy is impressive-GDP growth averaged 6.5 per cent per annum in the 1990s and 2000s. The economy also appears to have weathered the global financial crisis well, with a growth rate of 5.3 per cent in 2013, predicted to increase to 6 per cent for 2014 (World Bank 2014) and projected to increase to 6.3 per cent according to the National Development Plan II (Republic of Uganda 2015).

However, roughly 80 per cent of Ugandans still live in rural areas, primarily as peasant farmers. In 2012, agriculture accounted for 24 per cent of GDP but 82 per cent of employment (OECD 2014). Furthermore, about 50 per cent of economically active young people are not in income-generating jobs (Republic of Uganda 2010a). The growth experienced over the last decade is simultaneously associated with impressive economic trends and depressing levels of industrial transformation. ${ }^{1}$ Uganda's trade statistics are also unimpressive-the country's

\footnotetext{
${ }^{1}$ The services sector, for example, has impressively attracted high-quality telecommunications companies (such as MTN of South Africa), but is still dominated by tourism (and retail trade) (Kiiza 2007).
} 
export to GDP ratio has not grown since 2008, and is well below that of other sub-Saharan African (SSAn) countries.

The focus of this chapter is on the evolution of the industrial sector in Uganda. It will be argued that while the level of GDP growth has been impressive over the last two decades, the economy still relies on agriculture and low value-added industrial output for job creation, public finance, and exports. Uganda appears to have failed to industrialize, contrary to the promises of pro-market policies and macroeconomic stabilization. The industrial sector is populated by small-scale firms with limited manufacturing value addition. The larger industries are predominantly foreign owned, last-stage assembling firms. These realities point to the need for Uganda to rethink its premature adoption of economic liberalism, together with the associated 'private sector-led' industrial development strategy. For these pro-market approaches to work over the long term, the state must, over the short to medium term, coordinate industrial manufacturing, for example by encouraging foreign companies to partner with local industrialists and adhere to Asia-like performance targets. Once national firms become competitive, the country can gradually, and only gradually, liberalize the economy and integrate it into competitive global markets.

The rest of the chapter is organized as follows. Section 10.2 provides an overview of industrial development since independence in 1962. In Section 10.3 the current state of industry is discussed. Section 10.4 presents industrial policy, discussing in more detail some sector-specific policies and the relevant institutional set-up, while Section 10.5 presents the regulatory framework. Section 10.6 describes the key sunrise and sunset industries. Section 10.7 concludes the analysis.

\subsection{The Evolution of Industry: Historical Perspective}

When Uganda gained independence from Britain in 1962, the agricultural sector accounted for 60 per cent of GDP and, of the total population of 6.5 million, less than 25 per cent was in wage employment. Mining and industry were small sectors in the economy. Relative to other post-independent African nations, the extent of manufacturing activity was not insignificant, but the level of value-added industrial manufacturing was low. Living standards were also low; less than 15 per cent of the population lived beyond 45 years, and roughly 50 per cent of children died before the age of 15 (Elkan 1961).

The spirit of state-guided capitalist development, which started in the dying years of colonial administration, continued in the post-colonial era. While the First Five-year Development Plan for independent Uganda (1961/62-1965/66) focused on agricultural development, industrialization featured prominently 
in the Second Five-year Plan (1966/67-1970/71). The goals of this latter plan were consistent with the views of the Economic Commission for Africa (ECA). The ECA Conference held in Zambia in 1965 underscored the need for industrialization and economic transformation in the whole of eastern Africa, ${ }^{2}$ with priorities including the textile, wood and cork, rubber products, and iron and steel industries (Stoutjesdijk 1967).

As a result of the initiatives of the 1960s, GDP in 1966 prices grew by 4.8 per cent per year from 1963-70, while the population increased at an estimated rate of 2.6 per cent. Uganda's domestic savings averaged 13 per cent, a level that 'permitted implementation of an ambitious investment programme without undue pressure on domestic prices and the balance of payments' (World Bank 1982: 3). In the 1960s, the terms of trade for Uganda's exports were favourable and public finances were relatively healthy.

The development crisis in Uganda began in the 1970s with the rise to power of Idi Amin. Amin's administration destroyed the economy and disorganized industrial infrastructure. The statistical records of the 1970s and 1980s show a virtual absence of heavy industry. The bulk of manufacturing activities in Uganda (at a stage of development comparable to Taiwan in the 1950s and 1960s) were light industries characterized by low value addition. ${ }^{3}$

The availability of cheap labour and the high cost of imported technology meant that light industries were a natural starting point on the path to industrialization. However, output substantially declined in virtually all sectors after 1970. For example, in the machinery sub-category (which would serve as a basis for heavy industrialization), steel ingots declined by over 90 per cent from 19,500 tons in 1970 to only 1,900 in 1980. Superphosphate production (a potential growth pole of chemical industries) declined from 24,800 tons in 1970 to no production at all in 1980. At a stage of development when other countries in Asia were undergoing industrial transformation, Uganda registered declining output in both light industries and the growth poles for heavy industrialization. In 1980, Uganda's economy contracted by 5.2 per cent.

Following the virtual collapse of what was a very promising industrial sector in the 1970s and early 1980s, Uganda embarked on a broad range of policy and institutional reforms in the late 1980s and early 1990s (Siggel and Ssemogerere 2004). The main thrust of the reform process was to reduce the role of government in the economy and to promote the role of the private sector. Generous incentives (through the tariff code, for example) continued to provide support to both local and foreign investment.

\footnotetext{
2 In ECA terms, 'Eastern Africa' covered twelve member states: Uganda, Kenya, and Tanzania, plus Mauritius, Zambia, Ethiopia, Somalia, Malawi, Zimbabwe, Madagascar, Rwanda, and Burundi.

${ }^{3}$ See Obwona et al. (2014: Table 3).
} 


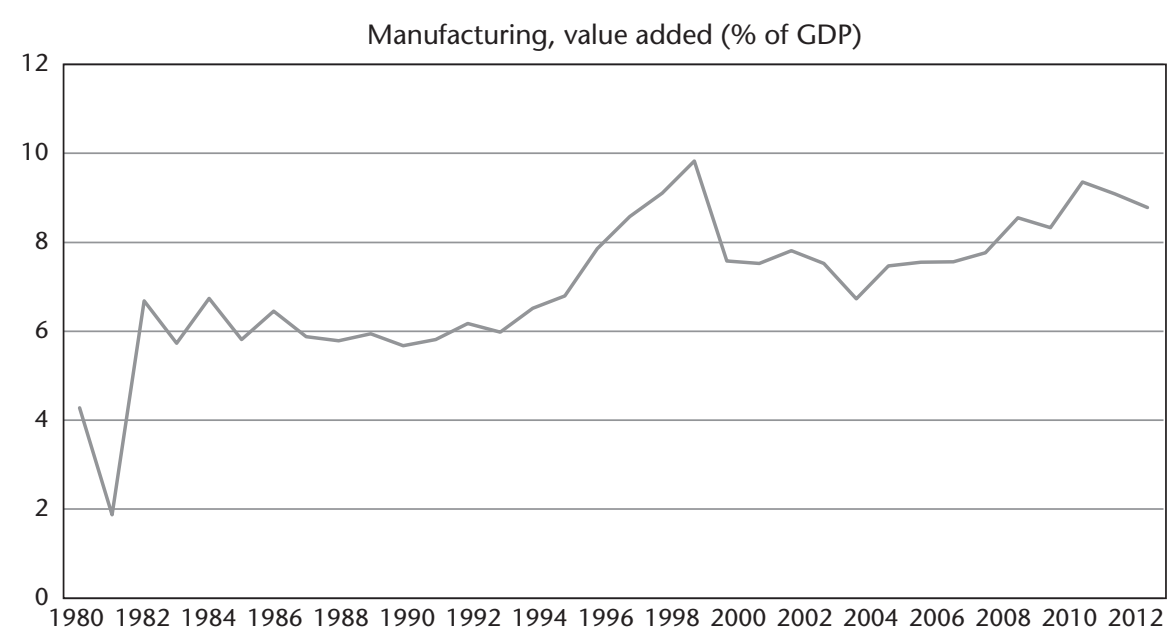

Figure 10.1 Manufacturing as a share of GDP, 1980-2008

Source: World Bank, World Development Indicators, available at: http://data.worldbank.org/datacatalog/world-development-indicators, accessed 17 November 2015.

Despite these efforts, the manufacturing sector has continued to play a peripheral role. As Figure 10.1 shows, while the share of agriculture in GDP declined from over 70 per cent in 1980 to about 25 per cent in 2008, the share of manufacturing in GDP improved only slightly, before declining to about 7 per cent. This falls below the average of 11 per cent for the least developed countries (UNCTAD 2008).

In short, while neoliberal Uganda has attained rapid growth, real manufacturing sector outcomes are still modest. Since the 1990s, the institutionalization of a conservative model of economic governance has been reflected in the current structure of the industrial sector in Uganda, to which we now turn our attention.

\subsection{The Structure of Industry}

The industrial sector in Uganda consists of construction, mining and quarrying, formal manufacturing, informal manufacturing, electricity supply, and water supply. In 2010/11, the construction sub-sector was the largest, accounting for 61 per cent of GDP, followed by formal manufacturing $(20.2$ per cent), water supply (6.9 per cent), informal manufacturing (6.6 per cent), electricity supply (3.9 per cent), and mining and quarrying (1.4 per cent) (Republic of Uganda 2010a, 2010b, 2011). 


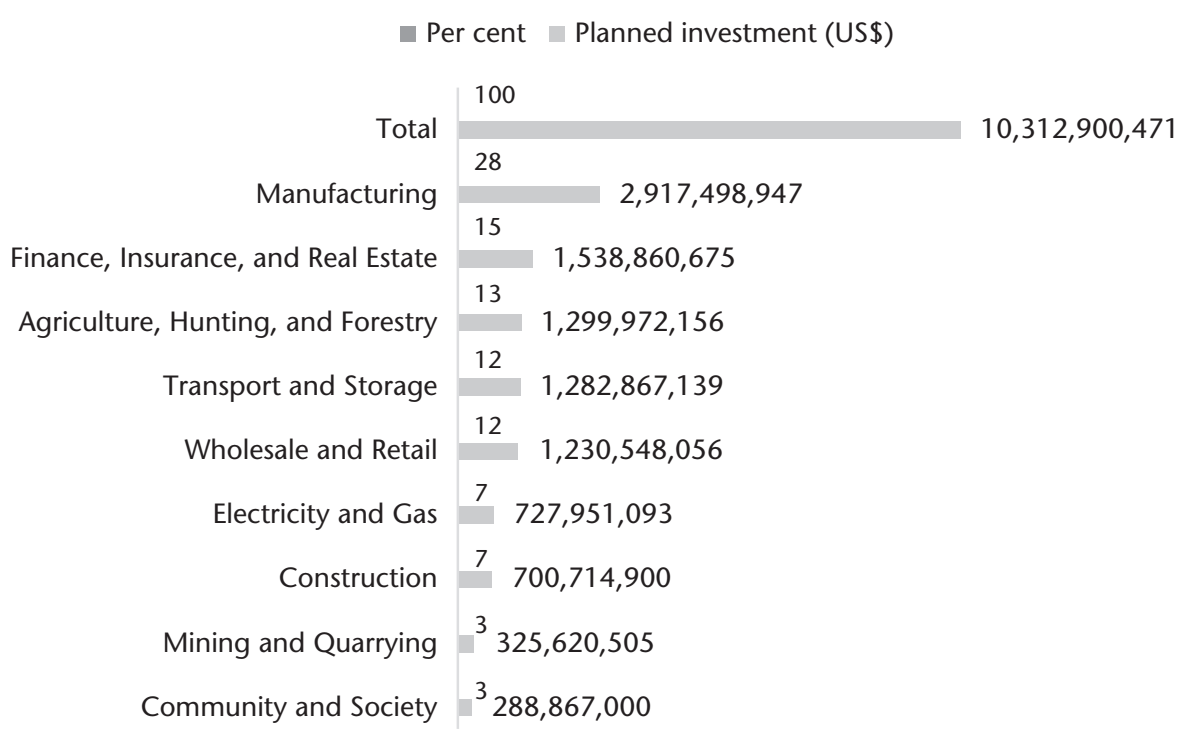

Figure 10.2 Cumulative flow of investment in Uganda between 1991 and 2009 (US\$) Note: The UIA has not conducted any empirical study to establish actual investment during this period. This implies that planned cumulative flows of investment should be used and interpreted with caution. It is likely that about a half of planned cumulative flows of investment are realized as actual.

Source: Uganda Investment Authority Database (2010), available at: <http://www.comesaria.org/site/ en/uganda-investment-authority.159.html , accessed 17 November 2015.

\subsubsection{Sectoral Composition: General Trends}

The contribution of the industrial sector to GDP growth between 2000 and 2011 can be seen in Obwona et al. (2014: Table 4). The industrial sector has experienced steady growth over the last decade, at an average of 7 per cent per annum.

Between 1991 and 2009 Uganda attracted substantial foreign direct investment (FDI), with the largest proportion (45 per cent) going into the industrial sector (Figure 10.2). Manufacturing received the largest share of FDI inflowsclose to one-third of the total, amounting to US\$2.9 billion.

In spite of the progress made in the industrial development of Uganda in the last decade, the sector remains small (Republic of Uganda 2010a, 2010b). In Section 10.4 we describe the key sub-sectors.

\subsection{Sub-sectoral Analysis}

\subsubsection{The Manufacturing Sector}

The manufacturing sector in Uganda remains relatively small and is dominated by subsidiaries of multinational corporations. The sector faces high costs 
of electricity, strong competition from imported products, and poor purchasing power in the domestic market. Contribution to total value added is small, averaging about 7.5 per cent over the period 1988-2009 (see Figure 10.3). This can be attributed to increased import competition following the premature adoption of economic liberalism in the 1980s and 1990s, the signing of the East African Community (EAC) treaty, as well as excess capacity at plant level owing to infrastructural constraints.

Most manufacturing production is for the domestic market, with manufactured exports contributing to just over one-quarter of total exports (Figure 10.4). The recent improvement in export performance is largely the result of new market opportunities in the Democratic Republic of Congo, South Sudan, and Rwanda.

Manufacturing, value added (\% of GDP)

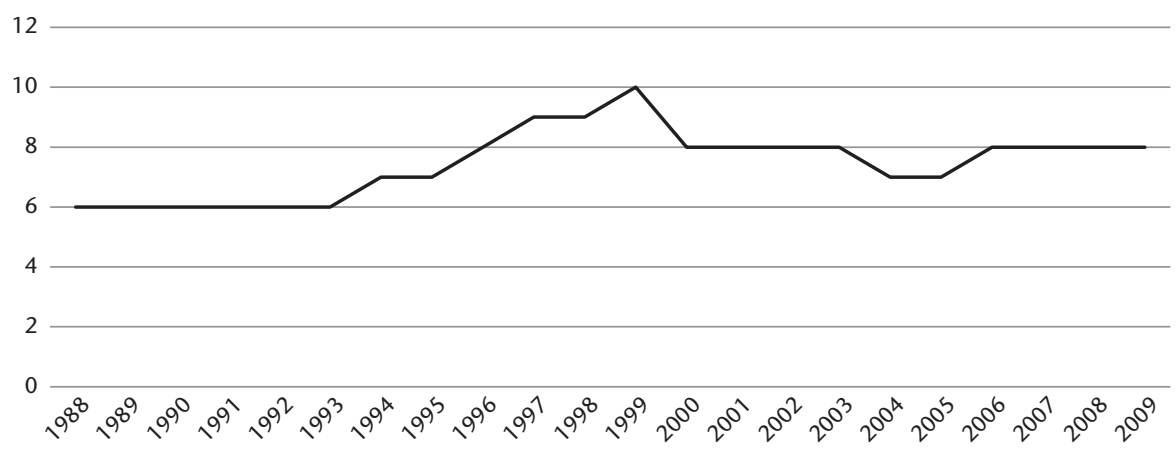

Figure 10.3 Manufacturing value added (\% of GDP), 1988-2009 Source: Statistical Abstracts of the UBOS (various years).

Manufactured exports (\% of merchandise exports)

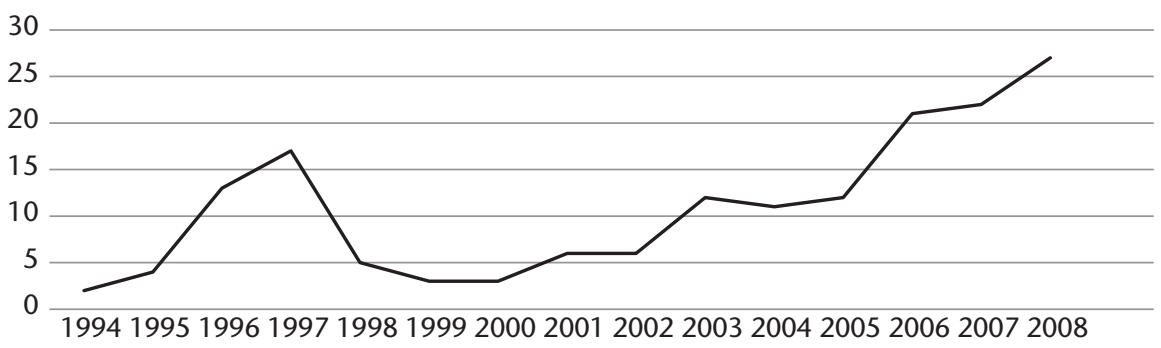

Figure 10.4 Manufactured exports (\% of total exports)

Source: Statistical Abstracts of the UBOS (various years). 
The main data source for describing manufacturing firms in Uganda is the Business Registry, collected by the Uganda Bureau of Statistics (UBOS 2007). ${ }^{4}$ The registry lists 3,280 formal manufacturing establishments employing five people or more in Uganda.

\subsubsection{SIZE DISTRIBUTION}

Small- and medium-scale enterprises (SMEs) account for over 90 per cent of enterprises (Republic of Uganda 2010a, 2010b). As illustrated in Obwona et al. (2014: Table 6) out of the 3,280 firms registered in 2006/07, 58 per cent employed between five and ten people. Firms that employed between eleven and twenty people account for 18 per cent of the total, while firms employing between twenty-one and fifty people, in this case medium-sized enterprises, constitute only 9 per cent of the total. The proportion of firms employing over 50 people is very small. ${ }^{5}$

\subsubsection{REGIONAL DISTRIBUTION}

During the 1960s and early 1970s, Jinja town in the eastern region was the main industrial hub of Uganda. This has since changed, with Kampala emerging as the major industrial town. There is a high concentration of manufacturing firms in the central region. ${ }^{6}$ The northern region has the lowest number. This could be because of the legacy of colonial policy that defined the North as a source of cheap labour for the southern half; inadequate infrastructure (such as roads and energy), and the conflict (roughly 1989-2010) that rendered northern Uganda unattractive to private business investors. This depressing situation is likely to change with the return of peace, backed by the government's efforts to build tarmac roads, and mobilize local, national, and donor resources for northern Uganda with a view to proactively unlocking the development potential of the North.

A further disaggregation of the distribution of firms by region shows that Kampala has the highest proportion of firms in all manufacturing sub-sectors except for coffee processing, grain milling, and tea processing. While the eastern region has the highest proportion of grain milling firms (32 per cent), the western region has a commanding lead in tea processing with about 60 per cent. Finally, the central region has the most coffee processing firms (51 per cent). The northern region is not specialized in any particular sector.

\footnotetext{
4 The large informal sector is not included in the registry, which is a major limitation.

5 We note that these statistics are outdated and therefore may not represent the current sector status.

${ }^{6}$ See Obwona et al. (2014: Table 7).
} 


\subsubsection{EMPLOYMENT}

According to the Business Register the manufacturing sector employed about 72,200 people in 2007 . The majority of employment is in firms of more than one hundred employees (52 per cent of the total). ${ }^{7}$

\subsubsection{OWNERSHIP}

The legal ownership of manufacturing firms consists mainly of sole proprietors (55 per cent), followed by private limited companies (29 per cent), and partnerships (11 per cent). This small proportion of private limited companies implies that most manufacturing firms are not listed and cannot therefore raise capital through the capital markets.

Other forms of ownership are domestic, foreign, and joint ventures. ${ }^{8}$ We compute the proportions of firms by ownership using the Private Sector Investment Survey data of 2009 collected by the Bank of Uganda. The largest proportion of manufacturing firms is wholly owned by foreigners, accounting for 42 per cent in 2009. The high presence of foreign-owned firms reflects government policy which has, since the formation of the Ugandan Investment Authority (UIA) in 1991, consistently albeit naively promoted FDI without any state-coordinated performance targets (such as partnering with local industrialists).

\subsubsection{PRODUCTIVITY}

To examine labour productivity we use the 2006 wave of the World Bank (WB) Enterprise Survey, which covers a sample of 358 firms. Labour productivity is computed as total annual sales divided by the total number of employees. The construction sub-sector has the highest labour productivity, while the garments sub-sector has the lowest. ${ }^{9}$

Descriptive statistics on technology usage of enterprises using the same data source are presented in Obwona et al. (2014: Table 11). We use two measures: the actual output of the establishment in comparison to the maximum output possible; and the use of email and websites by firms. Even when the average capacity utilization of all the sectors is above 70 per cent, there is still much more required to realize optimal technology usage. Overall the use of email and websites is low in the sector.

\subsubsection{Mining and Quarrying}

The mining industry in Uganda has a long history that is traceable to the pre-colonial era. Ancient kingdom states (such as Bunyoro-Kitara) developed

\footnotetext{
7 See Obwona et al. (2014: Table 8). $\quad{ }^{8}$ See Obwona et al. (2014: Table 9).

9 See Obwona et al. (2014: Table 10).
} 
the art of iron mining, smelting, and artisanal value addition to produce day-to-day tools such as spears and arrows (for national defence), and hoes, pangas, and knives (for household use) prior to the advent of colonialism. The mining activity continued on a larger scale in the colonial period with one key 'innovation'. The high value-added activities were, by colonial decree, located in the economy of the colonizing power.

In the 1950 s and 1960s, mining reached peak levels when the sector contributed to 30 per cent of export earnings and 7 per cent of GDP. This trend was reversed with the political and economic instability of the 1970s. Although in the 1990s the sector experienced a recovery, the contribution to GDP has since been maintained at less than 1 per cent. Production volumes have increased from 4,827 tons in 2005 to 17,620 tons in 2007 (Republic of Uganda 2010a). The monetary equivalent in exports grew from UGX173 million to UGX153,347 million (Republic of Uganda 2008).

\subsubsection{SIZE DISTRIBUTION}

The distribution of firms in the sub-sector by employment size is presented in Table 10.1. Evidently, the categories employing between five and ten people constituted the highest proportion. Given that there are hundreds of informal undertakings in the mining and quarrying sector, this analysis probably under-reports what is actually happening on the ground.

\subsubsection{REGIONAL DISTRIBUTION}

Most of the activities in the sub-sector are centred on quarrying, which is a low value-added extractive activity. The rapid expansion of quarrying is associated with the rapid growth of the construction sector, which requires raw materials such as hard core stones, clay, and sand. The Business Register reported a

Table 10.1 Distribution of firms in mining and quarrying by employment band

\begin{tabular}{|c|c|c|c|c|c|c|}
\hline $\begin{array}{l}\text { Employment } \\
\text { size band }\end{array}$ & $\begin{array}{l}\text { Mining of iron } \\
\text { ores and non- } \\
\text { ferrous metals }\end{array}$ & $\begin{array}{l}\text { Quarrying of } \\
\text { stones, sand, } \\
\text { and clay }\end{array}$ & $\begin{array}{l}\text { Other mining } \\
\text { and quarrying }\end{array}$ & Total & $\%$ & Scale \\
\hline 0 & 1 & 0 & 1 & 2 & 5.1 & Small \\
\hline $1-4$ & 4 & 0 & 0 & 4 & 10.3 & \\
\hline $5-9$ & 3 & 9 & 0 & 12 & 30.8 & \\
\hline 10-19 & 1 & 5 & 0 & 6 & 15.4 & \\
\hline $20-49$ & 2 & 4 & 1 & 7 & 17.9 & Medium \\
\hline $50-59$ & 1 & 3 & 1 & 5 & 12.8 & Large \\
\hline 100 plus & 2 & 0 & 1 & 3 & 7.7 & \\
\hline Total & 14 & 21 & 4 & 39 & 100 & \\
\hline
\end{tabular}

Source: UBOS Business Register (2007). 
regional concentration of quarrying activities in and around Kampala (55 per cent) where most construction is taking place, followed by the eastern and central regions (15 per cent each).

\subsubsection{EMPLOYMENT}

According to the National Development Plan (Republic of Uganda 2010a), the current employment status in the sub-sector is 130,000 people working as artisans and small-scale miners. More than 100,000 of the miners work in the production of industrial minerals such as salt, clay, sand, aggregates, limestone, and slates.

\subsubsection{OWNERSHIP}

The ownership of the firms in this analysis is recorded along business unit groupings as reported in UBOS (2007), and origin of capital, computed from the Bank of Uganda Private Sector Investment Survey data. The most dominant type of business unit is the private limited company, accounting for more than half. This is followed by the sole proprietor, capturing close to a third of firms. The Private Sector Investment Survey (2009) data reveal that the majority of firms are foreign owned (Table 10.2).

The informal sub-sector is largely dominated by local ownership, although the exact magnitude is not known. Informal businesses are mainly sole proprietorships operating on a very small scale.

\subsubsection{Construction}

The construction industry experienced tremendous growth following the end of the 1981-6 guerrilla war. Contribution to GDP in the recent past grew at an annual rate of 12 per cent from an average of 5 per cent in the 1990 s and early 2000s. The production of building materials is an important element of the

Table 10.2 Ownership of firms in mining and quarrying between 2007 and 2009

\begin{tabular}{|c|c|c|c|c|c|c|}
\hline \multirow[b]{2}{*}{ Ownership } & \multicolumn{2}{|c|}{2007} & \multicolumn{2}{|c|}{2008} & \multicolumn{2}{|c|}{2009} \\
\hline & Number & $\%$ & Number & $\%$ & Number & $\%$ \\
\hline Joint-venture majority foreign & 11 & 38 & 11 & 39 & 11 & 48 \\
\hline Wholly foreign & 12 & 41 & 12 & 43 & 12 & 52 \\
\hline Wholly local & 6 & 21 & 5 & 18 & - & - \\
\hline Total & 29 & 100 & 28 & 100 & 23 & 100 \\
\hline
\end{tabular}

Source: Authors' calculation based on data from Bank of Uganda (2009). 
construction sector. However, enterprises still depend heavily on imported machinery, spare parts, and raw materials.

\subsubsection{SIZE DISTRIBUTION}

The Business Register coverage of the construction industry was restricted to firms employing five people or more. A total of 282 construction firms were surveyed. The distribution of construction firms by employment size band is given in Figure 10.5. The firms employing between five and ten people had the highest proportion at 29 per cent, followed by firms employing between eleven and twenty people at 22 per cent. Very few firms employ one hundred or more.

\subsubsection{REGIONAL DISTRIBUTION}

The regional distribution of firms follows a similar pattern to that of other industries. The Business Register shows that Kampala had the highest number of construction firms, accounting for 63 per cent. This was followed by western and northern regions, each with 11 per cent.

\subsubsection{EMPLOYMENT}

The estimated total employment in the sector was close to 9,000 in 2007. The industry is dominated by male employees (78 per cent). These statistics significantly understate the total numbers employed. There are many casual and informal workers in the construction industry who contribute significantly to the sub-sector.

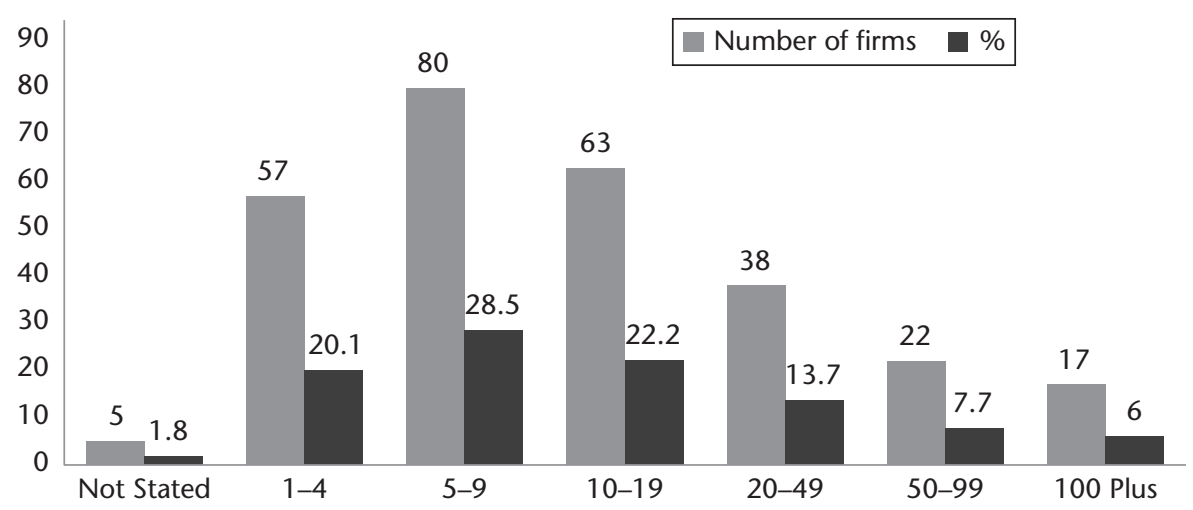

Figure 10.5 Construction industry firms by employment band Source: UBOS (2007). 


\subsubsection{OWNERSHIP}

Of the 282 construction firms in the Business Register, close to 80 per cent are private limited companies. This is followed by sole proprietorships with approximately 8 per cent and partnerships with 7 per cent. Table 10.3 illustrates the domestic and foreign ownership of firms in the industry. Almost half of all firms are wholly foreign owned and an additional 18 per cent consist of joint ventures.

\subsubsection{Summary}

This section described the current structure of industry in Uganda. There are no up-to-date statistics that are representative of the current state of the industrial sector, and there is a dominance of informality that is not covered by official surveys. Notwithstanding this caveat, we can summarize the key characteristics of the industrial sector as follows:

- Uganda has a very small proportion of large-scale manufacturing firms.

- Kampala has emerged as the major industrial town in Uganda over the last few decades.

- Sole proprietors and public limited companies form the major type of business ownership in Uganda, followed by partnerships.

- The majority of firms are foreign owned and the numbers are increasing in both the form of joint ventures and firms that are wholly owned by foreign nationals.

A number of challenges confront the industrial sector, particularly the manufacturing and mining sub-sectors. These sub-sectors struggle with weak institutional support, thanks to the erroneous but widespread claim that government has no business in business in an era of economic liberalization.

Table 10.3 Ownership in the construction industry

\begin{tabular}{|c|c|c|c|c|c|c|}
\hline \multirow[t]{2}{*}{ Ownership } & \multicolumn{2}{|c|}{2007} & \multicolumn{2}{|c|}{2008} & \multicolumn{2}{|c|}{2009} \\
\hline & Number & $\%$ & Number & $\%$ & Number & $\%$ \\
\hline Joint-venture majority foreign & 38 & 18 & 35 & 16 & 29 & 14 \\
\hline Joint-venture majority local & 8 & 4 & 8 & 4 & 8 & 4 \\
\hline Wholly foreign & 98 & 46 & 99 & 46 & 99 & 48 \\
\hline Wholly local & 71 & 33 & 75 & 35 & 72 & 35 \\
\hline Total & 215 & 100 & 217 & 100 & 208 & 100 \\
\hline
\end{tabular}

Source: Authors' calculation based on data from Bank of Uganda (2009). 
Additionally, locally owned industrial firms have limited access to credit; suffer low levels of technology; and have poor managerial capabilities. We will return briefly to a discussion of these 'binding constraints' once the industrial policy framework has been articulated.

\subsection{The Industrial Policy Framework}

The last two decades have witnessed a considerable shift in the industrial strategy of many African countries from direct government participation to a more indirect approach prescribed by the IMF/WB fraternity and other architects of economic liberalism. This section provides a description of Uganda's industrial policy framework.

\subsubsection{Macroeconomic Policies}

A stable macroeconomic environment is an important prerequisite for the promotion of market-led industrialization. The main goal of monetary policy since the early 1990s in Uganda has been the attainment of a low and stable general price level. The Bank of Uganda uses a monetary targeting approach to monitor developments in base money and weekly indicators of inflation and treasury bill rates (Katarikawe and Sebudde 2000). The adoption of a conservative monetary policy, and the restoration of the productive capacity of the economy have resulted in a decline in the inflation rate from a peak of 250 per cent in 1987 to an average of less than 5 per cent between 2000 and $2010 .^{10}$

The fiscal deficit, on the other hand, has continued to increase. The deficit as a percentage of GDP increased from about 2 per cent in 1991 to 13 per cent in 2013. It widened further in 2014 due to high levels of public investment.

Uganda continues to rely on aid financing. This approach to deficit financing poses a serious threat to macroeconomic stability. Monetary authorities have responded to the increased donor inflows through the sale and purchase of treasury bills ${ }^{11}$ and foreign exchange market operations. These responses can limit private sector access to credit and investment and spur an appreciation of the exchange rate, which can in turn hurt export competitiveness.

\footnotetext{
10 Increasing food prices pushed the inflation rate to 21.4 per cent in 2011 , but it has since fallen, in 2014 , to below 5 per cent.

11 In 1992, the government surrendered the treasury bills instrument to the Bank of Uganda and since then it has been entirely a monetary policy instrument.
} 


\subsubsection{Trade Policy Reform and its Implications for Industrialization}

Uganda's external trade policy has undergone substantial reform over the last two decades in line with the policy-based lending programme of the WB and World Trade Organization (WTO). At the heart of the reform process has been a reduction in tariffs and exchange rate devaluation whose object is to firmly integrate Uganda into the orbit of global capitalism. Uganda also continues to participate in regional economic groupings. It is a founding member of the EAC (which is now a Customs Union). It also gives preferential market access to imports from the Common Market for Eastern and Southern Africa (COMESA) trading block.

The impact of tariff reduction on the industrial sector is mediated by, among other things, the response of domestic import-competing industries through elasticity of supply and the domestic economy's elasticity of demand for imports. Uganda's import demand elasticity is estimated to be -1.22 (Hiau et al. 2005). In general, this suggests that there is only limited substitutability between imports and locally produced goods. This, combined with tariff reductions, has resulted in increased imports. In the context of an agrarian economy whose supply-side constraints have militated against rapid increases of exports, Uganda's balance of trade has been negatively affected.

\subsubsection{Sector-specific Policies}

Industry-specific policies usually aim to promote flagship activities within the industrial sector. In line with the country's liberal economic philosophy, however, the focus of industrial policy in Uganda has been to promote industries in a generic sense. The dominant economic ideology militated against industry-specific industrial policies, the kind that triggered value-added industrial transformation among the northeast Asian tigers.

In Uganda's case, the priority in the mid-1980s was to stabilize the economy, and generally to pursue the conservative economic policies treasured by the IMF/WB fraternity (Siggel and Ssemogerere 2004). Policies that were implemented in this respect are the Emergency Relief and Rehabilitation Programme of 1986 and the Economic Recovery Programme of 1987/88-1991/92. These were followed by the Way Forward I and II of 1990-5, reforming the tax system, liberalizing the financial sector and foreign exchange, and dismantling state-owned marketing monopolies. The Industrialization Policy and Framework 1994-9 sought to complement the Way Forward I and II by supposedly prioritizing investments that promoted expansion of the export base. The evidence on the ground shows a statistically insignificant share of valueadded manufactured products in Uganda's export basket. 
Admittedly, the growth of the industrial sector over the initial policy reform period averaged about 12 per cent, and its contribution to GDP increased from 3.5 per cent in 1986 to 9.5 per cent in 2004 . However, the contribution of the sector to direct employment and export earnings was quite dismal, standing at 5 per cent and 4 per cent, respectively.

The Medium-term Competiveness Strategy (2000-5) for the private sector sought to address bottlenecks to firm level competitiveness. The key priority areas included:

1 expanding the coverage of public infrastructure;

2 strengthening the financial sector to ensure improved access to credit;

3 improving financial services for micro- and small enterprises through licensing of micro-finance institutions;

4 strengthening the institutions for export promotion such as the UIA and the Uganda Export Promotion Board;

5 skills development and training.

This strategy was expanded by its successor, the Medium-term Competitiveness Strategy (2005-9). Uganda's National Industrial Policy was finalized in 2008. Its thrust is to develop an efficient and reliable infrastructure. Other pertinent aspects of industrial policy include the promotion of innovation to support industrial sector growth and the provision of a skilled labour force. These priorities are also echoed in the country's National Development Plan (NDP) 2010/11-2014/15. The problem, as already hinted, is the dearth of Asialike sector-specific industrial policies. This seems to explain why the level of technology deepening and industrial transformation is still dismal in Uganda.

\subsubsection{Institutional and Regulatory Framework}

The Ministry of Trade, Industry and Co-operatives provides the policy and regulatory oversight of industrial development in Uganda. It also provides policy guidance to the different statutory bodies handling different aspects of industrial development. Statutory bodies under the Ministry's supervision include:

1 Uganda National Bureau of Standards

2 Uganda Industrial Research Institute (UIRI)

3 Uganda Export Promotion Board (UEPB)

4 Management Training and Advisory Centre (MTAC)

\subsubsection{Summary}

Uganda has adopted a laissez-faire approach to industrial policy over the last two decades. The claim was that this pro-market policy regime was necessary 
for enabling the private sector to take the lead in shaping the structure and patterns of industrial development. The evidence on the ground is still unsatisfactory. For example, the level of manufacturing value added is still disappointing. The ability of manufacturing firms to create what the ILO calls decent jobs and create products that will compete in the national, regional, and global markets is still low. As already hinted, the major hindrances to firm level competitiveness include, but are not limited to, the poor quality of physical infrastructure, worsened by limited access to long-term oriented, affordable credit. Notwithstanding these issues/areas, the outlook for growth in the sector is likely to be positive, particularly if the state resumes its role of strategically guiding industrial policy and coordinating economic performance.

\subsection{Sunrise and Sunset Industries}

Section 10.4 highlights the poor performance of the industrial sector in Uganda, particularly the manufacturing sub-sector. In this section we document the decline of manufacturing. We also highlight a number of sectors where there is potential for growth.

\subsubsection{Textiles}

Textiles in Uganda rose in prominence in the 1950s and 1960s. Mills were established largely up-country, near sources of either raw materials or energy. A national Textile Board was established in the late 1960s to guide the industry, focusing on IS. In the early 1970s the textile mills were nationalized. In the context of political instability and the lack of spare parts associated with the Idi Amin administration of the 1970s, the mills eventually ran into disrepair and closed.

By the time of the divestiture of the government-owned mills in the 1990s, machinery was obsolete due to a long period of mismanagement. At its peak in 1972/73 the textile industry consumed approximately 400,000 bales of cotton-now consumption is about 15,000 bales per annum. Among other constraining factors are rampant counterfeits, second-hand clothing, and undervaluation/declaration of imports. Access to credit remains a challenge. The interest rate is-in the context of a liberalized, private-sector dominated financial sector-extremely high (between 18 and 24 per cent).

\subsubsection{Information and Communications Technology}

The ICT sector has grown considerably in the last few years. In the last two decades, Uganda, like most of the world, witnessed phenomenal growth in the telecommunications sector. This growth is attributed to the global 
technological advancements which rapidly spread to Africa. This, it would seem, was clear evidence that certain elements of economic liberalism are development enhancing, provided they are adopted with care.

The telecommunications sector in Uganda is characterized by the heavy involvement of multinational companies including MTN, Orange, Uganda Telecommunications Limited, Afri cell, and Airtel, with a total subscription of about 16 million, which is almost half of Uganda's total population. In 2009, total investment was US\$240 million, having grown from only US\$15 million between 1999 and 2000 (UCC 2010). The growth in revenue and investment in the sector has generated employment opportunities directly and indirectly for 300,000 people. Overall, the sector contributed 3.4 per cent to Uganda's GDP in 2009 (UCC 2010).

\subsubsection{Construction}

There are many firms in the building and construction industries, and the number is increasing every year. The industry is providing further scope for trade and investment opportunities in areas including the provision of low-cost housing, the provision of mortgage finance, and the construction of commercial buildings.

Uganda also has a road construction programme; the Uganda National Road Authority is mandated to develop and maintain the national roads network totalling about $20,000 \mathrm{~km}$. This means that large amounts of raw materials like aggregates, sand, steel, and timber will be required. Opportunities are available in the development of quarries and the establishment of factories to produce such materials. There is also evidence that firms producing construction materials like cement, steel products, and roofing materials are expanding at a fast rate.

\subsubsection{Mining}

Uganda has a long history of mining and extraction. Today, improvements in exploration activities have confirmed that the country has commercially viable but under-exploited mineral deposits of gold, oil, high-grade tin, and others (MTTI and UNIDO 2007). For example, the discovery of petroleum in the Lake Albert region has boosted the sector. Over the period 1997-2008, a total of US\$500 million in private capital was invested in upstream activities in the oil and gas sector (Republic of Uganda 2010a, 2010b).

\subsection{Conclusions}

The robust performance of the Ugandan economy over the last two decades is impressive, particularly when set against the backdrop of decades of political 
and economic instability. The economy, however, still relies to a large extent on agriculture, particularly in terms of employment, and as a source of revenue and export products. Uganda appears to have failed to industrialize, contrary to the promises of pro-market policies, macroeconomic stability, and the expanding regional market associated with regional integration.

The industrial sector is populated by small-scale firms that verifiably have limited manufacturing value addition. The vast majority of larger industries are foreign owned. Moreover, they are predominantly last-stage assembling firms with most of their activities concentrated around Kampala. These realities point to the need for Uganda to rethink its premature adoption of economic liberalism, together with the associated 'private sector-led' industrial development strategy. For these pro-market approaches to work over the long term, the state must, over the short to medium term, coordinate industrial manufacturing for example by encouraging foreign companies to partner with local industrialists and adhere to nationally designed, Asia-like performance targets. The aim is to promote technology transfer and increase local content. The ultimate goal is to ensure that Uganda develops a sustainable industrial development strategy that actively brings nationals (and supportive foreign capitalists) on board. Once the national firms become competitive, the country can gradually, and only gradually, liberalize the economy and integrate it into competitive global markets.

The state also has a key role to play in uprooting the 'binding constraints' to development that are outlined in the National Development Plan (2010-14). These include poor and inadequate physical infrastructure; erratic power supply; and high fuel and electricity tariffs, all of which impede industrial manufacturing. The WB Enterprise Survey data also reveal that firms perceive electricity to be the biggest constraint to business growth.

But this is not all. Local workers lack the appropriate technical skills, leading to lower productivity levels. Uganda also lacks the indigenous capacity to adapt and develop technology, and exhibits low capabilities in science, technology, and innovation. All of these point to the potential strategic role for the state in uprooting the country-specific constraints to capitalist development, in partnership with the private sector and development partners.

Despite these constraints, the recent performance of the Ugandan economy suggests that the outlook for the industrial sector is good. This can, to a large extent, be attributed to policy efforts aimed at improving infrastructure. Efforts to improve education and promote science and technology will also be of benefit to the sector in the future. Oil production also, which is due to start in 2018, offers significant potential for boosting economic activity. For example it will finance infrastructure investment and human capital development, provided Uganda navigates past the proverbial natural resource curse. 


\section{References}

Bank of Uganda (2009). Executive Summary of Findings for Private Sector Investment Survey (PSIS). Kampala: Bank of Uganda.

Elkan, W. (1961). Economic Development of Uganda. Nairobi: Oxford University Press.

Hiau, L. K., Nicita, A., and Olarreaga, M. (2005). 'Import Demand Elasticities and Trade Distortions', available at <http://elibrary.worldbank.org/doi/pdf/10.1596/18139450-3452>, accessed 12 February 2016.

Katarikawe, M. and Sebudde, R. K. (2000). 'Is the Reserve Money Program Still a Useful Operating Framework for the Conduct of Monetary Policy in Uganda?' Bank of Uganda Staff Papers 2(1): 1-20.

Kiiza, J. (2007). 'Developmental Nationalism and Economic Performance in Africa: The Case of Three Successful African Economies', in Ha-Joon Chang (ed.) Institutional Change and Economic Development. Tokyo and New York: UN University Press and Anthem, 281-300.

Ministry of Trade, Tourism and Industry (Uganda) (MTTI) and UN Industrial Development Organization (UNIDO (2007). Integrated Industrial Policy for Sustainable Industrial Development and Competitiveness: Part I. Industrial Development: Analysing Competitiveness, Growth Potentials and Investment Opportunities. Vienna: UNIDO.

Obwona, M., Shinyekwa, I., Kiiza, J., and Hisali, E. (2014). 'The evolution of industry in Uganda'. WIDER Working Paper 2014/021 World Institute for Development Economics Research.

Organisation for Economic Co-operation and Development (OECD) (2014). African Economic Outlook: Global Value Chains and Africa's Industrialisation. Paris: OECD.

Republic of Uganda (2008). Ministry of Energy and Mineral Development Annual Report. Kampala: Republic of Uganda.

Republic of Uganda (2010a). The National Development Plan 2010/11-2014/15. Kampala: National Planning Authority.

Republic of Uganda (2010b). The Background to the Budget 2010/11 Financial Year. Kampala: Ministry of Finance, Planning and Economic Planning.

Republic of Uganda (2011). The Background to the Budget 2011/12 Financial Year. Kampala: Ministry of Finance, Planning and Economic Planning.

Republic of Uganda (2015). The National Development Plan II 2015/16-2019/20. Kampala: National Planning Authority.

Siggel, E. and Ssemogerere, G. (2004). 'Uganda's Policy Reforms, Industry Competitiveness and Regional Integration: A Comparison with Kenya'. Journal of International Trade and Economic Development 13(3): 325-57.

Stoutjesdijk, E. J. (1967). Uganda's Manufacturing Sector. Nairobi: East African Publishing House.

Uganda Bureau of Statistics (UBOS) (various years). Report on the Uganda Business Register 2006/7. Kampala: UBOS.

Uganda Communications Commission (UCC) (2010). Status of the Communications Market-March 2010. Kampala: Government of Uganda. 
UN Conference on Trade and Development (UNCTAD) (2008). The Least Developed Countries Report, 2008: Growth, Poverty and the Terms of Development Partnerships. New York and Geneva: UNCTAD.

World Bank (1982). Uganda: Country Economic Memorandum. Washington, DC: World Bank.

World Bank (2014). Uganda Country Overview. Washington, DC: World Bank, available at www.worldbank.org, accessed 15 November 2015. 


\section{Part II \\ Industrial Development in Emerging Asia}





\title{
11
}

\section{Cambodia's Path to Industrial Development}

\author{
Policies, Lessons, and Opportunities
}

Sokty Chhair and Luyna Ung

\subsection{Introduction}

Cambodia emerged a newly independent nation in 1953 with ambitions for growth and development through the expansion of industry. Sixty years on, following decades of war and destruction, these ambitions are beginning to be realized with double-digit growth rates. On the surface, Cambodia appears to be an emerging economic success story. Digging deeper, however, reveals that this is not without uncertainties and challenges.

Cambodia has one of the fastest growing populations in the world. Between 1998 and 2008 the population increased from 11.4 million to 13.4 million, an average annual increase of 1.5 per cent. With the labour force projected to increase by 213,000 per annum between 2010 and 2013, the economy will come under increasing pressure to generate productive employment opportunities. It is against this backdrop that we explore the evolution of the economy.

Over the last sixty years Cambodia has experienced a number of very different political ideologies, each of which has had a strong influence on the evolution of industry. Section 11.2 describes each of these regimes. Since the 1993 election, overseen by the United Nations (UN), Cambodia has been in transition to a full market economy, following decades of war and isolation from international markets. Section 11.3 documents subsequent growth and development. Section 11.4 provides an overview of the policy environment. Section 11.5 documents the key sunrise and sunset sectors in Cambodia. The chapter concludes with a discussion of the opportunities and challenges facing Cambodia. 


\subsection{Evolution of Industry: Historical Perspective}

Limited documented evidence exits on the Cambodian economy prior to the civil war in 1970 and so we rely on three leftist scholarly works by Hou (1955), Khieu (1959), and $\mathrm{Hu}$ (1965). Among them, only Khieu (1959) focuses on industry. Most historians tend to focus on political rather than economic history due to the incidence of chronic civil war, genocide, and other issues during the last four decades. Exceptions include Vickery (1986), Ear (1995), and Slocomb (2010). We draw heavily from these works in our review of the industrial sector and economy in general in the period up to 1993. After 1993, many additional sources are available.

\subsubsection{Sihanouk Regime, 1953-70}

Cambodia gained full independence from France in 1953. During the colonial era emphasis was placed on agriculture, with household-based rice cultivation, the development of large rubber plantations, and integration into the French economy. ${ }^{1}$ Some factories were established to supply the domestic market, but most depended on imports for raw materials and were foreign owned or owned by the elite Chinese ethnic group.

The focus of the new Cambodian state that emerged in 1953 was on building Cambodia's industrial base through a policy of modernization-the trend in the newly independent states in Asia and Africa at that time. The Two-year Plan (1956-7) and the first Five-year Plan (1960-4) were introduced. The former concentrated on developing infrastructure and the latter on building factories (Delvert 1963). Slocomb (2010) documents how the Sihanouk regime largely accepted economic coexistence with foreign interests and investment. The economy could best be described as a mixed economy, merging individual capital and enterprise with state capital and supervision. There was a significant increase in the number of factories between 1955 and 1968, from 0 to 57 state/joint-owned factories, while small and medium private factories increased dramatically from 650 in 1965 to 3700 in 1968 (Ear 1995: 49).

During the cold war, Cambodia experienced significant investment in infrastructure, largely financed by donor interests. It was a strategically important location from a military perspective, particularly given the neutral foreign policy adopted by Prince Sihanouk. With the resulting foreign assistance from both sides, several mega-projects were built: the highway linking the

\footnotetext{
1 The first railway was built by France in 1922, connecting the northeastern part of the country to Phnom Penh. The purpose of the railway was to integrate Cambodia's economy to the world, rather than to promote development within Cambodia. In 1939, according to Khieu (1959), 80 per cent of products transported by the railway were destined for export markets.
} 
capital city Phnom Penh and the port city of Sihnoukville was built with American aid, and the port itself with French funding; France and Germany jointly funded railway construction connecting Phnom Penh to Sihnoukville; while a plywood factory was built with Chinese aid (Slocomb 2010). ${ }^{2}$ In all, only 2 per cent of the budget for the Five-year Plan was contributed by Cambodia, while 57 per cent of the contribution was from the USA, 23 per cent from China, and 17 per cent from France. Despite these developments, there is little by way of structural change evident during this period (Slocomb 2010). Manufacturing accounted for 8.6 per cent of GDP in 1962, increasing to 10.5 per cent in 1966. Meanwhile, agriculture remained at around 41 per cent of GDP. Cambodia's exports overwhelmingly depended on primary products.

The removal of protective tariffs at the end of 1969 heavily hit small enterprises, which accounted for 90 per cent of firms. A handful of large investors benefited from the policy change, but they too were affected by inflation and rising labour costs. Efforts were made to industrialize further through a policy of import substitution, but this had little success. By the end of this era the economic structure of Cambodia was similar to that of the newly independent economy in 1953.

\subsubsection{Khmer Republic, 1970-5}

In 1970 a civil war began in Cambodia, with each side supported by either China or the USA. Even before the regime change in 1970, the leaders of the coup, General Non Nol and Sisowath Sirik Matak, led the national salvation government from August 1969.

The new laissez-faire policy involved devaluing the currency, removing controls on foreign trade and banking, and reducing state involvement in enterprise. The most significant change to industrial policy was the disengagement of the public sector as the mechanism for development (Slocomb 2010). Rice and maize production was liberalized, but the state remained the monopoly power in some sectors. These policies were short-lived, and their implementation was interrupted by the civil war. The wartime economy depended solely on foreign assistance, mostly from the USA, for survival. The civil war had a significant negative impact on the production of rice, rubber, and corn. The manufacturing index, which had been 100 in 1960, fell to 73 in 1972 (Ear 1995).

\footnotetext{
2 A number of other factories were also built at this time. They included a 5,000-ton paper mill, a textile factory and a large cement factory built by the Chinese, and a palm sugar refinery, a tyre factory, and a tractor assembly plant by the Czech Republic.
} 


\subsubsection{Closed Economy, 1975-89}

The period spanning 1975-89 consisted of two rival regimes, both of which followed a Marxist ideology. Slocomb (2010) describes Cambodia during this period as a revolutionary economy. The extent to which the two regimes adopted Marxism was their main distinction. The former was much harsher and dogmatic while the latter was more pragmatic and responsive to local conditions.

\subsubsection{DEMOCRATIC KAMPUCHEA, 1975-9}

The Khmer Rouge came to power influenced heavily by Maoist ideology. The ambition was to make the transition to communism. The economic policy was to demolish capitalists, enslave the labour force, and focus on the rapid development of agriculture. To this end, the regime completely collectivized agriculture, nationalized all sectors of the economy, and adopted a policy of self-reliance. Phnom Penh and other provincial cities were emptied and the urbanites were forced to work as collective farmers in the countryside. Private ownership was completely banned and money was eliminated. From 1975 to 1979 , the bourgeoisie class was considered an enemy of the state and entrepreneurship disappeared. The regime also banned all international trade bar limited dealings with a few allied communist countries.

\subsubsection{PEOPLE'S REPUBLIC OF KAMPUCHEA, 1979-89}

After the liberation of Cambodia from the Khmer Rouge regime, the new People's Republic of Kampuchea (PRK) regime was left with little with which to restore an economy dominated by subsistence agriculture with little or no industry. ${ }^{3}$ The first priority was self-sufficiency and a guerrilla war with the Khmer Rouge, who were still at large along Cambodia's border with Thailand. Engineers, skilled workers, and other human resources had either fled to other countries as war refugees or fell victims of genocide. From 1979-89, economic policy focused on the eradication of hunger. State-owned enterprises were re-established with the aim of providing basic consumer goods and public utilities. $^{4}$

According to Vickery (1986: 128-9), there were three economic organizations in the system adopted by the PRK. First, there was the state, which controlled large industry, finance, transport, and official foreign commerce.

\footnotetext{
3 During the period of the PRK regime, only 63 out of 85 enterprises in Cambodia were potentially operational but only twelve factories were functioning producing textiles, tyres, plastics, and iron tools with raw materials supplied by international non-governmental aid agencies (Slocomb 2010: 215).

4 These included tobacco, cotton, and electricity companies, a mechanical workshop, spare parts, beverage and glassware factory, and a tyre factory.
} 
Second, there were the collectives, called solidarity groups, which controlled agricultural production. Third, there was the family, which involved small trade, handicraft, and home gardens. In 1986, 97 per cent of the rural population was in the collective sector, composed of more than 100,000 solidarity groups, each of which consisted of seven to fifteen families. This was not enough to feed the population of Cambodia, and immediate food relief was provided by Vietnam, the Soviet-bloc countries, and international humanitarian aid organizations.

In 1988, the total value of industrial production including handicraft was only US\$20 million, and it was dominated by state-owned enterprises (Slocomb 2010: 215). The share of industry in GDP was only 5 per cent in 1985 compared to 19 per cent in 1969 (Cosslet 1990). By 1985 only half of the pre-war plants had reopened and the ones that did produced far below full capacity (Cosslet 1990).

\subsubsection{State of Cambodia and the UN Period, 1989-93}

With the fall of the Soviet Union and the Eastern Bloc and Vietnam's Doi Moi policy beginning in 1986, Cambodia began the gradual process of economic reform, compounded by the signing of the Paris Peace Accords in October 1991. As part of the peace agreement the government relinquished the role of rehabilitation and reconstruction to the UN.

The International Committee on the Reconstruction of Cambodia, a consultative body which included the government and donors, monitored the process of transition from a command to a laissez-faire capitalist economy, and from domestic to export-oriented production (Slocomb 2010: 289). In the mid-1980s Cambodia introduced private property, leading to the gradual privatization of state-owned companies and the de-collectivization of agriculture. GDP experienced strong growth during this period. In 1988, the real GDP growth rate was 9.8 per cent. The rate of growth slowed in 1989 and 1990 to 3.5 and 1.2 per cent respectively, recovering thereafter to around 7 per cent in 1991 and 1992, largely driven by the build-up of the UN operation (Irvin 1993). Industry contributed to 15 per cent of GDP during this time.

These successes and market reforms were undermined by macroeconomic imbalances caused by declining state revenue, the removal of humanitarian aid from the Soviet Union, and high inflation caused by monetary financing of the budget deficit (RGC 2009). As a result, the inflation rate accelerated from 70 per cent in 1989 to 200 per cent in 1992. Inflation was stabilized in 1993 through reductions in the government deficit (Irvin 1993) but the high inflation rate of the previous years led to a decline in public confidence in the national currency and the permanent dollarization of the economy. 


\subsubsection{Kingdom of Cambodia, 1993-}

After the first general election in 1993 the government prepared and implemented a comprehensive macroeconomic policy and structural reform programme. The state monopoly of foreign trade was abolished in 1987, and the foreign investment law was brought into force in 1989, enabling private companies to engage in foreign trade. In the early 1990s trade policies were further liberalized-most quantitative restrictions and the licensing of imports were eliminated.

To promote industrial development, the government provided generous incentives to attract foreign direct investment (FDI). Tax exemptions were provided on imported intermediate goods and on the exporting of finished goods. Cambodia became a member of the ASEAN (Association of Southeast Asian Nations) Free Trade Area in 1999 and eventually the World Trade Organization (WTO) in 2003. Membership of these organizations placed further requirements on Cambodia to liberalize trade in goods and services and foreign capital ownership. The inflow of FDI increased from just US\$124 million in 1993 to US\$520 million in 2009 and to more than US\$1,500 million in 2012. ${ }^{5}$

Many state-owned activities have been terminated, and only economically viable enterprises are allowed to continue. Public enterprises compete with the private sector in most areas, and generally only survive due to geographical constraints on competition. According to the Economic Census conducted by the National Institute of Statistics (NIS 2011a) in 2011 (EC2011), private establishments accounted for 96 per cent of the total number of organizations, while state-owned establishments accounted for fewer than 3 per cent.

Over the last two decades, the Cambodian economy has grown at an average rate of 7.7 per cent per annum (RGC 2015), and 10.3 per cent during 2004-8 (Hang 2009). It is expected that it will sustain a growth rate of 7 per cent per annum in the years to come. Cambodia's growth performance ranked sixth across all countries, and the country had higher exports per capita than others at a similar level of economic development (World Bank 2009a).

\subsection{The Structure of Industry}

\subsubsection{Sectoral Composition}

As highlighted in Section 11.2, it was not until the early 1990s that industrial development was given prominence in economic policy in Cambodia. The growth of industry can be categorized into four different phases. The first

\footnotetext{
${ }^{5}$ Authors' calculations based on Ministry of Economy and Finance database (GDCEC 2014).
} 
phase, 1993-8, saw an increase in the share of manufacturing to GDP from 12 to 16 per cent. The second phase was from 1999-2003, when Cambodia had achieved full peace in 1998 and successfully integrated into ASEAN in 1999. At the end of 2004, growth in the garment sector, the driver of the manufacturing sector, faced uncertainty due to the expiration of the multifibre arrangement (MFA). The third phase of manufacturing development during 2004-7 began when Cambodia became a member of the WTO. During this phase, the share of the manufacturing sector in the economy reached its peak of more than 25 per cent of GDP. During the fourth and most recent phase, from 2008 to present, the growth rate of the manufacturing sector has subsided in the aftermath of the global financial crisis.

Cambodia's industrial sector is dominated by manufacturing and construction, which accounted for 70 and 20 per cent of establishments, respectively, in 2011. Food, beverages, and tobacco (FBT) and textile, wearing apparel, and footwear (TWF) together account for 80 per cent of value added of the manufacturing sector. In 2011, the number of industrial establishments was 77,048, of which the share of manufacturing was 93 per cent. ${ }^{6}$

\subsubsection{Size of Firms}

The number of enterprises in Cambodia has been increasing gradually, especially during the period of two-digit growth rates from 1999-2008. In 1999, the number of small and medium enterprises (SMEs) was estimated at about 25,000 , reaching 36,000 in $2009 .^{7}$

Chhair and Ung (2013: Table 9) show that in 2011 almost 91 per cent of industrial enterprises were micro-establishments. The 2009 Establishment Listing of Cambodia (EL2009), also produced by NIS, reveals that the overall number of establishments in the industrial sector declined between 2009 and 2011 but the number of large establishments grew by over 20 per cent. ${ }^{8}$

Table 11.1 compares the proportion of industrial establishments by firm size in 2003 (based on the Investment Climate Survey (ICS2003) conducted by the World Bank) with figures from the EC2011. We exclude establishments with fewer than five employees from the ICS2003 and EC2011 data. The figures suggest that the share of small and medium industrial establishments and value added increased between 2003 and 2011.

${ }^{6}$ The percentage of establishments by sub-sector of industry is shown in Chhair and Ung (2013: Table 7).

${ }^{7}$ Firms with fewer than five employees are defined as micro-establishments; from 5-20 employees as small establishments; from 21-50 employees as medium establishments; and over 50 employees as large establishments.

${ }^{8}$ A detailed sectoral composition by firm size is provided in Chhair and Ung (2013: Table 12). 
Table 11.1 Share of employment and value added of industrial establishments by firm size (\%)

\begin{tabular}{lcccccc}
\hline & \multicolumn{2}{c}{ Employment } & & \multicolumn{2}{c}{ Annual revenue } \\
\cline { 2 - 3 } \cline { 6 - 6 } & ICS2003 & EC2011 & & ICS2003 & EC2011 \\
\hline Small & 2.34 & 10.43 & & 2.14 & 7.18 \\
Medium & 2.28 & 3.62 & & 2.94 & 6.78 \\
Large & 95.37 & 85.95 & & 94.76 & 86.05 \\
Total & 137 & 7040 & & 137 & 7040 \\
\hline
\end{tabular}

Source: Authors' calculations based on ICS2003 from World Bank (WB 2003) and EC2011 (excluding firms with fewer than five employees) from National Institute of Statistics (NIS 2011a).

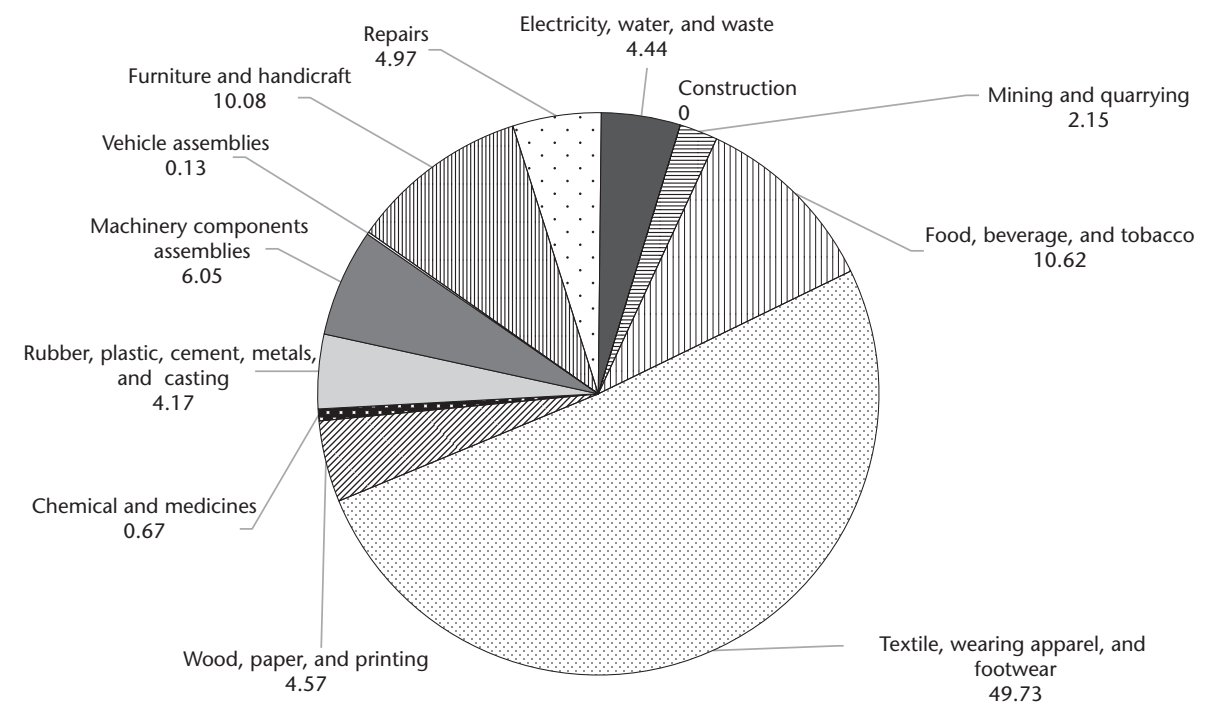

Figure 11.1 Sectoral composition of foreign owned firms Source: Authors' calculations based on EC2011 (NIS 2011a).

\subsubsection{Ownership Structure}

Cambodians own almost all micro and small industrial establishments, but only 37 per cent of large industrial establishments. Of the foreign-owned large establishments, 47 per cent are owned by Chinese and 12.5 per cent by Koreans and other Asian nationalities. As revealed in Figure 11.1, the majority of foreign owned firms are in the TWF sector and most of these are Chinese owned. Most foreign firms (over 62 per cent) were established in the last five years. There are only twenty-one foreign firms that have been established for more than twenty years. 


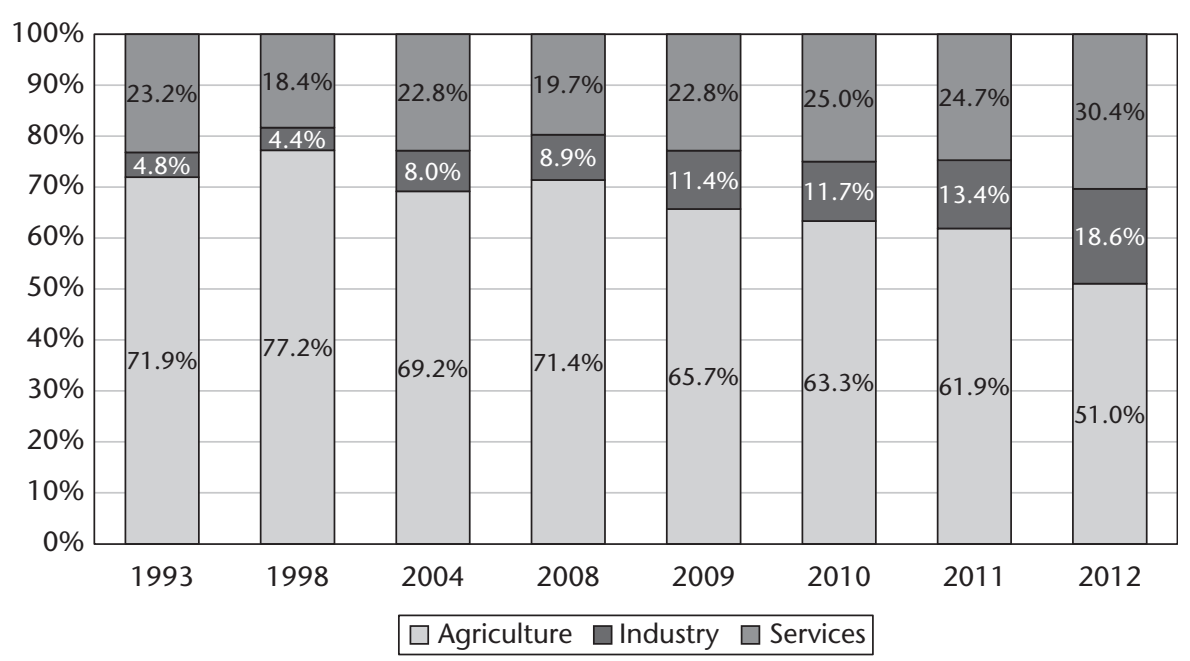

Figure 11.2 Share of employment by three main sectors Source: Authors' calculations based on NIS 1993; CSES (NIS various years).

\subsubsection{Employment}

Estimates of employment in Cambodia are complicated by high levels of migration, both within Cambodia and internationally. To measure sectoral share of employment, we use data from Cambodia's Socio-Economic Surveys (CSES) conducted by NIS (NIS various years), which asks household members for their main occupation over the last twelve months. This is illustrated in Figure 11.2.

According to this estimation, the share of employment in agriculture declined from almost 71.9 per cent in 1993 to 51 per cent in 2012. Industry and services accounted for 18.6 per cent and 30.4 per cent of employment respectively in 2012. These changes highlight the transformation of the economy from an agriculture base to an industrial and service base.

A disaggregation of employment by sub-sector is illustrated in Chhair and Ung (2013: Table 14). It reveals that there were 77,048 establishments in the industrial sector, which employed 554,058 people in 2011. TWF accounted for 67.6 per cent of industrial employment and FBT for 15.2 per cent.

It is possible that the EC2011 under-reports the number of workers employed by enterprises, probably by omitting informal companies. According to the CSES, and as revealed in Figure 11.3, the share of employment in TWF reached a peak of 57.7 per cent in 2011. The share dropped in 1997 due to an internal conflict, as well as to the world financial crisis in 2007. The FBT sector maintained a relatively stable share of employment of around 20 per cent from 1993-2001, increasing to 8.8 per cent in 2012. 


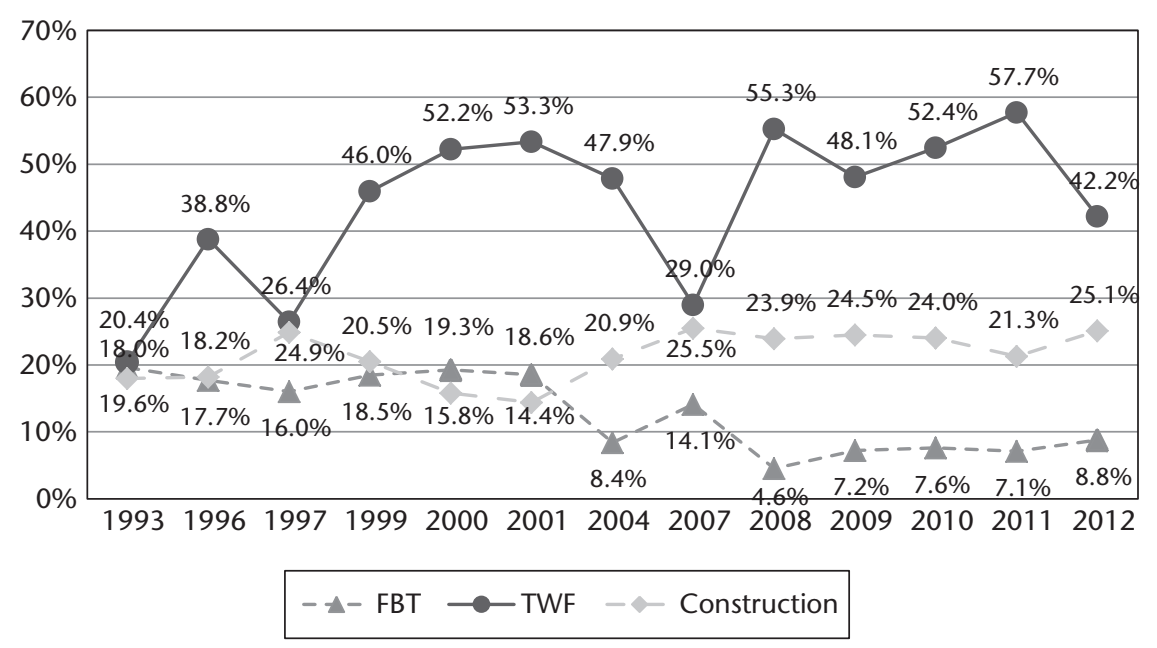

Figure 11.3 Share of the manufacturing sector

Note: The Labour Force Survey estimate of employment is based on short-term employment by asking respondents about the type of employment they were engaged in within the last week.

Source: Authors' calculations based on CSES (NIS various years) and Labour Force Surveys in 2000 (NIS 2000) and 2001 (NIS 2001).

The share of employment in construction was around 20 per cent in 1993 and reached 25.1 per cent in 2012. It should be noted that employment in construction is seasonal in nature, which is one possible reason why EC2011 under-reports the number of construction workers.

\subsubsection{Age of Firms}

The oldest possible establishments in Cambodia are those that started in 1979 after the Khmer Rouge regime. About 55 per cent have operated for five years or under. The proportion by sub-sector is illustrated in Table 11.2 along with a comparison with 2003 (based on ICS2003). The age of industrial firms represented in ICS2003 is similar to that of EC2011 (from which we exclude micro-establishments, employing fewer than five workers).

\subsubsection{Spatial Distribution}

Phnom Penh, Takeo, and Kampong Cham have the most industrial establishments of all provinces, a figure that correlates with the provincial population density. Kampong Cham Province (located 156 kilometres northeast of Phnom Penh) has a medium level of industrial development. The spatial distribution by firm size is presented in Table 11.3 and shows 
Table 11.2 Number of establishments by sub-sector and age group, 2011

\begin{tabular}{|c|c|c|c|c|c|}
\hline & All & $0-5$ years & $6-10$ years & $11-20$ years & $20+$ years \\
\hline Mining and quarrying & 177 & 97 & 26 & 33 & 21 \\
\hline Food, beverage, and tobacco & 31,891 & 17,384 & 6,667 & 5,613 & 2,227 \\
\hline Textile, wearing apparel, and footwear & 24,872 & 14,207 & 3,826 & 3,881 & 2,958 \\
\hline Wood, paper, and printing & 2,250 & 944 & 313 & 465 & 528 \\
\hline Chemical and medicines & 155 & 82 & 30 & 33 & 10 \\
\hline $\begin{array}{l}\text { Rubber, plastic, cement, metals, and } \\
\text { casting }\end{array}$ & 2,867 & 1,411 & 555 & 581 & 320 \\
\hline Machinery components assemblies & 4,684 & 2,673 & 797 & 787 & 427 \\
\hline Vehicle assemblies & 101 & 51 & 23 & 19 & 8 \\
\hline Furniture and handicraft & 2,993 & 1,590 & 588 & 648 & 167 \\
\hline Repairs & 924 & 560 & 152 & 159 & 53 \\
\hline Electricity, water and waste collection & 5,049 & 3,063 & 943 & 841 & 202 \\
\hline Construction & 187 & 101 & 36 & 41 & 9 \\
\hline Total & 76,150 & 42,163 & 13,956 & 13,101 & 6,930 \\
\hline$\%$ of firms EC2011 $(n=76,156)$ & & 55.37 & 18.33 & 17.20 & 9.10 \\
\hline$\%$ of firms ICS2003 $(n=208)($ firm size $=>5)$ & & 47.12 & 34.13 & 17.7 & 0.96 \\
\hline$\%$ of firms EC2011 $(n=6,943)($ firm size $=>5)$ & & 52.4 & 18.7 & 20.2 & 8.6 \\
\hline
\end{tabular}

Source: Authors' calculations based on EC2011 from NIS (NIS 2011a) and ICS2003 (WB 2003).

Table 11.3 Provincial spatial distribution of firms in industrial sector by firm size (\%)

\begin{tabular}{lcccrr}
\hline Provinces & Micro & Small & Medium & Large & Total \\
\hline Battambang & 4.08 & 6.61 & 4.34 & 0.65 & 4.25 \\
Kampong Cham & 10.8 & 10 & 11.89 & 5.88 & 10.71 \\
Kandal & 7.54 & 6.65 & 18.11 & 16.34 & 7.62 \\
Koh Kong & 0.33 & 0.61 & 0.57 & 0.16 & 0.35 \\
Phnom Penh & 9.65 & 28.33 & 33.96 & 59.8 & 11.64 \\
Preah Sihanouk & 0.96 & 1.63 & 1.89 & 3.27 & 1.03 \\
Takeo & 14.13 & 4.87 & 1.32 & 1.80 & 13.24 \\
Other provinces & 48.98 & 37.81 & 27.17 & 9.64 & 47.66 \\
Total (\%) & 100 & 100 & 100 & 100 & 100 \\
& 70,008 & 5,898 & 530 & 612 & 77,048 \\
\hline
\end{tabular}

Source: Authors' calculations based on EC2011 from NIS (NIS 2011a).

that larger firms tend to locate in Phnom Penh and Kandal (which circles Phnom Penh). This is probably due to the availability of good infrastructure and public services.

Table 11.4 reveals that 40 per cent of medium and large FBT establishments are in Phnom Penh. The next three provinces of importance are Kampong Cham, Battambang, and Kandal. Kampong Cham is rich with tobacco and rice millers while Battambang is a rice basket of Cambodia. Kandal benefits from its proximity to the capital. Svay Rieng, Sihanoukville, and Koh Kong are new production bases for medium and large enterprises due to the establishment of special economic zones in these provinces. 
Table 11.4 Provincial spatial distribution of medium and large firms in FBT and TWF (\%)

\begin{tabular}{lcccr}
\hline Provinces & FBT & TWF & Other industries & \multicolumn{1}{c}{ Total } \\
\hline Battambang & 10.08 & 0.57 & 2.42 & 2.36 \\
Kampong Cham & 14.29 & 2.28 & 14.11 & 8.67 \\
Kandal & 9.24 & 19.54 & 16.53 & 17.16 \\
Koh Kong & 0.84 & 0.00 & 0.60 & 0.35 \\
Phnom Penh & 40.34 & 61.1 & 35.48 & 47.81 \\
Preah Sihanouk & 5.88 & 1.52 & 3.02 & 2.63 \\
Svay Rieng & 2.02 & 0.84 & 1.52 & 1.66 \\
Takeo & 0.84 & 2.66 & 0.60 & 1.58 \\
Others & 17.65 & 10.82 & 25.20 & 17.78 \\
Total (\%) & 100 & 100 & 100 & 100 \\
& 119 & 527 & 496 & 1,142 \\
\hline
\end{tabular}

Source: Authors' calculations based on EC2011 from NIS (NIS 2011a).

\subsection{Industrial Policy}

Cambodia's industrial policy is built upon seven main points:

1 developing labour-intensive industries;

2 promoting the development of agribusiness;

3 developing industries which are based on the use of basic natural resources;

4 promoting SMEs, micro-enterprises, and handicrafts;

5 encouraging technology transfer and export product diversification;

6 establishing industrial and export processing zones;

7 increasing production of goods for import substitution.

At the core of this industrial policy is the focus on attracting investment into sectors where Cambodia has comparative advantages for export promotion. As such, a key component of industrial policy has involved reductions in barriers to exports and the import of business inputs. This is one of the main aspects of policy that is considered to have been effective. ${ }^{9}$

The Cambodia Industrial Development Policy (2015-2025) has a clear vision to maintain sustainable and inclusive high growth and transform and modernize Cambodia's industrial structure from labour-intensive industry to skill-driven industry by 2015 (RGC 2015). Targets for 2013-25 include: (1) economic diversification by increasing the share of industry in GDP from 24.1 per cent to 30 per cent and GDP's share of manufacturing from 15.5 per cent to 20 per cent; (2) export diversification by increasing exports of non-garment

\footnotetext{
9 A recent review of existing policy instruments by the World Bank (2009a: 88) found that most instruments lacked accountability, with the only exceptions being those focused on promoting exports.
} 
and footwear from 1 per cent to 15 per cent, processed agricultural products from 7.9 per cent to 12 per cent, and decreasing exporting of garment and footwear from 77 per cent to 50 per cent; (3) promotion of SMEs by registering SMEs and ensuring that 50 per cent of small enterprises and 70 per cent of medium enterprises have proper financial records and balance sheets.

\subsubsection{Macroeconomic Policy}

Cambodia's macroeconomic policy stance is largely consistent with its key objectives of attracting foreign investment and export promotion. As a largely dollarized economy, Cambodia relies mainly on a conservative fiscal policy to prevent inflationary pressures. Monetary policy has allowed a deepening of the financial sector. Current and capital accounts are open and there is no restriction on the exchange rate.

The main medium- to long-term goals of the National Bank of Cambodia (NBC), as set out in the National Strategic Development Plan (NSDP) (2009-2013) (RGC 2009, 2013) are to: (1) maintain price stability with an inflation target of under 5 per cent; (2) ensure the continued soundness of the financial sector; (3) continue to manage a floating exchange rate regime with a target of around KHR4100 per US\$; (4) maintain foreign reserves to finance at least three months of imports. International reserves increased from US $\$ 500$ million in 2000 (Hang 2010) to US\$6,027 million in 2015, excluding gold and special drawing rights (SDR) (NBC 2015).

In order to strengthen macroeconomic stability, the government sets out the following priorities: implementing a flexible fiscal policy to be consistent with monetary policy; diversifying the export base; keeping public debt at a manageable level; strengthening institutional coordination; enhancing private sector development; promoting labour market development; encouraging investment in key sectors and ensuring an increase in international reserves; continuing to implement a managed floating exchange rate regime to maintain stability of the Riel; strengthening public and investor confidence in the local currency to promote its greater use; and strengthening the supervision and management of liquidity, credit, and market risks in compliance with international standards (RGC 2013).

\subsubsection{Trade Policy}

A key feature of industrial policy in Cambodia is its emphasis on trade. The domestic market has been too small to support long-term growth, and so exportoriented investment is crucial. Cambodia has capitalized on the intra-regional 
complementarity that stems from differences in labour costs, the availability of natural resource endowments, and trading regulations.

Cambodia joined ASEAN in 1999 and the WTO in 2003. This marked the final step into the major regional and international organizations that govern international economic relations. For the garment industry the accession presented not only a challenge to become more competitive, but also opportunities for expansion because of the removal of the quotas for Cambodian exports to the 147 WTO members.

\subsubsection{Labour Market Policies}

Cambodia's labour market remains free and open in practice, though labour laws have been in place since 1992. The emergence of the garment sector led to new labour laws in 1997, which focused on freedom, the establishment of unions, and rights for demonstration. The 1997 law applies only to the garment sector and its related sectors. There were a total of 989 strikes between 2003 and 2014, averaging 1.6 per week (GMAC 2015b).

Minimum wages are a key feature. The legal minimum wage in Cambodian factories was US\$40 per month in 1997 for regular employees and it took thirteen years to increase to US\$61 in 2010 (GMAC 2015b). However, recently, it has increased steadily from US\$80 in 2013 to US\$117 in 2014 and US\$145 in 2015. ${ }^{10}$ Negotiations are now ongoing between factories, unions, and the government for further wage increases in 2016. To compare with competitors, in 2015, the minimum wage in Cambodia is equal to that of Vietnam; but average working hours per month and working days per year are fewer for Cambodia; while in Bangladesh and Myanmar the minimum wage is much lower at US\$70 and US\$78, respectively.

The better factory programme was introduced in 2010. The basic objective of the programme is to improve working conditions in Cambodia's textile and apparel sector, particularly through an independent monitoring system of working conditions in garment factories. This programme resulted from USA-Cambodia trade negotiations in exchange for market access to the USA.

\subsubsection{The Institutional and Regulatory Framework}

The government of Cambodia regards the private sector as the main impetus for the country's economic growth, and initiated the Government-Private Sector Forum (G-PSF). ${ }^{11}$ The Council for the Development of Cambodia (CDC) also

\footnotetext{
10 The minimum wage for 2014 and 2015 also includes mandatory allowances of US\$17.

11 G-PSF meets twice a year under the chairmanship of the prime minister and has eight working groups meeting regularly. It provides a vehicle for the private sector to raise its concerns and for the
} 
facilitates investment applications and decisions. The length of investment application procedures was reduced to a maximum of forty-five days. This law provides a clear and more liberal investment regime, with attractive incentives for FDI. According to CDC (2012: III1-2), to improve the business and investment climate and to comply with WTO regulations, the Royal Government of Cambodia has recently placed emphasis on updating and adopting new laws and regulations on investment, trade, and business.

\subsubsection{Sector Specific Policies}

\subsubsection{GARMENT SECTOR}

The garment sector is now one of Cambodia's fastest-growing for private investment. This is mainly the result of normalized trade relationship (NTR) agreements, first signed with the European Union in 1996 and then with the USA in 1997. The agreements were the result of Cambodia being granted most favoured nation (MFN) status and status under the generalized system preference (GSP) agreement. Between 1994 and 1999, Cambodia's garment exports grew by more than 100 per cent, from US\$495 million to US\$1,102 million, with about 90 per cent of garment shipments going to the USA. This strong performance prompted the USA to introduce quotas on twelve categories of Cambodian garment exports in 1999, but this measure did not significantly affect the expansion of the industry, whose exports continued to rise to almost US\$3,000 million in 2008 (Chan and Oum 2010). In 2014, exports rose to US $\$ 5,785$ million and were more diversified; 42.31 per cent were to the EU, 33.44 per cent to the USA, 8.96 per cent to Canada, and 5.29 per cent to Japan (GMAC 2015a).

Rapid development in the garment industry, combined with the country's democratization process, has resulted in the accelerated growth of unions. In 1998, the Clinton administration developed the US-Cambodian Trade Agreement on Textiles and Apparel (1999-2004) which linked market access to labour standards. The International Labour Organization (ILO)'s Better Factories Cambodia was instituted in 2010 for independent monitoring.

\subsubsection{TOURISM}

The policies for tourism are based on three basic principles of sustainability and poverty reduction, active promotion, and lengthening the average stay (RGC 2009). From 2009 to 2013, the government prioritized completing

government to be held accountable for its decisions. In 2012, G-PSF added another working group to promote the export of agro-processing products. This forum is viewed by investors as an important device for creating a sense of security for their investments (World Bank 2009a). Since this forum has the status of cabinet meetings, decisions made by the prime ministers are binding (ibid.). 
tourism plans, marketing studies, and tourism campaigns to raise regional and international awareness of Cambodia's tour programmes (Hahn et al. 2011). The Tourism Strategic Development Plan (2012-2020) and Cambodia Tourism Marketing Strategy (2015-2020) have a target of attracting 7 million foreign tourists in 2020 .

\subsection{Sunset and Sunrise Industries}

According to the World Bank (2009a: 18), the forestry and fisheries sectors accounted for 19 per cent of GDP growth in 1993-8 but only 2 per cent in 2003-8. Forest production accounted for 43 per cent of exports in 1994 and fewer than 1 per cent of exports in 2006. Out of concern for the rapid degradation of forest resources and fish stocks, the government banned logging in 2000 and reformed large commercial fishing lots in 2002. These two sectors which thrived in the 1990s became sunset industries in the 2000s. As these sectors have declined in importance, there are many sectors that are expected to grow in the coming years. Of these, the most significant are expected to be tourism, garments, banking, rice processing, and rubber processing.

The tourism sector in Cambodia has been growing at an exponential rate in the last decade, and has become the second largest income source for the Cambodian economy after the garment sector (Hahn et al. 2011). The development of this sector is mainly driven by political stability, World Heritage monuments, especially Angkor Wat, improved infrastructure, close proximity to tourism hubs, and government policies, most notably the Open Sky Policy. The number of international tourists has gradually increased from fewer than 120,000 in 1993 to 4.50 million in 2014 (MoT 2015b).

The garment sector has also experienced significant growth. The number of garment and footwear factories increased from just seven in 1994 to about 737 in 2015 employing about 600,000 workers (GMAC 2015a). According to the EIC (2009) most new materials and accessories are imported from China, Hong Kong, and Taiwan. Domestic supply of inputs would not only result in more jobs and value addition for the economy, but would also help make Cambodian garment products more competitive.

The garment sector has, nonetheless, contributed to employment generation, particularly for young female workers from rural areas. Based on examples from small sample surveys of garment workers, more than 90 per cent send remittances home, with the average annual amount ranging from US\$246 in 2007, amounting to 29 per cent of salaries earned, to US\$508 in 2009, amounting to 40 per cent of salaries earned (CDRI 2007; Luch 2010; Yagura 2011). 
Up until 2005, Cambodia's financial system was very underdeveloped, but the commercial banking sector (which remains small in absolute terms) has since caught up. Lending by commercial banks and micro-finance institutes (MFIs) has risen at a fast pace. Development has been disrupted by the world financial crisis but commercial loans have gradually begun to grow again. ${ }^{12}$ While the role of the banking sector in promoting growth remains small, and most of the growth achieved to date has been without bank finance (growth in credit has been largely directed to consumption, working capital, and real estate, see World Bank (2009a: 14)); there are signs that this sector is growing. For example, total deposits from and loans to customers grew by 36 per cent and 33.7 per cent respectively between 2013 and 2014 with 3.3 million depositors and 2.2 million creditors in 2014 (NBC 2014).

Rice exporting has benefited from trade preferences granted by the EU. The government further supports these exports through the introduction of the policy paper on 'Promotion of Paddy Rice Production and Export of Milled Rice' in 2010, with the target of paddy surplus of four million tons and milled rice export of one million tons by 2015. The official rice export figure in 2009 was only 15,500 tons with paddy production of 7,586,000 tons (CEFP 2011). It only exported 387,061 tons in 2014 and 283,825 tons in the first semester of 2015 (MAFF 2015). It is estimated that in total half a million tons of rice will be exported in 2015, half of the target (MAFF 2015).

Land use for rubber has increased because of rises in world demand, and has the potential to rise further. The total land area cultivated for rubber was 181,400 ha in 2010 and increased to 357,800 ha in 2014. Exports of rubber reached 42,000 tons in 2010 compared to 100,150 tons in 2014 (MAFF 2015). These developments suggest that rubber processing will also be one of the sunrise industries.

Table 11.5 highlights the sectors where the share of exports and value added are increasing and decreasing in relation to the sunset and sunrise industries. In the latest period, vegetable products, rubber, and foodstuffs are rising in importance, primarily due to the Everything but Arms (EBA) scheme that allows Cambodia to export agricultural goods to Europe tariff-free. Notably, wood and wood products have gained export share for 2008-12 as a result of forest clearance for the hydroelectricity project. The export of machinery/ electrical and plastic/rubber increased during the same period.

During the 1998-2004 period, when full peace was achieved, TWF gained a larger share of value added. Construction continued to boom between 2005 and 2007, before the world financial crisis hit in 2008. Rubber processing declined

\footnotetext{
12 According to the National Bank of Cambodia (NBC 2015: 21), there are thirty-six commercial banks, eleven specialized banks, eight foreign-subsidiary offices and forty-nine MFIs (of which seven take deposits) and forty-two rural credit operators in Cambodia.
} 
Table 11.5 Comparison of growth in exports and value added across sectors

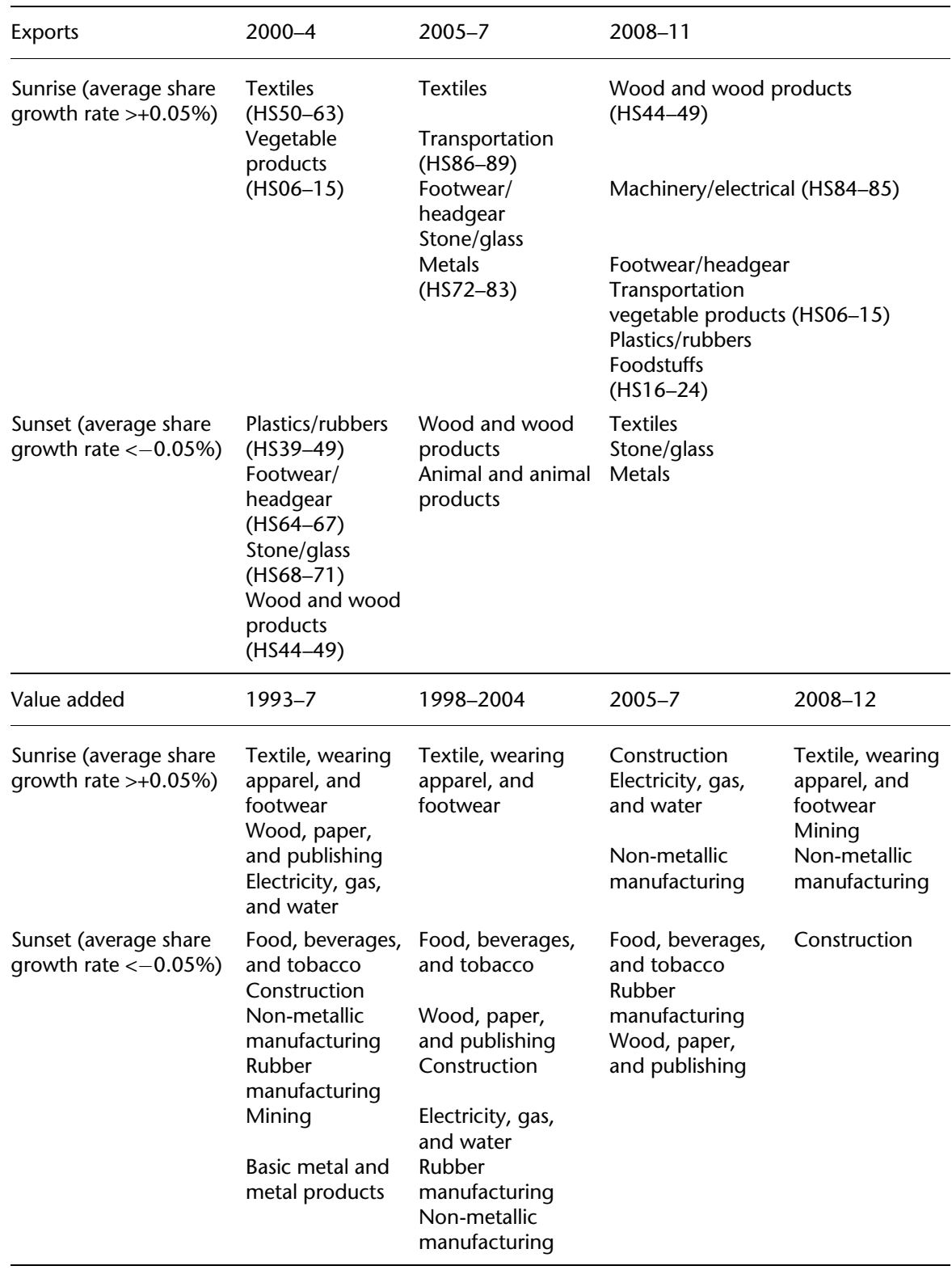

Note: Export data are based on the yearly Export Statistics produced by the General Department of Customs and Excise of Cambodia, Ministry of Economy and Finance (GDCEC 2014). Value added data are based on the National Accounts produced by NIS (NIS 2012).

Source: Authors' calculations. 
in share since 1993, but increased again between 2008 and 2012. FTB was in decline between 1993 and 2007, but gained momentum in 2008 after global food prices soared. The mining sector gained share in the 2008-12 period. Since 2007, licences on exploration of oil and gas in the Gulf of Thailand have been issued. This sector could continue to grow in future. Non-metallic manufacturing gained share for the periods 2005-7 and 2008-12.

\subsection{Conclusion}

Cambodia has experienced record growth rates during the last two decades and private enterprise is expanding at a rapid pace. The country emerged from the global recession quite strongly and is now on the road to recovery: economic growth is accelerating, inflation is under control, the exchange rate remains broadly stable, and international reserves continue to accumulate. More than a decade of structural reform, a sound and stable financial system, and well-timed and well-targeted policy stimuli have provided crucial support for the Cambodian economy.

Challenges remain, however, such as in issues surrounding corruption ${ }^{13}$ and accountability, infrastructural deficits, labour standards, and corporate social responsibility practices. A key risk factor for Cambodia's economic development is its dependence on a few key sectors such as garments, agroprocessing, tourism, and construction, all of which are vulnerable to foreign markets and investment fluctuations. While the policy of export-oriented FDI has played a very important role in modern job creation, the economy of Cambodia lacks diversification. There is also little evidence to suggest that export-oriented FDI firms have yielded technological spillover or other economic linkages with the domestic economy. Cambodia's Industrial Development Policy (2015-2025) aims to address these challenges.

The government during the last decade has focused attention on local SMEs by promoting productivity and finding markets for their products-for example, the rice policy introduced by the government in 2010. The aim is to boost the local rice processing industry, generate employment, and increase value added. This policy will be the model for the government to promote other agro-processing industries, most notably rubber processing. As the first policy to be independently adopted by the government of Cambodia, its introduction also signals a desire to overcome past problems of weak governance and co-ordination difficulties, which bodes well for future economic development.

13 In 2008, corruption was still the largest concern for businesses in Cambodia (World Bank 2009b). In 2011 Cambodia ranked 164 among 182 countries in the Corruption Perceptions Index by Transparency International. 


\section{References}

Cambodia Development Resource Institute (CDRI) (2007). 'Youth Migration and Urbanization in Cambodia'. Working Paper 36. Phnom Penh: CDRI.

Chhair, S., and L. Ung (2013). 'Economic History of Industrialization in Cambodia'. WIDER Working Paper No. 2013/134. Helsinki: UNU-WIDER.

Chan, S. and Oum, Sothea (2010). Impact of Garment and Textile Trade Preferences on Livelihood on Cambodia. Phnom Penh: Cambodian Economic Association.

Chhair, S. and Ung, L. (2013). 'Economic History of Industrialization in Cambodia'. WIDER Working Paper No. 2013/134. Helsinki: UNU-WIDER.

Committee for Economic and Financial Policy (CEFI) (2011). Review Report on the Implementation of the Policy Paper on the Promotion of Paddy Production and Rice Export (2010-2011). Phnom Penh: Royal Government of Cambodia.

Cosslet, T. L. (1990). 'The Economy', in Russell R. Ross (ed.) Cambodia: A Country Study. Washington, DC: Library of Congress.

Council for the Development of Cambodia (CDC) (2012). Cambodia Investment Guidebook. Phnom Penh: Japan International Cooperation Agencies.

Delvert, Jean (1963). 'L'économie cambodgienne et son evolution actuelle'. Tiers-Monde 4(13-14): 193-212.

Ear, S. (1995). 'Cambodia's Economic Development in Historical Perspective: A Contribution to the Study of Cambodia's Economy', available at <http:// citeseerx.ist.psu.edu/viewdoc/download?doi=10.1.1.558.2751\&rep=rep1\&type= pdf $>$, accessed 19 February 2016.

Economic Institute of Cambodia (EIC) (2009). Export Diversification and Value Addition for Human Development. Phnom Penh: Economic Institute of Cambodia.

Garment Manufacturers Association in Cambodia (GMAC) (2015a). Bulletin 2015. Phnom Penh: Garment Manufacturers Association in Cambodia.

Garment Manufacturers Association in Cambodia (GMAC) (2015b). History of Minimum Wage for Garment and Footwear Industry in Cambodia. Phnom Penh: Garment Manufacturers Association in Cambodia.

General Department of Customs and Excise of Cambodia (GDCEC) (2014). ASYCUDA Statistics. Phnom Penh: Ministry of Economy and Finance, available at $<\mathrm{http} / / /$ www.customs.gov.kh/publication-and-resources/statistics/>, accessed 23 February 2016.

Hahn, Chin Hee, Kim, Jong-il, Sohn, Wook, Chin, Yong-ju and Yoo, Kyengwon (2011). Policy Agenda for Cambodia in Growth, Finance, Industry and Trade. Knowledge Sharing Program. Sejong City: Ministry of Strategy and Finance and Korean Development Institute.

Hang, C. (2009). Cambodian Economy: Charting the Course of a Brogher Future. Phnom Penh: Asian Development Bank.

Hang, C. (2010). Cambodia's Macroeconomic Development. Presentation at the Annual Meeting of Cambodian Economic Association, February, Phnom Penh.

Hou, Y. (1955). 'Peasantry of Kampuchea: Colonialism and Modernization', in B. Kiernan and C. Boua (eds) Peasants and Politics in Kampuchea 1942-1981. Cambridge: Cambridge University Press, 34-68. 
$\mathrm{Hu}$, N. (1965). 'Land Tenure and Social Structure in Kampuchea', in B. Kiernan and

C. Boua (eds) Peasants and Politics in Kampuchea 1942-1981. Cambridge: Cambridge University Press, 69-86.

Irvin, G. (1993). 'Rebuilding Cambodia's Economy: UNTAC and Beyond'. Working Paper Series No 149. The Hague: Institute of Social Studies.

Khieu, S. (1959). Cambodia's Economy and Problems of Industrialization (trans. Laura Summer in 1976). New York, NY: Cornell University.

Luch, L. (2010). 'The Impact of Remittances from the Garment Factory Workers on Income: A Case Study in Rural Cambodia'. Journal of Rural Economics 82: 433-9.

Ministry of Agriculture, Forestry, and Fisheries (MAFF) (2015). Annual Report 2014-2015. Phnom Penh: Ministry of Agriculture, Forestry, and Fisheries.

Ministry of Tourism (MoT) (2012). Tourism Strategic Development Plan 2012-2020. Phnom Penh: Ministry of Tourism.

Ministry of Tourism (MoT) (2015a). Cambodia Tourism Marketing Strategy 2015-2020. Phnom Penh: Ministry of Tourism.

Ministry of Tourism (MoT) (2015b). Tourism Statistics: Report June 2015. Phnom Penh: Ministry of Tourism.

National Bank of Cambodia (NBC) (2014). NBC Annual Report 2014. Phnom Penh: National Bank of Cambodia.

National Bank of Cambodia (NBC) (2015). National Bank of Cambodia 1st Semester Report 2015. Phnom Penh: National Bank of Cambodia.

National Institute of Statistics (NIS) (2000). Cambodia Labor Force Survey 2000. Microdata. Phnom Penh: Ministry of Planning.

National Institute of Statistics (NIS) (2001). Cambodia Labor Force Survey 2001. Microdata. Phnom Penh: Ministry of Planning.

National Institute of Statistics (NIS) (2003). Survey of Industrial Establishments in 2000. Phnom Penh: Ministry of Planning.

National Institute of Statistics (NIS) (2011a). Economic Census of Cambodia 2011. Phnom Penh: Ministry of Planning.

National Institute of Statistics (NIS) (2011b). General Population Census of Cambodia 2008: Population Projections of Cambodia. Phnom Penh: Ministry of Planning.

National Institute of Statistics (NIS) (2012). National Accounts 2012. Phnom Penh: Ministry of Planning.

National Instutute of Statistics (NIS) (various years). Cambodia Socio-Economic Survey (2004, 2008-12). Microdata. Phnom Penh: Ministry of Planning.

Royal Government of Cambodia (RGC) (2009). National Strategic Development Plan Update 2009-2013. Phnom Penh: Ministry of Planning.

Royal Government of Cambodia (RGC) (2013). Rectangular Strategy Phase III. Phnom Penh: Ministry of Planning.

Royal Government of Cambodia (RGC) (2015). Cambodia Industrial Development Policy 2015-2025. Phnom Penh: Council of the Development of Cambodia.

Slocomb, M. (2010). An Economic History of Cambodia in the Twentieth Century. Singapore: National University of Singapore Press.

Vickery, M. (1986). Kampuchea: Politics, Economics and Society. London: Frances Pinter. World Bank (2003). Investment Climate Survey. Phnom Penh: World Bank. 
World Bank (2009a). Second Investment Climate Assessment: A Better Investment Climate to Sustain Growth in Cambodia. Phnom Penh: World Bank.

World Bank (2009b). Sustaining Rapid Growth in a Challenging Environment. Phnom Penh: World Bank.

Yagura, K. (2011). 'Does Labor Migration Offer Opportunities for Meeting Prospective Spouses? The Case of Migrant Workers in Cambodia'. Population, Space, and Place 18(3): 277-94. 


\title{
12
}

\section{The Evolution of Vietnamese Industry}

\author{
Nguyen Thi Tue Anh, Luu Minh Duc, and Trinh Duc Chieu
}

\subsection{Introduction}

One of the most important policy decisions for Vietnam during the Doi Moi process was the shift from a strategy of import substitution (IS) to one of export orientation. Obviously, Vietnamese policy makers wanted to avoid the failure of the Latin American economies and to learn from the successes of the industrialized nations and newly industrialized economies (NIEs) of East Asia, the renowned 'flying geese'. As a result, during the past decade, Vietnam's industrial output has grown at an average annual rate of 15.2 per cent and total annual exports have increased 18.1 per cent (GSO various years).

Undeniably, the industrial and export performance has been the key driver of economic growth, radically changing the country over the past two decades. Dynamic foreign direct investment (FDI) and the private sector played key roles in manufacturing and exporting activities, in contrast to the earlier monopolistic behaviour and inefficiency of the centrally planned state-owned enterprises (SOEs). Today, the remaining SOEs have become more active and competitive exporters, certainly a reflection of Vietnam's continued learning process at both country and cross-sector levels.

The industrial sector in Vietnam contributes to approximately 34 per cent of GDP, and manufacturing is by far the most important industrial sub-sector, accounting for 87 per cent of total industrial gross output. Within manufacturing the food and beverage industry stands out as the most important industry with around 19 per cent of total industrial output. However, other industries are growing rapidly and gaining importance, and include, for example, fabricated metal products, apparel, and pharmaceutical industries.

This chapter describes the evolution of Vietnamese industry, as well as its current characteristics, and is structured as follows. Section 12.2 delineates 
historical episodes of national industrial change, divided into four periods: 1954-75 (Vietnam's war); 1976-85 (socialist industrialization to the initiation of the Doi Moi); 1986-2005 (transition to a market economy); and from 2006 onwards (World Trade Organization (WTO) accession and further industrialization). Section 12.3 describes the current structure of Vietnam's industrial sector by industry composition, employment and firm size, ownership structure, and geographical distribution. The industrial policy framework is described in Section 12.4, including the macroeconomic policy, trade policies, labour market policies, the institutional and regulatory framework, and sector specific policies. In Section 12.5, so-called sunrise and sunset industries are identified. The final section (Section 12.6) concludes by exploring the main challenges facing current industrial development and presenting an outlook for the future.

\subsection{The Evolution of Industry}

The evolution of Vietnamese industry can be divided into four stages, with the main characteristics as illustrated in Table 12.1.

\subsubsection{Socialist Industrialization in the North, 1954-75}

Although gaining independence in 1945, Vietnam was at war with France until 1954 when the country split into two warring parts, each with a different political and economic ideology. In such a context, socialist industrialization was adopted in the North to support efforts to reunify the country.

Prior to independence, French colonial administration had pursued the development of agricultural production (rice and rubber) in the south and manufacturing and coal mining in the North. When colonial administration ended, the country was left with minimal infrastructure, a low income and mainly illiterate population, poor conditions for entrepreneurship, and an economy which overall was characterized by village-based subsistence agriculture.

Under the socialist model, the economy was entirely controlled by the state. Rural land reforms and a process of collective corporatization led the private sector to stand outside of the industrial production in the North. All state-supported technical and scientific research activities were devoted to serving heavy industry and the war effort. Most of the industrial development achievements in this period were enabled through foreign subsidies from Vietnam's socialist allies, such as China, the Soviet Union, and other Warsaw-bloc nations. 
Table 12.1 Vietnam's industrial policy matrix

\begin{tabular}{|c|c|c|c|}
\hline 1965-75 & $1976-85$ & 1986-2005 & 2006- \\
\hline & Policy plan & & \\
\hline \multirow[t]{2}{*}{$\begin{array}{l}\text { Socialist industrialization in the } \\
\text { north }\end{array}$} & $\begin{array}{l}\text { Socialist industrialization in the } \\
\text { centrally planning economy }\end{array}$ & $\begin{array}{l}\text { Doi Moi process and industrialization in the } \\
\text { transition towards market-oriented and open } \\
\text { economy }\end{array}$ & $\begin{array}{l}\text { Industrialization in post-WTO entry } \\
\text { period and economic restructuring } \\
\text { issues }\end{array}$ \\
\hline & Objectives and key industries & & \\
\hline \multirow[t]{3}{*}{$\begin{array}{l}\text { To prioritize the development of } \\
\text { heavy industry; the industry sector } \\
\text { was exclusively led by the SOEs } \\
\text { Shift from heavy industry (1961-5) } \\
\text { to light industry and agriculture } \\
\text { (1966-73) }\end{array}$} & $\begin{array}{l}\text { To overcome consequences of the } \\
\text { war and restore the country's } \\
\text { infrastructure network and } \\
\text { industrial bases, including the } \\
\text { state entrepreneurship } \\
\text { To concentrate on heavy industry }\end{array}$ & $\begin{array}{l}\text { 1991-5: Development of prioritized sectors: } \\
\text { heavy industry (cement, steel) and natural } \\
\text { resource-based industries (oil exploitation and } \\
\text { mining). Manufacturing sectors for domestic } \\
\text { demand (food stuff industries) and } \\
\text { simultaneous export of manufactured labour- } \\
\text { intensive products }\end{array}$ & $\begin{array}{l}\text { Policies of boosting economic } \\
\text { structural change towards } \\
\text { industrialization and modernization; } \\
\text { more export-oriented: continuation } \\
\text { of earlier priorities, but with greater } \\
\text { selection. }\end{array}$ \\
\hline & & $\begin{array}{l}\text { 1996-2000: Continuation of earlier priorities, } \\
\text { but with greater selection; development of light } \\
\text { export-oriented industries (textiles and } \\
\text { garments, footwear, paper production) }\end{array}$ & \\
\hline & & $\begin{array}{l}\text { 2001-5: Followed the objectives of the previous } \\
\text { period, but expansion of manufacturing sector } \\
\text { with a focus on development of high-tech } \\
\text { sectors }\end{array}$ & \\
\hline \multirow[t]{2}{*}{ 1965-75 } & $1976-85$ & 1986-2005 & 2006- \\
\hline & Instruments & & \\
\hline FFYP 1961-5 & $\begin{array}{l}\text { To continue the North's } \\
\text { interrupted FFYP (1960-5) by } \\
\text { incorporating the nationwide } \\
\text { Second Five-year Plan (1976-80) } \\
\text { Planning economy, no market- } \\
\text { based price mechanism }\end{array}$ & $\begin{array}{l}\text { + Protectionism for some certain industries } \\
\text { through tariff and non-tariff instruments such as } \\
\text { quota and import/export duties and export } \\
\text { subsidies } \\
\text { + Encourage private businesses and foreign- } \\
\text { owned enterprises with Law on Foreign } \\
\text { Investment in } 1987 \text { and Company Law in } 1991\end{array}$ & $\begin{array}{l}\text { + Specified many leading industries } \\
\text { for development. Strategies } \\
\text { approved for about } 39 \text { industries } \\
+ \text { Promotion of technology transfer } \\
\text { via foreign investment } \\
+ \text { Continued export production of } \\
\text { manufactured products }\end{array}$ \\
\hline
\end{tabular}


Table 12.1 Continued

\begin{tabular}{|c|c|c|c|}
\hline $1965-75$ & $1976-85$ & 1986-2005 & 2006- \\
\hline & \multicolumn{3}{|l|}{ Instruments } \\
\hline & & $\begin{array}{l}\text { + Implementation of Public Investment } \\
\text { Programme (1996-2000) } \\
\text { + Equitization of SOEs and building of state } \\
\text { economic groups to enhance the } \\
\text { competitiveness of the SOE sector in the } \\
\text { industry } \\
\text { + Development of IZs, EPZs to encourage export } \\
\text { production (1996-2001) }\end{array}$ & $\begin{array}{l}\text { + Promulgation of Law on } \\
\text { Investment and Law on Enterprise in } \\
\text { compliance with WTO commitments } \\
\text { + Removal of non-tariff, but } \\
\text { application of export tax rate at } 0 \% \\
\text { continued for most export products } \\
\text { to motivate export activities }\end{array}$ \\
\hline & \multicolumn{3}{|l|}{ Evaluation } \\
\hline $\begin{array}{l}\text { The FFYP } 1961-5 \text { was disrupted in } \\
1964 \text { because of US air strikes in the } \\
\text { north: large-scale constructions, } \\
\text { industrial infrastructure, } \\
\text { transportation systems were } \\
\text { severely damaged, shortage of } \\
\text { labour force due to the war }\end{array}$ & $\begin{array}{l}\text { High growth of heavy industry, but } \\
\text { bureaucratic and unprofitable } \\
\text { SOEs in industrial production; low } \\
\text { labour productivity, material and } \\
\text { technological shortfalls, and } \\
\text { insufficient availability of food and } \\
\text { consumer goods }\end{array}$ & $\begin{array}{l}\text {-'Picking-winner' approach; dualistic structure } \\
\text { of Vietnam's industrial sector } \\
\text { - Export structure was changed towards } \\
\text { increasing the share of manufactured products; } \\
\text { the main exporting products were still mining } \\
\text { and crude oil } \\
\text { - Inefficient SOE sector in industrial production; } \\
\text { low industrial labour productivity }\end{array}$ & $\begin{array}{l}\text { The IS sectors failed to grow and to } \\
\text { provide sufficient supply for other } \\
\text { downstream industries, including } \\
\text { export-oriented ones } \\
\text { The export-oriented sector had to } \\
\text { rely on inputs from imports } \\
\text { Desired spillover impacts from FDI, } \\
\text { particularly via technology transfer } \\
\text { and linkages with domestic } \\
\text { enterprises, were virtually non- } \\
\text { existent } \\
\text { Industrial policies failed to facilitate } \\
\text { firms' activities sufficiently } \\
\text { Remaining SOEs, including state } \\
\text { economic groups, inefficient } \\
\text { Industrial policy focused too much } \\
\text { on specific sectors and products, not } \\
\text { on improving competitiveness of } \\
\text { enterprises }\end{array}$ \\
\hline
\end{tabular}

Source: Vietnam's Five-year Socio-economic Development Plans covering the 5-year periods from 1961-2015, as approved by the National Assembly. 
The industrial policy pursued during the later part of the period, the socalled First Five-year Plan (FFYP) (1961-5), gave priority to the industrial sector. However, this plan was disrupted in 1964 when the US started air strikes in the North, preventing the development of heavy industry and tilting what economic activity remained towards light industry and agriculture.

All power stations, railway lines, roads, bridges, and sea and inland ports were seriously damaged by the US bombings during 1965-72 which interrupted transportation routes and energy supplies, including power and petroleum. Consequently, the distribution of raw materials and consumer goods was badly affected and delayed all large-scale construction. And, importantly, since the vast majority of the labour force was employed in the war effort, the rest of the economy was constrained by severe labour shortages.

\subsubsection{Socialist Industrialization in the Central Planning Economy, 1976-85}

Post-war Vietnam faced three major economic challenges: (1) to repair the consequences of the destructive war and restore the country's infrastructure and industrial bases, including state entrepreneurship; (2) to adopt and unify the centrally planned system for the whole country; (3) to continue the North's interrupted FFYP to incorporate a Second Five-year Plan (1976-80) as the nationwide strategy to achieve the ambitious target of building a socialist economy within twenty years.

During this period, industrial planning was the central function of the state's economic administration, with the government defining input and output levels for the entire economy. There was no market-based price mechanism, as open trade and private entrepreneurship was not officially recognized. Without a company law in existence, all industrial producers and traders were SOEs, governed directly by the ministries and provincial authorities, which led to a highly bureaucratic and unprofitable situation.

In the early 1980s, more than 80 per cent of national income came from the agricultural sector which was dominated by village-level 'collectives'. Growth of the agricultural and light industrial sectors outpaced that of heavy industry. Based on the scarce statistics that were (irregularly) published, industrial production grew at 9.5 per cent per annum from 1981-5 and income per capita at 6.4 per cent. But the economy was characterized by small-scale production, low labour productivity, high unemployment, material and technological shortfalls, and insufficiency of food and consumer goods. During the years 1976-85, when the economy faced a slowdown, national income was said to have met 80-90 per cent of needs, and inflation throughout the period remained in double digits. By 1985-6, Vietnam was on the brink of a socio-economic crisis. 


\subsubsection{The Transition from Centrally Planned to Market Economy, 1986-2005}

Against this backdrop, the government launched a comprehensive reformDoi $\mathrm{Moi}^{1}$ (renovation) in December 1986-to transform the economy from a centrally planned subsidy economy towards a socialist-oriented market economy that would combine state intervention (mainly in the form of planning) with free-market incentives and rules, where private businesses and foreign-owned enterprises would be encouraged. ${ }^{2}$

During the era steered by the Third Five-year Plan (1986-90), annual production of steel increased 8 per cent, cement 11 per cent, electricity 11 per cent, and zinc 10 per cent. New industries emerged, especially with the discovery of oil (made possible through joint ventures between the state and foreign oil companies) which increased government revenues and accounted for the greatest share of exports. In the space of a few years, Vietnam transformed from a food-insufficient country to the world's second largest exporter of rice.

The Doi Moi process strongly influenced the development of Vietnam's industry. During 1991-5, average annual industry growth rate reached almost 14 per cent, a pace that was maintained in later years. Remarkable growth was evident in all industrial products, for example, coal exploration topped over 26 million tons (or almost six times higher than in 1990); electricity (five times over the 1990 level); cement (ten times the 1990 level); and assembled televisions (almost eighteen times the 1990 level).

The Five-year Plan of 1996-2000 set out estimated figures for economic development, in which the targeted annual growth rate of agriculture, forestry, and fishery, industry, and service were set at $4.5-5,14-15$, and $12-13$ per cent respectively. This was intended to create a structural shift in the economy in which the share of industry in total output would be increased (which, as described in Section 12.3, has indeed been accomplished).

The main policy priority in this period was still heavy industry, where the goal was to meet domestic demand and exploit natural resources. However, there was added emphasis on certain sectors, including steel and cement. In addition, the development of light industries (mostly for export) such as textiles and garments, footwear, paper production, and handicrafts were selected as 'priority sectors' because of the comparative advantage Vietnam

\footnotetext{
1 Doi Moi was announced by the Vietnam Communist Party at its Sixth Party Congress in 1986.

2 This transition entailed several major changes in economic policy, including: (1) developing a multi-sector economy with the official recognition of the private sector; (2) removing subsidies and planning mechanisms, forcing state enterprises to become self-reliant; (3) abolishing price controls for consumption goods-importantly, industrial production was focused on three immediate needs including foods, consumer goods, and export goods; (4) encouraging foreign investment, since export-orientation was viewed as an important strategy for economic growth.
} 
enjoyed, particularly due to low labour costs. Manufacturing industries were encouraged to develop the food processing industry, with priority given to sugar cane. Policies for the agricultural sector were initially focused on the processing industries supporting agriculture, forestry, and fishery to reform the industrialization of the rural economy. In the service sector, concentration was on the upgrading and new construction of key infrastructure. Initially, special attention was given to the development of telecommunications, tourism, and consultation services on technology, finance (including audits), banking, and insurance.

During 1996-2000, a new Public Investment Programme was also implemented. In addition to state investment, the government sought to attract private investment through regulatory revisions to the Law on Enterprises in 1999 and the Law on Encouragement of Domestic Investment in 1998. In 2000, Foreign Investment Law was amended to create more favourable conditions for foreign investors. Finally, the establishment of export processing zones (EPZs) and industrial zones (IZs) was regarded as an important tool for achieving the goals of industrial policies, as these would conveniently provide the necessary infrastructure for new industries. These policies were successful in enabling the continued growth of industrial output.

The 2001-5 Five-year Plan continued the previous policies geared to boosting economic structural change towards industrialization and modernization, by promoting the development of industry, encouraging the service sector, and creating linkage between agricultural advancement and rural economic development. Although protection was maintained for some industries, ${ }^{3}$ it was more selective in terms of capital and technology. In addition, small and medium enterprises (SMEs) were supported through promotion policies.

Industrial policies in the 2001-5 plan, however, marked a significant change in approach, with a greater focus on SME development. In 2001, The Orientation of Industrial Development document issued at the Ninth Vietnam's Communist Party Congress identified eleven leading industries. ${ }^{4}$ But these priority sectors were very diverse (and not readily interlinked) and thus failed to attract industries that could leverage the development of others.

Over the period 1991-2005 GDP expanded, on average, at an annual rate of 7.6 per cent. In 2005, GDP per capita was US\$640 (compared to US\$200 in 1990). The savings ratio in GDP increased from 14.4 per cent (1990) to 35.6 per cent (2004). And the portion of the population below the poverty line dropped from 69 per cent (1990) to 29 per cent (2005).

\footnotetext{
${ }^{3}$ Mining and oil, metallurgical, cement, manufacturing mechanics, electronics, and primary chemical industries.

${ }^{4}$ These included: agricultural processing, paper, textiles, leather and footwear, electronics, information and communications technology (ICT), mechanical engineering, chemicals (chemical fertilizers), steel, gasoline, coal mining, and other mining.
} 
Dramatic changes were also observed in economic structure. The share of agriculture in GDP sharply declined from 46 per cent in 1988 to 21 per cent in 2005, while the share of industry increased from 22 per cent to 41 per cent. Employment in agriculture accounted for 73 per cent of total labour in 1990, but saw a reduction to 57 per cent in 2005, while employment in industry and construction increased from 12-18 per cent.

Over 48,000 private businesses were established during 1990-9, and this number soared once the Enterprise Law was enacted (1999). This development continued and in 2006 alone 45,691 new companies were registered, bringing the total number of private sector firms to over 200,000 by the mid-2000s. Private firms accounted for 42 per cent of total net turnover, foreign enterprise 22 per cent, and SOEs the remaining 36 per cent. At the same time the number of SOEs decreased from approximately 12,000 in 1990 to a fewer than 3,000 wholly SOEs in 2005.

\subsubsection{Industrialization Following WTO Accession, 2006-}

Vietnam's integration into the world economy was promoted by the bilateral trade agreements (BTA) and free trade agreements (FTA) signed with other countries but also by joining the WTO in 2007. In general, WTO membership had a significant impact on the economy, where Vietnam benefited from the high growth of its major trading partners (US and China), and particularly the high economic momentum of the East Asian countries (CIEM 2010). In 1986 Vietnam's foreign trade was valued at US\$1 billion. In 2011 this had increased to US\$211 billion. However, global integration has left Vietnam more exposed to world market price fluctuations. As Vietnamese exports rely heavily on imported inputs, the economy is particularly impacted by increases in the world market price of production materials and intermediates.

The goals outlined in the five-year plan for the period following WTO accession (2006-10) included: (1) enhancing economic growth, increasing efficiency, sustainability, and competitiveness of the economy; (2) active integration and creating a breakthrough in international economic integration; (3) creating a favourable environment for entrepreneurial development. The targeted economic structure during this period was output shares in the range 15-16 per cent for agriculture-forestry-fishery sector, 43-4 per cent for the industrial, and 40-1 per cent for the service sector. Because of the drive to preserve natural resources and protect the environment, mining industries are gradually losing importance, while manufacturing industries continue to grow despite stronger competition in the wake of Vietnam's accession to WTO. Finally, industrial plans were revised to upgrade and improve the existing EPZs and IZs towards greater involvement of both domestic as well as foreign investors. 


\subsection{The Current Structure of the Industrial Sector}

\subsubsection{Sectoral Composition}

The current sectoral composition is outlined in Table 12.2. It is obvious that the manufacturing sector's share in industry has expanded. The processing and manufacturing sector accounted for 81 per cent in 2000, but had risen to 87 per cent a decade later. In contrast, the share of mining has decreased from 13 to 8 per cent. Crude oil and gas makes up the greatest share of the mining sector, which nevertheless declined gradually during 2000-10. Oil exports have been reduced since 2010 to supply crude oil to Vietnam's Dung Quat refinery, but coal mining, on the other hand, has grown strongly, doubling its share from 1-2 per cent of total exports.

\subsubsection{Employment and Size of Firms}

For comparative purposes Figure 12.1 documents the size distribution of manufacturing firms in Vietnam, based on microdata from the Vietnamese Enterprise Survey (VES).

From Figure 12.1 it can be seen that there is no reason for suspecting a 'missing middle' in the Vietnamese context. ${ }^{5}$ Although the VES captures

Table 12.2 Structure of gross outputs of industrial sub-sectors and share of sub-sectors in GDP, 2000-10

\begin{tabular}{lccr}
\hline & 2000 & 2005 & 2010 \\
\hline Share of industrial sectors in GDP (\%) & 32.3 & 34.6 & 33.5 \\
Of which: & 9.2 & 10.6 & 11.0 \\
Mining and quarrying & 19.8 & 20.5 & 19.3 \\
Manufacturing & 3.3 & 3.5 & 3.2 \\
Electricity, gas, and water & & & \\
Structure of gross production outputs of industrial & & & \\
sub-sectors (\%) & 13.1 & 11.2 & 8.4 \\
Mining and quarrying & 81.2 & 82.8 & 86.5 \\
Manufacturing & 5.7 & 6.0 & 5.1 \\
Electricity, gas, and water & 100.00 & 100.00 & 100.00 \\
Total (\%) & 11.7 & 13.5 & 14.4 \\
Share of industrial employment in total employment (\%) & 0.6 & 0.8 & 0.6 \\
Mining and quarrying & 8.8 & 12.3 & 13.5 \\
Manufacturing & 2.3 & 0.4 & 0.3 \\
Electricity, gas and water & & & \\
\hline
\end{tabular}

Source: GSO (various years) available at <https://www.gso.gov.vn>, accessed 30 january 2016.

\footnotetext{
${ }^{5}$ Since the work of Liedholm and Mead (1999) and Tybout (2000) there has been much discussion about the 'missing middle' of medium-sized firms in developing countries. However, as documented in Hsieh and Olken (2014) there is surprisingly little empirical backing for the existence of such a missing middle.
} 


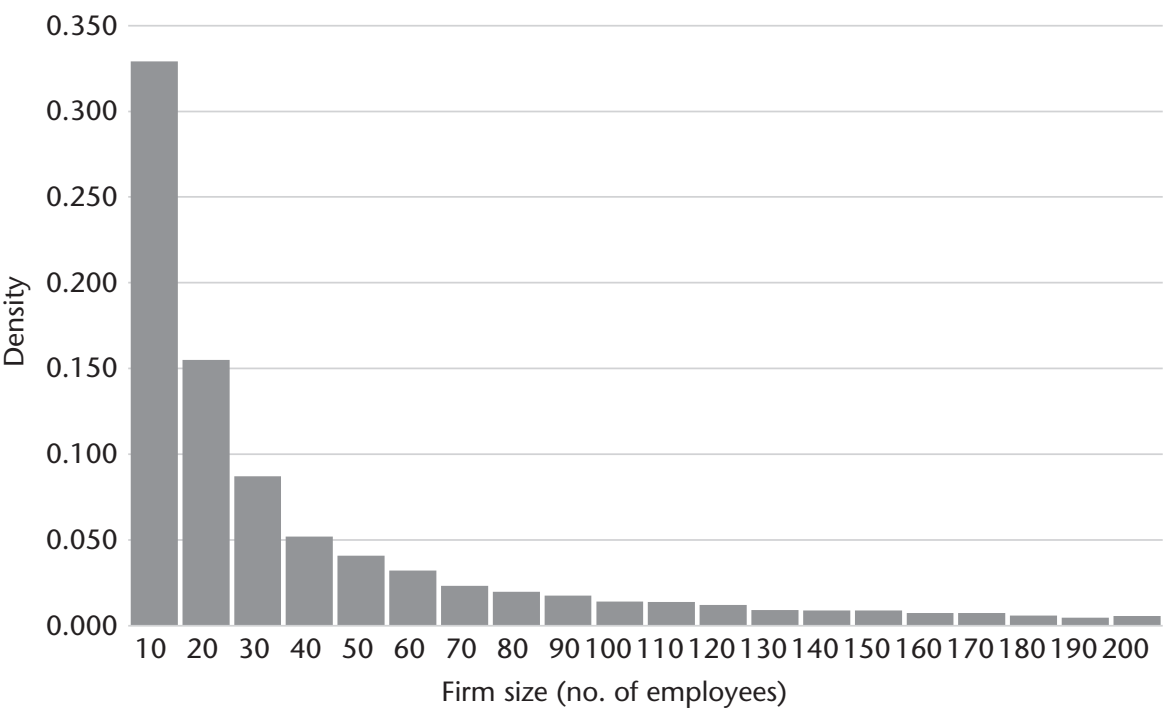

Figure 12.1 Firm size distribution by year, manufacturing only

Source: GSO (various years) available at <https://www.gso.gov.vn>, accessed 30 January 2016.

only registered firms, it is clear that the majority of firms in all three selected years (2002, 2007, and 2012) are micro-size (1-10 employees) and small (11-50 employees). In all years, the distribution of firm size is skewed to the right and is smoothly declining in firm size. There is no evidence found of bimodality or discontinuity in the firm size distribution, which can lead to the conclusion that there is no immediate evidence of a 'missing middle' in Vietnamese manufacturing firms.

Table 12.3 looks at the distribution of firm and employment shares by firm size category. Zooming in on 2012 it can be seen that although around 80 per cent of officially registered manufacturing firms are micro-size and small, they employ only 11 per cent of manufacturing workers. This shows that larger manufacturing firms are important for economy-wide job creation.

\subsubsection{Ownership Structure}

\subsubsection{INDUSTRIAL STRUCTURE BY OWNERSHIP}

While Vietnam's industry was dominated by SOEs before the Doi Moi, it is currently dominated by FDI and the domestic non-state sectors. This development is largely explained by the growth differences in the three sectors. Total industrial gross output from the state sector has grown at approximately 7 per cent since 2006. Corresponding figures of domestic non-state and FDI sectors were respectively 23 and 15 per cent. 
Table 12.3 Distribution of firm and employment shares

\begin{tabular}{|c|c|c|c|}
\hline \multicolumn{4}{|c|}{ Panel A: Distribution of firm size (\%) } \\
\hline & 2002 & 2007 & 2012 \\
\hline Micro (1-10 employees) & 22.4 & 31.2 & 44.7 \\
\hline Small (11-50 employees) & 38.0 & 38.6 & 34.7 \\
\hline Medium (51-300 employees) & 26.8 & 21.9 & 15.3 \\
\hline Large $(301+)$ & 12.8 & 8.3 & 5.3 \\
\hline \multicolumn{4}{|c|}{ Panel B: Distribution of employment by firm size (\%) } \\
\hline & 2002 & 2007 & 2012 \\
\hline Micro (1-10 employees) & 0.8 & 1.5 & 2.5 \\
\hline Small (11-50 employees) & 5.0 & 6.8 & 8.5 \\
\hline Medium (51-300 employees) & 20.0 & 21.7 & 21.1 \\
\hline Large $(301+)$ & 74.2 & 70.0 & 68.0 \\
\hline
\end{tabular}

Source: Authors' calculations based on GSO Enterprise Survey (GSO various years), available at <https://www.gso.gov.vn>, accessed 30 January 2016.

Table 12.4 Shares of total industrial and sub-sector gross output by ownership type (\%)

\begin{tabular}{|c|c|c|c|c|c|c|}
\hline & & \multicolumn{5}{|c|}{ Industrial sub-sector } \\
\hline & & $\begin{array}{l}\text { Mining } \\
\text { and } \\
\text { quarrying }\end{array}$ & Manufacturing & $\begin{array}{l}\text { Electricity, gas, } \\
\text { steam, and air } \\
\text { conditioning }\end{array}$ & $\begin{array}{l}\text { Water supply, sewerage, } \\
\text { waste management, and } \\
\text { remediation activities }\end{array}$ & $\begin{array}{l}\text { Total across } \\
\text { sub-sectors }\end{array}$ \\
\hline \multirow{3}{*}{2005} & State & 20.1 & 30.7 & 95.4 & 81.3 & 33.7 \\
\hline & Non-state & 8.0 & 33.2 & 1.8 & 14.6 & 29.0 \\
\hline & FDI & 71.9 & 36.1 & 2.8 & 4.1 & 37.3 \\
\hline \multirow{3}{*}{2010} & State & 26.7 & 18.6 & 95.0 & 67.7 & 23.3 \\
\hline & Non-state & 15.5 & 38.6 & 3.0 & 25.7 & 35.5 \\
\hline & FDI & 57.8 & 42.8 & 2.0 & 6.6 & 41.2 \\
\hline
\end{tabular}

Notes: Output is valued at constant 1994 prices.

Source: Author's computations based on data from GSO (various years), available at <https://www.gso.gov.vn>, accessed 30 January 2016.

Due to its rapid growth, the share of the FDI sector increased from 37 per cent in 2005 to 41 per cent in 2010 (Table 12.4), while the non-state went from 29 per cent in 2005 to 36 per cent in 2010. In contrast, the state sector's share dropped from 34 to only 23 per cent over the same period. Table12.4 indicates that growth of the FDI and domestic non-state sectors' output was very high within the manufacturing sector, where the two sectors by 2010 came to account for 43 and 39 per cent of total output, respectively. It should be noted that within the manufacturing sector, the state-owned sector dominated output in only three industries: tobacco, media, and coke and refined 
petroleum products, and accounted for only a small share in most other industries.

The story within mining and quarrying is different. Here the output share of the state-owned sector grew from 20 per cent in 2005 to 27 per cent in 2010. This shift is primarily due to takeovers of the previously entirely non-state dominated mining support services industry by the state-owned sector. There are at least two reasons as to why the non-state sector remains relatively small in the mining and quarrying context. First, most private firms are young with capital constraints, and therefore unable to compete with SOEs which can often enjoy economies of scale advantages. Second, the private sector is still excluded by law from investing in certain industries within the mining and quarrying sector. This includes, for example, the mining of coal and lignite and crude oil exploration.

The electricity, gas, steam, and air conditioning supply sector is almost entirely dominated by the state-owned sector, which accounted for around 95 per cent of total output throughout the period. Also in the water supply, sewerage, waste management, and remediation activities sector, the stateowned sector has remained dominant throughout the period; however, its share of total output has steadily declined. This structural change is largely driven by privatization of the sewerage industry, but also increasingly private takeovers of water collection and supply industries.

\subsubsection{Spatial Distribution}

Vietnamese industrial production is concentrated in the southeast and around the Red River Delta, particularly in the proximity of Hanoi and Ho Chi Minh City (HCMC). The southeast's share declined over the period 2005-10, but it still accounts for half of the country's industrial output. Ho Chi Minh City alone accounted for over 20 per cent of the country's total industrial output in 2010 (down from 24 per cent in 2005). The Red River Delta's regional share rose from 21.7 per cent to 25.0 per cent over the same period, and Hanoi's share stayed around 8 per cent throughout. Together, the two regions accounted for 74 per cent of industrial output in 2010 .

The spatial distribution of industries has, since the early 1990s, been driven largely by the policy of establishing different types of industrial zones (IZs). As of $2015,{ }^{6}$ there are 295 established IZs, of which only 212 are operational. The fact that several of the IZs are significantly underutilized may suggest that firm demand for land in IZs (especially outside the provinces of Hanoi and HCMC) is declining.

${ }^{6}<$ http://vietnamnews.vn/economy/267827/ministry-urged-to-destroy-ineffective-izs.html>, accessed 17 February 2016. 


\subsection{Industrial Policy Framework}

\subsubsection{Macroeconomic Policies}

In general, following the 1986 comprehensive reform, Vietnam's economic policies sought to promote high economic growth and, at the same time, to sustain macroeconomic stability. During the 2000s, economic growth relied heavily on expanding capacity through investment, and less on improving efficiency. Significant increases in the money supply to accommodate rising demand created inflationary pressure which triggered macroeconomic instability. Vietnam started to suffer from the global financial crisis and economic downturn in 2008: export growth languished and foreign direct inflows decreased. This experience showed that a weakness in Vietnam's macroeconomic policies has been excessive reliance on credit expansions to drive growth, and unfortunately, the additional credit has often gone into financing low-efficiency SOEs or real estate. The recent downfall of large SOEs and the collapse in the real estate market has caused severe problems for private companies, overturning the attempts at macro-stabilization of previous years.

\subsubsection{Trade Policies}

The reform of Vietnam's trade policy, which was the cornerstone of the Doi Moi strategy, had two main objectives. The first objective was to make the transition from a centrally planned to a market-based economy by: (1) liberalizing and linking domestic prices to world prices so that they would efficiently guide the allocation of resources; (2) increasing the number of trading entities beyond the initial number of centrally controlled foreign trade companies to avoid distortions in price signals through anti-competitive behaviour or through de facto quantitative restrictions; (3) developing trade policy instruments such as tariffs, quotas, and licences; (4) removing exchange rate distortions. This redesign of the trading system was inextricably linked with reform of the enterprise sector to allow indirect regulation through market prices to replace the direct regulation of enterprise outputs. The second objective was to promote export-oriented industries by redressing the anti-export bias embedded in the protectionist regime.

Significant changes in export and import regulations were introduced in the 2001-5 period. With a few exceptions, this enabled enterprises to export all types of goods. Furthermore, the list of banned export and import goods was extended to cover a five-year period (2001-5), thus replacing the earlier practice of lists being issued on an annual basis. Quotas on rice exports and fertilizer imports were abolished, and regulations for enterprises trading in these items were lifted. This created a clearer regulatory framework for export and import. Two main export-supporting policies were also issued by the 
government during this period. According to the first measure, enterprises could benefit from different types of credit. And, second, to encourage export of agricultural products, a 'reward' was introduced to major exporters of rice, coffee, pork, vegetables and fruit, cashew nuts, pepper, tea, peanuts, handicrafts, and plastic products.

WTO accession in January 2007 changed Vietnam's trade policies and legal framework. A new commercial law, replacing the earlier 1997 version, came into effect in 2006. At that time, regulations with regard to national subsidies and protection, anti-dumping, and anti-subsidizing changed significantly, and a more equal playing field for all economic sectors and enterprise types was introduced. Moreover, in compliance with WTO principles, the Vietnam Development Bank was reorganized from its previous incarnation for preferential credit arrangements, and the government committed to eliminating direct export support.

In addition to agreements within the WTO framework, Vietnam has entered into a series of other FTAs. ${ }^{7}$ Overall, the opening up of the Vietnamese economy has created new opportunities, and put Vietnamese exports on an equal footing with those from other WTO members.

\subsubsection{The Institutional and Regulatory Framework}

Vietnam's industrial policy framework is governed by a national SocioEconomic Development Strategy (SEDS) projected for a ten-year period. ${ }^{8}$ This is complemented by a five-year socio-economic development plan, as well as sector and industrial strategies and master plans. The Ministry of Industry and Trade is responsible for conducting and supervising industrial strategies and plans, while the Ministry of Planning and Investment undertakes the implementation of five-year plans articulated within the frame of the SEDS and national investment policy. The Ministry of Planning and Investment is further responsible for coordination with the private sector, through its Foreign Investment Agency, Enterprise Development Agency, and Department of Economic Zones. The most recent SEDS for 2011-20 highlights as priorities knowledge-intensive industrial production and higher local content in products. In addition, the document highlighted human-resources training as a central bottleneck that needs urgent attention.

\footnotetext{
7 ASEAN-China Free Trade Agreement (ACFTA), ASEAN-Korea Free Trade Agreement (AKFTA), Agreement on ASEAN-Japan Comprehensive Economic Partnership (AJCEP), and ASEAN-AustraliaNew Zealand Free Trade Agreement (AANZFTA). In addition, Vietnam signed the Vietnam-Japan Economic Partnership Agreement (VJEPA) which may affect textile and garment export performance in Japanese markets.

${ }^{8}$ Vietnam had completed two SEDSs in the last two decades: SEDS covering 1991-2000 and the other for 2001-10. The SEDS for 2011-20 was approved by the National Assembly in January 2011.
} 
Future restructuring efforts will be concentrated on three major areasinvestment, financial markets, and SOEs. As the anticipated spillover effects from FDI have been found rarely to materialize, and the decentralization of the licensing policy has proved inefficient, the government is rethinking its strategy and currently considering which sectors to single out for foreign investment and how to withdraw the excessively favourable incentives currently being offered to foreign investors. Similarly, the State Bank of Vietnam has encouraged commercial banks to focus on favourable credit schemes for firms operating within manufacturing or services.

\subsubsection{Sector Specific Policies}

Three key industries have been singled out as priority areas for the period until 2020: (1) mechanical engineering (automobile, shipbuilding, complete equipment, agricultural machinery, mechatronics); (2) electronic equipment, ICT; (3) products from new technologies (new energy, renewable energy, software, digital content). A further seven sub-industries have been identified as priorities: textiles, leather and footwear, plastic, agriculture-forestry-fishery processing, bauxite mining and processing, steel, and chemicals. The plastics industry was dropped from the priority industry list for 2011-15; and bauxite mining and processing as well as steel will be dropped from the list in 2016-20.

The fact that the plastics industry has expanded quickly (with an average annual growth rate of 20-25 per cent during 2005-10) thus gaining an internationally competitive position without support, may explain its removal from the priority industry list (VTIR 2011). Sustainable development seems to have been the reason for removing bauxite mining and processing from the 2016-20 list of priority industries. Finally, the steel industry's removal from the 2016-20 priority country list is presumably based on the rationale that Vietnamese steel products lack the competitive advantage of countries with a long tradition of manufacturing these products.

Government support for priority industries has focused on three main areas: the provision of a production site, trade promotion support, and R\&D activities. Production sites have been allocated promptly to support new, expansion, or intensive investment projects (including projects associated with relocating production). In terms of trade promotion, financial support has been available for building and developing enterprise brand names and improving international quality-management standards (through industry associations). Moreover, enterprises in prioritized industries have been free to introduce products on the Ministry of Industry and Trade's website, as well as to display and introduce their products freely at trade fairs and exhibitions at national and local levels. 
Financial support for enterprises in the prioritized sectors has also been available for R\&D-related activities. Central budget allocations have been directed towards: (1) efforts in technology transfers (including trial production under the technology transferred); (2) strengthening the capability of scientific and technological bodies (laboratories, laboratory standards, R\&D institutions, etc.); (3) researching and adapting modern technology or equipment to improve productivity, quality, and lower production costs. At the same time, funding from local-level budgets has been allocated for test/trial production (new products, materials, and auxiliary materials to replace imports) before technology or equipment is utilized in mass production. Incentive policies for priority industries have been extended to all leading/key industries. In addition financial support has been provided for manufacturing projects aimed at environmental protection.

However, most sector specific policies seem inadequate for achieving the goals listed in the government's planning documents. Most often these documents offer little more than a list of the general instruments such as tax reductions, protective barriers, or encouraging calls for investment. Another weakness is that not all of the necessary components of a sound strategy are included in the measures, such as research-supported reasoning, comparative advantage/disadvantage assessments, resource- and demand-supply projections, and risk management. But most importantly, an overall strategy covering the nation's entire industry does not exist, and currently too many sectors are targeted, impeding policy coherence.

Examples of failed sector specific strategies are many. One example is the steel industry, where production has been misaligned due to an inaccurate evaluation of domestic market demand. At present Vietnamese steel producers are not as competitive as steel imported from China and the Association of Southeast Asian Nations (ASEAN). But because of preferential/strategic policies, production capacity stands at roughly 9.0 million tons (excluding 1.5 million tons from five big projects) of which 6.0 million tons are sold domestically at subsidized prices.

However, positive examples also exist. The government's strategy for ICT is generally considered to have been better designed, with clear objectives to be achieved through relatively detailed policy instruments and focused projects. An important success factor of the ICT industry is market liberalization. At present, ICT markets are competitive, with multiple ISPs, software and hardware vendors, and several mobile phone networks. The use of computers and telecommunication devices is widespread and popular, and available at relatively low cost. Several Vietnamese ICT companies have actively invested in neighbouring countries as well as in Africa and Latin America.

The textile industry is another success story. It has been among Vietnam's top five exports since 2001. In 2010, it was valued at US\$11.2 billion, and 
ranked number one. But it is still very labour-intensive, and Vietnam is gradually losing its comparative advantage to other developing countries, such as Cambodia and Bangladesh. Efforts to lift garment exports to a higher position in the value chain have not been successful so far. Presently, 60 per cent of garment exporters are FDI companies.

\subsection{Sunrise and Sunset Industries}

In Nguyen et al. (2014: Table 6) are listed the ten industries with the highest share of total industrial output for the years 2001, 2007, and 2011. The food and beverages industry accounted for the largest share of output in all years. However, this share has been declining, and the output gap between food and beverages and other industries is narrowing. Further, the ranking of other industries in terms of output shares has changed, and new industries have emerged in the top-ten list, while others have disappeared from it. Thus, nonmetallic mineral products, which in 2001 ranked as the eighth largest industry in Vietnam in terms of share of total industrial output, was in 2007 and 2011 the second largest industry, based on the same criteria. And the metal products industry, which did not even reach the top ten in 2001, was the third largest industry in 2007 and 2011, while motor vehicles; trailers/semi-trailers, which ranked number three in 2001, had disappeared from the list in 2007.

The ranking of industry size in terms of the shares of all registered firms belonging to each industry has also undergone change over recent years. Nguyen et al. (2014) document that while the food and beverages industry accounted for 18.7 per cent of all registered firms in 2005 , this declined to just 12.8 per cent in 2011 , while the share of firms in the fabricated metal products industry had risen from 9.3 per cent to 14.1 per cent.

These developments attest to the speed of change in the structure of Vietnam's industrial sector. Against this background, the relevance of distinguishing 'sunrise' and 'sunset' industries when targeting industrial policies in Vietnam is evident. Sunrise industries are defined as emerging, fast-growing industries that are expected to become important for the economy, and replace the mature and declining sunset industries. Although sunset industries may continue to play an important role in the economy, their stagnant productivity and declining competitiveness and profitability gives way to new sectors. In the present analysis, three criteria are used to identify sunrise industries: ${ }^{9}$ (1) an average annual growth rate over the period 2005-11 which is above average in the industrial sector; (2) a growth rate above the industrial sector average in

\footnotetext{
9 Bearing in mind that in Vietnam, where most industries display a strong upward trend from an originally low base, it is hard to distinguish true sunrise industries.
} 
Table 12.5 Rates of industrial gross output of industries with growth at above average rates (\%)

\begin{tabular}{|c|c|c|c|c|c|c|c|}
\hline Industry & 2005 & 2006 & 2007 & 2008 & 2009 & 2010 & $\begin{array}{l}\text { Average } \\
2005-10\end{array}$ \\
\hline $\begin{array}{l}\text { Pharmaceuticals, medicinal, chemical, and } \\
\text { botanical products }\end{array}$ & 15.3 & 27.0 & 16.9 & 14.2 & 48.7 & 25.8 & 24.7 \\
\hline $\begin{array}{l}\text { Fabricated metal products (except machinery } \\
\text { and equipment) }\end{array}$ & 22.2 & 30.7 & 17.8 & 13.0 & 21.8 & 19.3 & 20.8 \\
\hline $\begin{array}{l}\text { Manufacture of computer, electronic, and } \\
\text { optical products }\end{array}$ & 35.6 & 18.4 & 19.0 & 6.3 & 24.3 & 18.2 & 20.3 \\
\hline Wearing apparel & 17.3 & 26.5 & 19.5 & 7.1 & 17.7 & 16.2 & 17.4 \\
\hline $\begin{array}{l}\text { Repair and installation of machinery and } \\
\text { equipment }\end{array}$ & 30.4 & -2.1 & 25.0 & 11.9 & 17.1 & 18.8 & 16.8 \\
\hline Furniture & 16.8 & 37.0 & 8.6 & 3.3 & 20.4 & 14.3 & 16.7 \\
\hline Manufacture of rubber and plastics products & 23.8 & 17.2 & 20.7 & 2.6 & 18.0 & 17.1 & 16.6 \\
\hline Basic metals & 17.8 & 12.6 & 18.2 & 10.1 & 33.5 & 6.8 & 16.5 \\
\hline Other transport equipment & 37.1 & 29.6 & 15.4 & 5.8 & 5.3 & 14.6 & 18.0 \\
\hline $\begin{array}{l}\text { Water supply; sewerage, waste management, } \\
\text { and remediation activities }\end{array}$ & 23.1 & 23.8 & 21.9 & 10.3 & 15.6 & 12.5 & 17.9 \\
\hline $\begin{array}{l}\text { Manufacture of motor vehicles; trailers and } \\
\text { semi-trailers }\end{array}$ & 38.9 & -5.2 & 39.7 & 9.8 & 14.7 & 1.6 & 16.6 \\
\hline Manufacture of paper and paper products & 20.6 & 13.3 & 28.2 & 1.7 & 15.5 & 17.5 & 16.1 \\
\hline Manufacture of electrical equipment & 29.5 & 41.4 & 6.7 & 2.2 & 7.7 & 8.7 & 16.0 \\
\hline Average across industries & 19.4 & 17.4 & 16.6 & 7.9 & 17.6 & 13.8 & 15.5 \\
\hline
\end{tabular}

Notes: Output in each year is valued at fixed 1994 prices. The average across industries excludes 'manufacture of coke and refined petroleum products' and 'manufacture of tobacco products' as output values of these industries are inherently volatile and sensitive to world market price fluctuations.

Source: GSO (various years), available at <https://www.gso.gov.vn>, accessed 30 January 2016.

at least three of the six years within the period; (3) above average growth in the number of firms operating within the industry during 2006-11. Tables 12.5 and 12.6 present the industries that fulfil each criterion individually.

The average annual growth rate of industrial output over the period 2005-11 was 15.5 per cent. Thirteen industries had average annual growth rates above this rate, ${ }^{10}$ twelve of which had growth rates above the average for at least three of the six years. Notably, and in accordance with its declining share of total industrial output, the food and beverage industry does not live up to the first criteria of being a sunset industry. However, it is clear that it remains an important sector. The pharmaceuticals, medicinal, chemical, and botanical products, and fabricated metal products merit highlighting as the industries with the highest average annual growth rates of output. While the former has been growing quickly from a very low base, and thus by 2011 had

\footnotetext{
10 An industrial sub-sector labelled 'other manufacturing' also grew at a higher rate (24.0 per cent) but is excluded due to the vagueness of its content.
} 
Table 12.6 Number of firms from 2005-11 in industries with above average firm number growth

\begin{tabular}{lc}
\hline Industry & $\begin{array}{c}\text { Growth in number } \\
\text { of firms (\%) }\end{array}$ \\
\hline Fabricated metal products & 242.8 \\
Other transport equipment & 216.9 \\
Publishing, printing, and reproduction of recorded media & 196.8 \\
Apparel & 194.7 \\
Electrical machinery and apparatus (not elsewhere classified) & 175.7 \\
Furniture & 160.5 \\
Wood and wood products & 155.5 \\
Rubber and plastics & 152.9 \\
Basic metals & 149.6 \\
Mining and quarrying & 143.7 \\
Chemicals and chemical products, including pharmaceuticals & 139.3 \\
Tanning and dressing of leather & 133.5 \\
Average across all industries & 132.1 \\
\hline
\end{tabular}

Source: GSO enterprise surveys (various years), available at $\langle$ https://www.gso.gov.vn>, accessed 30 January 2016.

not reached the top ten list of industries described earlier in this section, the latter has quickly become the third largest industry as its share of total industrial output, and was the only industry growing at a higher than average rate for all six years.

In part, as a result of the processes of deregulation and market liberalization under WTO entry, the number of enterprises in the industrial sector as well as the whole economy has grown massively in recent years. As such, the average growth in the number of firms from 2005-11 across industries within that sector was 132.1 per cent. Twelve industries grew at higher than average rates. However, a direct link does not always exist between an increasing number of new firms and industry growth; for example the cases of mining and quarrying, and the publishing, printing, and reproduction of recorded media industries both experienced growth in the number of firms above the industry average, while their gross output grew at rates well below the industrial average, at just 1.0 per cent and 9.7 per cent respectively. Meanwhile, the fabricated metal products sector once again emerges as top of the list, with a firm number growth of 242.8 per cent over the period. Based on the criteria mentioned, a further five industries qualify as 'sunset' industries: wearing apparel, furniture, other transport, equipment, and basic metals.

Table 12.7 presents rates of gross output of industries with growth at below average rates. Given the high average growth rate of Vietnamese industries, it would be a mistake to conclude that industries growing at below average rates are under stress. In fact, based on Table 12.7 only mining and quarrying stands out as a low-growth industry, which given its previous high share of total industrial output may be classified as a sunset industry. 
Table 12.7 Rates of gross output of industries with growth at below average rates (\%)

\begin{tabular}{|c|c|c|c|c|c|c|c|}
\hline Industry & 2005 & 2006 & 2007 & 2008 & 2009 & 2010 & $\begin{array}{l}\text { Average } \\
2005-10\end{array}$ \\
\hline Manufacture of food products and beverages & 18.5 & 18.8 & 16.0 & 7.2 & 12.7 & 17.0 & 15.0 \\
\hline $\begin{array}{l}\text { Manufacture of wood and of products of wood } \\
\text { and cork (except furniture) }\end{array}$ & 24.8 & 7.9 & 12.1 & 11.6 & 18.2 & 15.3 & 15.0 \\
\hline Manufacture of leather and related products & 9.8 & 17.2 & 14.1 & 2.1 & 25.7 & 18.4 & 14.6 \\
\hline $\begin{array}{l}\text { Electricity, gas, steam, and air conditioning } \\
\text { supply }\end{array}$ & 10.9 & 12.2 & 11.5 & 13.6 & 14.1 & 11.4 & 12.3 \\
\hline Manufacture of textiles & 7.0 & 24.4 & 5.9 & 5.4 & 14.5 & 14.3 & 11.9 \\
\hline $\begin{array}{l}\text { Manufacture of other non-metallic mineral } \\
\text { products }\end{array}$ & 8.6 & 18.2 & 12.6 & 14.9 & 7.3 & 8.9 & 11.8 \\
\hline $\begin{array}{l}\text { Manufacture of chemicals and chemical } \\
\text { products }\end{array}$ & 16.7 & 18.6 & 7.5 & 9.2 & 0.5 & 12.2 & 10.8 \\
\hline $\begin{array}{l}\text { Manufacture of machinery and equipment } \\
\text { not else classified (nec). }\end{array}$ & 35.0 & -22.6 & 24.2 & 4.2 & 13.1 & 9.8 & 10.6 \\
\hline Printing and reproduction of recorded media & 2.0 & -1.4 & 12.6 & 6.9 & 25.4 & 12.5 & 9.7 \\
\hline Mining and quarrying & -1.9 & -1.4 & -3.4 & 9.2 & 1.1 & 2.5 & 1.0 \\
\hline Average across industries & 19.4 & 17.4 & 16.6 & 7.9 & 17.6 & 13.8 & 15.5 \\
\hline
\end{tabular}

Note: Output in each year is valued at fixed 1994 prices. The average across industries excludes 'manufacture of coke and refined petroleum products' and 'manufacture of tobacco products' as output values of these industries are inherently volatile and sensitive to world market price fluctuations.

Source: GSO (various years), available at <https://www.gso.gov.vn>, accessed 30 January 2016.

\subsection{Conclusion}

\subsubsection{Main Challenges}

Vietnam has successfully implemented the programmes outlined in its SEDS for the period 2001-10. Yet the economy is faced with insufficient quality improvement, changes in important economic structures that are too slow, and little potential for current modality of growth. The industrial sector has been the key driver of growth in Vietnam during the last decades, accounting for a larger share of GDP and employment, and there has been a shift towards products with higher value added and technological content. Overall, Vietnam's industrialization strategy and industrial policy, however, seem to have placed greater emphasis on achieving a high rate of economic growth and economic structural change than on building up industrial competitiveness and new competitive industries for future growth.

Currently, Vietnam is working within the framework of the new SEDS (covering 2011-20). The plan strives to achieve three goals, including improvement of market-oriented institutions, infrastructure, and human resources for industrialization and modernization. Since the overall goal of the 2011-20 SEDS is to transform Vietnam into an industrialized country by 2020, the debate on current industrial policy is now focused on three major issues. 
First, industrial policy in the past has made little contribution to improving Vietnam's competitiveness. The dual nature of Vietnam's industrial sector is a weakness rather than a strength. The IS sectors have failed to grow and provide sufficient input for downstream industries, including export-oriented ones (e.g. textiles or chemical industries). Similarly, the export-oriented sector has had to rely heavily on imports, rather than input from domestic industries, because of the absence of local suppliers and supporting industries. Furthermore, desired spillovers from FDI, particularly via technology transfer and linkages with domestic enterprises, have been rare.

Second, earlier industrial policies failed to facilitate change in firm structure and the building of large-size private enterprises. Furthermore, facts on supporting policies (especially for exports) remained scattered among many different documents and were inconsistent, particularly with respect to the range and type of financial incentives and instruments used. Industrial policy also failed to stimulate enterprises to actively build partnerships as well as production linkages to reduce costs and improve productivity. Policy overemphasized specific sectors and products at the expense of improving the competitiveness of enterprises. In addition, Vietnam's firm structure has remained relatively unchanged: while the number of newly established private firms increased steadily after the Law on Enterprises took effect, most firms are SMEs.

Last, Vietnam still lacks a well-coordinated framework for industrial policy (sector specific policy, trade policy, macroeconomic policy, and other policies). Individual sector strategies and plans are developed in isolation, without coordination. With regard to investment policy, there is no discrimination among sectors, with the exception of sectors with investment priorities. Moreover, while production projects and export-oriented sectors have access to preferential credit policies the majority of beneficiaries are SOEs, rather than private enterprises.

\subsubsection{Outlook}

Industrial development, as outlined in the 2011-20 SEDS, can only be achieved by restructuring industrial production (such as increasing technology, local content, and linkages in regional and global production network; developing supporting industries and industrial clusters). But the SEDS has failed to provide adequate guidelines on sector strategies. Each development strategy and/or master plan sets out ambiguous targets/objectives and broad implementation measures without sufficient detail and feasibility assessments. Moreover, there is no industrial strategy extending beyond 2020 .

Vietnam is regarded as a relatively open economy following its WTO accession. Industrial policy should, therefore, aim to facilitate productivity gain (for example, learning by exporting) from export activities rather than simply endorse export expansion, to ensure the long-term growth of the economy. 
The policy is also expected to improve firm structure and build linkages between domestic and foreign-invested firms. This is an important point for Vietnam because the main beneficiary of past industrial policies has been the SOE sector which has enjoyed protectionist measures but remained relatively inefficient and uncompetitive.

Vietnam's SEDS for the period 2011-20 strongly underscores an exportoriented strategy for improving competitiveness at both aggregate- and firmlevel. While the manufacturing sector has expanded at a high rate of growth and made a considerable contribution to export and growth performance, the question of whether or not manufacturing firms could learn from exporting to increase productivity and competitiveness remains open.

\section{References}

Central Institute for Economic Management (CIEM) (2010). 'Impacts of International Economic Integration on Vietnamese Economy Three Years after Joining WTO'. CIEM Policy Report. Hanoi, Vietnam.

General Statistics Office (GSO) (various years). The Real Situation of Enterprises. Hanoi: Statistical Publishing House, available at <https://www.gso.gov.vn>, accessed 30 January 2016.

Hsieh, C.-T. and Olken, B. A. (2014). 'The Missing "Missing Middle"'. Journal of Economic Perspectives 28(3): 89-108.

Liedholm, C. and Mead, D. C. (1999). Small Enterprise and Economic Development. The Role of Micro and Small Enterprises. Routledge Studies in Development Economics. London and New York: Routledge.

Nguyen Thi Tue Anh, Luu Minh Duc, and Trinh Duc Chieu (2014). 'The Evolution of Vietnamese Industry'. WIDER working paper 2014/076, available at $<$ https://www. wider.unu.edu/sites/default/files/wp2014-076.pdf>, accessed 12 February 2016.

Tybout, J. R. (2000). 'Manufacturing Firms in Developing Countries: How Well Do They Do, and Why?' Journal of Economic Literature 38: 11-44.

Vietnam Trade and Industrial Review (VTIR) (2011). Master Plan on Development of the Plastics Industry, Vision 2020-2025. Proceedings from the Seminar, available at <http:// tapchicongthuong.vn/hoi-thao-quy-hoach-phat-trien-nganh-nhua-viet-nam-den-nam2020-tam-nhin-2025-14462p12c152.htm>, accessed 15 February 2016.

Vu Ngoc Lan, Phan Le Nga, Khong Van Tuyen, and Nguyen Viet Thang (2008). 'Steel Industry Analysis Report', available at www.wss.com.vn, accessed 30 January 2016. 


\section{3}

\section{Can Africa Industrialize?}

Carol Newman, John Page, John Rand, Abebe Shimeles, Måns Söderbom, and Finn Tarp

\subsection{Introduction}

Sub-Saharan Africa (SSA) began its post-independence economic development with a strong commitment to industry; a commitment that has never been realized. The region's failure to industrialize is partly due to bad luck. The terms of trade shocks and economic crises of the 1980s brought with them two decades of macroeconomic stabilization, trade liberalization, and privatization. Growth was slow and uncertain and there was little private investment in industry. When Africa re-emerged around the turn of the twenty-first century, African industry was no longer competing with the high-wage industrial 'North', as it had following independence. It was competing with Asia. Slow growth and fiscal austerity also meant that there was a growing gap in the basics-infrastructure, human capital, and institutions-between Africa and the rest of the developing world. The initial conditions for industrialization in 2000 were less favourable in relative terms than they had been in the 1960s. From the point of view of industrial development the timing of the region's economic decline and recovery was unlucky to say the least.

The failure to industrialize is also due to bad policy. Chapter 1 highlights the remarkable similarity in the policies for industrial development followed by SSAn countries: state-led import substitution (IS), Structural Adjustment, and reform of the investment climate. It is fair to conclude that none of these policy regimes succeeded in sparking dynamic industrial growth. Cambodia and Vietnam had per capita income levels similar to SSA as recently as ten years ago, but their industrial growth has been explosive. Both countries differed markedly from their SSAn counterparts with respect to the policies pursued for industrial development. Tunisia in North Africa followed a policy 
framework which in several important respects was similar to that of Cambodia and Vietnam with arguably similar results.

This chapter addresses what needs to be done by African governments to achieve more rapid industrialization. In doing so it also addresses the role of Africa's 'development partners', the bi- and multi-lateral aid institutions. Nowhere else in the developing world do aid donors exercise the degree of influence on public budgets and public policies that they have done in SSA, where donor funding ranges from 10 to 30 per cent of GDP (Page 2012b). For national priorities to change, donor priorities will have to change as well.

\subsection{Breaking in}

Despite Africa's late start, there are a several reasons why it can reasonably aspire to break into the global market for industrial goods. First, economic changes are taking place in Asia that create a window of opportunity for late industrializers elsewhere to gain a toehold in global markets. Second, the nature of manufactured exports themselves is changing. A growing share of global trade in industry is made up of stages of vertical value chains-or tasks-rather than finished products. Trade in tasks offers late industrializers an opportunity to enter global markets in areas suited to their factor costs and endowments of skills and capabilities. Third, trade in services and agro-industry is growing faster than trade in manufactures. These 'industries without smokestacks' broaden the range of products in which Africa can compete, and a number of them are intensive in location specific factors abundant in Africa.

\subsubsection{Competing with Asia}

East Asia has shown that it is possible for new entrants to succeed in global manufacturing, but the East Asian success story also shows what is needed. East Asia only broke into global markets on a massive scale around 1980, when the gap in per capita incomes and wages between China and the OECD economies had become sufficiently large to offset the productivity advantage of the OECD's incumbent industrial producers. Today, East Asia is the dominant producer of the types of manufactured goods that Africa will need to make if it is to succeed in global markets.

Africa is the world economy's poorest region in per capita terms. Other things being equal, this ought to be reflected in a lower overall level of wages than in other developing regions. ${ }^{1}$ Rising real wages in Asia may offer

\footnotetext{
1 There is a strand of the industrialization literature on Africa that questions whether wages themselves are actually low, relative to the region's per capita income. See for example
} 
Africa a second chance to industrialize. There are several reasons to think that the difference in wages between East Asia and Africa may become sufficiently large to offset some of East Asia's productivity advantage:

- Rising costs in China. China is growing so rapidly that it is likely to encounter rising costs in manufacturing production. Since 2005 real wage growth has accelerated significantly. Manufacturing wages rose from just over US\$150 a month in 2005 to around US\$350 in 2010 (Lin 2011). Stiffer enforcement of labour and environmental regulations, gradual expansion of safety net provisions, and the prospect of further increases in the value of the renminbi are likely to increase production costs (Dinh et al. 2012). Further, China has only a limited number of coastal cities. As these expand, they are likely to encounter diseconomies of congestion, and although Chinese manufacturers may shift production into the interior, this will increase transport costs.

- Growing domestic demand in Asia. Since the global financial crisis of 2008 Asia's established industrial economies-China included-have introduced domestic policies intended to reduce their dependence on exports. In China, targeted stimulus measures, including higher infrastructure investment, have helped strengthen domestic demand. In the region more broadly demand has benefited from strong credit growth (IMF 2014). The expansion of domestic demand is likely to cause some reorientation of manufacturing activity towards the local market, creating space for potential competitors in third country markets.

- International economic policy in China. There is some evidence that economic policy makers in China have made a decision to 'offshore' a portion of low-end manufacturing to Africa. By the end of 2009 China's outward foreign direct investment (FDI) in African manufacturing had reached a stock of US $\$ 2.02$ billion. The Chinese government currently offers tariff-free entry to more than 400 products from Africa's low income countries. In addition it is backing the construction of six overseas special economic zones (SEZs) in Africa. ${ }^{2}$

Whether Africa can realize its emerging low-wage advantage will depend on relative movements in unit labour costs, wages adjusted for productivity. There is evidence to suggest that while the average firm in Africa is less productive than its East Asian counterpart, some African firms have achieved productivity levels that are similar to those in Asia. Case-study research into African light manufacturing finds that in 'well managed' firms physical labour

Gelb et al. (2013). We have reviewed that literature and do not find it persuasive. See Newman et al. (2016).

2 Brautigam and Tang (2014). 
productivity-the number of items produced by a worker in a day-is comparable to China and Vietnam, although there is considerably more variation in African productivity levels (Dinh et al. 2012). Evidence from the World Bank Enterprise Surveys indicates that, controlling for per capita income, labour productivity in manufacturing does not appear to be consistently lower in SSA than in other regions (Dinh and Clarke 2012; Harrison et al. 2014). In contrast to the immediate post-Structural Adjustment period, Africa may be able to break into the market in some low-end, labour intensive manufacturing industries.

\subsubsection{New Opportunities}

There has been a spectacular reduction in transport and communications costs in the global economy over the past twenty years. Freight costs have halved since the mid-1970s, and international communication and coordination costs have plummeted. ${ }^{3}$ These technology-driven changes in transport and communications have opened up new opportunities for industrial development that were not available when Africa became independent. Two of these-trade in tasks, and industries without smokestacks-broaden the range of industrial activities in which African economies can break into global markets.

\subsubsection{TRADE IN TASKS}

In some manufacturing activities a production process can be decomposed into a series of steps, or tasks (Grossman and Rossi-Hansberg 2006). As transport and coordination costs have fallen, it has in many cases become efficient for different tasks to be located in different countries. Task-trade has expanded dramatically in the past twenty years. During 1986-90 imported intermediates constituted 12 per cent of total global manufacturing output and 26 per cent of total intermediate inputs. By 1996-2000 these figures had risen to 18 per cent and 44 per cent (UNIDO 2009). A recent estimate suggests that as much as 80 per cent of global trade is linked to the production networks of multinational corporations (UNCTAD 2013).

For late industrializers such as Africa trade in tasks has considerable potential. It is easier to master a single stage of the production process than to develop all of the capabilities needed for vertically integrated production. Task-trade was integral to the export success of Cambodia, Tunisia, and Vietnam. Exports of assembled garments from Cambodia and Vietnam have grown at double-digit rates over the past ten years. Tunisia has enjoyed

\footnotetext{
${ }^{3}$ For discussion of these issues see Hummels (2007) and Fink et al. (2002).
} 
similar growth in the assembly of garments and auto parts produced for the European market.

Success in attracting and retaining trade in tasks is by no means guaranteed. Low wages are important but not sufficient to attract end-stage assembly operations. Because end-stage tasks depend heavily on imported intermediate inputs, the institutions and infrastructure directly related to international trade (for example customs and ports) must be of a high standard. Taskbased investors are also footloose, as the experience of a number of African countries under the Africa Growth and Opportunity Act (AGOA) - the United States system of trade preferences for Africa-dramatically illustrated when the multi-fibre agreement expired in the second half of the 2000s (Edwards and Lawrence 2011).

\subsubsection{INDUSTRIES WITHOUT SMOKESTACKS}

Falling transport and communications costs have also created new globally traded activities in agriculture and services. Information and communications technology and task-based production have made many services, including sales and client services, tradable. Back office operations and accounting, which were previously integrated components of enterprises can now be spun off and subcontracted. Modern tradable services have many features in common with manufacturing. Like manufacturing, they benefit from technological change and productivity growth (Ghani and Kharas 2010). Some tradable services exhibit tendencies for scale and agglomeration economies similar to manufacturing, and the relationship between exports and innovation in services is similar to that of manufacturing (Ebling and Jans 1999). Global trade in services has grown faster than merchandise trade since the 1980s, and service exports from developing countries have almost tripled in the last ten years (World Bank 2010b).

As early global service providers transition from low-end to higher-end tradable services, there is growing room for African countries to step into the more standardized segments of the services market (Sudan et al. 2010). Offshore business services-such as data transcription and call centres-are one example. Unlike East Asia, most African countries use global languages such as English, French, Arabic, and Portuguese, which are great assets for communications based services. Tourism is a tradable service sector in which Africa has an important resource-based comparative advantage, and the region receives a growing share of world tourist arrivals for both cultural and wildlife tourism.

The transport of fresh produce over long distances became possible with the development of 'cold chains' linking production and consumption points. As transport costs have fallen, an increasing variety of horticultural products have been exported profitably, including fresh fruit, vegetables, and flowers. 
Production of out of season crops that can only be grown in northern regions in the summer-citrus, grapes, melons, green beans, peas, asparagus, and cut flowers-has become possible. The most recent trend has been to produce a range of high value, 'temperate' products all year round. Such items as prepared fruit salads, trays of prepared mixed vegetables, and flower bouquets in retail packs can be produced more cheaply in low income countries due to lower labour costs (Tyler 2005). There is a trend towards growing fresh fruit and vegetables to order under contract to major supermarkets.

\subsection{Changing the Investment Climate Agenda}

Whether Africa is able to take advantage of the opportunities offered by changing real wages and economic policies in East Asia, task-trade and the emerging importance of industries without smokestacks will ultimately depend on the policies and public actions undertaken by African governments. Since the late 1990s policy attention to industrialization by both donors and governments in SSA has focused on reform of the investment climate, the physical, institutional, and policy environment within which firms operate. Attention to these basics is not misplaced. Africa lacks the infrastructure, skills, and institutions needed to support industrial productivity growth.

Yet since 2000 efforts to improve the investment climate have had little impact on growth of the industrial sector. This is because investment climate reform programmes have been poorly designed and implemented. As originally conceived, the investment climate reform agenda was intended to balance reducing the physical constraints to industrialization, mainly infrastructure and skills, with reforms to the regulatory and institutional environment (Stern 2002). As implemented by the World Bank and the broader donor community, the focus of investment climate operations has been on pushing a narrow set of regulatory reforms. It is imperative that rebalancing takes place. For Africa to industrialize, greater attention and more resources must be directed to infrastructure and skills.

\subsubsection{The Critical Role of Infrastructure}

All of the SSA country studies highlight infrastructure deficiencies as a significant barrier to industrial development. Firm-level surveys identify lack of power as the greatest constraint, followed by transport. Infrastructure directly affecting international trade is badly deficient. Road infrastructure has received very little attention, and although concessions have been awarded to operate and rehabilitate many African ports and railways, financial commitments by 
the concessionaire companies are often small (Page 2012a). Domestic transportation infrastructure is also an important constraint to horticultural exports; vegetables, fruits, and flowers do not tolerate delays in getting to the airport. While the region has made considerable progress in the area of broadband connectivity - critical to success in tradable services-through regional submarine cables, a wide gap exists in national backbone networks and in interconnecting cities. About 87 per cent of Africa's population is unable to connect to the internet. Tourism development is constrained by lack of air and ground transport, utilities, and IT infrastructure.

Closing Africa's infrastructure gap will require around US\$93 billion a year, about 15 per cent of the region's GDP. Forty per cent of the total spending needs are for power alone (World Bank 2009). Existing spending on infrastructure in Africa amounts to about US $\$ 45$ billion a year. About US $\$ 15$ billion of this amount comes from external sources, including the private sector, official development assistance (ODA), and non-traditional development partners, mainly China. Even if potential efficiency gains could be fully realized, a funding gap of about US\$31 billion a year would remain, about 60 per cent of which is in power.

Despite the magnitude of the infrastructure gap, infrastructure financing by members of the OECD Development Assistance Committee (DAC) has fallen as a share of ODA since the early 1970s (Figure 13.1). For most of the 1990s and early 2000s, ODA to infrastructure in SSA remained steady at US $\$ 2$ billion a year, mainly financing public goods such as roads and water supply that were seen as aligned to the Millennium Development Goals (MDGs). Despite a

\section{Per cent of total ODA commitments}

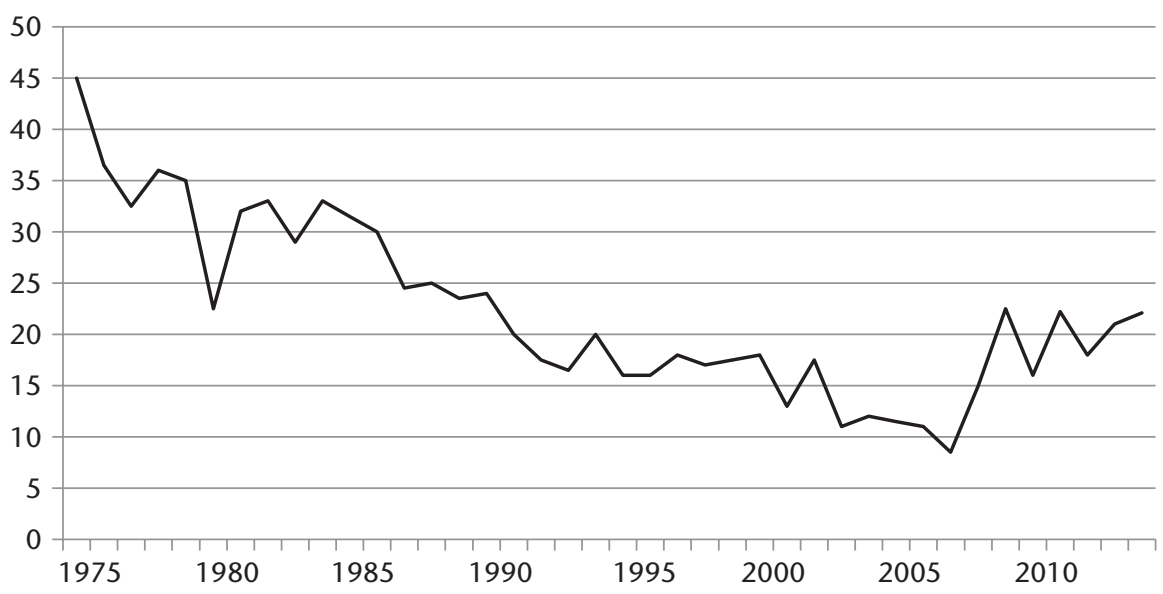

Figure 13.1 ODA for economic infrastructure

Source: OECD-DAC (2015) CRS online database; authors' calculations. 
recent rise in ODA for infrastructure, DAC donors have neglected power for two decades. The post-2015 development agenda offers African governments and their development partners an opportunity to re-prioritize infrastructure and to focus investments on raising industrial productivity.

\subsubsection{Closing the Skills Gap}

A survey of country experts from forty-five countries for the African Economic Outlook 2013 found that over 50 per cent of respondents cited lack of skills as a major obstacle which kept African firms from becoming competitive (AEO 2013). The country studies suggest that production-related skills are most lacking. Growing firms in Uganda import skilled labour. In Mozambique there is a significant shortage of technical and higher level skills, especially in maths and science, and firms see the lack of employee skills as a serious constraint to growth. In Ghana the survival and growth of firms is strongly correlated with the educational attainment of the owner. Service providers report they are constrained by the low educational levels of potential call centre workers and a lack of customer service management skills in the industry itself (Benner 2006). Education and training for tourism, both in language skills and in industry-specific skills, are deficient (Twining-Ward 2009). Employer surveys report that African university graduates are weak in problem solving, business understanding, computer use, and communication skills (World Bank 2007).

Closing the skills gap presents at least as daunting a challenge as closing the infrastructure gap. Most of the production-related skills described above are derived from post-primary education, including vocational and technical training. A recent report by the World Bank (Mingat et al. 2010) undertakes a number of education policy and financing simulations for thirty-three African countries. In the most ambitious scenario the aggregate gap in recurrent funding for post-primary education in 2020 amounts to US\$29.1 billion a year. Even in the most restrictive scenarios - those reflecting highly selective policies for coverage in upper secondary and tertiary education and low unit costs - the recurrent funding gap is projected at US\$3.4 billion a year for postbasic education, and the gap in capital funding for basic and secondary education is projected to be US\$2.6 billion a year.

The likelihood that these funding gaps will be addressed adequately is small. DAC donor commitments to all levels of education in Africa only approach US $\$ 4$ billion. Confronted with rising unit costs in primary education, increasing pressures on lower secondary education as a result of higher primary completion rates, and limited prospects of external finance, African governments need greater flexibility to reallocate expenditures from primary to postprimary education. While there is some scope in the new UN Sustainable 
Development Goals to do so, the fiscal reality is that even with more budget flexibility African governments will need to turn to private provision of education, especially at the tertiary and vocational-technical level.

\subsubsection{Institutional and Regulatory Reform}

Institutional and regulatory reform is important for Africa, and many countries have an unfinished agenda of reforms that need to be pursued. Surveys of manufacturing firms highlight a number of areas in which regulatory or administrative burdens impose cost penalties (Clarke 2005; Yoshino 2008; Farole 2011). The regulatory reform agenda of investment climate programmes, however, has often centred on the most widely used global benchmark of regulatory burden, the World Bank Doing Business report. Doing Business measures selected business regulations in nearly 190 countries and ranks the countries on ten dimensions, ranging from ease of opening and closing a business to investor protection. It has proved tempting for donors to suggest that African governments should target rapid progress in moving up the Doing Business rankings as the primary objective of institutional and regulatory reform.

The focus on Doing Business has been counterproductive for two reasons. First, because Doing Business was designed as a cross-country benchmarking exercise; it is not suited to the design of country specific regulatory reform programmes. The indicators do not capture country context nor can they be used to identify binding country-level regulatory constraints. ${ }^{4}$ Second, it has shifted the attention of both governments and donors away from the far more difficult task of identifying and funding priority expenditures in infrastructure and education to improve industrial productivity. In order to establish a relevant agenda for regulatory reform and for investment climate reform programmes more generally, African governments and their development partners will need to undertake the much harder task of working jointly with the private sector to identify the binding constraints imposed by the investment climate.

\subsection{Beyond the Investment Climate}

Africa entered the twenty-first century with large gaps in infrastructure, human capital, and institutions compared with other parts of the developing world. If it is to industrialize, it must get these basics right. At the same time,

\footnotetext{
4 See World Bank (2008) for an evaluation of the Doing Business programme, and Page (2012b) for a review of the evidence on the efficacy of the Doing Business reforms in Africa.
} 
while public actions to strengthen the investment climate are important, they alone are unlikely to make it possible for African industry to compete with the world's incumbent industrial producers. This is because the drivers of firm-level productivity growth outlined in Chapter 1 are interdependent. The country studies of Cambodia, Tunisia, and Vietnam illustrate the importance of addressing the basics, exports, agglomerations, and FDI in an integrated way.

\subsubsection{Mounting an Export Push}

For the vast majority of countries in Africa the export market represents the only option for rapid growth of manufacturing, agro-industry, and tradable services. The small size of Africa's economies and the low level of per capita income across the region mean that the scope for rapid industrial development based on domestic demand is limited. In addition to the benefit of an expanded market, there is evidence that in low income countries export success is closely linked to productivity growth in manufacturing. Because individual firms face high fixed costs of entering export markets, there is a risk that African economies will export too little, unless public policies are put in place to offset the costs to first movers.

Cambodia, Tunisia, and Vietnam each implemented a coordinated set of public investment, policies, and institutional changes designed to increase the share of industrial exports in GDP. Measures to establish a 'free trade regime for exporters' through various mechanisms to eliminate or rebate tariffs on intermediate and capital inputs used in export production were put in place. Taxes on exports were eliminated. Each country introduced regulatory and institutional reforms designed to lower the transaction costs faced by exporters in such areas as customs and business regulation. In some countries and in some periods financial incentives through the tax system or export finance were offered. With ascension to the World Trade Organization (WTO) these were reduced or eliminated. All three countries focused significant attention on trade related infrastructure in order to reduce the costs to producers of ports, domestic road and rail transport, and communications.

These interventions-designed to tilt the incentive structure towards exports-were similar to the 'export push' strategies that have been adopted by other countries in Asia since the 1970s (World Bank 1993). Several African countries-Ethiopia, Ghana, and Kenya among them-have placed recent emphasis on promoting exports. Unfortunately, there is little evidence that they have implemented the coherent set of policies that characterize an export push. To move from aspiration to implementation governments across the region will need to focus on three critical areas: policy and institutional reforms affecting exports, trade logistics, and regional integration. 


\subsubsection{POLICY AND INSTITUTIONAL REFORMS}

Rather than being undertaken piecemeal in an effort to satisfy scorekeeping by the donor community, regulatory reforms in Africa should first be undertaken to reduce the transaction costs faced by exporters. Tariff exemptions, duty drawbacks, and rebates of indirect taxes only improve competitiveness to the extent that they are well administered and timely. This is often not the case in Africa. Duty drawback, tariff exemption, and VAT reimbursement schemes are often complex and poorly administered, resulting in substantial delays. Port transit times are long, and customs delays on both imported inputs and exports are significantly longer for African economies than for Asian competitors. Export procedures-including certificates of origin, quality and sanitary certification, and permits—can also be burdensome (Clarke 2005; Yoshino 2008; Farole 2011).

Institutional reforms are also critical to the success of services and agroindustrial exports. The regulatory regime in telecommunications is important to remote tradable services, and tourism is sensitive to the behaviour of public officials ranging from immigration inspectors to the police. Horticultural exports, because they are perishable, are particularly vulnerable to delays in shipping caused by inefficient or corrupt inspection procedures at airports. Officials have the power to use delaying tactics to cause the financial loss of an entire consignment. The relatively slow growth of air-freighted fresh produce exports from West Africa has in part been blamed on corruption at airports.

\subsubsection{IMPROVING TRADE LOGISTICS}

Trade in tasks has greatly increased the importance of beyond the border constraints to trade. Because new entrants to task-based production tend to specialize in the final stages of the value chain, 'trade friction costs' - the implicit tax imposed by poor trade logistics-are amplified. African countries have an average ranking of 121 out of 155 countries in the World Bank (2010a) Trade Logistics Index. Only three of Africa's low income economies rank in the top half of the global distribution. Two-thirds are in the bottom third, and 36 per cent are in the bottom quintile. The region ranks especially badly in terms of trade related infrastructure, and poorly functioning institutions and logistics markets increase trade friction costs.

These constraints directly reduce Africa's ability to compete. Efficient African enterprises have factory floor costs comparable to Chinese and Indian firms for some product lines, such as garments. They become less competitive because of higher indirect business costs, many of which are attributable to deficient infrastructure and poor trade logistics (Eifert et al. 2008). In China, indirect costs are about 8 per cent of total costs; in Africa they are 18-35 per cent. Value chain analysis of exports identifies several choke points: high costs of import and export logistics, lack of timely delivery of inputs, and low speed 
to market (Subramanian and Matthijs 2007). Reducing these costs to the levels in China would save the average African firm the equivalent of 50 per cent of its wage bill (Eifert et al. 2008). Economical and efficient transport and coldstorage chains are essential for all types of horticultural products. Half the wholesale cost of African fresh produce in European markets is represented by the cost of transport, storage, and handling. As governments begin to close the infrastructure gap, priority should be given to investments in logistics infrastructure and to the complementary institutional and regulatory reforms needed to increase competition among logistics providers.

\subsubsection{STRENGTHENING REGIONAL INTEGRATION}

The small size of Africa's economies and the fact that many are landlocked make regional approaches to infrastructure and trade related services, customs administration, and regulation of transport in trade corridors imperative. For exporters in landlocked countries poor infrastructure in neighbouring, coastal economies, incoherent customs and transport regulations, as well as inefficient customs procedures and 'informal taxes' in transportation corridors slow down transit times to the coast and raise costs. Regional integration also opens up opportunities for African manufacturers to learn from regional markets before they attempt to break into global markets. Regional exports in the East African Community (EAC) for example have been growing substantially faster than exports to other destinations.

Tangible progress on regional integration has been slow. The size, scope, and objectives of Africa's regional organizations vary greatly. Many countries are members of several arrangements, resulting in a complex web of regional organizations, competition for resources, and inconsistencies in policy. Investments in regional infrastructure are hampered by the technical complexity of multi-country projects and the time required for decisions by multiple governments. Institutional reforms to improve trade logistics—such as common standards, regulations, and one-stop border facilities-have also moved slowly. Governments can give new momentum to regional integration efforts by first focusing on trans-border infrastructure and institutions.

Africa's development partners have not aggressively helped regional integration, preferring to deal with individual countries rather than regional organizations and limiting financial commitments to trans-border projects. Aid implementation and disbursement are particularly slow at the regional level. Aid agencies are also often better structured and equipped to deal with national partners. Donors need to make stronger efforts to harmonize their support to regional organizations, decrease the use of their own systems to channel aid flows to regional programmes, and to integrate their national aid programmes into their regional strategies. 


\subsubsection{Supporting Industrial Agglomerations}

In Cambodia, Tunisia, and Vietnam the export push was accompanied by policies designed to promote the formation of industrial clusters. Government commitment to spatial industrial policies in these countries was not accidental. The productivity enhancing effect of industrial agglomerations creates a collective action problem. If a critical mass of firms can be drawn into a new industrial location every firm will realize productivity gains from clustering. At the same time, there is no incentive for a single firm to move in the absence of others. One of the success factors in the industrialization experiences of both Cambodia and Vietnam was the decision by a critical mass of regional investors to relocate some low-end task-based production from higher cost economies in East Asia to both countries. A similar mass movement of European investors took place in Tunisia. More than 2,200 foreign owned firms are concentrated in Tunisia's offshore industrial zones. Africa in contrast has few large-scale, modern industrial clusters capable of generating localization economies.

Agglomeration has an important role to play in the development of competitive tradable services and agro-industry as well. Trade in services is skilled labour intensive and requires cognitive and language skills of a high level. This makes services exporters highly responsive to 'thick' labour markets where an abundance of highly skilled workers are found. In horticulture proximity facilitates the resolution of sector-wide coordination problems, for example the adoption of a common code of practice, the exchange of market information, and funding of research and extension. Agglomeration also improves vertical coordination between farmers and trader/processors.

\subsubsection{SPATIAL INDUSTRIAL POLICIES}

Governments can foster industrial agglomerations by concentrating investments in high quality institutions, social services, and infrastructure in a limited physical area such as an SEZ (UNIDO 2009; Farole 2011). Appropriate public policies to attract a critical mass of investors into such areas are a prerequisite to breaking into global markets. Beginning with Korea, Singapore, and Taiwan, SEZs have been a feature of East Asia's industrial landscape for decades. Often they were explicitly linked to the export push. Export Processing Zones (EPZs)—outward oriented industrial agglomerations-operated under the free trade and incentive regime for exporters and generally carried an export performance target as the price of admission. ${ }^{5}$

In countries with unreliable public infrastructure, services export companies look for customized facilities such as IT parks with modern office space,

\footnotetext{
${ }^{5}$ Much of the debate over the efficacy of EPZs is cast in terms of their role as an instrument of trade policy. The fact that they are also industrial clusters has only recently entered the literature (see UNIDO 2009; Farole 2011).
} 
high-speed broadband links, reliable power supply (including backup supply), security services, and ancillary infrastructure including banks, travel desks, restaurants, transportation systems, and hotel accommodation for visiting executives. The Software Technology Parks of India (STPI) initiative was launched by the Indian government in 1991 to overcome infrastructural and procedural constraints by providing data communication facilities, office space, and 'single window' statutory services in an SEZ. The technology parks proved essential to the growth of the industry in the broader environment of deficient infrastructure and bureaucratic red tape (Dongier and Sudan 2009).

To date Africa's experience with SEZs has been largely unsuccessful. A recent review of SEZs in Ghana, Kenya, Nigeria, Senegal, and Tanzania concluded that the programmes are underperforming. The SEZs had low levels of investment and exports, and their job creation impact was limited. The zones had few links with the domestic economy, and a much lower density of enterprises within the geographical boundaries of the SEZ than zones in Asia or Latin America (Farole 2011). Several SSAn countries, including Ghana, Nigeria, and Tanzania, have recently announced a commitment to improve the performance of their SEZs. To turn this from rhetoric into reality will require major changes.

\subsubsection{STRENGTHENING SPECIAL ECONOMIC ZONES}

African SEZs have failed to reach the levels of physical, institutional, and human capital needed to attract global investors (Table 13.1). For example, non-African SEZs had an average downtime from electricity outages of only four hours per month. The reported average downtime in African SEZs was forty-four hours per month. A similar pattern is observed in the institutions supporting the SEZs. Customs clearance times in African zones are about double that of their non-African competitors. Thus, a first order of business is to upgrade the performance of Africa's SEZs to international standards.

A major problem with SEZ performance in Africa has been that the management of the zones often lacks an understanding of the private investors it is

Table 13.1 Indicators of physical and institutional infrastructure in special economic zones

\begin{tabular}{lrr}
\hline & $\begin{array}{l}\text { Average Africa } \\
\text { sample }\end{array}$ & $\begin{array}{l}\text { Average non-Africa } \\
\text { sample }\end{array}$ \\
\hline Power outages (in hours downtime): & & 4 \\
Within SEZ & 44 & 46 \\
Outside SEZ & 95 & 3.4 \\
Import customs clearance times (in days): & 7.1 & 11.0 \\
Within SEZ & 10.3 & \\
Outside SEZ & & \\
\hline
\end{tabular}

Notes: Import clearance times through main port.

Source: Based on Farole (2011). 
attempting to support. Many of the SEZs in the case-study countries were managed by political appointees or former civil servants. Zone programmes were not linked with other institutions charged with industrial development, such as the FDI promotion agency. African governments have generally regarded SEZs as enclaves and most are not connected to domestic value chains, limiting their utility in fostering domestic supplier relationships. Often, zone programmes were put in place with little effort to support domestic investment into the zone or to promote links with firms outside the zone. Business support services, training, and skills upgrading were also frequently ignored. Management and institutional changes to fix these problems have low budgetary costs but potentially high pay-offs.

Africa's traditional suppliers of aid have tended to neglect SEZs. China on the other hand-building on its own success with spatial industrial policieshas launched a recent initiative to build export-oriented SEZs in Africa. The Chinese zone developers are obliged to construct high-standard infrastructure, promote the zone, and bring in world-class professional management. Host governments are expected to provide infrastructure outside the zones, including guaranteed supplies of electricity, water and gas, roads leading up to the zones, and improved port services (Brautigam and Tang 2011). The performance of the Chinese zones should provide some valuable lessons for African governments and traditional donors in implementing spatial industrial policies.

\subsubsection{Attracting Foreign Direct Investment}

Policies and institutions for attracting FDI were a key tool in the industrialization strategies of Cambodia, Tunisia, and Vietnam. In Tunisia the 'offshore' policy regime was specifically designed to attract European investors to a nearby task-based export platform. Cambodia's export industries are mainly the result of regional foreign investment which the government has been actively seeking to attract into its EPZs. Vietnam went through several phases in its relationship with foreign investors. In the early Doi Moi period the government took active steps to promote export-oriented foreign investment, but it also restricted the industries into which FDI could flow. Between 1996 and 2007, FDI was further restricted to sectors believed to be important to the development of domestic industrial capabilities. The FDI regime was liberalized in 2007, and the government has actively courted foreign investors.

\subsubsection{INSTITUTIONS FOR FDI PROMOTION}

Ireland's Industrial Development Authority provided an institutional model for attracting and keeping FDI that has defined international best practice since the 1960s (Barry 2004). A small, elite agency under the office of the 
president or prime minister is set up to deal with three phases of the foreign investment cycle: recruitment, embedding, and aftercare. Active recruitment requires convincing a potential investor about the suitability of the country. This is one reason why the formal link to and the active participation of the national chief executive is critical. The domestic regulatory and administrative framework may be complex, and the objective of embedding is to minimize its costs to the new foreign investor. This is a task that requires coordination across the government, independence, and a pragmatic focus on resolving difficulties. The aftercare process is concerned with removing unnecessary obstacles to the operation and growth of the enterprise and with generating good 'word of mouth' advertising to other potential investors.

Four features of effective FDI agencies play a crucial role in their success: active support of the chief executive, independence, high quality personnel, and focus (Page 2012a). Over the past decade all eight SSAn countries created or reformed institutions intended to attract FDI. Sadly, implementation has fallen short. With the possible exception of Ethiopia the FDI agency did not receive the sustained support of the president or prime minister. Without such high-level support the agencies became dependencies of line ministriesusually the Ministry of Industry-without the ability to coordinate across government. Personnel practices and compensation policies were not sufficiently attractive to make it possible to recruit high calibre staff, and the agencies were frequently burdened with multiple objectives, diluting focus. These institutional problems must be solved to attract foreign investors outside of the natural resources sector.

\subsubsection{LINKING FOREIGN AND DOMESTIC FIRMS}

Transmission of knowledge from foreign owned firms to other firms in the economy most often takes place through supply chain relationships. This is not altogether surprising. While firms have little incentive to transfer capabilities to competing enterprises, they may benefit from improvements in the capabilities of suppliers or customers. A striking finding of the African country studies is how few linkages exist in most countries between foreign and domestic investors. One area for action is to remove the obstacles that current policies-mainly in EPZs-place in the way of linkages between foreign and local firms. Once FDI agencies have established a track record for attracting international investors, they can turn to more selective recruitment of investors based in part on their willingness to engage with domestic suppliers. Both of these changes require strong coordination between the FDI agency, the line ministries responsible for domestic industrial development, and the agency administering the SEZ programme.

When natural resources are present foreign investors are often competing to gain access to the resource. This provides an opening for governments to 
encourage the formation of value chain linkages between foreign natural resource investors and domestic firms. It is also an area where governments will need to exercise great care. The world is littered with the results of unsuccessful 'domestic content programmes' based on quantitative targets imposed on foreign investors or 'offset' investments required as part of resource extraction agreements. A more fruitful approach would be for the public sector to develop programmes in partnership with the foreign investor to improve the technology and skills of potential supplying firms and quality certification processes for their outputs.

\subsection{Conclusions}

Meeting the challenge of industrialization will require new thinking both in Africa and among its development partners. One of the unifying themes in the eight sub-Saharan country case studies is the central role of donor-driven investment climate reforms. While investment climate reforms are needed, they must be re-prioritized and refocused. Urgent action is required to address Africa's growing infrastructure and skills gap with the rest of the world. However, for most African countries, investment climate reforms alone will not be enough to overcome the advantages of the world's existing industrial locations.

The country case studies of Cambodia, Tunisia, and Vietnam provide considerable insight into the key elements of a new industrialization strategy for Africa. All three countries shifted their policy stance relatively early in the process of industrial development towards active promotion of industrial exports. The export push was accompanied by policies designed to promote the formation of industrial clusters and attract FDI. SSA countries could have made such a strategic turn at the end of the Structural Adjustment period. None of them managed to do so.

While the failure to adopt an effective export-oriented industrialization strategy is lamentable, it can be rectified. In addition to implementing a changed investment climate reform agenda African governments need to mount an export push. This will require creating an effective free trade environment for exporters, reforming the regulations and institutions directly affecting foreign trade, and investing in better trade logistics. More strenuous efforts to achieve regional integration, and especially to build trans-border infrastructure and institutions, are also needed. Upgrading the performance of Africa's SEZs and Foreign Investment Agencies to world-class standards is an essential complement to the export push.

Today, in contrast with the turn of the century, changes in the global economy offer a window of opportunity for Africa to industrialize. Rising 
real wages and production costs in East Asia together with trade in tasks may open up a chance for some of Africa's more productive firms to break into the global market for manufactured goods. Tradable services and agro-industry provide new opportunities for industrialization, and Africa may be particularly well placed to exploit these openings based on a number of location specific sources of comparative advantage. Whether Africa can seize the moment depends in large measure on public policy. If African governments and their development partners continue with business as usual, success is unlikely. With a more strategic approach to industrial development and the commitment of the region's political leadership Africa can industrialize.

\section{References}

African Economic Outlook (AEO) (2013). Global Value Chains and Africa's Industrialization. African Development Bank, OECD and UNDP. Paris: OECD.

Barry, F. (2004). 'Export Platform FDI: The Irish Experience'. EIB Papers 9(2): 8-37.

Benner, C. (2006). " "South Africa on-call": Information Technology and Labor Market Restructuring in South African Call Centers'. Regional Studies 40: 1025-40.

Brautigam, D. and Tang, X. (2011). 'African Shenzhen: China's Special Economic Zones in Africa'. Journal of Modern African Studies 49(1): 27-54.

Brautigam, D. and Tang, X. (2014). “"Going Global in Groups”: Structural Transformation and China's Special Economic Zones Overseas'. World Development 63: 78-91.

Clarke, G. (2005). 'Beyond Tariffs and Quotas: Why Don't African Manufacturers Export More?' Policy Research Working Paper 4317. Washington, DC: World Bank.

Dinh, Hinh T., and Clarke, G. (2012). Performance of Manufacturing Firms in Africa: An Empirical Analysis. Directions in Development: Private Sector Development. Washington, DC: World Bank.

Dinh, Hinh T., Palmade, V., Chandra, V., and Cossar, F. (2012). Light Manufacturing in Africa: Targeted Policies to Enhance Private Investment and Create Jobs. Washington, DC: World Bank.

Dongier, P. and Sudan, R. (2009). Information and Communications for Development. Washington, DC: World Bank.

Ebling, G. and Jans, N. (1999). Export and Innovation Activities in the German Service Sector: Empirical Evidence at the Firm Level. Mannheim: Centre for European Economic Research.

Edwards, L. and Lawrence, R. (2011). AGOA Rules: The Intended and Unintended Consequences of Special Fabric Provisions. Paper presented at the CSAE Annual Conference, March, University of Oxford.

Eifert, B., Gelb, A., and Ramachandran, V. (2008). 'The Cost of Doing Business in Africa: Evidence from Enterprise Survey Data'. World Development 36(9): 1531-46.

Farole, T. (2011). Special Economic Zones in Africa: Comparing Performance and Learning from Experience. Washington, DC: World Bank. 
Fink, C., Matoo, A., and Neagu, I. C. (2002). 'Assessing the Impact of Communication Costs on International Trade'. Policy Research Working Paper 2929. Washington, DC: World Bank.

Gelb, A., Meyer, C., and Ramachandran, V. (2013). 'Does Poor Mean Cheap? A Comparative Look at Africa's Industrial Labor Costs'. Center for Global Development Working Paper 325. Washington, DC: Center for Global Development.

Ghani, E. and Kharas, H. (2010). 'The Service Revolution in South Asia: An Overview', in E. Ghani (ed.) The Service Revolution in South Asia. New York, NY: Oxford University Press, 1-32.

Grossman, G. and Rossi-Hansberg, E. (2006). The Rise of Offshoring: It's Not Wine for Cloth Anymore. Federal Reserve Bank of Kansas City's Proceedings, pp. 59-102.

Harrison, A. E., Lin, J. Y., and Xu, L. C. (2014). 'Explaining Africa's (Dis) Advantage'. World Development 63(C): 59-77.

Hummels, D. (2007). 'Transportation Costs and International Trade in the Second Era of Globalization'. Journal of Economic Perspectives 21(3): 131-54.

International Monetary Fund (IMF) (2014). Regional Economic Outlook: Asia and Pacific. Washington, DC: IMF.

Lin, J. (2011). 'From Flying Geese to Leading Dragons: New Opportunities and Strategies for Structural Transformation in Developing Countries'. Policy Research Working Paper 5702. Washington, DC: World Bank.

Mingat, A., Ledoux, B., and Rakotomalala, R. (2010). 'Developing Post-Primary Education in Sub-Saharan Africa: Assessing the Financial Sustainability of Alternative Pathways'. World Bank's Africa Human Development Series. Washington, DC: World Bank.

Newman, C., Page, J., Rand, J., Shimeles, A., Söderbom, M., and Tarp, F. (2016). Made in Africa: Learning to Compete in Industry. Washington, DC: Brookings Institution Press. OECD-DAC (2015). Creditor Reporting System (CRS) Online Database, available at <https://www.stats.oecd.org/Index.aspx?DataSetCode=CRS1>, accessed 14 October 2015.

Page, J. (2012a). 'Can Africa Industrialize?' Journal of African Economies 21(2, Special Issue): ii86-ii124.

Page, J. (2012b). 'Aid, the Private Sector and Structural Transformation in Africa'. UNUWIDER Working Paper 2012/21. Helsinki: UNU-WIDER.

Stern, N. (2002). The Investment Climate, Governance, and Inclusion in Bangladesh. World Bank Office of the Senior Vice President, Development Economics. Washington, DC: World Bank.

Subramanian, U. and Matthijs, M. (2007). 'Can Sub-Saharan Africa Leap into Global Network Trade?’ Policy Research Working Paper 4112. Washington, DC: World Bank.

Sudan, R., Ayers, S., Dongier, P., Muente-Kunigami, A., and Qiang, C. (2010). The Global Opportunity in IT-Based Services. Washington, DC: World Bank.

Twining-Ward, L. (2009). Sub-Saharan Africa Tourism Industry Research. Washington, DC: World Bank.

Tyler, G. (2005). 'Critical Success Factors in the African High Value Horticulture Sector'. Background paper for the Competitive Commercial Agriculture in Sub-Saharan Africa Study. Washington, DC: World Bank. 
UN Conference on Trade and Development (UNCTAD) (2013). World Investment Report 2013: Global Value Chains: Investment and Trade for Development. Geneva: UNCTAD.

UN Industrial Development Organization (UNIDO) (2009). Industrial Development Report, 2009. Vienna: UNIDO.

World Bank (1993). The East Asian Miracle: Economic Growth and Public Policy. New York: Oxford University Press.

World Bank (2007). Expanding the Possible in Sub-Saharan Africa: How Tertiary Institutions Can Increase Growth and Competitiveness. Washington, DC: World Bank.

World Bank (2008). Doing Business: An Independent Evaluation. Washington, DC: World Bank.

World Bank (2009). Transforming Africa's Infrastructure. Washington, DC: World Bank.

World Bank (2010a). Connecting to Compete: Trade Logistics in the Global Economy. Washington, DC: World Bank.

World Bank (2010b). Africa's Trade in Services and Economic Partnership Agreements. Washington, DC: World Bank.

Yoshino, Y. (2008). 'Domestic Constraints, Firm Characteristics, and Geographical Diversification of Firm-Level Manufacturing Exports in Africa'. Policy Research Working Paper 4575. Washington: World Bank. 


\section{Index}

Note: As each chapter (except the first and last) pertains to a particular country, the sub-headings for each country have not been double-entered as main entries, so the reader is advised to locate main entries of interest under the country headings.

\section{ADELCHI 45}

African Development Bank 1 agricultural sector, and structural transformation 5

agro-industries 88

agglomeration 269

export push 267-8

infrastructure 263

new opportunities 261-2

aid donors 204, 258, 268

Akosombo Textile Limited (ATL) 63

Amin, Idi 191, 193, 206

Angola 93-4

Angolan Liberation Popular Movement (MPLA) 93-4

ANNABELA 45

ARA 45

Associação Industrial de Moçambique (AIMO) 107, 108

Association of Southeast Asian Nations (ASEAN) 218, 219, 226, 250

balance of payments, and structural adjustment loans 9

Bangladesh 226, 251

Bank of Mozambique 109

Barcelona Declaration 184

Bata 157

Benin 150

Botswana 80, 152

Brazil 80, 163

Bretton Woods institutions 139 see also International Monetary Fund; World Bank

British American Tobacco 157

British East Africa Company 156

Brookings Institution 1

Brown Shoe Company 45

Burkina Faso 150

\section{Cambodia 213-31, 273}

agricultural sector 13-14, 214-17, 221 agro-industries 225, 231 apparel/garments sector $219,221-2,224-7$, 231, 260

ASEAN 218, 219, 226

Cambodia Tourism Marketing Strategy 228

civil war 215

closed economy 216-17

competition/competitiveness 218, 228

construction sector 219, 222, 229, 231

consumer goods 216

context 3

corruption 231

Council for the Development of Cambodia (CDC) 226-7

current account 225

electrical and electronics sector 229

employment 213, 221-2, 226, 228, 231

entrepreneurship 14, 216

and the EU 227, 229

Everything but Arms (EBA) scheme 229

evolution of industry 214-18

exchange rates 225,231

exports $17-18,215,218,224-5,227-30$

FDI 15, 19, 214, 218, 225, 227, 231, 271

financial/banking sector 215, 229

fisheries sector 228

Five-year Plans 214, 215

food and beverage sector 219, 221-2, 223, 224,231

food relief 217

foreign exchange 225

forestry sector 228

gas sector 231

Government-Private Sector Forum

(G-PSF) 226

handicraft sector 217, 224

human capital 216

imports 218

import substitution 215,224

industrial agglomeration 18, 222-4, 269

Industrial Development Policy 224-5, 231

industrial policy $224-8$

industrialization $13,257-8$

industrial relations 226 
Cambodia (cont.)

inflation $215,217,225,231$

infrastructure 214-15, 223, 228, 231

institutions $225,226-7$

investment climate 224, 225

joint ventures 214

Khmer Rouge 13, 215, 216, 222

liberalization of trade/economy 218

licensing 218

machinery sector 229

macroeconomic policy 15, 218, 225

maize sector 215

marketing 228

mining sector 231

National Bank of Cambodia (NBC) 225

National Strategic Development Plan

(NSDP) 225

oil sector 231

Open Sky Policy 228

ownership types 214, 218, 220

People's Republic of Kampuchea (PRK) 13,216

privatization 14,217

productivity 231

quotas 226

regulations $226-7$

rice sector $214,215,223,229,231$

rubber sector $214,215,229-31$

sectoral composition 218-19

service sector 221

Sihanouk regime 214-15

size of firms 219-20

special economic zones 18

standards 231

state ownership 14, 214, 216, 217, 218

structural reform and the export push 14-15, 20, 218, 266

structure of industry 4, 218-24

sunset and sunrise industries 228-31

tariffs 215

tasks, trade in 260

taxation 218

technology 224

textile sector 219, 221-2, 224, 226, 251

tobacco sector $219,221-2,223,224,231$

tourism 227-8, 231

Tourism Strategic Development Plan 228

trade policy $218,225-6$

Two-year Plan 214

unions 227

utilities sector 216

value added in manufacturing 8

wage levels 226

wood sector 229

World Bank 218, 219, 226, 227

Canada 227
China

Africa's infrastructure 263

and Cambodia 215, 215n, 220, 228

competition with OECD countries 258

domestic demand 259

FDI to Africa 259

infrastructure 259

international economic policy 259

productivity 164,260

rising costs 259

special economic zones in Africa 271

steel sector 250

textile sector 85

trade logistics 267-8

transport 259

and Tunisia 185

value added by manufacturing 1,80

and Vietnam 236, 242

wage levels $185,258,259$

Coca-Cola 101, 157

Common Market for Eastern and Southern Africa (COMESA) 76, 204

communications

costs 226

export push 267

see also information and communications technology

competition/competitiveness 10, 16

between Africa and Asia 258-60

human capital 264

and productivity $86-7$

trade logistics 267-8

corruption 267

Côte d'Ivoire 150

customs

export push 266, 267, 268

industrial agglomeration 270

Czech Republic 215n

Democratic Republic of Congo 195

Development Bank of Ethiopia 46

East African Breweries 157

East African Community (EAC) 195, 204

collapse 73,163

regional exports 268

revival 76

Economic Commission for Africa (ECA) 193

Economic Community of West African States (ECOWAS) 128, 131

education see human capital

Egypt 80, 175, 188

Electricidade de Moçambique (EDM) 108

employment, and productivity 86

Engineering Capacity Building 44

entrepreneurship 10

Eskom 108 
Ethiopia 27-48

Agricultural Development Led

Industrialization (ADLI) 42, 46

agricultural sector 27, 29, 31, 33

agro-industries $37,42,47$

apparel/garments sector 36-7, 41, 43, 47

benchmarking 44

cement sector 28

Central Statistics Agency (CSA) 32

challenges $46-8$

chemical sector $33,37,47,83$

civil service 47

competition/competitiveness 30, 42, 43-4, 47, 48

construction sector $32,42,47$

context 2

cottage/handicraft sector 32

current industrial policy framework 42-3

current structure of manufacturing

sector $31-40$

customs 47

Dergue regime $7,29-30$

economic performance 31

Engineering Capacity Building Program

(ECBP) 43

engineering sector $33,37,47$

Enhanced Structural Adjustment Facility (ESAF) 30

entrepreneurship 45, 46, 47

Ethiopian Leather and Leather Products

Technology Institute (ELLPTI) 44

Ethiopian People's Revolutionary Democratic

Front (EPRDF) regime 30-1, 42, 46

evolution of industry 28-31

exports $36-8,42-3,45,47,266$

fabricated metals sector 41

FDI 19, 36, 272

five-year development plans 28, 31, 42, 43, 45,46

flower sector $42,43,45-6,47$

food and beverage sector $28,32 \mathrm{n}, 33,36,41$

foreign exchange 43,45

furniture sector 33,41

GDP, share of manufacturing in 5

grain mills sector 33

Growth and Transformation Plan (GTP) 42

human capital $43,44,45$

IMF 30

Imperial regime 28

imports 37,38

import substitution $28,29,42,47$

industrial agglomeration 37-40

Industrial Development Strategy (IDS) 31, 42,46

industrialization 7

industrial policy in practice $43-6$

infrastructure 47 innovation 48

iron sector 37,41

Kaizen 45

Kaizen Training Institute 45

Leather Industry Development Institute

(LIDI) 43,44

leather sector $33,36-7,42,43-5,47$

liberalization of trade/economy 30

macroeconomic policy $29,30,42$

marketing 44-5

meat sector 42,47

metal sector 33,47

Ministry of Trade and Industry (MoTI) 44, 46

new directions 12

non-metallic minerals sector 32n, 33, 37, 41

ownership types 36

paper and printing sector 37,41

patterns of industrial productivity 40-1

pharmaceuticals sector 47

Plan of Action for Sustainable Development and Eradication of Poverty (PASDEP) 31, $42,43,45,46 n$

price controls $30 \mathrm{n}$

productivity 40-1

Revolution 29

rubber and plastics sector 36, 37

sectoral composition of industrial sector 33, 34,41

service sector 31

size of firms $33,40-1$

state ownership 29-30

steel sector 41

structural adjustment 10, 30, 46

structural characteristics 4

Sustainable Development and Poverty

Reduction Program (SDPRP) 31

Ten-year Development Plan 29

Ten-year Perspective Plan 29

Textile and Apparel Institute 44

textile sector $28,32 \mathrm{n}, 33,36-7,41-5,47$

Textile sector Development Institute

(TIDI) 43, 44

twinning programmes 44

value added in manufacturing $8,12-13$

wood sector 37

World Bank 30

European Union

and Cambodia 227, 229

Euro-Med initiative/Barcelona

Declaration 12, 184

and Tunisia $12,17,175-6,179,183-5,187$, 261, 269

exchange rates, and Washington Consensus 9 exports

changing nature of 258

comparative framework 15, 17-18

emerging Asia 14-15 
exports (cont.)

Export Processing Zones (EPZs) 269

infrastructure 263

maintaining an export push 266-8

service sector 261

Federal Reserve 9

First World War 156-7

foreign direct investment (FDI)

attracting 271-3

comparative framework $15,18-19$

foreign exchange 9,10

France

and Cambodia 13, 214, 215

patents 188

and Senegal 146, 149, 151

and Tunisia 174, 176-7, 184, 185

and Vietnam 236

Gambia 150

General Agreement on Tariffs and Trade (GATT) 175, 184

geographic distribution see industrial agglomeration

German East Africa Company 156

Germany

and Cambodia 215

and Senegal 139

and Tanzania 156

and Tunisia 184, 185

Ghana 50-70

Acheampong administration 52

agricultural sector 51-2, 54

agro-industries 56, 62, 69-70

apparel/garments sector $62-3$

building materials sector 51

Busia administration 52

Business Assistance Fund (BAF) 55, 58

cement sector 69

competition/competitiveness $53,54,56,57$, $63,66,67-8,70$

construction sector $55,56,58-60,62,69$

context 2

Convention Peoples Party (CPP) 50-1

current structure of industrial sector 58-66

Divestiture Implementation Programme 57

Economic Recovery Programme (EERP) 53, 54,57

electrical and electronics sector 51, 83

electricity rates 150

electricity supply $53,54,56,58,59,60$

emerging policy issues 70

employment 57, 59-60, 62, 63, 66, 68

evolution of industry $50-8$

exchange rates 52-5, 57, 67

Export Processing Zones (EPZs) 55, 61, 62

exports $51-2,56-7,63-7,266$
FDI 19, 55, 62, 63

food and beverage sector 63,66

foreign exchange 52, 57, 62

Fund for Small and Medium Enterprises

Development (FUSMED) 55, 58

gas sector $62,67,69$

GDP, share of manufacturing in 5

Ghana Competition Commission 67

Ghana Free Zones Board (GFZB) 58, 61, 62

Ghana Investment Centre (GIC) 53, 58, 62

Ghana Standards Board 63, 69

Ghana Textile Manufacturing Company

(GTMC) 63

Ghana Textile Product (GTP) 63

Ghana Trade and Investment Gateway

(GHATIG) 55, 58

GIPC Act 58

Growth and Poverty Reduction Strategies (GPRS) 56

growth rate of industry and sub-sectors 53-4

IMF 56

imports $54,57,62,67$

import substitution 50, 51-2, 57, 62

income distribution 70

industrial agglomeration 18, 60-2, 70

industrialization $6,7,9$

industrial policy framework 66-70

industrial relations 54

inflation 67

infrastructure $51,54,58-9,62$,

68,69

institutions 68-9

interest rates $52,53,57,63$

investment climate 11,68

iron sector 70

joint ventures 51,60

liberalization of trade/economy 50, 51, 53-4, 56-8, 62

licensing 51, 53, 57

machinery sector 51

macroeconomic policy 51, 52, 53, 67

marketing 56

mining sector 51, 55-6, 58-60, 69

National Agency for the Protection of

Consumers 67

National Industrial Policy 69

National Liberation Council (NLC) 52n

National Redemption Council 52

new directions 12

Nkrumah administration 50-1, 52n

oil sector 58, 60-2, 67, 69-70

ownership types 60,63

poverty 70

Poverty Reduction Strategy Programme

(PRSP) 56

power 54, 56, 58, 62, 69

price controls 52,57 
Private Enterprise and Export Development Fund (PEED) 55

privatization 53,57

productivity 63-6

quarrying sector $56,58,59,60$

regulations 68-9

research and development 69

sectoral composition of industrial sector 58-9

service sector 52,58

size of firms 59

skills gap 264

special economic zones 270

standards $68-9$

state ownership 51, 60

steel sector 70

structural adjustment 10, 11, 53, 62

structural characteristics 4

tariffs $51,53,57,58$

textile sector $62-3,69$

Trade and Investment Programme (TIP) 55, 58

trade policy $11,53,57,67$

value added in manufacturing 8, 12, 13

wage levels 66

water supply 53-4, 56, 58-60, 69

World Bank 56

Global Services Location Index (GSLI) 187

Great Britain

and Ghana 6,50

and Kenya 156

and Nigeria 115

and Tanzania 156

and Uganda 191, 192

Herfindahl Index 151

Hong Kong 228

human capital

Africa 257, 262, 264-5

comparative framework 15-16

investment climate $262,264-5$

skills gap $264-5$

import substitution (IS) 6-9, 257

India

Leather and Leather Products Technology

Institute 44

productivity 164

Software Technology Parks of India 270

textile sector 85

trade logistics 267

and Tunisia 185

Indonesia 164

industrial agglomeration

comparative framework 15, 18

supporting 269-71

information and communications technology (ICT)

industrial agglomerations 269-70 investment climate 263

service sector 261

infrastructure

Africa 257

comparative framework 15-16

export push 266, 267

industrial agglomeration 269, 270, 271

investment climate 262-4

tasks, trade in 261

innovation, service sector 205

institutions

Africa 257

comparative framework $15,16-17$

export push 266, 267, 268

FDI promotion 271-2

investment climate 262, 265

tasks, trade in 261

interest rates, and Washington Consensus 9

International Committee on the

Reconstruction of Cambodia 217

International Convention and

Centre 106

international financial institutions (IFIs) 9, 10 see also World Bank

International Labour Organization (ILO)

76,227

International Monetary Fund (IMF) 9

internet connectivity 263

investment climate 273

Africa 11, 12, 257, 262-5

emerging Asia 14

see also foreign direct investment

Ireland 271-2

Italy $184,185,188$

Japan 227

Jordan 175, 188

Kagera war 163, 170

Kampala agreement 158

Kenya 72-89

agricultural sector $73,80,82$

agro-industries 77,88

apparel/garments sector $73,75,77,81-3,85$, 87-8

British East Africa Company 156

cement sector 86

chemical sector 88

churning 83

communication sector 77

competition/competitiveness $74,75,81,85$, 86-7

construction sector 86

consumer goods 77

context 2

corruption 75

crime 75 
Kenya (cont.)

Economic Management for Renewed Growth study 74

Economic Recovery Strategy 75, 76, 86

electrical machinery sector 83,88

employment 72-3, 77, 81-2, 83

entrepreneurship 76, 84

Essential Goods Production Support

Programme 74

evolution of industrial policies $72-5$

Export Compensation Scheme 74

Export Processing Zones (EPZs) 74, 75

Export Promotion Council 74

exports 73-7, 86, 89, 266

FDI 19, 76, 156

food and beverage sector $73,77,81,82$, 85,88

foreign exchange 76

forestry sector 80

furniture sector 77,83

GDP, share of manufacturing in 5

human capital 89

imports $74,76,80,86$

import substitution $72-3,76,80$

industrial agglomeration 77

industrialization 7, 75-7, 156

industry promotion policies, industries, and laws 78-9

informal sector $73,76,77,81$

infrastructure $75,80,86,89$

inter-East Africa trade 158

investment climate 11

iron sector 86

joint ventures 88

Kenya Association of Manufactures 86

leather sector $73,77,87$

legal status of firms 85

liberalization of trade/economy $74,76,80$, 81,85

licensing 74

macroeconomic policy 76

Manufacturing under Bond (MUB) 74

metal sector 83,85

motor vehicle repairs 77

National Industrial Policy (NIP) 75, 88

National Rainbow Coalition (NARC) government 76

new directions 12

oil crisis 73

oil sector $77,86,88$

ownership types $84-5,88$

paint sector 83

paper and printing sector 73,86

poverty 75

Poverty Reduction Strategy Paper 75

power 89

price controls 74,76 productivity $72,75,86-8,89$

quotas 75

real estate sector 86

research and development 89

rubber and plastics sector 86

sectoral composition of industrial

sector $77-80$

security 89

size of firms $82-3,88-9$

soap sector 83

special economic zones 270

steel sector 86

structural adjustment 10, 74, 76

structure of industrial sector 4, 77-85

sunrise and sunset industries 85-6

tariffs $72,74,156$

textile sector $73,77,81-2,85,88$

tobacco sector $73,79,81,82$

trade policy 86

transport 77,89

value added in manufacturing $8,12-13$, 79,80

VAT 74

Vision 2030 12, 75, 76, 86

wage levels 87

water supply 89

wood sector 77

World Bank 74

Korea, Republic of 80, 220, 269

Latin America, structural adjustment loans 9

Learning to Compete 1-2

liberalization of trade/economy 10, 257

Liberia 150

logistics, trade 267-8

Lon Nol 215

Malawi 108

Malaysia 80

Mali 150

Mauritius 7n, 17n, 80, 152

Metal Box 157

Millennium Development Goals (MDGs) 263

Morocco 175, 188

Mozambique 92-111

agricultural sector 92-3, 95-6

aluminium processing 102

apparel/garments sector 104

balance of payments 95, 100

building materials sector 107

cashew sector 94

chemical sector 104

civil war 95-7

coal sector 101, 102

competition/competitiveness 17,104 , 106, 109

construction sector 94-6, 101-4, 111 
context 2

corruption 106

current structure of industrial sector 101-4

domestic savings 109

Economic Rehabilitation Program (PRE) 96, 97, 98, 104, 105, 109

electricity supply 93, 101-2, 103, 108

employment 93, 97, 101, 103, 104, 107

entrepreneurship 104, 106-8, 109, 111

evolution of industry 92-101

exchange rates 105

exports 93-4, 96, 101, 105-6

FDI 19, 100, 101, 103-4

financial/banking sector 109

fisheries sector 95, 96

food and beverage sector 102, 104

foreign exchange 98

Frelimo government 7, 94, 95, 96

furniture sector 104

gas sector 101, 102

human capital 95, 100, 107-8

IMF 104

imports 100, 105-6

import substitution 94, 96

industrial agglomeration 18

industrialization 7

Industrial Policy and Strategies (IPSs) 11, 99-101, 111

industrial policy framework 104-10

inflation 105

informal sector 96

infrastructure 93, 96, 101, 111

innovation 109

Institute for the Promotion of micro, small, and medium enterprises (IPEME) 106

institutions 17, 100, 106

interest rates 109

investment climate 11, 100, 106, 109

Investment Promotion Centre 106

iron sector 94

joint ventures 100

liberalization of trade/economy $96,97-8$, 100,104

liberalization war 7,94

licensing 111

literacy 107

machinery sector 104

macroeconomic policy $104-5$

metal sector 95, 96, 102, 104

minerals sector 104

mining sector 94, 100-4

Ministry of Finance 105

Mozambique Revenue Authority 105

new directions 12

oil crisis 94

oil sector 94, 95, 108

ownership types 103-4 paper and printing sector 104

Plano de Fomento 93, 94

power 94-5, 104, 108

price controls 105

privatization 97, 98, 100, 104, 105

productivity $96,97,98$

profits 106

publishing sector 104

regulations 106

Renamo 96

research and development 110

rubber sector 95

size of firms 102-3

skills gap 264

soap sector 95

Social and Economic Rehabilitation Program (PRES) 96

state ownership 95, 97, 103

steel sector 94

structural adjustment 11, 97

structural characteristics 4

sugar sector 94, 105

tariffs 105

taxation 105

technology 109-10

textile sector 94, 95, 96, 98, 104

trade policy 105-6

transport 16,94

value added in manufacturing 8,13

VAT 105, 106

water supply 94-5, 101-3, 108

wood sector 104

World Bank 97, 104, 107

MTN 191n

multi-fibre agreement (MFA) 219, 261

Multilateral Investment Guarantee Agency (MIA) 106

Museveni, Yoweri 191

Myanmar 226

Niger 150

Nigeria 115-34

Agricultural Credit Guarantee Scheme Fund (ACGSF) 133

agricultural sector 115-16, 118-20, 129, 131,133

agro-industries 132-3

apparel/garments sector 122-6

balance of payments 119

Bank of Industry (BoI) 121, 127, 132

Bureau of Public Enterprises (BPE) 132

cement sector 118

Central Bank of Nigeria 127, 131,133

civil war $115,117,118,133$

cocoa sector 120

communication sector $125,128,132$ 
Nigeria (cont.)

competition/competitiveness $11,120,121$, 126, 128, 129

construction sector 123, 124, 125

consumer goods 119, 120, 131

context 2

corruption $124-5,133$

crime 124,125

customs 128, 132

Customs and Excise Department 132

domestic savings 128

Duty Drawback Scheme 131

Economic and Financial Crimes Commission (EFCC) 132

Economic Implementation Team 127

ECOWAS 128, 131

electrical and electronics sector 126

electricity supply $124,125,130$

employment 119, 127

enterprise zones 130

entrepreneurship 118, 121, 130

evolution of industry $116-22$

exchange rates 121, 128, 129

Export Development Fund Scheme 131

Export Processing Zones 131

exports 115, 119-20, 123, 126, 128, 131-2

FDI 19, 117, 123, 126, 133

Federal Ministry of Finance 128

Federal Ministry of Industry, Trade and Investment 127

Federal Ministry of Science and Technology 127

financial/banking sector 131-2

food and beverage sector 122-6, 132

foreign exchange $117,119,120$

free trade zones 126

furniture sector 123, 124, 125

gas sector $115,129,132,133$

human capital 118, 120-1, 123-4, 129,130

ICT sector 126-7, 132

IMF 116, 117, 119, 120

imports 119, 120, 128, 131

import substitution $115,117-18$

Independent Corrupt Practices and Other

Related Offences Commission 132

industrial agglomeration 126, 130

industrialization 7,9

industrial parks 130

industrial policy framework 127-33

inflation 119, 120, 128, 129

infrastructure 117-18, 124, 126, 129, 132,133

innovation 121,122

institutions 131-2

interest rates $119,121,128,129$

investment climate 11,129 iron sector 118

joint ventures 133

liberalization of trade/economy 117 , 121-2, 128

machinery sector 126

macroeconomic policy 128-9

Manufacture-in-Bond Scheme 131

marketing 120, 121

minerals sector 133

mining sector 133

National Agency for Food, Drug

Administration and Control 132

National Association of Small-Scale Industrialists 128

National Communication Commission 132

National Development Plans 117, 118-19

National Economic Council (NEC) 127

National Economic Empowerment and Development Strategy (NEEDS) 11, 121, 128,131

National Economic Management Team 127

National Economic Reconstruction Fund (NERFUND) 121

National Information Technology Development Agency (NITDA) 132

National Planning Commission 127

Nigerian Export Promotion Council 127, 132

Nigerian Agricultural and Cooperative Bank 132

Nigerian Agricultural, Cooperatives and Rural Development Bank 132

Nigerian Bank for Commerce and Industry 132

Nigerian Customs Service 128

Nigerian Enterprises Promotion Act 118

Nigerian Export Processing Zone Authority (NEPZA) 126, 127

Nigerian Industrial Development Bank 132

Nigerian Investment Promotion Commission (NIPC) 127, 131, 132

Nigerian National Petroleum Corporation 133

Nigeria Vision 2020 (NV20:2020) 122, 129,133

Oil and Gas Export Free Zone 131

Oil \& Gas Free Zone Authority 126

oil crisis $116,118-19$

oil sector $115-17,128-9,132-3$

paper and printing sector 118

Peoples Bank 132

poverty 115

power 117,133

price controls 120

privatization $120,121,128$

productivity $119,125-6$

quotas 138 
Raw Materials Research and Development Council (RMRDC) 121, 127

regulations 131-2

research and development 121

rubber sector 120

salt sector 118

science and technology (S\&T) policy 120-1

sectoral composition of industrial

sector $122-3$

service sector 133

Seven Point Agenda (SPA) 128-9

size of firms 123

Small \& Medium Enterprises Development Agency of Nigeria (SMEDAN) 127, 132

Small and Medium Industries Equity

Investment Scheme 121

special economic zones 270

standards 121, 132

Standards Organisation of Nigeria

(SON) 121, 132

steel sector 118

structural adjustment $10,11,116,117,119-21$

structure of industry $4,122-7$

tanning sector 120

tariffs $120,121,128,131$

taxation $118,120,132-3$

technology $118,120-1,122,123-4$

textile sector $119,120,122,123,124,125,127$

tobacco sector 126

trade policy 131

transport 123, 124, 125

value added in manufacturing $8,12,13$

wage levels 120,123

water supply 124

wood sector $123,124,125$

World Bank 116, 117, 119, 122

official development assistance (ODA) 263-4

offshoring 261

Organisation for Economic Co-operation and Development (OECD) 258, 263-4

Overseas Private Investment Corporation (OPIC) 106

\section{PETROMOC 108}

Portugal 92, 93-4, 95

poverty and productivity 86

power

comparative framework 16

industrial agglomeration 270

investment climate 262

Prebisch-Singer hypothesis 155

Printex 63

privatization 10,257

productivity

Africa versus Asia 259-60

and export push 266 industrial agglomerations 269

and poverty 86

and profitability 86

pursuit of industry 1-20

Africa 6-13

comparative framework 15-19

emerging Asia 13-15

industrialization, structural transformation, and growth 3-5

regional integration, strengthening 268

regulations

comparative framework 16-17

export push 266, 268

investment climate 262, 265

Rwanda 76, 195

SABMiller 101

Second World War 156

Senegal 136-53

Accelerated Growth Strategy (SCA) 11, 142,143

Agency for the Development and Supervision of SMEs (ADEPME) 142

agricultural sector 136, 137, 147, 152

agro-industries 147, 152

balance of payments 140

brain drain 149, 153

Centre Unique de Collecte de Information (CUCI) 148

chemical sector 144, 147, 149, 152

competition/competitiveness 136,140 , 142-3, 151

construction sector $144,146,147,149,152$

context 2

customs 138, 141

Dakar Industrial Free Trade Zone (ZFID) 138-9

electricity supply $144,149-50,152-3$

employment 140, 142, 144-8, 153

entrepreneurship 141, 143

evolution of industrial policy 137-43

exchange rates 143

exports 136, 138, 140, 151-2

FDI $19,143,146-7,153$

financial/banking sector 141-2

fisheries sector 144

food and beverage sector 144, 149, 152

foundry sector 149

glassware and pottery sector 144, 146, 152

human capital 143, 149-50, 153

import substitution $137-8,139,151$

industrial agglomeration 18, 142, 143, 153

industrialization 6-7

industrial policy $150-1$

industrial redeployment policy (PRI) 143

industrial zones $138-9,142$ 
Senegal (cont.)

inflation 140

informal sector 142,152

infrastructure $141,143,150,152-3$

innovation 136, 143

investment climate $11,138,140$

Investment Promotion and Major Projects Agency (APIX) 142

leather sector 144

liberalization of trade/economy 139-40, 141-2, 151

literacy 149

machinery sector 144

marketing 139

metallurgy 149

Modernization Office 142

National Agency of Statistics and Demography (ANSD) 148

National Company for Industrial Research and Development (SONEPI) 138

National Industrial Policy (NIP) 141

National Social and Economic Development Strategy (SNDES) 143

new agricultural policy (NPA) 140

new industrial policy (NPI) 140

oil sector 152

paper and printing sector 147

poverty 143

power $143,149-50$

price controls 141

privatization 141, 153

productivity 147-50

profits 136

regulations 141

rubber sector 144, 149

Senegalese Export Creation Agency

(ASEPEX) 142

Senegalese Standards Institute 142

Senegal National Electricity Company

(SENELEC) 150, 153

service sector $136,137,144$

size of firms 143-4

special economic zones 270

standards 142

structural adjustment 10, 139-40, 151

structure of industrial sector $4,143-7$

sugar sector 144,149

sunrise and sunset industries 151-2

tariffs 138, 139, 140-1, 151

taxation 138-9, 140, 141, 148

trade policy 150-1

transport 153

utilities sector 144

value added in manufacturing $8,12-13$

water supply 144,153

service sector 258

agglomeration 269-70 export push 267

innovation 205

new opportunities 261

structural transformation 5

Seychelles 152

Sihanouk, Prince 214-15

Singapore 80, 269

Sisowath Sirik Matak 215

Software Technology Parks of India (STPI) 270

South Africa 80, 108, 152

South African Development Community

(SADC) 99, 105, 106, 108

South Sudan 195

Soviet Union 14, 217, 236

Spain 184, 188

spatial distribution see industrial agglomeration special economic zones (SEZs) 269-71, 272

Special Programme of Assistance for Africa 10

state ownership 6-9, 10

Statistical Abstract and Economic Survey 87

structural adjustment and transformation 3-5 Africa 9-11, 257

emerging Asia 14-15

Swaziland 108

Taiwan 193, 228, 269

Tanganyika Development Corporation 158

Tanganyika Packers 157

Tanzania 155-72

agricultural sector $156,163,165,167,170-1$

agro-industries 157, 170

apparel/garments sector 162

Arusha declaration 7, 157, 160, 161, 170

balance of payments 161-2, 163, 165, 166

Basic Industrial Strategy (BIS) 162n, 166, 170

chemical sector 170

civil service 165

coffee sector 163

competition/competitiveness $11,164,168$, $169,171,172$

consumer goods $158,161,162-3$

context 2

current account 158, 163, 164

customs 168

East African Community 168

East African Strategy (EAS) 162n, 166

Economic and Social Action Programme (ESAP) 155, 166

Economic Development Zones 170

Economic Recovery Programme (ERP) 155, 165-6, 170

electricity charges 108

employment 157, 159-60, 162, 166-8, 171,172

engineering sector 167

entrepreneurship 157

exchange rates $161,162,165,170$ 
Export Processing Zone (EPZ) Act 168-9

Export Rebate System (ERS) 163

exports 157-8, 162-3, 165, 167-9

FDI 19, 157, 159, 160

fertilizer sector 170

Finance Act 161

Five-year Development Plans 155, 157, 159-60

food and beverage sector 157,163 , 169,171

foreign exchange 161, 163, 164, 168

Foreign Investment Protection Act 157

furniture sector 171

GDP, share of manufacturing in 5

General Retention Scheme (GRS) 163, 170

historical developments 155-7

human capital 157, 159, 164, 172

IMF 163

imports 158, 161, 162, 163, 164, 170

import substitution 157-60, 163, 167, 170

income distribution 162

industrialization $7,9,155,157-70$

inflation 161, 163, 164, 165, 167, 168

infrastructure $157,170,171-2$

innovation 171,172

Integrated Industrial Development Strategy

(IIDS) 11, 155, 169-70

interest rates 167

investment climate $11,158,159,165-8,170-1$

iron sector 170

joint ventures 160

Kagera war 163,170

leather sector 170

liberalization of trade/economy 155 , 165,167

licensing 160, 164, 170

life expectancy 159

literacy 156

machinery sector 170

macroeconomic policy 167,168

marketing 165

Maximum Growth Strategy (MGS)

162n, 166

metal sector 158

mining sector 169

Mixed Strategy (MS) 162n, 166

monitoring and evaluation (M\&E) 172

National Development Corporation 160

National Economic Survival Programme (NESP) 163, 170

National Industries Licensing and Registration Act 160

National Investment Act 170-1

National Price Control Advisory Board 161

New Retention Scheme 170

oil crisis 161,163

ownership types $159,160,166$ poverty 171

power $16,157,171-2$

Price Control Act 161

price controls $161,164,170$

privatization $155,165,167,171$

productivity 158-61, 163-4, 166-7, 169,170

regulations $158,160,161,170$

research and development 165

SIDO 170

Small-scale Rural Strategy (SSRS) 162n, 166

special economic zones 270

state ownership 160, 166, 170

State Trading Corporation 160

steel sector 170

structural adjustment 10, 11, 162, 163-70

structural characteristics 4

Sustainable Development Policy for Tanzania (SIDP2020) 167-8, 169, 171

Sustainable Industrial Development

Programme 155

Tanzania Industrial Research Development Organization (TIRDO) 165

tariffs $156,165,168$

taxation $158,159,166,170-1$

technology 162, 165, 167, 168, 171, 172

textile sector $166,167,170,171$

three-year development plan (TYP) 157-60

tobacco sector 169,171

tourism 171

transport 171

twenty-year basic industry strategy 162

value added by manufacturing $8,12,13,80$

Vision 2025168

wood sector 171

World Bank 165-6

tariffs

export push 266, 267

structural adjustment 10

tasks, trade in 258, 260-1, 267-8

taxation, and export push 266, 267

technology

communications costs 260

transport costs 260

see also information and communications technology

telecommunications see communications; information and communications technology

Togo 150

tourism

export push 267

infrastructure 263

new opportunities 261

skills gap 264

trade logistics 267-8

training see human capital 
transport

comparative framework 16

costs, in global economy 260, 261

export push 266, 268

investment infrastructure 262-3

Tunisia 174-89, 273

agricultural sector $174,177,180,182$

agro-industries 182-4, 188-9

apparel/garments sector 178, 182-3, 185,

188-9, 261

Arab Spring 176, 180-2

automotive components 176, 177, 180, 261

balance of payments 184

Barcelona Declaration 184

building materials sector 188-9

chemical sector $183,188-9$

civil service $174,176-7$

communication sector 176

competition/competitiveness $7,12,175$, $179,183-5,189$

context 2-3

corruption 176

current account 178, 179, 180

customs 178, 186

diversification 152

Economic Recovery and Structural

Adjustment Programme (ERSAP) 175, 179

electrical and electronics sector 176,180 , $183,184,185,188-9$

electricity supply 174,177

employment 176-8, 180-5, 189

entrepreneurship 176

and the EU 12, 17, 175-6, 179, 183-5, 187, 261,269

evolution of industry $176-82$

exchange rates 175,179

Export Promotion Centre (CEPEX) 174, 178

exports 17-18, 20, 174-80, 183-9, 266

FDI $7,19,175-7,179-83,185-7,271$

food and beverage sector $174,178,182,183$, $184,188-9$

free trade agreement (FTA) 175

gas sector 186

human capital 175, 177, 180, 187, 189

ICT sector 181

imports $175,177-8,183-4$

import substitution 174,177

industrial agglomeration $18,178,181$, 189,269

industrialization $7,257-8$

Industrial Land Agency (AFI) 178

Industrial Modernization Programme

(PMI) 12, 175, 179, 185

industrial policy $185-8$

Industry Promotion Agency (API) 174, 177-8, 184

inflation 178,179 infrastructure $175-6,181,187,189$

innovation $187-8$

institutions 174,177

investment climate 176-82, 186, 188, 189

investment law (Law 72-83) 178, 186

joint ventures 180

leather sector $178,183,188-9$

liberalization of trade/economy 175 , 176,179

literacy 177,181

machinery sector 184

mechanical industry sector $176,180,183$, 188-9

mining sector 174

Ministry of Higher Education Scientific

Research and Technology (MHESRT) 187

new directions 12

offshoring 184-5, 187

oil crisis 184

oil sector $177,184,186$

ownership types $178,183,186$

paper and printing sector 177

patents 187

poverty 177,181

power 181,182

privatization $175,179,180,186$

productivity $178,179,184$

Programme de mise à niveau 12, 175, 179, 187

research and development 187-8

rubber sector 188-9

service sector $175,176,180,182$

social security contributions 182

steel sector 177

structural adjustment 10, 179, 183, 184

structure of industry $4,182-5$

sunrise and sunset industries 188-9

tariffs 175,184

tasks, trade in 260-1

taxation 175, 177, 178, 179, 182, 186

technology $175,180,185$

textile sector $174,176-8,180,182-5,188-9$

tourism 174, 175-8, 180, 181

trade policy 175,179

transport 174, 176, 177, 181

value added in manufacturing 8,13

VAT $175,179,186$

wage levels 178,185

water supply 174,177

World Bank 175, 184

Uganda 191-209

agricultural sector 191-2, 194, 208

aid financing 204

Amin regime 191, 193, 206

apparel/garments sector 199

balance of payments 193

Business Register 195, 198, 200, 201, 202 
chemical sector 193

civil war 191

coffee sector 198

communication sector $191 \mathrm{n}$

competition/competitiveness 192, 195, 204, 205, 206

construction sector $194,199,200$,

201-2, 207

context 2

corruption 191

customs 204

domestic savings 193

Economic Recovery Programme 205

electricity supply 194, 208

Emergency Relief and Rehabilitation

Programme 205

employment 191-2, 198, 200, 202, 205,208

evolution of industry 192-4

exchange rates 204

exports 192-3, 195, 197, 199, 204-5, 208

FDI 19, 76, 192-3, 195-6, 198, 200,

202-3, 208

Five-year Development Plans 192-3

foreign exchange 204, 205

gas sector 208

GDP, share of manufacturing in 5, 194

grain milling sector 198

human capital 205, 208, 209

ICT sector 207

IMF 203, 205

imports 193, 195, 204, 207

import substitution 206

industrial agglomeration 18, 197-8, 200,

202, 208

industrialization 7

Industrialization Policy and Framework 205

industrial policy framework 203-6

inflation 203

informal sector 194, 195n, 199, 200

infrastructure 193, 195, 198, 205-9

innovation 205

institutions 16-17, 203, 205-6

inter-East Africa trade 158

interest rates 207

investment climate 193, 198, 204, 205

iron sector 199

joint ventures 202, 203

Kagera war 163

Kenyan exports to 76

liberalization of trade/economy 192, 195, 203, 207, 208

life expectancy 192

machinery sector 193

macroeconomic policy 203-4

Management Training and Advisory Centre

(MTAC) 206
Medium-term Competitiveness

Strategies 205

mining sector 192, 194, 199-201, 203, 207-8

Ministry of Trade, Industry and Cooperatives 205-6

National Development Plans (NDPs) 191, 200, 205, 208

National Industrial Policy 205

National Resistance Movement 191

oil sector 208, 209

ownership types 198, 200-1, 202, 203

power 16, 150, 208

productivity 198-9

quarrying sector 194, 199-201, 207

regulations 205-6

sectoral composition of industrial

sector 195, 196

service sector $191 \mathrm{n}$

size of firms 195-7, 199-200, 201

skills gap 264

state ownership 206

structural adjustment 10, 11

structure of industry $4,194-5$

sub-sectoral analysis 195-203

sunrise and sunset industries 206-8

tariffs 156, 193, 204

taxation 205

tea processing sector 198

technology 199, 203, 205, 208, 209

Textile Board 206

textile sector $206-7$

tourism $191 \mathrm{n}$

trade policy 204

transport 16

treasury bills 203, 204

Uganda Bureau of Statistics (UBOS) 195

Uganda Export Promotion Board

(UEPB) 205, 206

Uganda Industrial Research Institute (UIRI) 206

Uganda National Bureau of Standards 206

Ugandan Investment Authority

(UIA) 198, 205

value added by manufacturing $8,12,13$, 80, 197

water supply 194

Way Forward I and II 205

World Bank 203, 204, 205

United Nations (UN)

Cambodia 217

Development Programme (UNDP) 107

Industrial Development Organization (UNIDO) 107

Sustainable Development Goals 264-5

University World Institute for Development Economics Research (UNU-WIDER) 1 
United States of America

African Growth and Opportunities Act

(AGOA) 75, 76, 85, 261

and Cambodia 215, 226, 227

Clinton administration 227

Federal Reserve 9

and Kenya 75, 76, 85

Patent and Trademark Office (USPTO) 187-8

quotas 227

Treasury 9

and Vietnam 14, 239, 242

value-added tax (VAT), and export push 267

Vietnam 235-56, 273

agricultural sector 236, 239-42, 248

apparel/garments sector 235, 240, 251, 253,260

bauxite sector 249

cement sector 240

chemical sector 255

coal sector 236, 240, 243, 246

communication sector 241

competition/competitiveness $14,235,242$, $249,250,254-6$

construction sector 239,242

consumer goods 239

context 3

current structure of industrial sector 243-6

Department of Economic Zones 14, 248

Doi Moi 14, 217, 235, 240, 244, 247, 271

domestic savings 241

electrical and electronics sector 249

electricity supply 240,246

employment 239, 242, 243-4, 245

Enterprise Development Agency 14, 248

entrepreneurship 236, 239, 242

evolution of industry 236-42

exchange rates 247

export processing zones (EPZs) 14, 241,242

exports 17-18, 235, 240, 242, 247-8, 250-1, 255-6, 266

fabricated metals sector $235,251,252-3$

FDI 19, 235, 240, 242, 244-5, 247, 249, 251, 255-6, 271

fertilizer sector 247

financial/banking sector 241, 248, 249

fisheries sector 240, 241, 242

Five-year Plans 239, 240, 241, 242

food and beverage sector 235, 240, 241,

251,252

food relief to Cambodia 217

Foreign Investment Agency (FIA) 14, 248

Foreign Investment Law 241

forestry sector $240,241,242$

furniture sector 253 gas sector 243

handicraft sector 240

human capital 248, 254

ICT sector 249,250

imports 242, 247, 255

import substitution 235, 255

industrial agglomeration 18, 246, 269

industrialization $13,14,257-8$

industrial policy framework 247-51

industrial zones (IZs) 14, 241, 242, 246

inflation 239, 247

infrastructure 236, 239, 241, 254

institutions 248-9

investment climate 247, 249, 255

Law on Encouragement of Domestic Investment 241

Law on Enterprises 241, 242, 255

liberalization of trade/economy 250, 253

licensing 249

lignite mining 246

literacy 236

macroeconomic policy 14,247

mechanical industry sector 249

media sector 245,253

metal sector 251, 253

mineral sector 251

mining sector 242, 243, 246, 253

Ministry of Industry and Trade 248, 249

Ministry of Planning and Investment 14,248

motor vehicles sector 251

oil sector 239, 240, 243, 246

Orientation of Industrial Development 241

ownership types 244-6

paper and printing sector 240, 253

pharmaceuticals sector 235, 252-3

poverty 241

power 239

price controls $240 \mathrm{n}$

privatization 246

productivity $235,239,245-6,250$, 253-6, 260

Public Investment Programme 241

quarrying sector 246,253

quotas 247

real estate sector 247

regulations $247,248-9$

research and development 249, 250

rice sector 236, 240, 247

rubber sector 236, 249

sectoral composition 243

service sector $240,241,242$

sewerage sector 246

size of firms 243-4, 245

Socio-Economic Development Strategy

(SEDS) 248, 254, 255, 256 
special economic zones 18

standards 249

State Bank of Vietnam 249

state ownership $14,235,239,242,244-7$, $249,255,256$

steel sector $240,249,250$

structural characteristics 4

structural reform and the export push 14, 15,20

sugar sector 241

sunrise and sunset industries 251-4

tasks, trade in 260

technology 241, 250, 255

textile sector 240, 250-1, 255

tobacco sector 245

tourism 241

trade policy $14,247-8$

transport 239, 253

value added in manufacturing 8

Vietnam Development Bank 248

wage levels 226

war with the US 14, 239

water supply 246
World Bank 242, 248, 253, 255

zinc sector 240

wage levels

Africa versus Asia 258-9

OECD countries 258

and productivity 86

tasks, trade in 261

Washington Consensus 9-11

welfare 86,181

West African Economic and Monetary Union (WAEMU) 141

West African Monetary Union (WAMU) 140-1

World Bank (WB)

Doing Business report 265

investment climate 11,262

manufacturing datasets 87

Private Sector Development Program 107

Trade Logistics Index 267

Washington Consensus 9

Zambia 108, 150 